\title{
A clinical trial for uniform multidrug therapy for leprosy patients in Brazil: rationale and design
}

\author{
Gerson Oliveira Penna ${ }^{1 /+}$, Maria Araci de Andrade Pontes ${ }^{2}$, Rossilene Cruz ${ }^{3}$, \\ Heitor de Sá Gonçalves ${ }^{2}$, Maria Lúcia Fernandes Penna ${ }^{4}$, Samira Bührer-Sékula ${ }^{5}$
}

${ }^{1}$ Núcleo de Medicina Tropical, Universidade de Brasília, Brasília, DF, Brasil

${ }^{2}$ Centro de Dermatologia Dona Libânia, Fortaleza, CE, Brasil ${ }^{3}$ Fundação de Dermatologia Tropical e Venereologia Alfredo da Matta,

Manaus, AM, Brasil ${ }^{4}$ Departamento de Epidemiologia e Bioestatística, Universidade Federal Fluminense, Rio de Janeiro, RJ, Brasil ${ }^{5}$ Instituto de Patologia Tropical e Saúde Pública, Universidade Federal de Goiás, Goiânia, GO, Brasil

Leprosy will continue to be a public health problem for several decades. The World Health Organization (WHO) recommends that, for treatment purposes, leprosy cases be classified as either paucibacillary or multibacillary $(M B)$. A uniform leprosy treatment regimen would simplify treatment and halve the treatment duration for MB patients. The clinical trial for uniform multidrug therapy (U-MDT) for leprosy patients (LPS) in Brazil is a randomised, open-label clinical trial to evaluate if the effectiveness of U-MDT for leprosy equals the regular regimen, to determine the acceptability of the U-MDT regimen and to identify the prognostic factors. This paper details the clinical trial methodology and patient enrolment data. The study enrolled 858 patients at two centres and $78.4 \%$ of participants were classified as MB according to the WHO criteria. The main difficulty in evaluating a new leprosy treatment regimen is that no reliable data are available for the current treatment regimen. Relapse, reaction and impaired nerve function rates have never been systematically determined, although reaction and impaired nerve function are the two major causes of nerve damage that lead to impairments and disabilities in LPS. Our study was designed to overcome the need for reliable data about the current treatment and to compare its efficacy with that of a uniform regimen.

Key words: leprosy - protocol - clinical trial - uniform multidrug therapy

Despite the proposed elimination of tropical diseases (WHO 2011, 2012), leprosy will continue to be a public health problem for several decades (Scollard 2005, Talhari \& Penna 2005). With the increasing decentralisation of control activities, primary public health centres will be responsible for diagnosing and managing patients to achieve programme sustainability (Banerjee et al. 1997, Penna \& Penna 2007, Penna et al. 2012).

In 1981, the World Health Organization (WHO) recommended a multidrug therapy (MDT) for leprosy treatment (WHO 1982). The WHO currently recommends that leprosy cases be classified as either paucibacillary (PB) or multibacillary (MB) based on the number of skin lesions. Patients with six or more lesions are classified as MB and treated for 12 months with a MDT that comprises three drugs: rifampicin, dapsone and clofazimine. Patients with fewer than six lesions are classified as PB and treated for six months with a two-drug MDT: rifampicin and dapsone (WHO 1997a).

Since 1989, Brazilian scientists have been calling for a uniform leprosy treatment that would not require disease classification (Penna et al. 2012). Similarly, tuberculosis (TB) can be viewed as a historical example of a

+ Corresponding author: gpenna@gpenna.net

Received 29 May 2012

Accepted 29 August 2012 disease that is more infectious and pathogenic than leprosy that has been treated with a combination of drugs since the 1960s. The treatment regimen for all types of patients has changed over the years, but currently, all pulmonary TB patients, both smear-negative ("PB") and smear-positive ("MB") cases, are treated for six months. There is no doubt that this policy increases patient adherence to treatment and improves the performance of health workers in the field (WHO 1997b, 2002).

Analogously, many believe that the regular 12-month leprosy MB course can be shortened for a considerable proportion of, if not all, MB patients. Shortening the treatment in conjunction with increased treatment uniformity could help field programmes, particularly in situations where leprosy control is integrated into general health services. A uniform leprosy treatment regimen would simplify treatment in the field and halve the treatment duration for MB patients. This change may increase the treatment completion rates, given that these rates are consistently better for PB patients compared to MB patients. Previous results from different control programmes (WHO 1994) and research projects (BecxBleumink 1992) have demonstrated that relapse rates following MDT were low, approximately $0.2 \%$ annually among MB cases with the 24-dose regimen (Jesudasan et al. 1996, Dasananjali et al. 1997, Li et al. 1997). The low relapse rates suggested that there was room to shorten the course of MDT to fewer than the 24 supervised monthly doses of rifampicin plus self-administered doses of dapsone and clofazimine (Vijayakumaran et al. 1996, Li et al. 1997). A 12-month treatment course for MB leprosy 
has been generally recommended by the WHO since 1998 (WHO 1997a). Although some studies suggest that post-MDT relapse rates may be significantly higher in the MB patients who have an initial bacterial index (BI) $\geq 4$ (Jamet \& Ji 1995), the present leprosy disease group includes few patients with those characteristics. Furthermore, the total number of relapses among these patients would account for a minimal percentage of cases in a control programme (WHO 1997b).

The objective of this clinical trial is to evaluate whether uniform (U)-MDT for leprosy is clinically and statistically equivalent in efficacy to the regular regimen (R-MDT), to determine patient tolerability of the U-MDT regimen among PB patients and to identify the prognostic factors that might influence the U-MDT outcomes.

The current paper presents detailed methodology of the clinical trial and the data obtained from patients thus far.

\section{SUBJECTS, MATERIALS AND METHODS}

Study design - An open-label, randomised clinical trial design was used to compare two treatment regimens (R-MDT vs. U-MDT) with monthly patient follow-ups during the treatment period and for the first six months following treatment cessation for the MB patients in the U-MDT study group. This procedure was followed by yearly post-treatment visits for six years. The study population included newly diagnosed, previously untreated PB and MB leprosy patients (LPs) and returning defaulters and relapse cases, provided that the last treatment dose was more than five years prior to enrolment in the study. All of the patients were between the ages of six65. Patients were excluded if they were receiving TB or steroid treatment, had overt signs of acquired immune deficiency syndrome, were not residing permanently in the area or were unable to visit the clinic every month during the treatment and follow-up periods (Fig. 1).

Study location - A pilot study of 78 patients was conducted at the Federal University of Minas Gerais (UFMG) from November 2004-June 2006 to test all of the study protocols and clinical report forms (CRF). Following adjustments to those protocols, based on the pilot study, patients were recruited from March 2007-February 2012 at two national leprosy reference centres: Dona Libânia (Fortaleza, state of Ceará) and Alfredo da Matta (Manaus, state of Amazonas). A multidisciplinary team composed of 12 physicians (including pathologists and neurologists), nine nurses, five physiotherapists and five biochemists was responsible for patient recruitment and monitoring.

Regular patients - A patient receiving regular PBMDT or U-MDT treatment is considered a "regular patient" when he/she completes six months of treatment within nine months. A patient receiving regular MBMDT treatment is considered a "regular patient" when he/ she completes 12 months of treatment within 18 months.

Irregular patients - Irregular patients are patients that complete treatment, but do not do so in the required nine or 18 months, as specified above. Instead, irregular patients who receive $\mathrm{PB} / \mathrm{U}-\mathrm{MDT}$ and MB-MDT treatment complete their regimens within 12 and 24 months, respectively. These patients will be subject to follow-up evaluations, but their "irregular patient" status will be clearly indicated for data analysis purposes in this study.

Defaulters - A patient receiving regular PB-MDT or U-MDT treatment is considered a "defaulter" if he/ she does not complete six months of treatment within 12 months. A patient receiving regular MB-MDT treatment is considered a "defaulter" if he/she does not complete 12 months of treatment within 24 months. A patient who does not complete treatment within the required period will be removed from the study.

Screening log - All of the patients who were examined in the reference centres as possible LPs were registered in the screening log (Fig. 2).

Randomisation - The patients were randomised to ensure valid comparisons between the treatment regimens (R-MDT and U-MDT) in each subgroup after being classified into $\mathrm{PB}$ and $\mathrm{MB}$ based on their number of skin lesions (Fig. 1). A random list of numbers was prepared using the CRF. The randomisation codes on the worksheet were covered with the same material that is utilised for lottery scratch cards; therefore, the printed numbers were not visible. The randomisation numbers for the PB patients were revealed at the beginning of chemotherapy; for the MB patients, the number was revealed on the day the patient arrived for their sixth treatment dose.

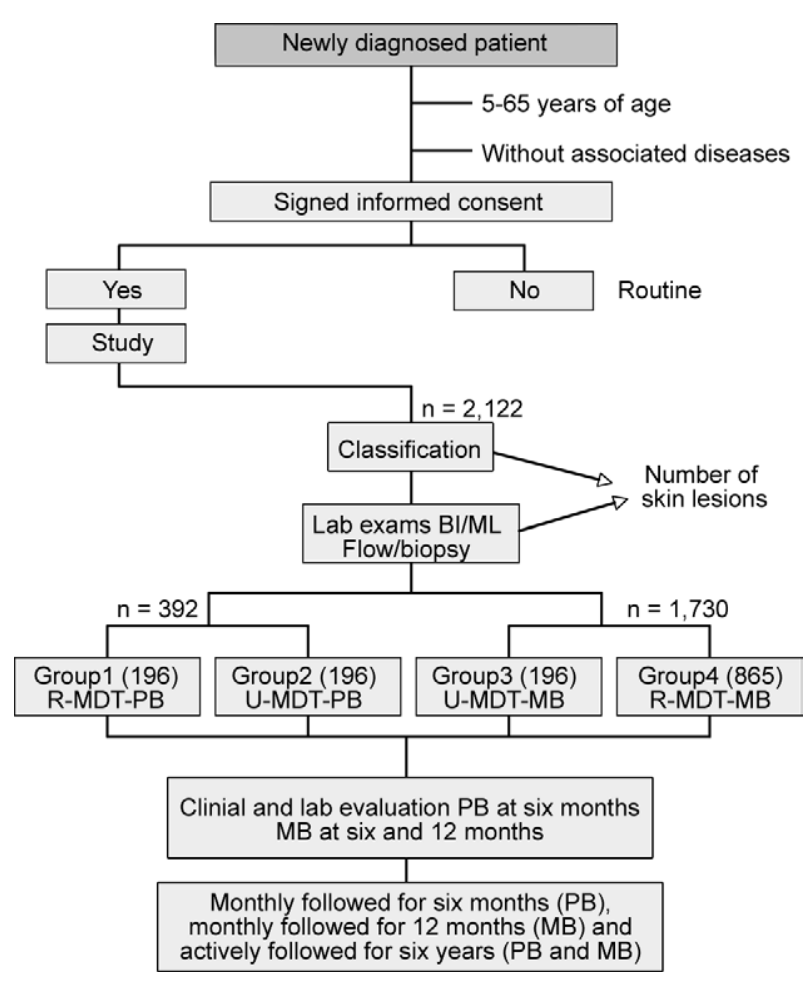

Fig. 1: clinical trial for uniform multidrug therapy (U-MDT) for leprosy patients in Brazil. BI: bacterial index; MB: multibacillary; PB: paucibacillary. 
Patient information - The patient characteristics and clinical parameters were recorded and the number of lesions and affected nerves were registered. Slit-skin smears were also taken to identify those patients with high BI and the ML Flow test was used to detect antiMycobacterium leprae phenolic glycolipid-I (PGL-I) antibodies (Bührer-Sékula et al. 2003, Oskam et al. 2003). As a baseline for all new entries and again for the patients who were suspected of relapse during the follow-up period, punch biopsies were taken for histopathological analyses. The additional test results were considered in the final patient classification that was used in the analysis.

Study groups - The U-MDT PB and U-MDT MB groups consisted of the patients who received the sixmonth U-MDT regimen, as defined by the WHO protocol, which corresponded to six months of MB-MDT treatment with three drugs.

Control groups - The R-MDT PB and R-MDT MB groups consisted of the patients who received the standard WHO treatment regimens: six months of treatment with two drugs for the PB patients and 12 months of treatment with three drugs for the MB patients.

Reactions and impaired nerve function - If a patient developed reactions or impaired nerve function, he/ she received appropriate treatment and remained in the study. All of the reaction and impaired nerve function episodes were registered.

Reaction or relapse - If there was difficulty distinguishing between reaction and relapse (5\% of all reactions/relapses) then an independent and experienced specialist was consulted.

Laboratory exams - To evaluate the side effects and toxicities of the three drugs, in addition to the standard clinical examinations, the patients underwent monthly

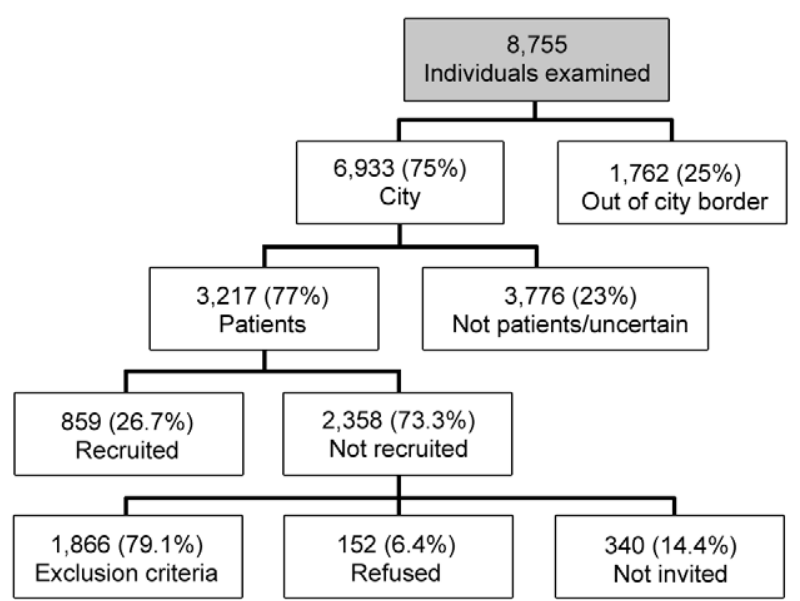

Fig. 2: screening $\log$ for recruitment of patients from March 2007February 2012 in Manaus, state of Amazonas, and Fortaleza, state of Ceará, Brazil. laboratory testing during treatment to monitor any haematological or hepatic alterations (full blood tests and transaminases).

Treatment - The patients were randomly assigned to one of two study sub-groups according to the standard $\mathrm{PB} / \mathrm{MB}$ classification (based on the number of skin lesions). The patients returned to the clinic for monthly medical evaluations and to receive new monthly blister packs, which is consistent with the current standard of care in the leprosy control programme in Brazil. Whenever reactions and impaired nerve function occurred in either study group, the affected patients were treated according to standard protocol.

Follow-up during treatment - The patients were monitored monthly for adverse reactions, impaired nerve function or side effects. In addition, the patients were asked to return to the clinic immediately if they experienced reactions or impaired nerve function.

Follow-up after treatment - Slit-skin smears are taken at the end of treatment and during follow-up for the patients who were slit-skin positive at the beginning of treatment. The U-MDT MD study group patients are examined for reactions and impaired nerve function monthly for six months after the end of treatment. The patients are actively monitored for reactions, impaired nerve function and relapses once yearly for six years post-treatment. In addition, the patients were asked to return to the clinic if any adverse reactions or side effects occurred (reactions, impaired nerve function and relapse). If relapse is suspected, slit-skin smears will be taken and serum tested to confirm or support the clinical diagnosis. If a patient is diagnosed as a relapse case, they will be treated according to standard practice: six additional doses for the $\mathrm{PB}$ patients and 12 additional doses for the MB patients. The event will be recorded and considered the end point of follow-up for data analysis purposes.

The U-MDT/CT-BR clinical report form and standard operating procedures are available as Supplementary data.

Ethical considerations - The study was performed under international (Helsinki) and Brazilian research regulations regarding human beings and was approved by three regional research ethical committees from the states involved in the study as well as the National Ethical Research Commission. Written informed consent was obtained from all the patients prior to inclusion in the study. For patients aged six-17 years, written parental consent was required. Data confidentiality was strictly guaranteed. The patients were free to leave the study and opt for the R-MDT regimen outside the study (ClinicalTrials.gov identifier: NCT00669643).

Sample - In both treatment groups, the sample size was based on the hypothesis of equivalence for the disease cure, absent relapses or reactions. Given that relapse is the less frequent event, the sample size was based on its estimated frequency. We assumed that the 12-month overall cumulative relapse rate of R-MDT after nine years of follow-up would not exceed $1 \%$; there- 
fore, we set a threshold for the acceptable occurrence of relapse following U-MDT equal to $2.6 \%(1 \% \pm 1.6 \%)$. To ensure $80 \%$ power to detect a statistically significant difference in the relapse rates $(1 \%$ of persons treated according to R-MDT vs. $2.6 \%$ for persons treated with U-MDT), a sample size of 1,181 persons was required for each branch of the study. The data analysis will be multivariate to control for other prognostic factors, such as the patients' bacterial loads.

\section{RESULTS}

Profile of patient enrolment to date - At the end of February 2012, 858 patients were enrolled in this study: $79 \%$ in Fortaleza and 21\% in Manaus. Fig. 2 shows the screening log for patient recruitment and Table I shows the distribution by study centre. Table II shows the baseline characteristics (age, sex, the number of nerves affected, the BI and the PGL serologic result) for the enrolled patients in each classification group.

\section{DISCUSSION}

There are multiple leprosy care paradigms and the need for a robust, evidence-based response has motivated previous investigation into the viability of uniform treatment for all LPs, independent of their clinical classifications (Lockwood \& Suneetha 2005, van et al. 2010, WHO 2010, Penna 2011, Penna et al. 2011). This uniform treatment would be a step forward in controlling a disease that will affect Brazil for the foreseeable future, perhaps with incapacitating consequences (Penna et al. 2009).

The lengthy treatment course has become one of the main obstacles to implementing MDT (Ganapati et al. 1992), particularly in regions where the existing health infrastructure is poor and inaccessible. Leprosy classification is a problem for general health workers who have only received one or two days of training, particularly where leprosy control is fully integrated into health services; the number of areas where this situation occurs will increase in coming years (Barreto et al. 2011). In cultures where

\section{TABLE I}

Enrolment status by leprosy type according to World Health Organization criteria based on number of skin lesions and by study centre, uniform multidrug therapy trial, Brazil 2011

\begin{tabular}{lccc}
\hline & \multicolumn{3}{c}{ Patients enrolled } \\
\cline { 2 - 4 } Centres & $\begin{array}{c}\text { Paucibacillary } \\
(<6 \text { lesions }) \\
\mathrm{n}(\%)\end{array}$ & $\begin{array}{c}\text { Multibacillary } \\
(\geq 6 \text { lesions })\end{array}$ & $\begin{array}{c}\text { Total } \\
\mathrm{n}(\%)\end{array}$ \\
\hline CDERM & 126 & 552 & $678(79)$ \\
FUAM & 59 & 121 & $180(21)$ \\
\hline Total & $185(21.5)$ & $673(78.4)$ & $858(100)$
\end{tabular}

CDERM: Dermatology Centre Dona Libânia, Fortaleza, state of Ceará; FUAM: Foundation of Tropical Dermatology and Venereology Alfredo da Matta, Manaus, state of Amazonas. only partial skin examination can be conducted, a classification system that is based on a skin lesion count is difficult to implement consistently (WHO 1997b, 2002).

Recently, an open-field, non-controlled treatment trial was conducted to determine the efficacy of a sixmonth treatment regimen that consisted of three drugs (rifampicin at $600 \mathrm{mg} / \mathrm{month}$, dapsone at $100 \mathrm{mg} /$ day and clofazimine at $50 \mathrm{mg} /$ day as well as $300 \mathrm{mg} / \mathrm{month}$ ) for all LPs; the trial was coordinated by the National Institute of Epidemiology of the Indian Council of Medical Research. From November 2003-May 2007, 2,912 patients (India, 2,746, China, 166) were enrolled, with 39\% of patients classified as MB solely on the number of skin lesions, $3 \%$ of whom had grade 2 disabilities. During the follow-up, only 27 patients $(0.9 \%)$ developed new lesions, $78 \%$ of which were caused by reactions. Six patients had clinically confirmed relapse and $2.9 \%$ of patients were lost during the follow-up period. In the study, $85.9 \%$ of the patients completed treatment and $19 \%$ had inactive skin lesions. In general, the PB patients responded better than the MB patients $(27 \%$ vs. $6 \%, \mathrm{p}<0.001)$. In the post-U-MDT follow-up, at the end of the first $(n=2013)$ and second years $(\mathrm{n}=807)$, the lesions were inactive in $49 \%$ and $46 \%$ of patients, respectively [59\% (year 1) and $57 \%$ (year 2) in PB, 37\% (year 1) and 28\% (year 2) in $\mathrm{MB}, \mathrm{p}<0.001]$ (Kroger et al. 2008).

\section{TABLE II}

Baseline characteristics of patients enrolled for uniform multi-drug therapy trial, Brazil 2011

\begin{tabular}{|c|c|c|c|}
\hline Characteristic & $\begin{array}{c}\text { Paucibacillary } \\
\text { n (\%) }\end{array}$ & $\begin{array}{c}\text { Multibacillary } \\
\text { n (\%) }\end{array}$ & $\begin{array}{l}\text { Total } \\
\mathrm{n}(\%)\end{array}$ \\
\hline Patients enrolled & $185(22)$ & $673(78)$ & $858(100)$ \\
\hline \multicolumn{4}{|l|}{ Age group (years) } \\
\hline$\leq 14$ & $20(10.8)$ & $37(5.5)$ & $57(6.6)$ \\
\hline $15-64$ & $163(88.1)$ & $634(94.2)$ & 797 (92.9) \\
\hline 65 & $2(1.1)$ & $2(0.3)$ & $4(0.5)$ \\
\hline \multicolumn{4}{|l|}{ Sex } \\
\hline Male & $62(33.5)$ & 447 (66.4) & $509(59.4)$ \\
\hline Female & $123(66.5)$ & $226(33.6)$ & $349(40.6)$ \\
\hline \multicolumn{4}{|l|}{ Nerve lesions } \\
\hline 0 & 165 (89.2) & $389(57.8)$ & $554(64.6)$ \\
\hline 1 & $6(3.2)$ & $95(14.1)$ & $101(11.8)$ \\
\hline 2 & $8(4.3)$ & $96(14.3)$ & $104(12.1)$ \\
\hline$\geq 3$ & $6(3.2)$ & $93(13.8)$ & 99 (11.5) \\
\hline \multicolumn{4}{|l|}{ Slit skin smear (BI) } \\
\hline 0 & $174(94.6)$ & $192(28.5)$ & $366(42.6)$ \\
\hline $0.1-2.99$ & $10(5.4)$ & $158(23.5)$ & $168(19.6)$ \\
\hline$\geq 3$ & 0 & $324(48)$ & (37.7) \\
\hline Not informed & - & - & $1(0.1)$ \\
\hline \multicolumn{4}{|l|}{ PGL-I serology } \\
\hline 0 & $155(83.8)$ & $174(25.8)$ & $329(38.4)$ \\
\hline $1-3$ & $29(15.7)$ & $327(48.5)$ & $356(41.5)$ \\
\hline$>4$ & $1(0.5)$ & $171(25.3)$ & $172(20)$ \\
\hline Not informed & - & $1(0.5)$ & $1(0.1)$ \\
\hline
\end{tabular}

BI: bacterial index; PGL-I: phenolic glycolipid-I. 
This non-controlled trial did not include slit-skin smears or skin biopsies, which makes the determination of relapse unreliable. Additionally, because this trial did not include BI, it is not possible to evaluate which group of patients required longer treatment (Ji \& Grosset 1990).

The main problem when evaluating any new treatment regimen for leprosy is the lack of reliable data available for the current treatment regimen. The relapse, reactions and impaired nerve function rates have never been systematically determined (Ji 1985) and reactions and impaired nerve function are the major causes of nerve damage that leads to impairments and disabilities in LPs (Ji 1998).

Our study was designed to overcome the need for reliable data about the current treatment regimen and to statistically compare its efficacy with that of a uniform regimen.

This independent study was coordinated by the Tropical Medicine Centre of the University of Brasília (NMT/ UnB) with the participation of the Institute of Public Health and Tropical Pathology of the University of Goiás. This study received funding from the Department of Science and Technology and National Council for Scientific and Technological Development (403293/2005-7). It was conceptualised, designed and developed by the NMT/ UnB in partnership with the Royal Tropical Institute of Amsterdam and with scientific support from members of the International Federation of Anti-leprosy Association Medical Commission during all phases, except for the pilot study, which was used to test the research forms at the Clinical Hospital of the UFMG. The study has an independent scientific steering committee that included Drs Celina Maria Turchi Martelli, Diana Lockwwod, Euzenir Sarno, Ji Bahong ${ }^{\dagger}$, Maria Leide Wand-del-Rey de Oliveira, Paulo Roberto Lima Machado, Vijaykumar Pannikar and Sinésio Talhari. Three of these committee members also form the Database Monitoring and Security Committee: Drs Maria Leide Wand-del-Rey de Oliveira, Paulo Roberto Lima Machado and Sinésio Talhari. Their tasks are the following: (i) assessing the field protocol before intake, (ii) assessing the results at the end of the monthly follow-up period, (iii) performing a mid-term evaluation of the results after six years of follow-up and (iv) performing a final evaluation.

\section{ACKNOWLEDGEMENTS}

To Duane Hinders, for review of the English version, and to Edite Damásio da Silva, for reviewing the figures.

\section{REFERENCES}

Banerjee DK, Rmott-Lancaster RD, McKenzie S 1997. Experimental evaluation of possible new short-term drug regimens for treatment of multibacillary leprosy. Antimicrob Agents Chemother 41: 326-330.

Barreto ML, Teixeira MG, Bastos FI, Ximenes RA, Barata RB, Rodrigues LC 2011. Successes and failures in the control of infectious diseases in Brazil: social and environmental context, policies, interventions and research needs. Lancet 377: 1877-1889.

Becx-Bleumink M 1992. Relapses among leprosy patients treated with multidrug therapy: experience in the leprosy control program of the All Africa Leprosy and Rehabilitation Training Center (ALERT) in Ethiopia - practical difficulties with diagnosing relapses, operational procedures and criteria for diagnosing relapses. Int J Lepr Other Mycobact Dis 60: 421-435.
Bührer-Sékula S, Smits HL, Gussenhoven GC, van Leeuwen J, Amador S, Fujiwara T, Klatser PR, Oskam L 2003. Simple and fast lateral flow test for classification of leprosy patients and identification of contacts with high risk of developing leprosy. J Clin Microbiol 41: 1991-1995.

Dasananjali K, Schreuder PA, Pirayavaraporn C 1997. A study on the effectiveness and safety of the WHO/MDT regimen in the northeast of Thailand; a prospective study, 1984-1996. Int J Lepr Other Mycobact Dis 65: 28-36.

Ganapati R, Shroff HJ, Gandewar KL, Prasad Rao BR, Pai RR, Kute AS, Fernandes TX, Revankar CR, Pawar PL 1992. Five year follow-up of multibacillary leprosy patients after fixed duration chemoterapy. Health cooperation papers. Int J Lepr 60: 421-435.

Jamet P, Ji B 1995. Relapse after long-term follow up of multibacillary patients treated by WHO multidrug regimen. Marchoux Chemotherapy Study Group. Int J Lepr Other Mycobact Dis 63: 195-201.

Jesudasan K, Vijayakumaran P, Manimozhi N, Jeyarajan T, Rao PS 1996. Absence of relapse within 4 years among 34 multibacillary patients with high BIs treated for 2 years with MDT. Int $J$ Lepr Other Mycobact Dis 64: 133-135.

Ji B 1985. Drug resistance in leprosy - a review. Lepr Rev 56: 265-278.

Ji B 1998. Why multidrug therapy for multibacillary leprosy can be shortened to 12 months. Lepr Rev 69: 106-109.

Ji B, Grosset JH 1990. Recent advances in the chemotherapy of leprosy. Lepr Rev 61: 313-329.

Kroger A, Pannikar V, Htoon MT, Jamesh A, Katoch K, Krishnamurthy P, Ramalingam K, Jianping S, Jadhav V, Gupte MD, Manickam P 2008. International open trial of uniform multi-drug therapy regimen for 6 months for all types of leprosy patients: rationale, design and preliminary results. Trop Med Int Health 13: 594-602.

Li HY, Hu LF, Huang WB, Liu GC, Yuan LC, Jin Z, Li X, Li JL, Yang ZM 1997. Risk of relapse in leprosy after fixed-duration multidrug therapy. Int J Lepr Other Mycobact Dis 65: 238-245.

Lockwood DN, Suneetha S 2005. Leprosy: too complex a disease for a simple elimination paradigm. Bull World Health Organ 83: 230-235.

Oskam L, Slim E, Bührer-Sékula S 2003. Serology: recent developments, strengths, limitations and prospects: a state of the art overview. Lepr Rev 74: 196-205.

Penna GO 2011. Leprosy: the need to employ evidence-based medicine in control policies around the world. Lepr Rev 82: 210-212.

Penna ML, de Oliveira ML, Penna GO 2009. The epidemiological behaviour of leprosy in Brazil. Lepr Rev 80: 332-344.

Penna ML, Pedrosa VL, Pereira ES, Penna MLF, Pedrosa VL, Pereira ES 2012. Leprosy decline in Amazonas state, Brazil. Tropical medicine and international health. Trop Med Int Health 17: 244-246.

Penna ML, Penna GO 2007. Trend of case detection and leprosy elimination in Brazil. Trop Med Int Health 12: 647-650.

Penna ML, Temporao JG, Grossi MA, Penna GO 2011. Leprosy control: knowledge shall not be neglected. J Epidemiol Community Health 65: 473-474.

Scollard DM 2005. Leprosy research declines, but most of the basic questions remain unanswered. Int J Lepr Other Mycobact Dis 73: $25-27$.

Talhari S, Penna G 2005. Considerations about global policy for leprosy control. Rev Soc Bras Med Trop 38: 362-364.

van BW, Cross H, Declercq E, Deepak S, Lockwood D, Saunderson P, Smith WC, Batty J, Nahodilova L, Soutar D, Augustine V, Ebenso B 2010. Review of leprosy research evidence (2002-2009) and implications for current policy and practice. Lepr Rev 81: 228-275. 
Vijayakumaran P, Jesudasan K, Manimozhi N 1996. Fixed-duration therapy (FDT) in multibacillary leprosy: efficacy and complications. Int J Lepr Other Mycobact Dis 64: 123-127.

WHO - World Health Organization 1982. Chemotherapy of leprosy for control programmes. WHO Tech Rep Ser 675: 1-33.

WHO - World Health Organization 1994. Leprosy unit. Risk of relapse in leprosy, WHO, Geneva, $20 \mathrm{pp}$.

WHO - World Health Organization 1997a. Leprosy elimination. WHO Seventh Expert Committee, WHO, Geneva, 43 pp.

WHO - World Health Organization 1997b. Shortening duration of treatment of multibacillary leprosy. Weekly Epidemiol Rec 72: 125-132.

WHO - World Health Organization 2002. Uniform MDT regimen for all leprosy patients. Available from: who.int/entity/lep/resources/SWG02.pdf

WHO - World Health Organization 2010. Leprosy (Hansen disease). Report by the Secretariat, Executive Board 128th Session, EB128/16. Available from: apps.who.int/gb/ebwha/pdf_files/ EB128/B128_16-en.pdf.

WHO - World Health Organization 2011. Working to overcome the global impact of neglected tropical diseases: first WHO report on neglected. Available from: who.int/neglected_diseases/2010report/ en/index.html.

WHO - World Health Organization 2012. Accelerating work to overcome the global impact of neglected tropical diseases - A roadmap for implementation, WHO, Geneva, $15 \mathrm{pp}$. 


\section{STANDARD OPERATIONAL PROCEDURES}

\section{SOP}

\section{$U-M D T$}

Dona Libânia National Dermatological Reference Centre Fortaleza (CE)

Alfredo da Matta Foundation - Manaus (AM) 
Independent study to establish the efficacy of the six dose uniform MDT regimen

(U-MDT) for leprosy patients

\section{Index}

SOPs

Page

UMDT 001

SCREENING LOG

3

UMDT 002 HEALTH CENTRE PATIENT CHART

4

UMDT $003 \quad$ ADMISSION OF PATIENT TO PROTOCOL 5

$\begin{array}{lll}\text { UMDT } 004 & \text { PATIENT CONSENT FORM (CF) }\end{array}$

$\begin{array}{lll}\text { UMDT } 005 & \text { RANDOMISATION }\end{array}$

$\begin{array}{lll}\text { UMDT } 006 \quad \text { CRF - U-MDT } & 11\end{array}$

$\begin{array}{lll}\text { UMDT } 007 & \text { STUDY COMMENCEMENT }\end{array}$

$\begin{array}{lll}\text { UMDT } 008 & \text { PATIENT HISTORY } & 14\end{array}$

$\begin{array}{lll}\text { UMDT } 009 & 16\end{array}$

UMDT 010 DERMATOLOGICAL-NEUROLOGICAL EXAMINATION 18

UMDT 011 SIMPLIFIED NEUROLOGICAL FUNCTION AND COMPLICATIONS EXAM 24

UMDT 012 LABORATORY EXAM REQUESTS 32

UMDT 013 DRAWING AND STORAGE OF BLOOD 33

$\begin{array}{lll}\text { UMDT } 014 & \text { BIOPSY } & 36\end{array}$

$\begin{array}{lll}\text { UMDT } 015 & \text { HISTOPATHOLOGICAL EXAM }\end{array}$

$\begin{array}{lll}\text { UMDT } 016 \quad \text { BACILLOSCOPY } & 43\end{array}$

UMDT $017 \quad$ ML FLOW TEST

UMDT 018 PREPARATION OF REAGENTS FOR THE SULFONURIA TEST

$\begin{array}{lll}\text { UMDT } 019 & \text { SULFONURIA TEST } & 58\end{array}$

$\begin{array}{lll}\text { UMDT } 020 & \text { MONTHLY VISITS } & 61\end{array}$

$\begin{array}{lll}\text { UMDT } 021 & \text { LEPROSY REACTIONS }\end{array}$

$\begin{array}{lll}\text { UMDT } 022 & \text { SIDE EFFECTS OF MDT }\end{array}$

$\begin{array}{lll}\text { UMDT } 023 & 75\end{array}$

$\begin{array}{lll}\text { UMDT } 024 & \text { PATIENT WITHDRAWAL FROM STUDY }\end{array}$

APPENDIX I of SOP U-MDT 012

APPENDIX I of SOP U-MDT 013

APPENDIX I of SOP U-MDT 015 


\section{SCREENING LOG}

\section{OBJECTIVE:}

To determine if the person will be able to participate in the study

\section{RESPONSIBLE:}

- Project secretary

- Physician / Nurse (assistant)

\section{PRECAUTIONS:}

- Estimate expenses and availability of supplies for this study.

\section{MATERIAL}

- Patient registry screening log

- Standard screening log

- Black pen

\section{PROCEDURES}

\section{Project Secretary}

1. Include all patients that were enrolled as possible leprosy patients in the patient registry screening log.

2. Fill out spaces 1 to 5 on the form, with information received from the patients

3. Fill out the patient's name on the standard screening log.

4. Forward the standard screening log to the physician or nurse to complete.

5. At the end of each work shift, collect all standard screening logs filled out by the nurses and physicians.

6. Complete spaces 6 and 7 on the patient registry screening log with information taken from the standard screening log that was filled out for each patient.

7. File the forms in the appropriate folder labelled U-MDT/SCREENING LOG, located in the study's coordination office.

\section{Physician / Nurse (assistant)}

1. Review the inclusion and exclusion criteria.

2. Indicate on the standard screening log the reason for non-inclusion of the patient in the study.

NOTE: It is of the utmost importance that the standard screening log is completed so that the research coordinators can track the reasons for non-inclusion in the study. 


\section{HEALTH CENTRE PATIENT CHART}

\section{OBJECTIVE:}

To prepare the health centre patient chart (source document) to include all U-MDT protocol forms to be completed during patient visits for the duration of the study.

\section{RESPONSIBLE:}

- Sector worker responsible for opening patient charts

\section{PRECAUTIONS:}

- Estimate expenses and availability of supplies for this study.

\section{MATERIALS:}

- Registration book for the opening of patients' charts

- One brown envelope

- $\quad$ Ball-point pen

- $\quad$ Colour sticker for the identification of participants in patient chart

- $\quad$ Patient visit and follow-up card

- Forms:

- Standard patient chart

- Epidemiological notification form

- Health centre monthly follow-up card

\section{PROCEDURES:}

1. Note the following data in the registration book of patient charts:
a. Patient's full name
b. Date of birth
c. Date chart opened
d. Complete address with telephone number
e. Registration number in the health centre (chart number)

2. Identify the patient's envelope with: full name and health centre registration number.

3. Add the documents completed by the physician into the envelope

4. Fill out the patient's identification and visit follow-up card, writing down the health centre registration number, the patient's name, and give it to the patient.

5. Send the patient chart to the Medical Records Service. 


\section{SOP U-MDT 003}

\section{ADMISSION OF PATIENT TO PROTOCOL}

\section{OBJECTIVE:}

To ensure that all procedures for patient inclusion into protocol are followed.

\section{RESPONSIBLE: ‘}

Physician on duty

\section{PRECAUTIONS:}

Verify that all necessary materials are available.

\section{MATERIAL:}

- 1 Clinical Report Form (CRF) -- U-MDT

- 1 loose copy of the consent form (CF).

- Black pen.

- Health Centre Patient Chart

- White coat

\section{PROCEDURES:}

1. Fill out the Patient Chart according to routine procedure.

2. Review the inclusion and exclusion criteria to ensure the eligibility of the patient.

a. Obtain demographic information and age of the patient.

b. Evaluate the cutaneous lesions and/or systemic symptoms.

c. Review history of previous treatment or treatment history for leprosy in the past 5 years.

d. Check history of intolerance to any of the drugs used.

e. Check for serious associated diseases e.g. HIV / AIDS, tuberculosis, malaria, cutaneous leishmaniasis, visceral leishmaniasis, lymphomas, leukaemia and immunosuppression.

f. Check for the presence of any difficulties in complying with study procedures.

3. Inform the patient about the study and the benefits and risks of treatment.

4. If the patient agrees to participate, fill out the patient identification data and his/her legal guardian (if applicable), (page $07 \mathrm{CRF}$ ) using black pen. 
5. Fill out the consent form (CF) and write down the names of the patient or any witnesses and/or the legal guardian (pages 08 and 09 of CRF) on both copies.

6. Date and sign the CF in the appropriate spaces.

7. Give the patient the 2 copies of the CF for him or his legal guardian (if the patient is a minor) and the witness (if illiterate) for them to date and sign using black pen.

8. Give the patient a copy of the CF.

9. Assign a number to the patient, according to the sequence of enrolment in the study.

10. Fill out the "form for study commencement" from the block of forms according to SOP U-MDT 007.

11. Give instructions regarding the procedures for patient exams.

12. If the inclusion and exclusion criteria are not completed, or if the CF is not signed, the patient will be directed to the nursing department to undergo routine health centre procedures according to its protocols. 


\section{SOP - U-MDT 004 \\ PATIENT CONSENT FORM (CF)}

\section{OBJECTIVES:}

To guarantee the enrolment of the patient in the study and initial procedures.

To guarantee the patient's rights as a volunteer and his/her confidence in the research team.

\section{RESPONSIBLE:}

Physician on duty

\section{PRECAUTIONS:}

- Always have copies of the consent form (CF) available in the centre.

- Make sure the CF forms include all the correct pages.

- Besides explaining the CF to the patient, give the patient time to read and become familiar with the study in order to avoid problems in the future.

- Do not begin other procedures before certifying the signature of the patient, witness and principal investigator.

- If the patient is illiterate, the signature can be substituted by a right thumb print.

\section{MATERIAL:}

1. One CRF.

2. One copy of the Consent Form.

3. Black pen.

4. Stamp pad (if necessary).

\section{PROCEDURE:}

1. If the patient is illiterate, find a witness to be present at the time of the procedure. The first option for a witness should be the person accompanying the patient; the second should be another patient at the health centre.

2. Give a copy of the CF to the patient.

3. Read the CF, explaining the procedures that will be followed.

4. Make sure all the questions are answered.

5. If necessary, let the patient read the CF again.

6. Give both copies of the CF to patient, witness and principal investigator for signatures in the corresponding spaces.

7. Give one copy of the signed CF to the patient; the other will be filed in the CRF. 


\section{SOP - U-MDT 005}

\section{RANDOMISATION}

\section{OBJECTIVE:}

To ensure that all patients' participation is randomised to reduce the probability of systematic errors.

\section{RESPONSIBLE:}

- General Research Coordinator

- Local Research Coordinator

\section{MATERIAL:}

- Randomisation table

- Black pen

\section{PRECAUTIONS:}

The eligibility criteria to enter the study will be determined at the beginning of the study. Patients that meet the inclusion criteria will be randomised into experimental (U-MDT) and control (R-MDT) groups. Prompt action will be important because the experimental group treatment for paucibacillary $(\mathrm{PB})$ patients will begin therapy with 3 drugs, and the control group with 2 drugs. The multibacillary (MB) patients will only be allocated to the experimental or control group after 6 months, at which time the experimental group will stop treatment for Hansen's disease, while the control group will finish the 12 months of therapy.

\section{PROCEDURES:}

The MDT-U co-ordination centre will create a randomisation table with codes for all the patients in the study based on a random list of numbers, using the study entrance sequence according to CRF number. The space in the worksheet that contains the randomisation code is covered with the same material utilised in lottery scratch cards so that the printed numbers are not visible. This code will determine the directions for treatment of each patient as follows: when the code corresponds to an odd number, the patient will be part of the experimental group 1 or 3 (UMDT), according to their classification as PB or MB, respectively. When the code corresponds 


\section{Independent study to establish the efficacy of the six dose uniform MDT regimen \\ (U-MDT) for leprosy patients}

to an even number, the patient will be part of control group 2 or 4 (R-MDT), according to their classification as PB or MB, respectively.

The study will enrol/randomise 392 PB patients and $1730 \mathrm{MB}$ patients eligible from Fortaleza and Manaus for the experimental and control groups.

This spreadsheet will be sent to the local coordinator of each recruiting centre, who will be responsible for the allocation of the patients to the study groups. For PB patients, the randomisation results will immediately be made known after the inclusion of the patient in the study. The randomisation results of each MB case will be kept blind in the spreadsheet until the patient completes 6 doses of the MDT regimen, at which point the local coordinator will reveal the code.

The local research coordinators will be responsible for:

- Coordinating data collection according to the eligibility criteria and the conclusion of the six doses of $P Q T / M B$.

- Keeping the patient randomisation spreadsheet under his/her watch.

- Coordinating the implementation of the directions for each patient's treatment.

The Data Manager of the coordination centre will be responsible for:

- Coordinating the preparation of the spreadsheet with the randomisation codes;

- Maintaining under his supervision a copy of the spreadsheet containing the randomisation results.

\section{DEFINITIONS:}

Study enrolment: The point at which the patient, after having met the initial eligibility criteria during the screening process and freely offering consent to participate in the study, is accepted and initiates the leprosy MDT regimen.

Allocation: The act of randomly designating a patient to either the experimental or the control treatment groups.

Eligibility: Determined during screening based on the inclusion/exclusion criteria for the study. The patients who meet the eligibility criteria and agree to participate in the study are enrolled in the study, randomised into the experimental or the control treatment groups and begin leprosy MDT in accordance with the operational classifications.

NOTE: the inclusion of patients with single lesions will cease when it reaches $20 \%$ of the total of PB patients in each recruiting centre. These numbers correspond to approximately 50 patients with a single lesion at the Dona Libânia Reference Centre and 25 patients with a single lesion at 
Independent study to establish the efficacy of the six dose uniform MDT regimen

(U-MDT) for leprosy patients

the Alfredo da Matta Foundation. The database coordination is responsible for informing the local coordinators that the recruitment of single lesion patients must be discontinued.

\section{SPREADSHEET FOR PATIENT RANDOMISATION}

\begin{tabular}{|c|c|c|c|c|c|c|c|}
\hline \multirow[t]{2}{*}{ CRF no. } & \multirow[t]{2}{*}{$\begin{array}{c}\text { Patient chart } \\
\text { number }\end{array}$} & $\begin{array}{c}\text { Inclusion } \\
\text { date }\end{array}$ & \multirow[t]{2}{*}{$\begin{array}{l}\text { Operational } \\
\text { Classification }\end{array}$} & \multirow{2}{*}{$\begin{array}{c}\begin{array}{c}\text { Randomisation } \\
\text { code }\end{array} \\
\mathbf{x x x x}\end{array}$} & \multicolumn{2}{|c|}{ Allocation Group } & $\begin{array}{l}\text { Group } \\
\text { allocation } \\
\text { date }\end{array}$ \\
\hline & & & & & $\square$ R-MDT & $\square$ U-MDT & \\
\hline & & & & $\mathbf{x x x x}$ & $\square$ R-MDT & $\square$ U-MDT & \\
\hline & & & & $\mathbf{x x x x}$ & $\square$ R-MDT & $\square$ U-MDT & \\
\hline & & & & $\mathbf{x x x x}$ & $\square$ R-MDT & $\square$ U-MDT & \\
\hline & & & & $\mathbf{x x x x}$ & $\square$ R-MDT & $\square$ U-MDT & \\
\hline & & & & $\mathbf{x x x x}$ & $\square$ R-MDT & $\square$ U-MDT & \\
\hline & & & & $x x x x$ & $\square$ R-MDT & $\square$ U-MDT & \\
\hline & & & & $x x x x$ & $\square$ R-MDT & $\square$ U-MDT & \\
\hline & & & & $\mathbf{x x x x}$ & $\square$ R-MDT & $\square$ U-MDT & \\
\hline & & & & $\mathbf{x x x x}$ & $\square$ R-MDT & $\square$ U-MDT & \\
\hline & & & & $\mathbf{x x x x}$ & $\square$ R-MDT & $\square$ U-MDT & \\
\hline & & & & $\mathbf{x x x x}$ & $\square$ R-MDT & $\square$ U-MDT & \\
\hline & & & & $x x x x$ & $\square$ R-MDT & $\square$ U-MDT & \\
\hline & & & & $x x x x$ & $\square$ R-MDT & $\square$ U-MDT & \\
\hline & & & & $x x x x$ & $\square$ R-MDT & $\square$ U-MDT & \\
\hline & & & & $x x x x$ & $\square \mathrm{R}-\mathrm{MDT}$ & $\square$ U-MDT & \\
\hline & & & & $x x x x$ & $\square$ R-MDT & $\square$ U-MDT & \\
\hline & & & & $x x x x$ & $\square$ R-MDT & $\square$ U-MDT & \\
\hline & & & & $x x x x$ & $\square$ R-MDT & $\square$ U-MDT & \\
\hline & & & & $\mathbf{x x x x}$ & $\square$ R-MDT & $\square$ U-MDT & \\
\hline & & & & $\mathbf{x x x x}$ & $\square$ R-MDT & $\square$ U-MDT & \\
\hline & & & & $\mathbf{x x x x}$ & $\square$ R-MDT & $\square$ U-MDT & \\
\hline & & & & $x x x x$ & $\square$ R-MDT & $\square$ U-MDT & \\
\hline & & & & $x x x x$ & $\square \mathrm{R}-\mathrm{MDT}$ & $\square$ U-MDT & \\
\hline & & & & $x x x x$ & $\square$ R-MDT & $\square$ U-MDT & \\
\hline
\end{tabular}




\section{SOP - U-MDT 006}

\section{$\underline{\text { CRF - U-MDT }}$}

\section{OBJECTIVE:}

To organise the necessary materials for patients participating in U-MDT trial.

\section{RESPONSIBLE:}

Project Secretary

\section{PRECAUTIONS:}

Estimate expenses and availability of supplies for this study.

\section{MATERIALS:}

- U-MDT CRF

- Black pen

\section{PROCEDURES:}

1. Check the appointment book of each attending physician for the study patients scheduled for the following day.

2. At the end of each day, set aside the CRFs of the patients scheduled for the following day.

3. At the beginning of each day, take the selected CRFs to the offices of the attending physicians.

4. Provide blank CRFs for the inclusion of new patients in the study, following the numerical sequence of inclusion in the study.

5. Provide blank copies of the informed consent forms, for inclusion of new patients in the study.

6. Ensure that a black pen is available in each medical consulting room for recording the information in the patient's CRF.

7. At the end of the attending physician's shift, collect all CRFs, used or not.

8. File the CRFs in numerical order, in the coordination office 


\section{SOP - U-MDT 007 \\ STUDY COMMENCEMENT}

\section{OBJECTIVE:}

To use the same methodology for all individuals participating in the trial.

\section{MATERIAL}

- White coat

- Black pen

- Patients charts

- CRF - U-MDT

\section{PROCEDURES}

\section{Physician}

1. After patient's enrolment in study protocol according to SOP 003 , begin completion of the CRF according to the order of admission into the study.

2. Classify the patient as $\mathrm{PB}$ or $\mathrm{MB}$, considering only the number of skin lesions regardless of the number of nerves affected, as per WHO guidelines.

3. The following tests and procedures must be done at the beginning of the study (treatment can be initiated before results are obtained)

a. Take the patient history systematically, according to SOP 008.

b. Conduct a general physical and dermato-neurological examination, according to SOP 009 and 010.

c. Determine de disability grade, according to SOP 011.

d. Request laboratory and histopathological tests, according to SOP 012.

\section{Laboratory}

1. Obtain blood samples for the laboratory tests and store serum, according to SOP 013.

2. Conduct the ML Flow test and attach the test results in the appropriate space, according to SOP 016

\section{Histopathology}

1. Obtain a sample of skin lesion fragments, according to SOP 014

2. Forward the material for histopathological examination, according to SOP 015. 
Independent study to establish the efficacy of the six dose uniform MDT regimen

(U-MDT) for leprosy patients

\section{Nursing}

1. Check the patient's operational classification.

2. For PB cases, verify the randomisation result for each patient.

3. Administer the medication under study to the patient.

4. Register in the "Investigational Dose Registration Form":

a. The number of pills given

b. Lot number

c. Expiration date

NOTE: The principal investigator must review all the data registered in visit and study commencement forms and sign at the bottom of each page. 
Independent study to establish the efficacy of the six dose uniform MDT regimen

(U-MDT) for leprosy patients

\section{SOP - U-MDT 008 \\ PATIENT HISTORY}

\section{OBJECTIVE}

To use the same methodology of data collection for all individuals participating in the study.

\section{RESPONSIBLE:}

Attending physician

\section{MATERIALS}

- White coat

- Black pen

- Patient Chart

- $\quad$ CRF - U-MDT

\section{PROCEDURES}

The information below will be collected through interviews with study participants and registered on the corresponding forms of the CRF and patient charts:

1. Identification data: (register on patient chart and the CRF)
a. Name
b. Sex: $M=$ male, $F=f e m a l e$
c. Date of birth: dd / $\mathrm{mm} /$ yyyy
d. Profession / occupation
e. Mother's name
f. Telephone
g. Complete Address (w/ neighbourhood)

2. Main symptoms (register on the standard patient chart of the health centre)

3. History of present disease (register on the standard patient chart)
a. Elapsed time since onset of symptoms
b. Contact with leprosy patients
c. Symptoms suggestive of leprosy 
d. BCG immunisation

4. Systematic review of patient history (register complaints in the patient chart and on page19 of the CRF, along with the physical examination findings).
a. Cardiovascular
b. Musculoskeletal
C. Respiratory
d. Gastrointestinal
e. Hepatic
f. Metabolic-endocrine
g. Genitourinary
h. Neurological
i. Psychiatric
j. Haematological-lymphatic
k. Others

5. Previous disease history (register in the patient chart)
a. Diseases and surgeries
b. Tobacco use
c. Alcohol use
d. Routine use of other medications
e. Investigate related diseases that could increase the risk of toxicity to the study drugs, such as: jaundice, hepatitis, arthritis/gout, convulsion, neuropathy, or diseases associated with diminished lifespan, such as diabetes mellitus, kidney failure and cancer.




\section{SOP -U-MDT 009 \\ PHYSICAL EXAMINATION}

\section{OBJECTIVE}

Use the same methodology of physical examination for all individuals participating in the study.

\section{MATERIALS}

- White coat

- Flashlight, batteries

- Tongue depressor

- Stethoscope

- Monofilament set

\section{PROCEDURES}

1. Register in the patient chart and in the Clinical-dermatological Evaluation Form (page 19 of the CRF) only the positive findings, along with the symptoms mentioned in the patient history (SOP 008).

2. The physical examination should be conducted in the following sequence and according to patient's complaints:

\section{Head and neck:}

a. Face: presence of infiltration

Eyebrows (hair loss and/ or madarosis)

Facial asymmetry

b. Eyes: mucous membrane of the ocular cavity: pink or pale, jaundiced or anicteric.

Madarosis of eyelashes

Ptosis of the eyelid

c. Nose: Check if there is nasal septum collapse

Dryness or crusting of the mucous membrane

Presence of exudates (mucous, serous, sanguineous)

d. Oral cavity: describe existing lesions

Examine teeth and palate

e. Ears: Presence of secretion

Presence of infiltration in the ear lobes

Presence of nodules in the ear lobes

f. Neck: Thickening of the retroauricular nerve 


\section{Cardiovascular system}

a. Heart rate: count the number of heart beats in a minute with the patient lying on his back;

b. Auscultation: describe the cardiac rhythm as regular/irregular, with or without murmurs;

c. Blood pressure

\section{Respiratory system}

a. Respiratory rate: carefully observe the movement of the thorax and abdomen, count the number of breaths during 30 seconds and multiply by 2 ;

b. Respiratory auscultation: this should be done in a quiet environment with the thorax of the patient uncovered. The patient should breathe slowly and deeply with the mouth opened without making noises. The auscultation should begin on the posterior thorax followed by the lateral and anterior faces of the thorax.

\section{Abdomen}

a. Hepatomegaly: present/absent

b. Splenomegaly: present/absent

c. Other alterations (describe)

Lymphonodes (in case of peripheral lymphadenomegaly, describe):

a. Location (cervical, axillary, supraclavicular, inguinal/femoral, other locations),

b. Consistency: soft or hardened, with or without fluctuation,

c. Adherence or non-adherence to deep tissues,

d. Presence or absence of inflammation (pain, heat, redness),

e. Presence or absence of fistulas (spontaneous or not) with draining of secretion.

\section{Extremities:}

a. Observe and palpate the arm and leg joints, detecting possible signs of inflammation,

b. Observe limitation of joint movements,

c. Oedema: present/absent,

d. Describe other abnormalities that may be present

\section{Genitourinary system:}

a. Normal / abnormal (in case of abnormalities, describe them) 


\section{SOP - U-MDT 010 \\ DERMATOLOGICAL-NEUROLOGICAL EXAMINATION}

Describe in Patient Chart and on page 18 of the CRF, any dermatological alterations encountered:

1. Describe the type of lesion, according to the following definitions:

a. Maculae: circumscribed areas different from the surrounding skin that is not elevated or depressed without superficial alterations;

b. plaques: solid structures, flattened, with easily-detected borders when passing a finger over the lesion; these can take variable forms (circular, oval, irregular), frequently erythematous;

c. Papules: solid elevation of the skin, small in size (up to $0.5 \mathrm{~cm}$ in diameter), superficial, well defined;

d. Nodules: solid, circumscribed lesions, elevated or not, above $0,5 \mathrm{~cm}$ in diameter, soft or firm consistency; when located in the hypodermis, they are more noticeable through palpation than inspection;

e. Infiltration: alteration in thickness and increase in the consistency of skin, with small evidence of ridges, imprecise limits and, eventually, erythema;

f. Anaesthetic area: area of skin without evident lesions, but with clear alteration of thermal, dolorous and/or tactile sensibility.

2. Describe alterations in lesion coloration, according to the following definitions:

a. Hypochromic: lighter than surrounding skin

b. Erythematous: of pinkish or reddish colouration

c. Hyperchromic: darker than surrounding skin

d. Normochromic: similar to regular skin 
3. Register the total of existing cutaneous lesions:
a. One to ten: register the exact number of lesions
b. Over 10: record code 11.
c. Presence of diffuse infiltration, without individual lesions: record code 88 .

4. Describe alterations in sensitivity in areas of lesions, according to the following definitions and abiding by the protocol below (item 5 ):
a. Altered: an abnormal response is observed every time the test is performed.
b. Dubious: different responses are observed when the test is performed.
c. Normal: correct response is observed every time the test is performed.

\section{Test of sensitivity of lesions:}

Changes in sensitivity of cutaneous lesions are caused by the impaired functioning of the cutaneous nerve branches. Usually there is a reduction of sensibility (hypoesthesia), and sometimes a complete absence of sensibility (anaesthesia). In the initial phase there may be an increase of sensibility (hyperesthesia).

5.1. The thermal sensibility test can be done using cold and hot water, or cotton wool soaked in ether.

\section{Test using hot and cold water:}

Necessary material: 2 test tubes, one with cold water, the other with water heated to $45^{\circ} \mathrm{C}$.

\section{Procedures:}

a. Explain to the patient how the test will be done.

b. Touch the healthy skin and the suspected area with the cold and hot test tubes, alternately.

c. Ask the patient to identify if the tube is cold or hot.

d. Touch the skin only with the bottom of the tube as touching it with the side of the tube will provide a larger contact area that could give a false result.

e. Take into consideration answers such as "colder" and "warmer".

f. Compare the results and make a conclusion about the alteration of sensibility. 
Independent study to establish the efficacy of the six dose uniform MDT regimen
(U-MDT) for leprosy patients

\section{Test with the ether-soaked cotton}

Necessary material: one cotton ball soaked in ether; another dry.

\section{Procedures:}

a. Explain to the patient how the test will be done

b. Touch the healthy skin and the suspected area with the dry or the ether-soaked cotton ball, alternately.

c. Ask the patient to mention when he feels a cold sensation.

d. Compare the results and make a conclusion about any alteration of sensibility.

\subsection{Test for tactile sensibility}

Necessary material: Thin strand of cotton wool

\section{Procedures:}

a. Explain to the patient how the test will be done and make sure they understand it correctly.

b. Touch the healthy skin and the suspected area alternately with the strand of cotton wool.

c. Ask the patient to let you know when he feels contact.

d. Compare the results and make a conclusion as to alterations of sensibility.

e. Remember that the tactile sensibility test can be normal even when the thermal and pain sensibility have already presented alterations.

6. Register the number of impaired nerves, whether thickened, painful and/or with altered neural function on p. 18 of the CRF, in the area of corresponding innervation, according to the protocol below (item 7).

\section{Examination of Peripheral Nerves:}

The main impaired nerves in leprosy are the ulnar, median, radial and radial cutaneous branch in the upper limbs, the fibular and tibial in the lower limbs, the auricular and supraorbital in the head. These main nerves should be systematically palpated before and during treatment, and also during the follow-up visits after treatment. Compare the palpated nerve on one side with the nerve on the opposite side, observing the texture, thickness, presence of nodules and adherence. Observe the face of the patient during examination to detect any signs of pain. 


\section{Independent study to establish the efficacy of the six dose uniform MDT regimen \\ (U-MDT) for leprosy patients}

a. Ulnar nerve-should be palpated at the level of the elbow at the trochlear notch, with the elbow flexed and the hand of the patient resting on the arm of the examiner.

b. Median Nerve - rarely palpable, because it passes deeply beneath the skin at wrist level. Determine if the patient feels pain or a shocking sensation when tapped.

c. Radial Nerve - the elbow should be flexed with the forearm of the patient supported by the hand of the examiner. The palpation should be done the upper arm, approximately two finger-widths behind the entrance of the deltoid.

d. Fibular Nerve - palpated at the level of the lower leg, approximately two fingerwidths behind and below the head of the fibula, with the patient seated, knees flexed and feet planted on the floor.

e. Posterior Tibial Nerve - palpated at the level of the ankle, behind and below the medial malleolus nerve, with the patient seated, knees flexed and feet planted on the floor or being held by the examiner.

f. Auricular Nerve - turn the head of the patient towards the shoulder opposite the side that will be examined and palpate the nerve located above the sternocleidomastoid muscle.

Regarding thickness, register findings according to the following scale:

$>0=$ normal; $1=$ thickened; $2=$ nerve abscess

Regarding pain, the intensity reported by the patient will be used, according to the following scale:

$>0=$ no pain; $1=$ weak pain; $2=$ strong pain

8. Determine and register the operational classification by the number of skin lesions, without regard to the number of nerves affected, as per the WHO classification (enter this information on page 18 of the CRF).

a. Paucibacillary (PB): cases with as many as 5 cutaneous lesions

b. Multibacillary (MB): cases with 6 or more cutaneous lesions

9. Determine and record the clinical classification as described below (enter on page 18 of CRF):

a. Indeterminate Leprosy(1)

One or few cutaneous lesions, normally presenting a skin lesion lighter than the normal skin, not elevated, with undefined borders, altered thermal sensibility, normal or slightly altered pain sensibility and tactile sensibility intact. There is no thickening of the nerve trunks. 
b. Tuberculoid Leprosy(2)

Skin lesion or plaques with papules or tubercles at the edges with hair loss, hypohidrosis or anhidrosis and clear loss of sensibility. Small number of lesions with asymmetric distribution. The nerve trunks are affected.

c. Lepromatous Leprosy(3)

Hypochromic or erythematous lesions, infiltrated, with irregular edges, papules, plaque infiltration, nodules (leproma), diffuse infiltrations in the face that can progress to madarosis of the eyelashes and eyebrows, deepening of the natural skin creases, altering the individual's appearance, often referred to as leonine face. The lesions are symmetrically distributed. The nerve trunks are affected.

d. Borderline Tuberculoid Leprosy(4)

More numerous skin lesions, more extensive and clinically similar to those of tuberculoid leprosy, tending to be symmetric. Numerous nerve trunks affected, plaque lesions with irregular borders that tend to form satellite lesions.

e. Borderline Borderline Leprosy(5)

Numerous skin lesions with poorly defined external edges and normally at the centre (foveolar or having a "Swiss cheese" appearance), plaque lesions, sometimes resembling the tuberculoid type; papular or tuberous lesions and infiltration similar to those observed in the lepromatous cases. There is a tendency towards symmetric distribution and considerable involvement of nerve trunks.

f. Borderline Lepromatous Leprosy(6)

Numerous skin lesions of differing types, such as infiltration, plaques (some foveolar), poorly defined external borders and nodules. There is a tendency towards symmetric distribution and thickening of many nerve trunks.

\section{IMPORTANT NOTE}

After receiving the exams results, the patient's physician, along with the study coordinators, both local and general, shall determine the final operational classification of the patient, which will be entered on page 18 of the CRF. 


\section{SOP - U-MDT 011}

\section{SIMPLIFIED NEUROLOGICAL FUNCTION AND COMPLICATIONS EXAM}

\section{OBJECTIVE}

To use the same methodology for determining the disability grade of all individuals participating in the study.

\section{MATERIAL}

- White coat

- Black pen

- Coloured pen set -- green, blue, purple, red, orange and black

- Flashlight

- Monofilament set

- Snellen eye chart

- Metric ruler

\section{PROCEDURES}

The information below will be collected by interviewing and examining the study participant: It should be recorded on the Simplified Neurological Function and Complications Exam Form at the beginning of the study, at the sixth month mark for patients of groups 3 and 4 , at the end of the treatment for all groups and following each leprosy reaction. (Procedure timetable - page 13 of the CRF)

\section{Nose}

a. Ask if the patient has a stuffy nose, increased secretion or persistent malodour.

b. Lightly press the tip of the nose and, using a flashlight, check the inside of the nostrils to determine if there is crusting due to drying, blisters and erosion spots in the mucosa, or perforation of the septum cartilage.

c. Register findings in the "Simplified Neurological Function and Complications Exam Form", using the code: Yes $(\mathrm{Y})$ or No $(\mathrm{N})$

\section{Eyes}

a. Ask the patient if he/she has burning, aching, redness or itching of the eyes.

b. Observe if patient blinks spontaneously. 
c. Evaluate the eyelid muscle tone:

i. Ask the patient to close his eyes slowly and, using the examiner's little finger, lift the upper eyelid, observing and feeling its resistance and its return to the original position once the eyelid is released:

- Diminished resistance indicates paresis

ii. Ask the patient to close his eyes forcefully and observe for symmetric wrinkling of the eyelids:

- Asymmetric wrinkling indicates paresis

- Presence of a gap between the eyelids with the eyes closed indicates lagophthalmos:

iii. With the patient closing the eyes softly and then forcefully, observe and measure (in $\mathrm{mm}$ ) the gap.

d. Observe:

i. Conjunctiva: hyperaemia, secretion, scars, nodules, ulcers.

ii. Cornea: transparency, homogeneity or reflection, scars, foreign bodies, vascularisation, white spots.

iii. Trichiasis - ingrown eyelashes.

iv. Ectropion - eversion of the eyelid.

v. Cataract - through the pupil, observe if the lens is whitened.

e. Visual acuity

i. Evaluation using eye chart

ii. The line 0.8 on the table should be located at eye level for the patient

iii. Set it 5 or 6 metres from the patient

iv. Explain the procedure to the patient

v. Evaluate each eye separately

vi. Use a black pencil to point to each optotype of the chart starting with the largest:

- $\quad$ Register the line that the patient correctly identifies $2 / 3$ of the optotypes

- If the patient cannot read the biggest one ( 0.05 or 0.1$)$, hold up a varying number of fingers and have him/her count them, starting at a distance of 6 metres and moving closer step by step:

- Take into account the distance in which the patient correctly counts the number of fingers 2 or 3 times.

- If he is not able to count correctly at a distance of 1 metre, check if the patient can perceive hand movements at that distance. If not, check if he/she is able to perceive light. 


\section{Independent study to establish the efficacy of the six dose uniform MDT regimen \\ (U-MDT) for leprosy patients}

$>$ Register disability on the Simplified Neurological Function and Complications Exam Form, using: Yes $(\mathrm{Y})$ or No $(\mathrm{N})$

\section{Upper limbs}

a. Observe:

i. Skin: hair loss, dryness, alterations of colour, conditions of the nails, oedema, calluses, scars, fissures, infiltration, macerations, traumatic or dermatologic lesions, conditions of the spaces between the fingers.

ii. Muscles: muscle volume of the thenar and hypothenar regions, the first and subsequent interosseus spaces and in the forearm.

iii. Fingers: observe the form and alignment of the metacarpals with the phalanx, the presence of deformities, bone absorption, retraction and the position of the fingers.

b. Nerve palpation

i. Ask the patient about presence of pain before beginning palpation

ii. Palpation of the main nerves must be done systematically, always comparing the palpated nerve on one side with the nerve on the opposite side, observing its thickness, texture, presence of nodules and if it has any type of adherence to surrounding tissues.

iii. Observe the patient's face during the palpation to detect any expression of pain.

iv. Ulnar Nerve - should be palpated at the level of the elbow at the trochlear notch, with the elbow flexed and the hand of the patient resting on the forearm of the examiner.

v. Median Nerve - rarely palpable, because at wrist level, it passes deeply beneath the surface of the skin. Determine if the patient feels pain or a shocking sensation when tapped.

vi. Radial Nerve - the elbow should be flexed with the forearm of the patient supported by the hand of the examiner, and the palpation should be done on the upper arm using two finger widths behind the entrance of the deltoid.

$>$ Register in the "Simplified Evaluation of the Neural Function Form", using the scale: normal $(\mathrm{N})$, thickened $(\mathrm{T})$, painful $(\mathrm{P})$.

$>$ Evaluation of Muscle Strength:

i. Ulnar nerve: ask the patient to extend the little finger (abduction) and maintain this position while the examiner tries to push it inward.

ii. Median nerve: ask the patient to keep the hand in a horizontal position and to raise the thumb and point it up (abduction), maintaining this position while the examiner tries to push it down. 


\section{Independent study to establish the efficacy of the six dose uniform MDT regimen \\ (U-MDT) for leprosy patients}

iii. Radial nerve: ask the patient to close the hand, flex the wrist backwards (extension) and hold this position while the examiner tries to push the hand down. When it is not possible to extend back, the hand is classified as having dropped.

$>$ Enter the results of this evaluation on the Simplified Neurological Function and Complications Exam Form, using the following scale:

\begin{tabular}{|l|l|l|}
\hline STRENGTH & LEVEL & DESCRIPTION \\
\hline \multirow{3}{*}{ strong } & 5 & $\begin{array}{l}\text { Can execute the full range of movement with } \\
\text { maximum resistance }\end{array}$ \\
\hline \multirow{3}{*}{ reduced } & 4 & Can execute full movement with partial resistance \\
\cline { 2 - 3 } & 3 & Can execute full movement with no resistance \\
\cline { 2 - 3 } & 2 & Can execute partial movement \\
\hline \multirow{3}{*}{ paralysis } & 1 & Muscle contraction without movement \\
\cline { 2 - 3 } & 0 & Paralysis, no movement \\
\hline
\end{tabular}

Inspection and sensitivity evaluation

\section{Test using the monofilament kit}

i. The monofilament is applied to the patient's skin perpendicularly which makes it bend. This bend point should not touch the skin of the patient so as to avoid an extra stimulus. Maintain this pressure for 1-1.5 seconds. Avoid sudden as well as very slow movements.

ii. If the filament slips when it touches the skin, disregard the patient's response and repeat the test at the same point.

iii. Ask the patient to answer "yes" when he/she can feel the monofilament, or point to the spot that is being touched.

iv. If there is any doubt, repeat the test at each point twice, to be sure of the result.

v. In case of positive and negative answers at the same point, consider it a correct response if the patient is right on at least 1 of 3 attempts.

vi. Begin the test using the green monofilament $(0.05 \mathrm{~g})$ at all the indicated points on the form.

vii. For each point tested, the green monofilament $(0.05 \mathrm{~g})$ and the blue one $(0.2 \mathrm{~g})$ should be applied 3 times in a row to ensure that the patient feels it. The remaining monofilaments in general, should only be applied once.

viii. At the points where the patient cannot feel the green monofilament, do the evaluation using the blue one and then the other monofilaments in order. 
Enter the answer on the Evaluation Form, colouring each point with the appropriate pen colour, or key code corresponding to each filament.

- $\quad$ Test 6 points on the hand, three in the area of ulnar innervation and three in the median nerve area.

\begin{tabular}{|c|c|c|}
\hline MONOFILAMENT & INTERPRETATION & CODE \\
\hline Green $(0.05 \mathrm{~g})$ & "Normal" sensibility in hands and feet. & $\begin{array}{l}\text { Green } \\
\text { dot }\end{array}$ \\
\hline Blue $(0.2 \mathrm{~g})$ & $\begin{array}{l}\text { Reduced sensibility in the hand, with difficulty in } \\
\text { relation to the lighter weight. Within normal range for } \\
\text { the foot. }\end{array}$ & Blue dot \\
\hline Purple $(2.0 \mathrm{~g})$ & $\begin{array}{l}\text { Reduced protective sensibility for the hand, but } \\
\text { enough to prevent damage. Difficulty discriminating } \\
\text { between form and temperature. }\end{array}$ & $\begin{array}{l}\text { Purple } \\
\text { dot }\end{array}$ \\
\hline Dark red $(4.0 \mathrm{~g})$ & $\begin{array}{l}\text { Loss of protective sensitivity for the hand and most } \\
\text { parts of foot. Vulnerable to tissue damage. Loss of } \\
\text { differentiation between hot and cold. }\end{array}$ & Red dot \\
\hline Orange $(10.0 \mathrm{~g})$ & $\begin{array}{l}\text { Loss of protective sensitivity for the foot, however may } \\
\text { still feel deep pressure and pain. }\end{array}$ & Red "X" \\
\hline Magenta $(300 \mathrm{~g})$ & Sensitivity to deep pressure, may still feel pain. & $\begin{array}{l}\text { Red } \\
\text { circle }\end{array}$ \\
\hline None & $\begin{array}{l}\text { Loss of Sensibility to deep pressure, normally cannot } \\
\text { feel pain. }\end{array}$ & Black dot \\
\hline
\end{tabular}

Observe and record on the Simplified Neurological Function and Complications Exam Form:

i. Mobile claw $(M)$ - reduction of active mobility of the joints and maintenance of the range of passive movement, even if this does not reach $100 \%$.

ii. Fixed claw (S) - when there is a loss of $25 \%$ or more of the passive mobility of the joint.

iii. Ulnar claw: affects the 4th and 5th digits

iv. Median claw: affects 2nd and 3rd digits.

v. Bone absorption in digits

vi. Wound

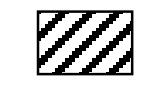

$\sum_{n+3}^{m}$

\section{Lower limbs}

\section{Palpation of the nerves}

- Fibular nerve- should be palpated two finger-widths behind and below the head of the fibula, with the patient seated with knees flexed and feet firmly on the floor. Damage to this nerve results in drop foot or an everted foot. 
- Tibial posterior nerve - should be palpated at ankle level, behind and below the medial malleolus, with the patient seated, knees flexed and feet on the floor or held by the examiner's hand.

- Register on the Simplified Neurological Function and Complications Exam Form, using the scale: normal $(N)$, thickened $(T)$, painful $(P)$.

Evaluation of Strength :

- To test the fibular nerve:

- $\quad$ ask the patient to lift the hallux (dorsiflexion) and keep it in this position, while the examiner tries to push it down;

- $\quad$ ask the patient to lift the entire foot (dorsiflexion) and keep it in this position, while the examiner tries to push it down;

- Write down on the Simplified Neurological Function and Complications Exam Form, using the following scale:

\begin{tabular}{|l|l|l|}
\hline STRENGTH & LEVEL & DESCRIPTION \\
\hline \multirow{3}{*}{ strong } & 5 & $\begin{array}{l}\text { Can execute the full range of movement with } \\
\text { maximum resistance }\end{array}$ \\
\hline \multirow{3}{*}{ reduced } & 4 & Can execute full movement with partial resistance \\
\cline { 2 - 3 } & 3 & Can execute full movement with no resistance \\
\cline { 2 - 3 } & 2 & Can execute partial movement \\
\hline \multirow{3}{*}{ paralysed } & 1 & Muscle contraction without movement \\
\cline { 2 - 3 } & 0 & Paralysis, no movement \\
\hline
\end{tabular}

Inspection and sensitivity evaluation

\section{Test using the monofilament set}

The monofilament is applied to the patient's skin perpendicularly which makes it bend. This bend point should not touch the skin of the patient so as to avoid an extra stimulus. Maintain this pressure for 1-1.5 seconds. Avoid sudden as well as very slow movements.

$>\quad$ If the filament slips when it touches the skin, disregard the patient's response and repeat the test at the same point

$>\quad$ Ask the patient to answer "yes" when he/she can feel the monofilament, or point to the spot that is being touched.

$>\quad$ If there is any doubt, repeat the test at each point twice, to be sure of the result. 


\section{Independent study to establish the efficacy of the six dose uniform MDT regimen (U-MDT) for leprosy patients}

$>\quad$ In case of positive and negative answers at the same point, consider it a correct response if the patient is right on at least 1 of 3 attempts.

$>$ Begin the test using the green monofilament $(0.05 \mathrm{~g})$ at all the indicated points on the form.

$>$ For each point tested, the green monofilament $(0.05 g)$ and the blue one $(0.2 \mathrm{~g})$ should be applied 3 times in a row to ensure that the patient feels it. The remaining monofilaments in general, should only be applied once.

$>\quad$ At the points where the patient cannot feel the green monofilament, do the evaluation using the blue one and then the other monofilaments in order.

$>$ Enter the answer on the Evaluation Form, colouring each point with the appropriate pen colour, or key code corresponding to each filament.

$>\quad$ In the foot, test 9 points, seven in the area of innervation from the posterior tibial, one in the region of the saphenous nerve (heel) and one at the plantar arch.

\begin{tabular}{|c|c|c|}
\hline MONOFILAMENT & INTERPRETATION & LEGEND \\
\hline Green $(0.05 g)$ & "Normal" sensibility in hands and feet. & Green dot \\
\hline Blue $(0.2 \mathrm{~g})$ & $\begin{array}{l}\text { Reduced sensibility in the hand, with difficulty in relation to the } \\
\text { lighter weight. Within normal range for the foot. }\end{array}$ & Blue dot \\
\hline Purple $(2.0 \mathrm{~g})$ & $\begin{array}{l}\text { Reduced protective sensibility for the hand, but enough to } \\
\text { prevent damage. Difficulty discriminating between form and } \\
\text { temperature. }\end{array}$ & Purple dot \\
\hline Dark red $(4.0 \mathrm{~g})$ & $\begin{array}{l}\text { Loss of protective sensitivity for the hand and most parts of } \\
\text { foot. Vulnerable to tissue damage. Loss of differentiation } \\
\text { between hot and cold. }\end{array}$ & Red dot \\
\hline Orange $(10.0 \mathrm{~g})$ & $\begin{array}{l}\text { Loss of protective sensitivity for the foot, however may still } \\
\text { feel deep pressure and pain. }\end{array}$ & Red "X" \\
\hline Magenta $(300 \mathrm{~g})$ & Sensitivity to deep pressure, may still feel pain. & Red circle \\
\hline None & $\begin{array}{l}\text { Loss of Sensibility to deep pressure, normally cannot feel } \\
\text { pain. }\end{array}$ & Black dot \\
\hline
\end{tabular}

Observe and register on the "Simplified Evaluation of Neural Function and Complications Form":

- Mobile claw $(\mathrm{M})$ - reduction of active mobility of the joints and maintenance of the range of passive movement, even if this does not reach $100 \%$.

- Fixed claw (S) - when there is a loss of $25 \%$ or more of the passive mobility of the joint.

- Tibial posterior claw: affects all toes

- Bone porption in digits

- Wound $\sum_{n w}^{M m}$ 
Independent study to establish the efficacy of the six dose uniform MDT regimen

(U-MDT) for leprosy patients

Fill out the disability grade according to the $\mathrm{WHO}$, using the classification below:

\begin{tabular}{|c|c|}
\hline GRADE & CHARACTERISTICS \\
\hline 0 & No problems with eyes, hands and feet due to leprosy \\
\hline 1 & $\begin{array}{l}\text { Loss or reduction of the sensibility in the eyes } \\
\text { Loss or reduction of the sensibility in hands and/or feet (Does not feel the } 2 g \\
\text { monofilament / purple) }\end{array}$ \\
\hline 2 & $\begin{array}{l}\text { Eyes: lagophthalmos and/or ectropion; trichiasis; central corneal opacity; visual acuity } \\
\text { less than } 0.1 \text { or cannot count fingers from a distance of } 6 \mathrm{~m} \text {. } \\
\text { Hands: atrophy/hypotrophy and/or traumatic lesions; claws; digit absorption; dropped } \\
\text { hand } \\
\text { Feet: atrophy/hypotrophy and/or traumatic lesions; claws; digit absorption; dropped } \\
\text { foot, ankle contracture }\end{array}$ \\
\hline
\end{tabular}

Report the highest level of disability found. 
Independent study to establish the efficacy of the six dose uniform MDT regimen

(U-MDT) for leprosy patients

$$
\text { SOP - U-MDT } 012
$$

\section{LABORATORY EXAM REQUESTS}

\section{OBJECTIVE}

- To guarantee the collection of necessary materials for the protocol as well as for the storage of blood/tissue samples.

Request and record the results of the following tests at the beginning of the study:

- Complete haemogram

- Glucose

- Urea

- Creatinine

- Bilirubin

- $\quad$ SGOT

- SGPT

- C- Reactive Protein

- Bacilloscopy (Search for AFB) in ear lobes, elbow (R and L), and cutaneous lesions

- ML-Flow

- Histopathology, using the standard form (appendix I of SOP-U-MDT 012)

Request and record the results of the following tests at each monthly visit:

- complete haemogram

- SGOT

- SGPT

- C- Reactive Protein

Request and record the results of the following tests at each reactional episode:

- C- Reactive Protein

Request and record the results of the following tests if relapse is suspected:

- Bacilloscopy, elbow (R and L), and cutaneous lesions

- ML-flow

- Histopathology

- C- Reactive Protein 


\section{SOP - UMDT 013}

\section{DRAWING AND STORAGE OF BLOOD}

\section{OBJECTIVE:}

To use the same methodology for all individuals participating in the study.

\section{NECESSARY MATERIAL:}

- Tourniquet

- Hydrophilic cotton

- $70 \%$ alcohol

- Blood testing tubes

- without blood thinners

- with EDTA

- needle for vacuum drawing

- Anti-septic bandages

- Slide

\section{PRECAUTIONS:}

In all procedures, observe the Standard Protocol of Laboratorial Best Practice.

\section{PROCEDURE:}

1. Check the patient's information at the time of exam request, remembering to check that the date of birth has been registered.

2. Identify the tubes with the patient's initials and date of birth.

3. Draw and process the samples according to lab routines, following the Standard Protocol of Best Practice for safely handling biological samples.

4. Store the samples, filling out the Sample Distribution form (Appendix I of SOP-UMDT 013)

a. Number of patient's chart; 
b. Number of the patient's CRF in the study (AM0001/CE0001, AM0002/CE0002, etc);

c. Time - identifies the month of the treatment or month of follow-up after the treatment has ended; the first visit corresponds to point ZERO (0), that is, before the beginning of the treatment.

The following table relates the time with the treatment doses:

\begin{tabular}{|c|c|}
\hline TIME & DOSE \\
\hline M0 & Before $1^{\text {st }}$ dose \\
\hline$M 1$ & $2^{\text {nd }}$ dose visit \\
\hline$M 2$ & $3^{\text {rd }}$ dose visit \\
\hline$M 3$ & $4^{\text {th }}$ dose visit \\
\hline$M 4$ & $5^{\text {th }}$ dose visit \\
\hline M5 & $6^{\text {th }}$ dose visit \\
\hline M6 & $7^{\text {th }}$ dose visit \\
\hline$M 7$ & $8^{\text {th }}$ dose visit \\
\hline$M 8$ & $9^{\text {th }}$ dose visit \\
\hline$M 9$ & $10^{\text {th }}$ dose visit \\
\hline$M 10$ & $11^{\text {th }}$ dose visit \\
\hline$M 11$ & $12^{\text {th }}$ dose visit \\
\hline$M 12$ & $1^{\text {st }}$ year visit post-ttmt \\
\hline$M 13$ & $2^{\text {nd }}$ year visit post-ttmt \\
\hline$M 14$ & $3^{\text {rd }}$ year visit post-ttmt \\
\hline$M 15$ & $4^{\text {th }}$ year visit post-ttmt \\
\hline$M 16$ & $5^{\text {th }}$ year visit post-ttmt \\
\hline
\end{tabular}

d. Name of the patient;

e. Date of birth (this information is of the UTMOST importance for the correct identification of patients with the same name; do not forget to enter it)

f. Date of sample collection;

g. Signature of the professional who took the sample;

2. According to the Standard Protocol of Best Practice for safely handling biological samples, divide the sample in three tubes, one from each box (A. B, C). Note that the code on the bottom of the three tubes must be the same of the column of tube identification ( $\mathrm{N}$ tube) in the control spreadsheet of sample distribution.

3. The numbering of the boxes must follow a direct numerical order:

- Alfredo da Matta Foundation: AM 001 A (white caps) AM 001 B (red caps) e AM $001 \mathrm{C}$ (transparent blue caps).

- Dona Libânia Dermatology Centre: CE 001 A (yellow caps) CE 001 B (green caps) e CE 001 C (blue caps).

4. Close the tubes with the corresponding colours, according to the instructions above. 
5. Place the tubes in the boxes AM001ACEM001A, AM001B/CEM001B e AM001C/ CEM001C, following the sample control plan and the layout of samples in an ELISA plate (see scheme below).

\section{SAMPLE DISTRIBUTION IN BOXES}

\begin{tabular}{|c|c|c|c|c|c|c|c|c|c|c|c|}
\hline 1 & 2 & 3 & 4 & 5 & 6 & 7 & 8 & 9 & 10 & 11 & 12 \\
\hline A 1 & A 2 & A 3 & A 4 & A 5 & A 6 & A 7 & A 8 & A 9 & A 10 & A 11 & A 12 \\
\hline B 1 & B 2 & B3 & B4 & B 5 & B 6 & B 7 & B 8 & B 9 & B 10 & B 11 & B 12 \\
\hline $\mathrm{C} 1$ & C 2 & C 3 & C 4 & C 5 & C 6 & C 7 & C 8 & C 9 & C 10 & C 11 & C 12 \\
\hline D 1 & D 2 & D 3 & D 4 & D 5 & D 6 & D 7 & D 8 & D 9 & D 10 & D 11 & D 12 \\
\hline E 1 & E 2 & E 3 & E 4 & E 5 & E 6 & E 7 & E 8 & E 9 & E 10 & E 11 & E 12 \\
\hline F 1 & F 2 & F 3 & F 4 & F 5 & F 6 & F 7 & F 8 & F 9 & F 10 & F 11 & F 12 \\
\hline G 1 & G 2 & G 3 & G 4 & G 5 & G 6 & G 7 & G 8 & G 9 & G 10 & G 11 & G 12 \\
\hline H 1 & H 2 & H 3 & H 4 & H 5 & Н 6 & H 7 & H 8 & H 9 & H 10 & Н 11 & H 12 \\
\hline
\end{tabular}

IMPORTANT: the codes of the tubes ( $\mathrm{N}$ tube) follow this scheme, whereby rows are identified by letters $(A, B, C, D, E, F, G$ and $H)$ and columns are identified by numbers $(1,2,3,4,5,6$, $7,8,9,10,11$ and 12). 


\section{SOP - UMDT 014 \\ BIOPSY PROCEDURES}

\section{OBJECTIVE:}

To use the same methodology for all individuals participating in the study.

\section{NECESSARY MATERIAL:}

- One vial containing $10 \%$ buffered formaldehyde ( $40 \%$ aldehyde- $100 \mathrm{ml} ; 1$ tablet of phosphate $\mathrm{pH} 7.0$, distilled water- $900 \mathrm{ml}$ ), approximately $20 \mathrm{ml}$ for a $5 \mathrm{~mm}$ biopsy;

- A $3 \mathrm{~mm}, 4 \mathrm{~mm}$, and $5 \mathrm{~mm}$ skin biopsy punch (3mm for the face and $4 \mathrm{~mm}$ or $5 \mathrm{~mm}$ for other areas), sterile and disposable;

- Topical anaesthesia (lidocaine without vasoconstrictors);

- Gauze and anti-septic material for cleaning (alcohol);

- Small, curved tip scissors;

- Small anatomic tweezers;

- $3 \mathrm{ml}$ syringe with $27 \times 8$ needle for insulin syringes;

- Suture hook;

- Suture thread -- nylon 4.0 and 6.0 for face;

- Kelly tweezers;

- Gauze and bandages.

\section{PROCEDURES:}

1- Select for testing the lesions that are most representative, attempting to collect material from the borders that demonstrate signs of "activity" (erythema, infiltration or oedema).

2- Clean the area.

3- Apply the anaesthesia to the lesions and other chosen sites.

4- Remove the biopsy with a punch at the edge of the lesion.

5- Avoid compressing the tissue. If necessary, use sterile hypodermic needles to facilitate the procedure.

6- Place the sample immediately in the $10 \%$ buffered formaldehyde.

7- Stitch the site from which the biopsy was taken.

8- Cover with bandages.

9- Schedule the removal of the stitches, according to the health centre's protocols. 
Independent study to establish the efficacy of the six dose uniform MDT regimen

(U-MDT) for leprosy patients

10-Fill out the Histopathology Request Form.

11-Send the biopsy to the histopathology lab within $\mathbf{8}$ hours of the collection, providing the following mandatory information:

a) Type of material sent;

b) Site of removal (it should be clearly indicated on the anatomical chart), giving details regarding the description of the lesion from where the sample was taken;

c) Description of the lesions;

d) Patient's clinical classification;

e) Age, sex, duration of lesions, result of bacilloscopy (if taken). 


\section{SOP - U-MDT 015}

\section{HISTOPATHOLOGY EXAM}

\section{OBJECTIVE:}

To use the same methodology for all individuals participating in the study.

\section{METHODOLOGY:}

- The specimen should be cut in half when collected with a $5.0 \mathrm{~mm}$ punch, after removal. The other sized punches should be included whole.

- The specimens should be left in formaldehyde for twelve hours and then inserted into the tissue processor for preservation in paraffin.

- After placed in histological paraffin, the specimens should be sectioned using a rotating microtome; each section should be five micrometres in thickness.

- Each slide should have at least 5-6 cuts.

- One slide is to be stained with haematoxylin and eosin and another by the Fite-Faraco or Wade-Klingmuller methods.

- For each batch of slides, it is necessary to use one positive slit skin smear control slide.

\section{STAINING TECHNIQUES}

\section{I -Wade Staining}

\section{Reagents}

Ziehl-Nielsen dye

$$
\begin{array}{lr}
\text { Phenol } & 8 \mathrm{ml} \\
\text { Absolute Ethanol } & 20 \mathrm{ml} \\
\text { Basic fuchsin (powder) } & 2 \mathrm{~g} \\
\text { Distilled water } & 200 \mathrm{ml}
\end{array}
$$

Methylene blue dye

$$
\begin{array}{lr}
\text { Distilled water } & 99 \mathrm{ml} \\
\text { Methylene blue } & 0,5 \mathrm{~g} \\
\text { Glacial acetic acid } & 0,5 \mathrm{ml}
\end{array}
$$

Differentiator

$$
\begin{array}{lr}
70 \% \text { ethanol } & 99 \mathrm{ml} \\
\text { Pure chloridic acid } & 1 \mathrm{ml}
\end{array}
$$

De-paraffin solution

$\begin{array}{ll}\text { Terebenthene } & 60 \mathrm{ml} \\ \text { Vaseline } & 30 \mathrm{ml}\end{array}$

Wade method for slide staining techniques 
1. Remove the cuts from low-heat with the slide and put them in the steriliser for 5 minutes.

2. Remove the paraffin from the cuts with the terebenthene - Vaseline solution -2 rounds of 15 minutes in the steriliser.

3. Pass through 3 cubes with absolute ethanol.

4. Wash under running water (10 minutes).

5. Dry with filter paper.

6. Cover the slide with fuchsin filtered for 25 minutes.

7. Wash quickly under running water.

8. Remove the excess dye with acid-alcohol solution for approximately 3 seconds.

9. Wash under running water for one minute.

10. Stain with the blue methylene solution for 1 minute.

11. Wash under running water.

12. Dry in the steriliser or at room temperature.

13. Assemble the slide with Canada balsam.

Result:

- Bacilli presenting violet coloration.

- Background of the cut in pale blue.

\section{$\underline{\text { II - Staining with Haematoxylin-Eosin }}$}

\section{Reagents}

Harris Haematoxylin

$\begin{array}{lr}\text { Haematoxylin } & 5 \mathrm{~g} \\ \text { 95\% ethanol } & 50 \mathrm{ml} \\ \text { Aluminium potassium sulphate } & 100 \mathrm{~g} \\ \text { Distilled water } & 1000 \mathrm{ml} \\ \text { Mercury oxide } & 2,5 \mathrm{~g}\end{array}$

Preparation:

1. Dissolve the haematoxylin in the ethanol and the aluminium potassium sulphate in distilled water, with the aid of heat.

2. Mix the two solutions and boil as quickly as possible.

3. Remove from heat and add the mercury oxide slowly and carefully, reheat until it boils and count one minute.

4. Remove from heat and immerse in a basin with ice water immediately.

5. Add $4 \mathrm{ml}$ of acetic acid, when the dye has cooled 
Eosin

$\begin{array}{lr}\text { Eosin } & 2,5 \mathrm{~g} \\ \text { Distilled water } & 50 \mathrm{ml} \\ 95 \% \text { alcohol } & 200 \mathrm{ml} \\ 80 \% \text { alcohol } & 750 \mathrm{ml} \\ \text { Acetic acid } & 5 \mathrm{ml}\end{array}$

Preparation:

a. Dissolve the eosin in the distilled water and add the $95 \%$ alcohol.

b. Add the $750 \mathrm{ml}$ of $80 \%$ alcohol and $5 \mathrm{ml}$ of acetic acid.

\section{Haematoxylin-Eosin slide staining techniques.}

1. Remove paraffin from the histological slices in a stove for 10 minutes.

2. Put in xylene immersion ( 2 immersions of 5 minutes each).

3. Hydrate in alcohol immersions with decreasing concentration. Begin with 2 flasks of absolute alcohol, 5 minutes each, and then in 1 flask of alcohol $96^{\circ}$ for five minutes.

4. Wash under running water.

5. Stain with the haematoxylin solution for 10 minutes.

6. Wash under running water without letting the material separate from the slide.

7. Stain with eosin for two minutes.

8. Wash under running water.

9. Run again through the set of alcohol flasks with decreasing concentration. Begin with 2 flasks of absolute alcohol, 5 minutes each, and then in 1 flask of alcohol $96^{\circ}$ for five minutes.

10. Dry at room temperature.

11. Run through xylene ( 2 immersions of 3 minutes each)

12. Assemble the slide with Canada balsam.

\section{DESCRIPTION OF HISTOPATHOLOGY FINDINGS (MICROSCOPIC READING)}

- The description of the histopathological exam must be done in standardised form (Appendix I of SOP-UMDT 015)

- Use microscopic magnification of 10, 25, 40 and 100X

- Evaluate the quality of the specimen.

- Determine if there are epidermal alterations or not

- Determine the presence of dermal infiltrates 
-What are the cell types of the infiltrate

- Location of the infiltrate

- Define if nerve sheathes were visualised in the samples examined

- Determine if pill-erector muscle was visualised in the samples examined

- Determine if there is collagen or intercellular oedema

- Indicate if vasodilatation and/or congested blood vessels were observed

- Indicate presence of necrosis

- Note if cutaneous annexes are present

- Presence or absence of subcutaneous annexes.

- Morphological characteristics of the bacilli identified (whole, fragmented, granular, bacillary remains)

- Indicate the bacteriological index for each granuloma $(0-6+)$

\section{CLASSIFICATION CRITERIA:}

(I) INDETERMINATE LEPROSY

- Discrete, non-specific infiltrates with small cells, mononuclear, perineural and perivascular, containing lymphocytes, non-differentiated histocytes and fibroblasts. Exam report only indicates compatibility and is affirmative if acid-fast bacilli are identified.

\section{(TT) TUBERCULOID LEPROSY}

- Granulomas of epithelioid cells, with numerous lymphocytes in the periphery and surrounding giant cells. The infiltrates can affect the base layer of the epidermis. Slit skin smears will almost always be negative. The final result is suggestive of leprosy when there is presence of bacilli within the nerve sheaths. The bacteriological index of the granulomas will be $0-1$.

\section{(BT) BORDERLINE TUBERCULOID LEPROSY}

- Granulomas of epithelioid cells, with Langerhans-type giant cells predominating, permeated by lymphocytes and histocytes. There is variable infiltration of the sub-epidermal zone. Usually, the nerve sheathes are inflamed. Bacilloscopy can be negative or positive with a limited number of bacilli. If negative, the exam report should note compatibility with a positive diagnosis. A positive bacteriological index of the granulomas will be in the range of 0-2. 
(BB) BORDERLINE BORDERLINE LEPROSY

- Granuloma of epithelioid cells, without giant cells and few and diffuse lymphocytes. The granulomas do not affect the epidermis; nerves are usually thickened and identifiable. Bacilli are always present in varying amounts. The bacteriological index of the granulomas will be 3-4.

\section{(BL) BORDERLINE LEPROMATOUS LEPROSY}

- Inflamed infiltration from macrophagic granulomas, with numerous lymphocytes densely grouped over some parts of the granuloma but not over the whole granuloma; some accumulation of epithelioid cells between the macrophages, with or without lymphocytes or with a combination of a moderate number of lymphocytes and non-differentiated cells from the granuloma. The nerves in general present with perineural covering from some cell infiltrates that can invade the nerve. Layer of sub-epidermal collagen is intact. Bacilli are always present and the bacteriological index of the granulomas will be 4-5.

\section{(LL) LEPROMATOUS LEPROSY}

- Inflamed infiltration macrophagic granuloma without epithelioid cells and few lymphocytes. Dense infiltrates, compact, separated from the epidermis by a collagen strip (Unna band). Bacilli are always present and the bacteriological index of the granulomas will be 5-6. 


\section{SOP - U-MDT 016}

\section{BACILLOSCOPY}

\section{OBJECTIVE:}

To use the same methodology for all individuals participating in the study.

\section{MATERIAL:}

- Exam request;

- Glass slide (new) with frosted end;

- Spirit lamp;

- Alcohol;

- Cotton;

- Marking pencil or regular pencil;

- Matches;

- No. 3 scalpel handle and no. 15 scalpel blade;

- Container for storage and transportation of samples;

- Antiseptic bandages;

- Gloves;

- Tweezers to produce ischemia at the site of incision (can be done by pinching the skin firmly between your thumb and forefinger).

- Container for disposal of used material.

\section{PRECAUTIONS:}

- Ensure that all necessary materials are available.

- All materials should be disposable.

- For each set of slides, it is necessary to use one AFB positive control slide

\section{PROCEDURES:}

\section{Sites for sample collection:}

a) In patients with visible cutaneous lesions, the sample should be collected from the right ear lobe (RL), left elbow (LE) and two more active lesions.

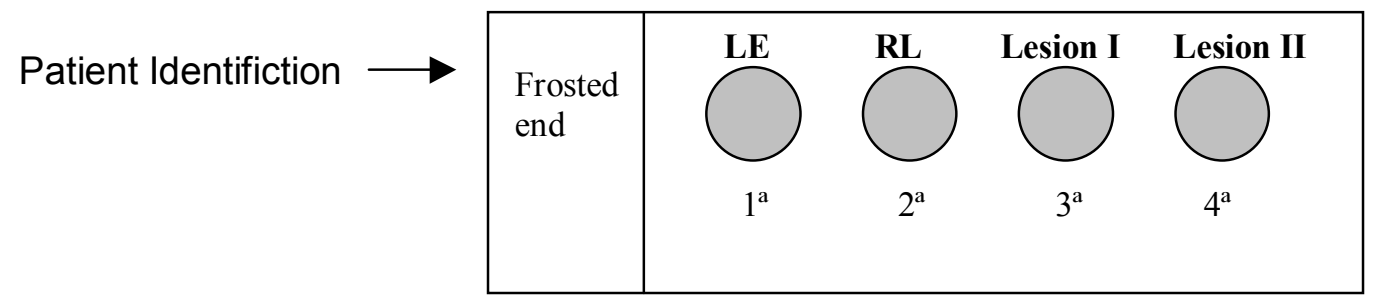

Fig. 1 - Example of smear position on slide - patient with multiple lesions 
b) In patients with a single lesion, the sample should be collected from the left and right ear lobes (RL and LL), left elbow (LE) and from the lesion.

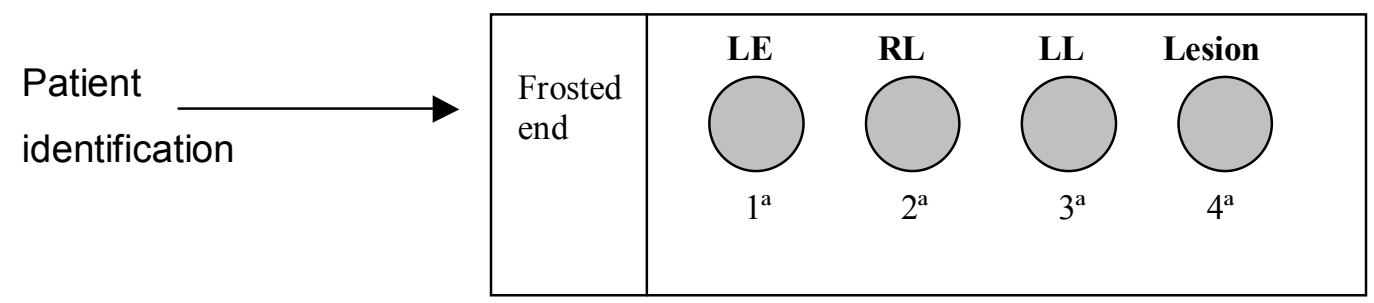

Fig. 2 -- Example of smear position on slide - patient with single lesion

c) In patients with no visible active lesions, collect samples from the $\mathbf{R}$ and $\mathbf{L}$ ear lobes, and $R$ and $L$ elbows.

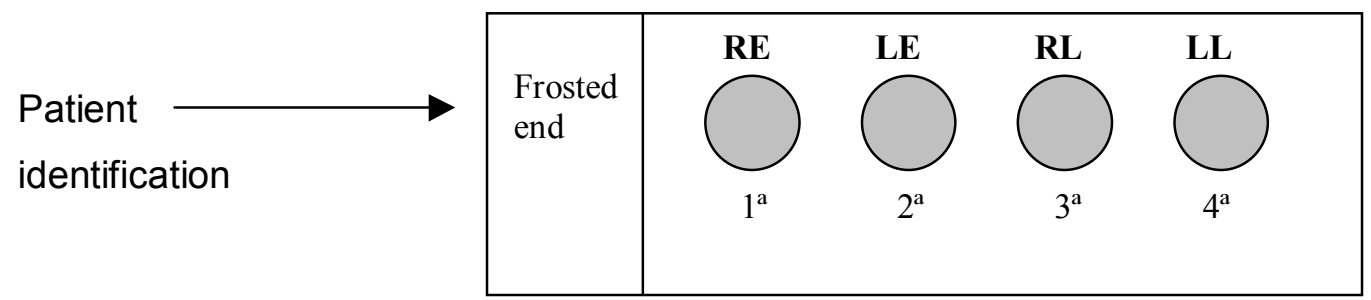

Fig. 3 -- Example of smear position on slide - patient with no visible cutaneous lesions

\section{Sample collection:}

a) Make the patient comfortable; explain the procedure that will be carried out. If the patient is a minor, explain the procedure to their parent/guardian;

b) Identify sampling sites by following points indicated on the exam request;

c) Hold the slide by the edges to avoid touching the spots where the sample will be distributed;

d) Identify the slide with the patient's initials and registration number;

e) Select the site for sample collection and clean it;

f) Pinch the skin, and maintain pressure to remove blood from surrounding area (ischemia), keep the pressure until the end of the sample removal;

g) Make a cut in the skin of approximately $5 \mathrm{~mm}$ long by $3 \mathrm{~mm}$ deep. If it starts to bleed, dry it with a cotton wad. Position the scalpel blade at a 90 degree angle to the cut, scrape the edge and the bottom of the incision to obtain enough visible material for the smear;

h) Release the pressure and smear the material on the glass slide making circular movements from the centre to the edge in an area of approximately $5-7 \mathrm{~mm}$ in diameter;

ATTENTION: maintain a consistent amount of material in the area of smear, to guarantee its uniformity. 


\section{Independent study to establish the efficacy of the six dose uniform MDT regimen (U-MDT) for leprosy patients}

i) Clean the scalpel blade with a cotton ball soaked in alcohol and then sterilise it by passing it through the flame of an alcohol lamp. This sterilisation should be done between sample collections from one site to another for the same patient, to avoid carrying AFB-positive lymph from one collection site to another that may not be positive;

j) The first smear should be placed at the edge closest to the patient identification information on the slide and the second next to the first keeping a space of about $0.5 \mathrm{~cm}$ between samples and,

k) Follow the order of the requested points from exam request.

\section{Fixation:}

The slides containing the samples should be air dried for about 5-10 minutes until they are completely dry, to guarantee a proper fixation. This is done using the spirit lamp or Bunsen burner, passing the slide quickly 2-3 times through the flame, with the smears facing upwards and never in direct contact with the flame. Be careful not apply too much heat, because that can alter the morphologic-staining characteristics of the bacilli present in the smear.

\section{Staining of the smear: (ZIEHL- NEELSEN)}

a) Place the slide on a staining rack;

b) Cover the slide with ZIEHL-NEELSEN carbol fuchsin until the smears are totally covered.

c) Immediately after applying the fuchsin, heat the slide gently by holding a lit alcohol lamp underneath it, until vapour begins to rise from the fuchsin. Make sure the stain does not boil.

d) Stop heating and set timer for 5 min.

e) Remove the slide from the rack and wash it under a running tap.

f) Cover the slide with decolourising reagent (1\% acid-alcohol) until it becomes pinkish in colour.

h) Wash the slide again under running tap.

i) Place the slide in the rack, cover it with methylene blue stain until the smears are totally covered for $1 \mathrm{~min}$. Rinse it with water and leave it to dry in the drying rack in an inclined position at room temperature.

\section{Slit skin smear microscopy reading:}

It is very important to move the microscope correctly over the smear. During the reading, never go back to the same place already examined, so as to avoid an incorrect final result. In selecting the fields to examine, avoid the ones containing many red blood cells and focus on those areas with many macrophages. Count the bacilli in each microscope field, including isolated bacilli, some in small groups which can be viewed individually, and globi of bacilli. The 
number of bacilli in a globi cannot be counted, although it can be estimated. A large one contains about 100 bacilli, a medium size one has approximately 60 bacilli, and a small one around 30 bacilli. In reality, almost all the smears with clusters have numerous isolated bacilli that can be adequately counted. Limit each smear with a marking pencil, drawing around each existing smear on the slide, or drawing a line between the smears, so that it will be less confusing.

5.1. Microscopic movement over the slide: (delimit the smear using blue marking pencil).

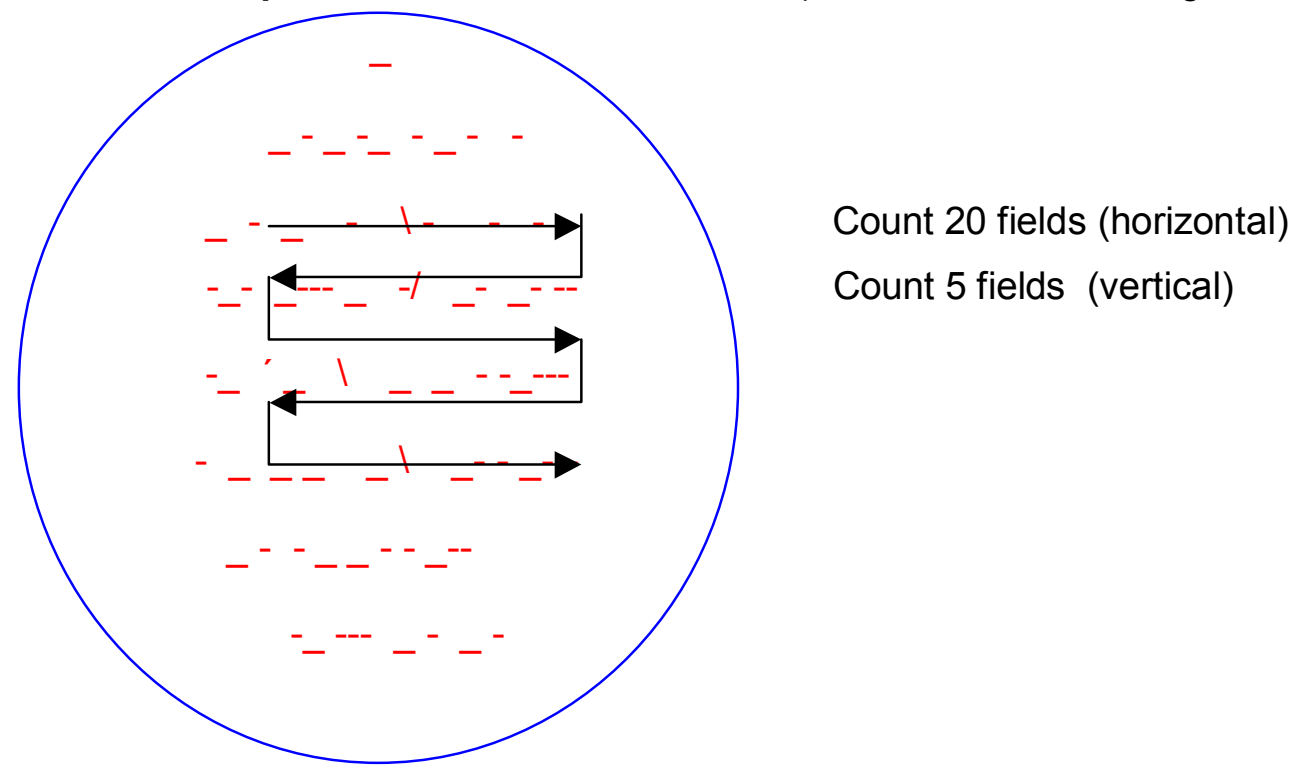

5.2. Morphology of the bacilli under optic microscope:

In a POSITIVE smear for Mycobacterium leprae, the bacilli are either isolated or in clusters.

\subsection{1 - In the case of ISOLATED bacilli, observe and describe:}

- INTACT Bacilli: Bacilli that after staining, are completely red, without any colouration gaps in the cell wall.

- FRAGMENTED Bacilli: Bacilli that present small gaps in their cell wall due to interruption of the synthesis of its components. After staining, only parts of the body of the bacilli that have cell wall will be red.

- GRANULATED Bacilli: These are bacilli that present significant gaps in their cell wall. Sometimes after staining, only a few small dots will be red. 


\subsection{2 - If GROUPS of bacilli are present, observe and describe:}

- $\quad$ CLUSTERS of bacilli: Bacilli that are very close to each other forming small and long rods. The light from the microscope passes through the spaces between them.

- Bacilli in GLOBI: These are structures made with a colourless substance that forms between the bacilli, keeping them connected in an organized form. The light emitted by the microscope does not pass through them because there is no free space between the bacilli. For counting, the globules can be:

- SMALL: Around 30 bacilli.

- MEDIUM: Around 60 bacilli.

- LARGE: Around 100 or more bacilli.

\subsubsection{Calculation of the Bacteriological Index (BI):}

To calculate the Bacilloscopic or Bacteriological Index (BI), use the logarithm scale proposed by RIDLEY in1964.

\subsubsection{Logarithmic Scale of RIDLEY:}

( 0 ) - Absence of bacilli in 100 examined microscopic fields.

(1) - Presence of 1 to 10 bacilli, in 100 microscopic fields examined.

( 2 ) - Presence of 1 to 10 bacilli, in 10 microscopic fields examined.

( 3 ) - Presence of 1 to 10 bacilli, on average, in each microscopic field examined.

( 4 ) - Presence of 10 to 100 bacilli, on average, in each microscopic field examined.

( 5 ) - Presence of 100 to 1000 bacilli, on average, in each microscopic field examined.

( 6 ) - Presence of more than 1000 bacilli, on average, in each microscopic field examined.

\subsubsection{Calculation of the average $\mathrm{BI}$ of the Patient:}

The Average Bacteriological Index should be calculated by adding the indexes found for each collection site, divided by the total number of collection sites.

EX: Right ear lobe $=4$

Left ear lobe $\quad=3 \quad \mathrm{BI}=17 / 4=4.2$

Left elbow $\quad=4$

Lesion $\quad=6$ 


\section{Quality Control:}

After reading the skin smear slides, store them in appropriate laboratory containers. These slides are important because study supervisors will examine the samples later and evaluate the quality of the skin smear exams. The sample of slides should be selected from the laboratory registry, based on the $\mathrm{BI}$. Approximately 20 to $30 \%$ of the smears should be negative, 50 to $60 \%$ should have a BI of 1,2 or 3 and no more than $20 \%$ should have a $\mathrm{BI}$ of 4,5 or 6 . At the time of re-examination, the results should be given to the supervisor after the two outcomes are compared and correlated. The results of the supervisor's readings should be returned, along with the slides. The differences found should be identified and corrected.

\section{Preparation of the reagents used during the Staining Procedure:}

\subsection{ZIEHL- NEELSEN staining (used at the Centre of Dermatology Dona Libânia)}

a) - Decolourising solution ( $1 \%$ acid-alcohol):

Ethyl Alcohol P.A. $99 \mathrm{ml}$

Hydrochloric Acid concentrated P.A. $1 \mathrm{ml}$

- Add $50 \mathrm{ml}$ of ethyl alcohol P.A to a graduated cylinder.

- Add the concentrated hydrochloric acid $(1 \mathrm{ml})$ to the alcohol, drop by drop; complete the volume to the $100 \mathrm{ml}$ mark on the cylinder with ethyl alcohol.

- Keep the solution in appropriate container at room temperature.

b) - Methylene blue (ZIEHL- NEELSEN contrast):

Methylene blue powder. $.10 \mathrm{~g}$

Distilled water $1000 \mathrm{ml}$

Absolute ethanol. $50 \mathrm{ml}$

- Dissolve the methylene blue powder with ethanol in a small bowl.

- Add distilled water, until the final volume reaches $1000 \mathrm{ml}$.

- Transfer to the appropriate vial, let it rest for 24 hours.

- Filter before use.

c) - ZIEHL-NEELSEN Carbol Fuchsin:

Basic Fuchsin powder. $10 \mathrm{~g}$

Ethyl Alcohol P.A. $100 \mathrm{ml}$

Phenol $.55 \mathrm{ml}$

Distilled water. $1000 \mathrm{ml}$ 
- Dissolve the basic fuchsin with ethyl alcohol P.A or pure ethanol.

- Add the phenol and homogenise.

- Transfer to a graduated cylinder and add distilled water until the final volume reaches $1000 \mathrm{ml}$.

- Wait 24 hours, filter and transfer to an amber vial, keeping it sheltered from light at all times.

- Mix and filter before use.

\subsection{KINYOUN staining (used at Alfredo da Matta Foundation)}

a) - Preparation of Kinyoun Carbol Fuchsin:

Basic fuchsin powder ....................... $4 \mathrm{~g}$

Ethyl alcohol P.A ........................... 20ml

Phenol crystals.............................. $8 \mathrm{~g}$

Distilled water..................................100ml

- Dissolve the fuchsin with ethyl alcohol PA in a small bowl;

- Transfer to the appropriate vial (beaker);

- Dissolve the phenol crystals (low heat, $56^{\circ} \mathrm{C}$ ) and mix it to the fuchsin solution;

- Heat the distilled water and slowly add it to the vial containing the fuchsin and phenol, with circular movements;

- After reaching the final volume, heat the vial with the dye on low heat (do not let it boil);

- Store in vial containing glass beads and sheltered from light for 24 hours;

- Mix and filter before use.

b) - Staining through the Kinyoun method (cold staining):

- Wait for the smear to completely dry at room temperature;

- Fix the smears through heat. This is done using the ethanol flame or Bunsen burner, passing the slide quickly 2-3 times through the flame, with the smear side facing upwards and never in direct contact with the flame;

- Immerse the slide in the appropriate support (vial) containing the KINYOUN fuchsin for five minutes ( $5 \mathrm{~min})$;

- Remove the slide from the rack, washing quickly with running water;

- Drip the decolourising solution (acid-ethanol, 1\%) on the smears until they reach a pinkish colour;

- Wash the slide again with running water; 
Independent study to establish the efficacy of the six dose uniform MDT regimen

(U-MDT) for leprosy patients

- Immerse the slide in the appropriate support (vial), containing the methylene blue dye (the same as Ziehl-Neelsen) for five minutes ( $5 \mathrm{~min})$;

- Remove the slide from the support, wash it with running water and let it dry at room temperature;

- Microscopy.

\section{Disposal of materials}

The disposal of material is a very important topic. The slides or any other potentially contaminated material must be eliminated in special containers.

\section{Slides}

The scalpel blades used to collect material must be handled with care and disposed in special boxes for the disposal of sharp materials that are already in use by the health service. When the boxes are full, send them to the recommended location, according to the routine of the health centre.

\section{Alcohol compresses/gloves}

All potentially contaminated material must be handled with care and disposed in appropriate containers in use at the health centre. 


\section{SOP U-MDT 017}

\section{FLOW TEST}

\section{Objective:}

Detect the presence of IgM antibodies specific to Mycobacterium leprae in the blood sample.

\section{Material necessary:}

- alcohol swab

- needle

- capillary tube

- adhesive bandage

- ML Flow test kit

- container for the disposal of used material

\section{Material collection}

1- Prepare, in a tray, the material to collect a blood sample: alcohol swab, needle, capillary tube and adhesive bandage.

2- Remove the ML Flow test kit from its protective wrapping and place it flat on a surface with the round receptacle for the sample and the rectangular window of the test kit facing upwards.

3- Observation: the rectangular window located at the centre of the test device, contains 2 strips: one containing the antigen $(\mathrm{T})$, located closer to the sample receptacle and, a control strip (C).

4- Open the alcohol pad wrapping.

5- Explain to the patient the procedure that will be done.

6- Clean the tip of the left index finger with the alcohol pad (if left handed, then do this on the right index finger).

7- Prick the skin using the needle, and immediately place it in the sharp materials waste container. 


\section{Independent study to establish the efficacy of the six dose uniform MDT regimen \\ (U-MDT) for leprosy patients}

8- Touch the blood with the end of the capillary tube and collect about 5 micro-litres of blood (corresponds to $0.5 \mathrm{~cm}$ ). Use this blood directly to immediately perform the ML Flow test.

9- Clean the pricked finger with the alcohol pad, place the adhesive bandage and ask the patient to apply pressure to it for a minute to stop the bleeding.

\section{EXECUTION OF THE ML FLOW TEST}

1- Place $5 \mu$ of blood in the round receptacle and add 4 drops (or $125 \mu$ ) of the running buffer solution to the same location.

2- Set the timer for 5 minutes.

3- Close the vial with the buffering solution and store it at room temperature for later use.

4- Read the result after 5 min.

5- Observation: Results read more than 20 min after the addition of blood and sample fluid are not valid.

6- To open the test device, fold the test cartridge backwards.

7- With a tissue paper dry the excess liquid by pressing on the top of the paper filter, where the blood drop was placed.

8- Immediately write down the patient's initials and the date of birth and also his/her code on the back of the test.

9- Allow the test to dry.

10- The test must be taped to the sheet containing the patient's results.

\section{TEST READING}

1- After the addition of the buffering solution to the receptacle where the blood sample was placed, a colour reaction will be visible moving through the test and control strips. This shows that the test is working.

2- The control strip should always show colour.

3- The colour in the control band guarantees the integrity of the detection reagent, but is not a control of the quality of the sample.

4- If the control band does not show any colour, the test is not working.

5- A negative result is indicated by the absence of a line in the detection strip and its presence in the control strip.

6- A positive result is indicated by the presence of a strong line both in the detection and control strips. 
Independent study to establish the efficacy of the six dose uniform MDT regimen

(U-MDT) for leprosy patients

7- The pigmentation of the antigen band indicates the presence of $\operatorname{lgM}$ antibodies specific for Mycobacterium leprae.

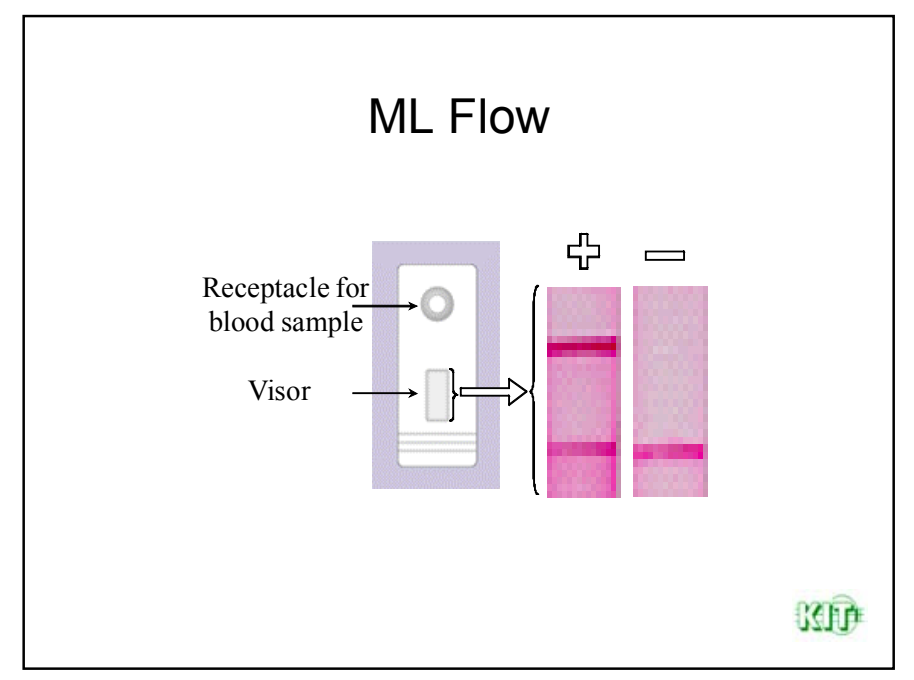

The intensity of the positive result varies from $1+$ to $4+$. See picture below.

The intensity $4+$ is equal to the intensity obtained at the control band, or sometimes can be higher.

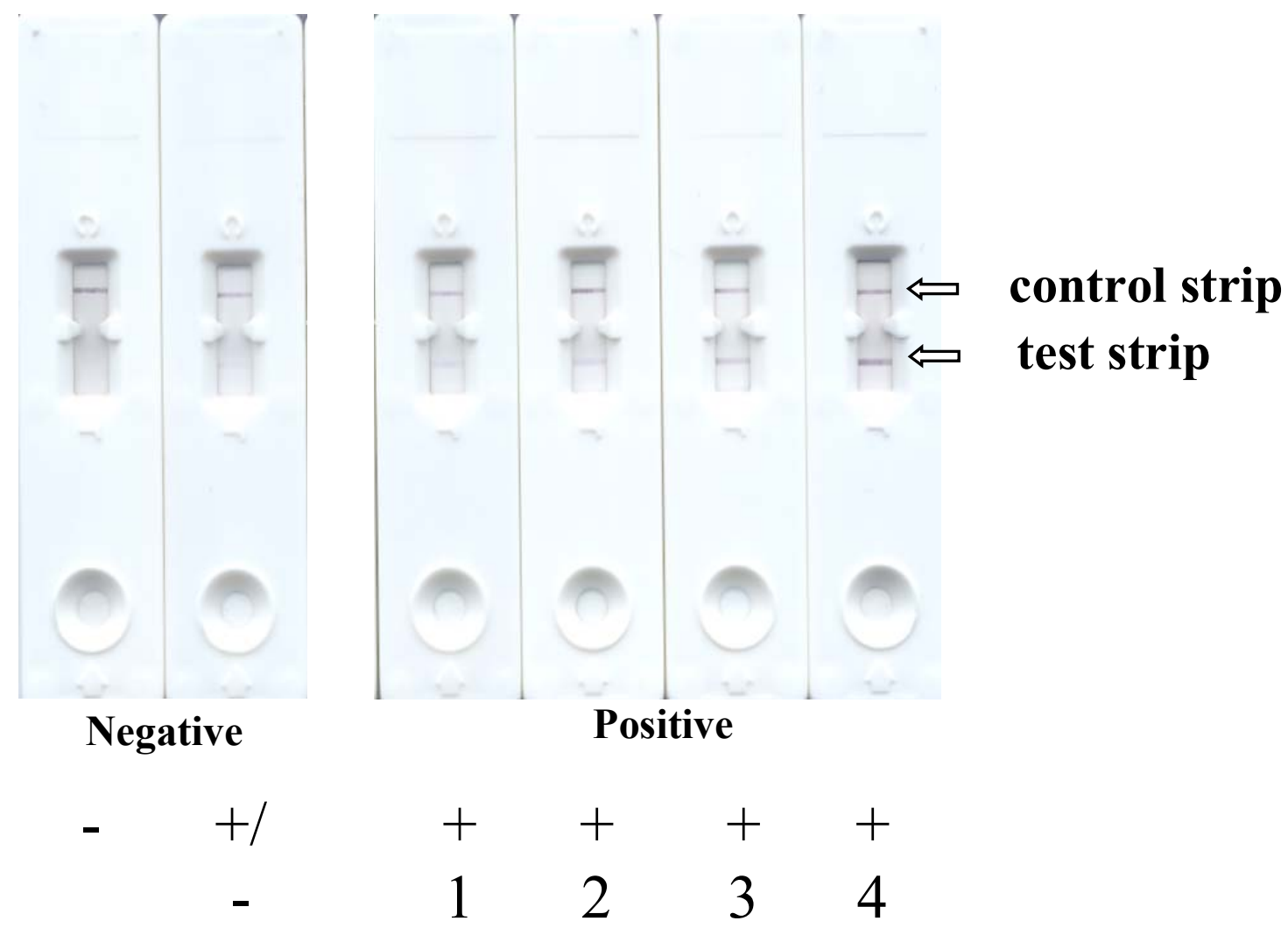


Independent study to establish the efficacy of the six dose uniform MDT regimen

(U-MDT) for leprosy patients

\section{DISPOSAL OF WASTE MATERIALS}

The disposal of materials is a very important topic. The needles, capillary tubes and any other potentially infected material must be disposed of in special containers.

\section{NEEDLES - CAPILLARY TUBES}

The needles and capillary tubes used for cutaneous smears and for the lateral flow, must be handled carefully and disposed of in special boxes for the disposal of sharp materials that are in use at the health centre. When the boxes are full, send them to the recommended location, according to the routine of the health centre.

\section{ALCOHOL SWABS - TEST CARTRIDGE - GLOVES}

All material potentially contaminated must be handled with care and disposed in the appropriate containers in use at the health centre. 


\section{PREPARATION OF REAGENTS FOR SULFONURIA TESTING}

\section{OBJECTIVE:}

To prepare the control and reagents necessary for testing the presence of dapsone in patients' urine.

\section{MATERIAL:}

- 1 litre cylinder;

- $500 \mathrm{ml}$ cylinder;

- Pipettes;

- Distilled water;

- Concentrated chloridic acid - $\mathrm{HCl}$

- Normal urine - urine of a donor who is not on any medication that contains dapsone or sulfone.

- Dapsone - 4,4' Diaminodiphenyl Sulfone (D -2505 Sigma)

$\mathrm{HCl}$ solution at approximately $1 \mathrm{~mol} / \mathrm{l}$ - expires after one year.

1. Follow the routine for preparing solutions, adding $100 \mathrm{ml}$ of chloridic acid to $1000 \mathrm{ml}$ of distilled water.

2. Transfer to capped flask and label properly (name of the solution, date, signature of the responsible)

Preparing the NEGATIVE control - solution A - expires after one week.

1. Mix $90 \mathrm{ml}$ of normal urine with $10 \mathrm{ml}$ of $\mathrm{HCl} 1 \mathrm{~mol} / /$ solution.

2. Transfer to capped flask and label properly (name of the solution, date, signature of the responsible);

Preparing the dapsone stock solution - solution B - expiration date undetermined.

1. Mix $1 \mathrm{~g}$ of dapsone in $100 \mathrm{ml}$ of $\mathrm{HCl} 1 \mathrm{~mol} / \mathrm{l}$.

2. Transfer to capped flask and label properly (name of the solution, date, signature of the responsible). 
Preparing the diluted dapsone solution - solution $\mathbf{C}$ - expires after one year.

1. Mix $1 \mathrm{ml}$ of the dapsone stock solution - solution B - in $49 \mathrm{ml}$ of distilled water.

2. Transfer to capped flask and label properly (name of the solution, date, signature of the responsible).

Preparing the POSITIVE control - solution D - expires after one week.

This solution contains approximately $5 \mathrm{ml} / \mathrm{l}$ of dapsone in acid urine.

1. Mix $1 \mathrm{ml}$ of the diluted dapsone solution - solution $\mathbf{C}-$ in $39 \mathrm{ml}$ of the control.

2. Transfer to capped flask and label properly (name of the solution, date, signature of the responsible).

\section{STORAGE AND EXPIRATION}

\section{Test strips:}

The strip covered with filter paper must be kept in plastic with silica desiccants and stored at $4^{\circ} \mathrm{C}$. Well-stored testing strips can be used for years, although it is important to undertake control quality reviews to ensure that they are still valid. Tests for use during a period of one week, when not stored at $4^{\circ} \mathrm{C}$, must be kept in complete darkness.

\section{Controls:}

Controls must be stored at $4^{\circ} \mathrm{C}$. 


\section{SOP U-MDT 019}

\section{SULFONURIA TEST}

\section{OBJECTIVE:}

To determine the regularity of the treatment through the detection of dapsone residue in the urine.

\section{MATERIAL:}

1. Flask for collecting urine

2. Test paper

3. $1 \mathrm{~N} \mathrm{HCl}$ solution

4. Pipettes

\section{RANDOMISATION}

Person Responsible - study coordinator

$10 \%$ of each week's patients will be tested. The person responsible for randomisation must list, each Friday, all the patients scheduled to receive the supervised dose during the following week. The chart numbers for these patients should be placed in an opaque receptacle, and a simple random drawing should be done, pulling from the recipient as many numbers as are determined by the following table:

\begin{tabular}{|l|l|}
\hline $\begin{array}{l}\text { Total of patients scheduled to receive } \\
\text { medication during the week }\end{array}$ & Number of patients who'll take the test \\
\hline 01 to 10 patients & choose 01 number by lot \\
\hline 11 to 20 patients & choose 02 numbers by lot \\
\hline 21 to 30 patients & choose 03 numbers by lot \\
\hline 31 to 40 patients & choose 04 numbers by lot \\
\hline 41 to 50 patients & choose 05 numbers by lot \\
\hline 51 to 60 patients & choose 06 numbers by lot \\
\hline 61 to 70 patients & choose 07 numbers by lot \\
\hline 71 to 80 patients & choose 08 numbers by lot \\
\hline 81 to 90 patients & choose 09 numbers by lot \\
\hline 91 to 100 patients & choose 10 numbers by lot \\
\hline
\end{tabular}

After the drawing, underline in red the names of the patients who will take the test.

\section{COLLECTION:}

Responsible persons: nursing department

1. When the patient arrives, before administering the dose, explain that they have been randomly selected to take the test.

2. Provide a collecting flask and ask the patient to provide a urine sample.

3. Send the material to the lab. 


\section{QUALITY CONTROL OF THE TEST STRIPS:}

Responsible: laboratory personnel

The quality control of the strips will be done on Monday, in the lab. After performing the control, the lab will provide only the sufficient amount of strips for the nursing section to perform the tests of one week. The laboratory will also be responsible for providing the $\mathrm{HCl} 1 \mathrm{~mol} / \mathrm{l}$ solution, being careful to label with $\mathrm{HCl} 1 \mathrm{~mol} / /$ solution and informing that it is a toxic and corrosive solution.

1. Prepare the material for the test: negative control $(A)-$ positive control $(D)-1 \mathrm{~N}$ solution of $\mathrm{HCl}$ - pipettes - SAMPLE.

2. Remove two strips from wrapping and place them on a counter.

3. On one of them, add a drop of negative control $(A)$ and on the other, one drop of positive control.

4. Add slowly to the sample 3 to 4 drops of the $\mathrm{HCl}$ solution, in the middle of the sample.

5. Observe that a colour will move from the middle to the edges of the test.

6. Read the test results immediately after the complete cleansing, using the $\mathrm{HCl}$ solution, of the test area.

\section{EXECUTION OF THE TEST:}

Responsible: nursing department

1. Remove a test strip from its wrapping and place it on a counter.

2. Add a drop of the SAMPLE to the test strip.

3. Add slowly to the sample 3 to 4 drops of the $\mathrm{HCl}$ solution, in the middle of the sample.

4. Observe that a colour will move from the middle to the edges of the test.

\section{READING}

1. Read the test results immediately after the complete cleaning of the test area, using the $\mathrm{HCl}$ solution.

> Observation: The results should be read immediately. If the reading of the results is done after more than $5 \mathrm{~min}$ from the addition of the $\mathrm{HCl}$, they are not valid

2. Immediately write down the results of the test in the appropriated form.

\section{INTERPRETATION OF THE TEST RESULTS:}

- A negative result is indicated by the absence of a central stain as observed in the negative control.

- A positive result is indicated by the presence of a central stain equal to or larger in size than the one observed for the positive control. 
Independent study to establish the efficacy of the six dose uniform MDT regimen

(U-MDT) for leprosy patients

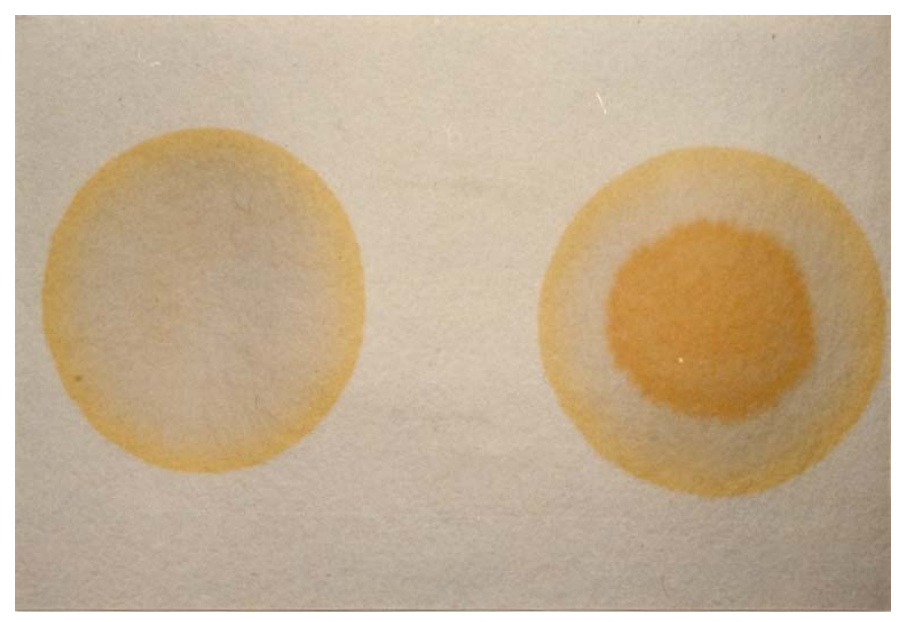

Sulfonuria test results:

Negative test on the left and

Positive on the right.

\section{DISPOSAL OF MATERIAL}

The disposal of material is a very important issue. The test paper, the pipettes, the sample vials or any other potentially contaminated material must be eliminated in special containers. 


\section{SOP U-MDT 020}

\section{MONTHLY VISITS}

\section{OBJECTIVE}

To use the same methodology for all individuals participating in the study.

\section{MATERIAL}

- White coat

- Black pen

- Health Centre Patient Chart

- $\mathrm{CRF}-\underline{\mathrm{U}-\mathrm{MDT}}$

\section{PROCEDURES}

The following tests and procedures should be executed during the monthly visits (PB -6 months; MB - 12 months)

\section{Physician}

1. Fill out the CRF according to the patient registration information in the study.

2. Clinical-dermatological evaluation: verify the following aspects of cutaneous lesions: colour, sensibility and infiltration, entering findings in the CRF according to the evolution observed: if there was regression, improvement, worsening, or no changes observed. In case of multiple lesions, consider the evolution of the majority of lesions.

3. Verify the presence of side effects and register them on the monthly evaluation form, analysing their severity according to SOP 022.

4. Neurological exam: proceed to palpating the nerve trunks and register in: Peripheral Nerve Examination Form.

5. Determine if there are symptoms of reactional episodes and evaluate the degree of seriousness for each one of them. Record them on the Form for Follow-up of Reactional Episodes.

6. Begin treatment of the reactional episodes, if necessary, according to SOP 021.

7. During scheduled visits, classify the disability grade and enter it on the CRF form.

8. Verify the use of other medications and enter this on the Simultaneous Medication Registration Form. On this form, you should not include medication used for treatment of reactional episodes. 
Independent study to establish the efficacy of the six dose uniform MDT regimen

(U-MDT) for leprosy patients

9. Observe the existence of any side effects for other medications and register them in "Log of Side Effects" in the CRF, including the side effects of anti-reactional drugs.

10. Request the laboratorial exams according to SOP-012

\section{Laboratory}

1. Obtain blood sample for clinical-laboratorial tests.

2. Record the results for $C$ Reactive Protein, complete haemogram and transaminases (SGOT/ SGTP).

3. Register the sulfonuria results.

4. Store the blood/serum sample, according to SOP-UMDT 013.

\section{Nursing}

1. Administer the study medication to the patient. Enter the following information on the Investigational Dose Registration Form:

a. the number of pills given

b. the lot number

c. the expiration date

2. Observe the regularity of dose administration, according to what has been established in the study protocol:

a. PB patients - must receive six doses in 9 months, maximum.

b. MB patients

i. U-MDT group: must receive six doses in 9 months, maximum.

ii. R-MDT group: must receive twelve doses in 18 months, maximum.

\section{OBSERVATION:}

A maximum of one unsupervised dose of MDT will be permitted, in the condition that it is impossible for the patient to come to the recruiting centre that month. 


\section{LEPROSY REACTIONS}

\section{OBJECTIVE}

Use the same procedures and definitions for the collection of information related to leprosy reactions occurring in the participants of this study.

\section{PRECAUTIONS}

Episodes of leprosy-related reactions are acute inflammatory events, resulting from the activation of an auto-immune response to M.leprae.

They can be Reverse Reaction (type 1 reaction); Erythema Nodosum Leprosum (type 2 reaction); Neuritis (isolated or associated with type 1 or type 2 reactions).

\section{MATERIAL}

- White coat

- Black pen

- Health Centre Patient Chart

- $\mathrm{CRF}-\underline{\mathrm{U}-\mathrm{MDT}}$

- Monofilament set

\section{PROCEDURES}

1. Check the skin, nerves and eyes, to identify signs of a leprosy reaction.

2. Examine and ask the patient:

a) Overall symptoms:

- $\quad$ Check for fever, malaise, nausea, anorexia and other systemic symptoms.

- Inquire about the presence of headaches, arthralgia, swelling of lymphnodes and cervical / axillary ganglia, enlargement and pain in the testicles.

b) Skin

- It is important to examine all the skin of the patient

- Check for pain and oedema in the skin lesions.

- Determine if inflammation is present in the lesions.

- Examine the hands and feet to determine presence of oedema, muscular atrophy and/or reduced function of sweat glands.

- Check for the presence of painful nodules in subcutaneous. 
c) Nerves

- Ask the patient if there is any reduction of sensibility or strength in hands and feet.

- Ask about difficulties in performing daily tasks.

- Ask about pain, burning and/or tingling sensation in the nerves.

- Palpate the nerves to evaluate for hypersensitivity or pain.

- Test for loss of sensitivity in hands and feet, using the set of monofilaments.

- Test the muscle strength of hands and feet.

d) Eyes

- Ask the patient if there is pain in the eyes, photophobia or recent loss of eyesight (worsening of visual acuity).

- Look for signs of inflammation: hyperaemia or irregularity in the form of the pupils.

- Test the muscle strength of the eyelids.

3. Compare the results of this clinical examination with those of the previous examination.

4. Record the results of the clinical examination in the patient's chart. Describe in the chart the alterations found in the skin and nerves, according to the following definitions:

\section{DEFINITIONS}

\section{Reversal Reaction (Type 1 Reaction)}

The most common clinical characteristic of this type of reaction is the inflammation of pre-existing cutaneous lesions that become more erythematous, even vinous, and new lesions may appear. If the oedema is greatly accentuated, the lesions can peel and even ulcerate. The sensibility of the lesions is generally exacerbated, and patients may complain of intense pain even for small injuries. They might recur and last for months or even years. Systemic symptoms such as fever, malaise, anorexia, can accompany the more serious reactions, but this is less frequent than in type 2 reactions. Swelling of the hands, feet and face may be present. Neuritis is the most important manifestation of the type 1 reaction, occurring by itself or in association with cutaneous lesions.

\section{Erythema Nodosum Leprosum (Type 2 Reaction)}

The lesions of erythema nodosum leprosum (ENL) are the most common manifestation and sometimes the only one for type 2 reactions. They are characterized by erythematous nodules, 2 to $5 \mathrm{~mm}$ in diameter, tender to the touch or even painful in the absence of external stimuli. They can be few or many more frequently localized in 
Independent study to establish the efficacy of the six dose uniform MDT regimen

(U-MDT) for leprosy patients

legs and arms and less frequently in trunk and, in several cases they can disseminate. They can be superficial or quite deep, which in this case makes them more palpable than visible, and can sometimes ulcerate. In general, they occur in outbreaks with intermittent spells of fever, and tend to recur in the same parts of the body. If they don't totally disappear, a chronic, painful panniculitis can develop that sometimes lasts for months or years. Some patients have reactions with blisters, erythematous plaques and ulcerations - a reaction of the polymorphous erythema type.

Neuritis is a common manifestation, but is less intense than in the type 1 reaction. Iritis and episcleritis are also common, and can be the only manifestation of the reaction, as well as being present at the time of diagnosis. Symptoms of the upper respiratory apparatus, and others, such as epistaxis, can worsen and even ulcerate. Orchitis can be acute, with oedema and pain in the testicles, which can rapidly atrophy, or even occur without symptoms, with little pain and oedema, but lead to gradual loss of function. Pain and oedema in lymphnodes can accompany or occasionally be predominant in type 2 reactions. Rarely, necrosis may occur. Oedema and pain in the feet and hands can happen more frequently than in type 1 reactions, or occurs in the joints, simulating arthritis. The term of "reaction" hands and feet is used when there is diffuse and acute inflammation of all soft tissue of the hands and feet, such as tenosynovitis, myositis, arthritis e osteitis, which can leave retractile dysfunction. General symptoms like fever, exhaustion, malaise, headache, anorexia, insomnia and depression are more commonly seen than in type 1 reactions. Hepatomegaly and splenomegaly can be present.

\section{Neuritis}

The condition of neuritis manifests itself through spontaneous neural pain or when nerve trunks are palpated, and can be associated with sensation, motor or sudden autonomic deficit. The nerve diameter may or may not be thickened.

While palpating the nerves, it's important to watch the face of the patient for expressions of pain. Always compare a palpated nerve from one side to the other side, observing thickness, texture and the presence of nodules. 
Classification of neural pain and presence of NEURITIS.

\begin{tabular}{|l|l|l|}
\hline Level & \multicolumn{1}{|c|}{ Neural pain } & Neuritis* \\
\hline 0 & Absent & No \\
\hline 1 & $\begin{array}{l}\text { Light }- \text { when distracted the patient does not manifest pain at } \\
\text { palpation. }\end{array}$ & No \\
\hline 2 & $\begin{array}{l}\text { Moderate - even when distracted, the patient manifests pain at } \\
\text { palpation. }\end{array}$ & Yes \\
\hline 3 & $\begin{array}{l}\text { Severe - the patient pulls away the member in a defensive } \\
\text { movement. }\end{array}$ & Yes \\
\hline
\end{tabular}

${ }^{*}$ Consider neuritis only when the status found is described as moderate or severe (2 or 3).

\section{Silent neuropathy}

The state of silent neuropathy occurs when the patient presents sensibility and/or recent motor deficit ( $<6$ months of duration), in an area innervated by one or more nerve trunks, with no sign of reverse reaction or erythema nodosum and with no pain or neural hypersensitivity.

\section{Sensibility deficit}

Test six spots in each hand and nine spots in each foot, according to what has been described in SOP 011 (Simplified Neurological Exam).

The following conditions, when compared with previous records, represent a case of neuritis, with or without pain at nerve palpation.

1) Worsening of at least three levels of monofilament in any spot OR;

2) Worsening of two levels of monofilament in one spot AND at least one level in another spot OR;

3) Worsening of one level of monofilament in three or more spots corresponding to the trajectory of the same nerve.

\section{Motor deficit}

Test six muscles in each side of the patient's body: one muscle that affects the eyelid, three muscles of the hand and two muscles in the foot, according to what has been described at the Simplified Neurological Evaluation SOP.

Consider motor deficit to be present if the response to the test for any muscle is less than four, in the gradual scale of muscular strength. 
The decrease of strength in a muscle of more than two levels, when compared to previous exams, represents the onset of neuritis, with or without pain at nerve palpation.

\section{Neural thickness}

Consider the following scale to define neural thickness:

0 - absent

1 - doubtful

2 - defined.

Only the "defined" scale (2) should be included as neural thickness.

Register on the CRF, on the "Diagnosis and Follow-up of Reactions" form, according to the codes below. Remember that one or more options are acceptable.

1- Reverse Reaction

2- ENL

3- Necrosing ENL

4- Polymorphic Erythema

5- Arthritis

6- Lymphadenopathy

7- Orchitis

8- Iritis / Iridocyclitis

9- Reaction hand and foot

10- ENL + necrosing ENL

11- ENL + Polymorphic Erythema

12- ENL + Orchitis

13- ENL + Arthritis

14- ENL + Lymphadenopathy

15- ENL + Iritis / Iridocyclitis

16- ENL + reaction hand and foot

17- Mixed reaction / Type $1+$ Type 2

18- Neuritis
19- Neuritis + Reverse reaction

20- Neuritis + ENL

21- Neuritis + Mix Reaction

22- Neuritis + necrosing ENL

23- Neuritis + Polymorphic Erythema

24- Neuritis + Arthritis

25- Neuritis + lymphadenopathy

26- Neuritis + Orchitis

27- Neuritis + Iritis / Iridocyclitis

28- Neuritis + reaction hand and foot

29- Neuritis + ENL + necrosing ENL

30- Neuritis + ENL + polymorphic erythema

31- Neuritis + ENL + Orchitis

32- Neuritis + ENL + Arthritis

33- Neuritis + ENL + Lymphadenopathy

34- Neuritis + ENL + Iritis / Iridocyclitis

35- Neuritis + ENL + Reaction hand and foot

- Involvement:

1 - Cutaneous

2 - Neural

3 - Cutaneous + neural

4 - Cutaneous + systemic 
$5-$ Neural + systemic

6 - Cutaneous + neural + systemic

- Precipitating factors of the reactions:

1) Intervening infections

2) Pregnancy

3) Surgery

4) Physical and/or psychological stress

5) Medication

6) Vaccinations

7) Unidentified

8) Others - specify which.

- Treatment used:

1) Corticosteroid

2) Thalidomide

3) Clofazimine

4) Pentoxifylline

5) Corticosteroid + Thalidomide

6) Corticosteroid + Clofazimine

7) Corticosteroid + Pentoxifylline

8) Thalidomide + Clofazimine

9) Thalidomide + Pentoxifylline

10) Corticosteroid + Thalidomide + Clofazimine

11) Corticosteroid + Thalidomide + Pentoxifylline

12) Corticosteroid + Pentoxifylline + Clofazimine

13) Corticosteroid + Pentoxifylline + Clofazimine + Thalidomide

14) Other - specify which. 


\section{SIDE EFFECTS OF MDT}

\section{OBJECTIVE:}

To detect the occurrence of signs or symptoms that may be related to the use of any medication in the course of Multi-Drug Therapy. Determine the measures to be taken in case side effects should occur, according to their type and the drug responsible.

MATERIAL

- White coat

- Black pen

- Health Centre Patient Chart

- CRF - U-MDT

\section{PROCEDURES}

- During each monthly visit, inquire the patient as to the presence of symptoms and observe signs that may be related to adverse effects of the medication used in MDT.

- On the monthly visit form, only the side effects that may be related to medication used in MDT should be recorded.

- Adverse effects related to other medications in use, including anti-reaction medications, must be written on the Registration of Side Effects form (page 126 of the CRF).

- Critical side effects that indicate the need for suspension of MDT must be registered on the Description of Critical Side Effects (page 127 of the CRF).

- Classify the side effects, according to their severity, using the tables below. In these tables, DLA means "daily life activities". 


\begin{tabular}{|c|c|c|c|}
\hline \multicolumn{4}{|c|}{ Dermatological } \\
\hline Sign or symptom & Mild & Moderate & Severe \\
\hline Itching & Mild or localised & $\begin{array}{c}\text { Intense or } \\
\text { disseminated, without } \\
\text { interfering in DLA }\end{array}$ & Interfering in DLA \\
\hline Xerosis & Asymptomatic & $\begin{array}{l}\text { Symptomatic without } \\
\text { interfering in DLA }\end{array}$ & $\begin{array}{c}\text { Symptomatic, } \\
\text { interfering in DLA }\end{array}$ \\
\hline $\begin{array}{l}\text { Cutaneous } \\
\text { pigmentation }\end{array}$ & Mild or localised & Intense or spread & Not applicable \\
\hline $\begin{array}{l}\text { Cutaneous Rash / } \\
\text { erythrodermia }\end{array}$ & $\begin{array}{l}\text { macular or papular } \\
\text { eruption, or erythema, } \\
\text { with no associated } \\
\text { symptoms }\end{array}$ & $\begin{array}{l}\text { macular or papular } \\
\text { eruption, or erythema, } \\
\text { with itching or other } \\
\text { symptoms, and } \\
\text { localised peeling } \\
\text { affecting less than } \\
50 \% \text { of body surface }\end{array}$ & $\begin{array}{l}\text { Severe or spread } \\
\text { erythema or macular, } \\
\text { papular or vesicular } \\
\text { eruption; peeling } \\
\text { affecting } 50 \% \text { or more } \\
\text { of body surface. }\end{array}$ \\
\hline Photodermatitis & $\begin{array}{l}\text { Erythema without } \\
\text { pain }\end{array}$ & Erythema with pain & Erythema with peeling \\
\hline
\end{tabular}

\begin{tabular}{|c|c|c|c|}
\hline \multicolumn{4}{|c|}{ Gastrointestinal (1/2) } \\
\hline Sign or symptom & Mild & Moderate & Severe \\
\hline Abdominal pain & $\begin{array}{l}\text { Mild discomfort; does } \\
\text { not interfere in } \\
\text { behaviour. }\end{array}$ & $\begin{array}{c}\text { Pain or use of } \\
\text { medication interferes } \\
\text { in behaviour, but does } \\
\text { not interfere in DLA. }\end{array}$ & $\begin{array}{c}\text { Pain or use of } \\
\text { medication interferes } \\
\text { in DLA. }\end{array}$ \\
\hline $\begin{array}{l}\text { Intestinal } \\
\text { constipation }\end{array}$ & $\begin{array}{l}\text { Occasional or } \\
\text { intermittent } \\
\text { symptoms. }\end{array}$ & $\begin{array}{l}\text { Persistent symptoms, } \\
\text { making the regular use } \\
\text { of laxatives necessary. }\end{array}$ & $\begin{array}{l}\text { Symptoms interfere in } \\
\text { DLA. }\end{array}$ \\
\hline Nausea & $\begin{array}{l}\text { Loss of appetite; } \\
\text { does not interfere in } \\
\text { eating habits. }\end{array}$ & $\begin{array}{c}\text { Altered intake of food, } \\
\text { with significant weight } \\
\text { loss or } \\
\text { malnourishment. }\end{array}$ & $\begin{array}{l}\text { Inadequate intake of } \\
\text { calories and liquids. }\end{array}$ \\
\hline Vomit & $\begin{array}{l}01 \text { episode in } 24 \\
\text { hours. }\end{array}$ & $\begin{array}{c}2-5 \text { episodes in } 24 \\
\text { hours }\end{array}$ & $\begin{array}{c}\geq 6 \text { episodes in } 24 \\
\text { hours }\end{array}$ \\
\hline Diarrhoea & $\begin{array}{l}\text { Increase of less than } \\
4 \text { daily defecations } \\
\text { more than usual. }\end{array}$ & $\begin{array}{c}\text { Increase of } 4-6 \text { daily } \\
\text { defecations more than } \\
\text { usual. }\end{array}$ & $\begin{array}{c}\text { Increase of } 7 \text { or more } \\
\text { daily defecations, more } \\
\text { than usual, interfering } \\
\text { with DLA and } \\
\text { requesting intravenous } \\
\text { rehydration. }\end{array}$ \\
\hline
\end{tabular}


Gastrointestinal (2/2)

\begin{tabular}{lccc}
\hline Sign or symptom & Mild & Moderate & Severe \\
\hline Anorexia & $\begin{array}{c}\text { Loss of appetite } \\
\text { without interfering } \\
\text { with eating habits. }\end{array}$ & $\begin{array}{c}\text { Altered intake of food, } \\
\text { with significant weight } \\
\text { loss or } \\
\text { malnourishment. }\end{array}$ & $\begin{array}{c}\text { Important weight loss } \\
\text { or malnourishment. }\end{array}$ \\
\hline Hepatitis* & Not applicable & jaundice & $\begin{array}{c}\text { Pre-comatose phase, } \\
\text { presenting involuntary } \\
\text { tremors. }\end{array}$ \\
\hline Cholecystitis $^{*}$ & $\begin{array}{c}\text { Asymptomatic with } \\
\text { laboratorial / } \\
\text { radiographic } \\
\text { findings. }\end{array}$ & $\begin{array}{c}\text { Symptomatic, } \\
\text { requesting specialized } \\
\text { medical intervention. }\end{array}$ & $\begin{array}{c}\text { Radiological, } \\
\text { endoscopic or surgical } \\
\text { intervention is } \\
\text { recommended. }\end{array}$ \\
\hline \hline${ }^{*}$ Hepatitis e Cholecystitis should be registered in the Critical Side Effects form (page127 do CRF).
\end{tabular}

Haematological

\begin{tabular}{|c|c|c|c|}
\hline Sign or symptom & Mild & Moderate & Severe \\
\hline Red cell count & $\begin{array}{l}\text { Slight cellular } \\
\text { reduction } \\
\text { reduction } \leq 25 \% \text { or } \\
\text { normal according to } \\
\text { age. }\end{array}$ & $\begin{array}{l}\text { Moderate cellular } \\
\text { reduction or reduction } \\
>25 \%-\leq 50 \% \text { of } \\
\text { normal according to } \\
\text { age. }\end{array}$ & $\begin{array}{l}\text { Severe cellular } \\
\text { reduction or reduction } \\
>50 \%-\leq 75 \% \text { of } \\
\text { normal according to } \\
\text { age. }\end{array}$ \\
\hline Haemoglobin & $<\mathrm{LLN}-10.0 \mathrm{~g} / \mathrm{dl}$ & $<10.0-8.0 \mathrm{~g} / \mathrm{dl}$ & $<8.0 \mathrm{~g} / \mathrm{dl}-6.5 \mathrm{~g} / \mathrm{dl}$ \\
\hline Haemolysis & $\begin{array}{l}\text { Only laboratorial } \\
\text { evidence of } \\
\text { haemolysis. }\end{array}$ & $\begin{array}{l}\text { Evidence of red cell } \\
\text { destruction and } \\
\text { reduction of } \geq 2 \mathrm{gm} \text { of } \\
\text { haemoglobin, } \\
\text { transfusion is not } \\
\text { indicated. }\end{array}$ & $\begin{array}{l}\text { Transfusion or medical } \\
\text { intervention } \\
\text { (corticosteroids) is } \\
\text { necessary. }\end{array}$ \\
\hline $\begin{array}{l}\text { Meta- } \\
\text { hemoglobinemia } \\
\text { (clinical findings) }\end{array}$ & $\begin{array}{l}\text { Purplish or cyanotic } \\
\text { lips. }\end{array}$ & $\begin{array}{l}\text { Cyanotic extremities, } \\
\text { light dyspnoea. }\end{array}$ & $\begin{array}{c}\text { Overall status is } \\
\text { compromised, intense } \\
\text { dyspnoea. }\end{array}$ \\
\hline $\begin{array}{l}\text { Bleeding } \\
\text { (epistaxis, purpura, } \\
\text { etc) }\end{array}$ & $\begin{array}{l}\text { Discreet bleeding, no } \\
\text { need for intervention. }\end{array}$ & $\begin{array}{l}\text { Symptomatic bleeding, } \\
\text { with indication for } \\
\text { medical intervention. }\end{array}$ & $\begin{array}{l}\text { Intense bleeding, } \\
\text { requesting admittance } \\
\text { to a hospital and/or } \\
\text { blood transfusion. }\end{array}$ \\
\hline
\end{tabular}




\section{Overall symptoms}

\begin{tabular}{lccc}
\hline Sign or Symptom & Mild & Moderate & Severe \\
\hline Weight loss & $\begin{array}{c}5 \text { to }<10 \% \text { of initial } \\
\text { weight. }\end{array}$ & $\begin{array}{c}10 \text { to }<20 \% \text { of initial } \\
\text { weight. }\end{array}$ & $\geq 20 \%$ of initial weight. \\
\hline Dyspnoea & $\begin{array}{c}\text { Shortness of breath, } \\
\text { the patient is able to } \\
\text { climb a flight of stairs } \\
\text { without needing to } \\
\text { stop. }\end{array}$ & $\begin{array}{c}\text { The patient cannot } \\
\text { climb one flight of } \\
\text { stairs or walk 100m } \\
\text { without needing to } \\
\text { stop. }\end{array}$ & $\begin{array}{c}\text { Makes it impossible to } \\
\text { perform DLA. }\end{array}$ \\
\hline Fatigue & $\begin{array}{c}\text { Doesn't interfere in } \\
\text { DLA }\end{array}$ & $\begin{array}{c}\text { Makes it difficult to } \\
\text { perform some DLA. }\end{array}$ & Interferes in DLA. \\
\hline Fever & $38,0-39,0^{\circ} \mathrm{C}$ & > 39,0 - 40,0 $0^{\circ} \mathrm{C}$ & $>40^{\circ} \mathrm{C}$ \\
\hline Myalgia & $\begin{array}{c}\text { Mild muscular pain, } \\
\text { does not interfere in } \\
\text { behaviour. }\end{array}$ & $\begin{array}{c}\text { Moderate muscular } \\
\text { pain; pain or the use of } \\
\text { medication interferes } \\
\text { in behaviour, but not in } \\
\text { DLA. }\end{array}$ & $\begin{array}{c}\text { Severe muscular pain; } \\
\text { pain or use of } \\
\text { medication interferes } \\
\text { in DLA. }\end{array}$ \\
\hline \hline
\end{tabular}

\section{Neurological}

\begin{tabular}{lccc}
\hline Sign or symptom & Mild & Moderate & Severe \\
\hline Headache & $\begin{array}{c}\text { Light headache, } \\
\text { does not interfere in } \\
\text { behaviour. }\end{array}$ & $\begin{array}{c}\text { Moderate headache; } \\
\text { pain or use of pain- } \\
\text { killers interferes in } \\
\text { behaviour, but not in } \\
\text { DLA. }\end{array}$ & $\begin{array}{c}\text { Severe headache; pain } \\
\text { or use of pain-killers } \\
\text { interferes in DLA. }\end{array}$ \\
Depression & $\begin{array}{c}\text { Moderate mood } \\
\text { alteration, not } \\
\text { interfering in } \\
\text { behaviour. }\end{array}$ & $\begin{array}{c}\text { alteration, interfering in } \\
\text { behaviour but not in }\end{array}$ & $\begin{array}{c}\text { Severe mood } \\
\text { alteration, interfering in } \\
\text { DLA - suicidal } \\
\text { thoughts. }\end{array}$ \\
\hline \hline
\end{tabular}




\section{CONDUCT TO BE APPLIED IN CASE OF SIDE EFFECTS:}

\section{Nausea and vomiting}

- Investigate if those effects occurred after taking the supervised dose or after the self-administered doses of MDT.

- Investigate cause (gastro-intestinal intolerance, viral or drug-induced hepatitis, etc), through the patient history information, physical exam and requests for complementary exams.

- In case it relates to the self-administered dose, orient the patient to take it after a meal.

- In the case of repeated vomiting, suspend treatment, removing the patient from the study - fill out the study withdrawal form, according to SOP 024.

\section{Cutaneous effects or dryness}

- Prescribe the daily application of mineral oil or urea cream after showering, and orient the patient to avoid exposure to direct sunlight.

\section{Jaundice}

- Investigate if the existence of this side effect relates to the administration of the supervised dose or to self-administered doses.

- Evaluate previous history for alcoholism, hepatitis and other hepatic diseases;

- Request complementary exams for differential diagnoses;

- If there is an alteration of indicators of liver function, with values greater than twice the normal value, suspend treatment and remove the patient from the study - fill out the study withdrawal form, according to SOP 024 .

\section{Haemolytic anaemia}

- Remember that most patients tend to improve as the treatment goes on;

- Give the patient folic acid: 5 to $10 \mathrm{mg} / \mathrm{day}$

- In severe cases:

- suspend treatment;

- refer the patient to a haematologist for evaluation and treatment. 


\section{Meta-hemoglobinemia}

- Mild: suspend dapsone and observe. Usually it disappears gradually after suspending medication.

- Severe: refer for hospital admittance and intravenous administration of methylene blue, 1 to $2 \mathrm{mg} / \mathrm{kg}$ of body weight, in $1 \%$ solution, during 5 minutes. If the cyanosis does not disappear in one hour, repeat the medication, in the same proportions, never exceeding $7 \mathrm{mg} / \mathrm{kg}$ of body weight. Methylene blue should not be used for G6PD (glicose6 phosphate dehydrogenase) deficient.

- Other measures to be taken: diminish the absorption of dapsone through emetics and gastric lavage, haemodialysis, peritoneal dialysis or exsanguinous-transfusion, use of manitol and urea to increase the excretion of dapsone.

\section{Pseudoflu syndrome}

- Immediately suspend rifampicin and evaluate the severity of the case;

- In mild cases, administer anti-histamine, anti-thermal and keep the patient under observation for at least 6 hours;

- In moderate and severe cases, administer corticosteroids (hydrocortisone $500 \mathrm{mg} / 250 \mathrm{ml}$ of saline - $30 \mathrm{drops} /$ minute IV), and then oral corticosteroids (prednisone) with progressive reduction of dosage until complete removal.

7. Mild Pharmacodermy to Stevens-Johnson Syndrome, exfoliative dermatitis or erythrodermia caused by dapsone.

- Suspend, definitively, treatment with dapsone.

- Depending on the severity of the pharmacodermy, refer for hospital admittance.

- In case of suspected hypersensitivity syndrome related to dapsone, request complete blood scan, hepatic and renal functions, refer for hospital admittance. 
Independent study to establish the efficacy of the six dose uniform MDT regimen

(U-MDT) for leprosy patients

\section{POP MDTU 023}

\section{RELAPSE}

\section{OBJECTIVE}

To detect the presence of signs or symptoms that may indicate leprosy relapse.

\section{MATERIAL}

- White coat

- Black pen

- Patient Chart

- $\quad$ CRF - U-MDT

\section{PRECAUTIONS}

Always verify the possibility that the manifestations are caused by a leprosy reaction. Confirmation of relapse will only be done after discussing the case with the study's general coordinators.

\section{CRITERIA FOR SUSPECTING RELAPSE}

\section{Paucibacillary Patients PB:}

1. Appearance or ongoing presence of Reversal Reaction (RR), with cutaneous effects and/or neuritis, three years after release from treatment with MDT (RFT).

2. Slow or gradual appearance of new lesions (skin and nerves) and/or worsening of residual lesions, three years after discharge. Cases that had improved cutaneous condition, but saw reactivation of lesions following gradual reduction of corticosteroids should also be included.

3. Absence of significant improvement of lesions 1 to 2 weeks after beginning treatment with prednisone $1 \mathrm{mg} / \mathrm{kg} /$ day.

4. Patients that fall outside the criteria above, but who present clinical signs of relapse, including tuberculoid cases

5. Even beyond the three-year period, the physician should consider the possibility of relapse any time the clinical signs are strongly suspicious.

\section{Multibacillary Patients MB:}

1. Continuation or worsening of reactions (type 1 or type 2) five years after release from MDT treatment;

2. Appearance of new lesions (skin and nerves) and/or exacerbation of residual lesions after RFT that do not respond to treatment with corticosteroids and/or thalidomide; 


\section{Independent study to establish the efficacy of the six dose uniform MDT regimen}

(U-MDT) for leprosy patients

3. Bacilloscopic exam with intact bacilli present;

4. Increase of 2+ of $\mathrm{BI}$ (at any site) when compared to the BI taken at RFT, when available;

5. Clinical-histopathological correlation: AFB intact even with negative bacilloscopy.

6. Even beyond the five-year period, the physician should consider the possibility of relapse any time the clinical signs are strongly suspicious.

\section{PROCEDURES}

The following tests and procedures should be done when active leprosy relapse is suspected, and registered in the Relapse Registration Form (page 132 of the CRF).

1. Collect information regarding previous treatment:

- Initial clinical classification

- $\quad$ Date the previous treatment ended

- $\quad$ Occurence of reactions during and after treatment

- Initial bacilloscopy, with BI present.

- Initial ML Flow, with intensity present.

2. Ask when the current symptoms began;

3. Take the patient's history and perform a full physical exam, following SOPs 008 and 009.

4. Perform the dermatological-neurological exam, according to SOP 010.

- Describe the type, alterations of colour, total number and sensibility alterations of the lesions, entering the results on the patient chart.

- Register the number of affected nerves--thickened, painful and/or presenting altered neural function, in the area of corresponding innervation.

5. Determine and record the operational classification, according to the number of skin lesions, regardless of the number of nerves afflicted, as per WHO classification.

- Paucibacillary (PB): cases with up to 5 cutaneous lesions.

- Multibacillary (MB): cases with 6 or more cutaneous lesions.

6. Determine e register the clinical classification as described in SOP 010.

7. Evaluate the Disability Grade, according to SOP 011.

8. Request the following tests: bacilloscopy, biopsy and ML Flow, according to SOP 012 . .

9. Compare the results of the clinical examination with those of the previous exams.

\section{TESTS TO CONFIRM RELAPSE}

To confirm the suspicion of relapse, beyond a detailed clinical examination and the results of conventional laboratory exams, such as bacilloscopy, biopsy and ML-flow, the following tests must be performed: 


\section{Independent study to establish the efficacy of the six dose uniform MDT regimen (U-MDT) for leprosy patients}

1. ELISA (Enzyme Linked Immunosorbent Assay) technique - for detection of IgM antibodies against PGL-1:

- It will be done with the same blood sample used to perform the ML-flow test.

- Inform the study's general coordination of the existence of the sample so that the conduction of the exam can be scheduled.

2. Study of resistance to medication:

- Before doing the biopsy, verify the availability of the reference laboratory for receiving the material below (Laboratory for Mycobacterial-Applied Molecular Biology (Room 31 / 33) - Mycobacterial Department - Oswaldo Cruz Foundation (FIOCRUZ). Av. Brasil, 4365. Manguinhos - RJ. CEP 21045-900). Once the shipping of the material has been agreed by the Laboratory, then:

a. Take a skin fragment through biopsy with 4 or $5 \mathrm{~mm}$ punch.

b. Store the skin fragment in a sterile glass flask containing $70 \%$ ethanol.

c. Seal off the cap of the flask with adhesive tape, and identify it with the patient's information.

d. Send it to the reference lab.

3. Inoculation in mouse footpad

- Before doing the biopsy, check:

- The patient's bacteriological index. Only perform this test for patients with $\mathrm{BI} \geq 3$.

- Availability of the reference laboratory (Microbiology Laboratory - Lauro de Souza

Lima Institute, rodovia Comandante João Ribeiro de Barros km 226, caixa postal 3021 , CEP 17034-971) to receive the material. Once the shipping of the material has been agreed by the Laboratory, then:

b. Take a skin fragment through biopsy with 4 or $5 \mathrm{~mm}$ punch.

c. Store the skin fragment in a dry, sterile glass flask with rubber cap.

d. Seal off the cap of the flask with adhesive tape and identify it with the patient's information.

e. Put the flask inside a surgical glove, tying its opening with a knot.

f. Place the glove inside a styrofoam box containing packs of recyclable ice (DO NOT USE DRY ICE); the box can be small, but must be made of strong material, so as not to break or crack during shipping; seal it with adhesive tape, identify it as containing perishable material and send it as quickly as possible to the reference laboratory. 


\section{POP MDTU 024}

\section{PATIENT WITHDRAWAL FROM STUDY}

\section{OBJECTIVE}

To detect the occurrence of situations in which the research participant must be officially removed from the study.

\section{RESPONSIBLE}

Local Coordinator, after obtaining authorisation from general coordinator.

\section{Definition of removal}

Patient whose clinical progress will not be registered on the CRF from the date of removal onward. Observe that every recruited patient will be analyzed until the period stipulated.

\section{PROCEDURES}

1. To withdraw the patient complete the following data in the CRF:

a. Wether the patient completed the full course of treatment or not, enter the date of the last dose taken.

b. If the course of MDT was not completed, inform why:

\section{Patient requested to be removed from the study}

The voluntary patient who, for whatever personal reason, decides and requests to be withdrawn from the study, even if means that he/she has received all doses but does not wish to participate in the follow-up period, will be removed from the study.

2. Unable to reach the patient during the treatment period. Specify if the address was not located, if the patient moved to a new residence or to another State.

3. Violation of Protocol - incorrect inclusion criteria used during recruitment.

Any voluntary patient will be removed from the study who, during the time of the study, develops any of the conditions listed in the exclusion criteria.

\section{Violation of Protocol - treatment irregularity.}

Any voluntary patient will be removed from the study who has participated irregularly in the study and will not finish treatment within the period defined in the research protocol. The patient will be removed at the time it becomes impossible for them to finish treatment, under the following definitions:

PB Patients: U-MDT e R-MDT groups -the point at which the sum of defaulted doses reaches four months. 
Independent study to establish the efficacy of the six dose uniform MDT regimen

(U-MDT) for leprosy patients

MB Patients: U-MDT group - the point at which the sum of defaulted doses reaches four months. R-MDT group - the point at which the sum of defaulted doses reaches seven months.

\section{Side effects.}

Any patient will be removed from the study who presents severe side effects to the MDT drugs, that justify the suspension of the drug in question. The withdrawal from the study will take effect from the date the physician removes or replaces any component of MDT.

\section{Intervening disease.}

Any patient who, during the period of treatment, presents any intervening disease that justifies the interruption of the drugs used at the MDT.

\section{To register an active search on follow-up after the completion of MDT, include the} following information:

1. Patient was lost to the study during the follow-up period, after the completion of MDT.

Patients who cannot be found during the follow-up period, even after repeated attempts at recovery, will not be removed from the study, as long as:

- For each patient with a telephone, at least three calls will be made to request their presence at the Health Centre;

- For those patients who do not have a telephone, at least three letters will be mailed requesting their presence at the Health Centre;

- For each patient who does not answer the phone call and/or letters, at least three active search visits will be made to his/her residence.

2. Death

All patients who pass away during the study, no matter the cause of death, will have their death certificate attached to the chart and duly noted on their CRFs.

3. Others

Other situations that are not listed in this protocol, but for which the removal of the patient from the study is recommended, must be communicated and discussed with the study's coordinators so that the withdrawal procedures for each case are determined in consultation with the Data and Safety Monitoring Board (DSMB). 
Independent study to establish the efficacy of the six dose uniform MDT regimen

(U-MDT) for leprosy patients

APPENDIX I of SOP UMDT 012

\section{PROJECT: MDT - U}

Name:

Age:

Date of Birth:

1

Sex:

Date of request:

Chart no.:

CRF:

\section{HISTOPATHOLOGICAL EXAM REQUEST}

Site of biopsy:

Description of lesion:

Duration of lesion: months. Alteration of sensibility: ( )Thermal ( )Pain ( )Tactile

No. of lesions:

$\mathrm{Bl}:$

Diagnostic hypothesis:

Differential Diagnosis: 


\section{CONFIDENTIAL DOCUMENT}

Dona Libânia National Dermatological Reference Centre Fortaleza, CE

Independent study to evaluate the efficacy of the Six-dose uniform MDT regimen (U-MDT) for leprosy patients

\section{PATIENT CHART}

General coordinator: Dr. Gerson Penna, MD, PhD

Principal Researchers

Dr. Gerson Penna, MD, PhD

Dr. Samira Bührer-Sékula, PhD

Researchers at the Dona Libânia National Dermatological Reference Centre

Dr. Maria Araci Pontes

Dr. Heitor de Sá Gonçalves 


\section{Dona Libânia National Dermatological Reference Centre Fortaleza (CE) INFORMED CONSENT FORM}

The study must be explained orally to children in a simple way allowing them to understand, as much as possible, what will happen in the study.

(1) Explanation of the Consent Form:

Title of the study:"Independent study to establish the efficacy of the six-dose uniform MDT

Principal investigators: regimen (U-MDT) for leprosy patients".

Principal investigator: Dr. Gerson Oliveira Penna, Tropical Medicine Unit, University of Brasilia Principal investigator at the Dona Libânia National Dermatological Reference Centre: Dr. Maria Araci Pontes

(2) Information regarding participation in the study:

Institutions: Tropical Medicine Unit, University of Brasilia

Dona Libânia National Dermatological Reference Centre

You have been invited to participate in a medical research study. It is important for you to understand the general principles that will be applied to all participants of this study: (1) Your participation is voluntary. (2) You may decide to withdraw from the study before initiating treatment, or at any subsequent time. You will not be penalised or lose your right to treatment if you decide not to participate. (3) After reading this explanation, feel free to ask any questions you have to understand the study completely.

You are presenting symptoms that might be LEPROSY (HANSEN'S DISEASE), a curable disease that is treated with various types of medicines given at the same time. When leprosy is not treated, it can cause physical deformities. The study you are invited to be part of voluntarily is a clinical study that will attempt to better understand this disease, especially in relation to the length of time needed for treatment, because for some forms of the disease, the current treatment period is still very long.

Some researchers think that the length of treatment can be reduced without compromising patient cure. Read the information carefully before giving your consent. By signing this consent form you are agreeing to participate in the clinical research called:"Independent study to establish the efficacy of the six dose uniform MDT regimen (U-MDT) for leprosy patients".

The objective of this study is to verify if one treatment regimen can be used for all leprosy patients, reducing the treatment to 6 months for those patients who at the present time are being treated for 12 months.

(3) Procedures to be followed:

If you agree to participate in this study, after signing the consent form, we will fill out your medical form, do a physical examination and run some laboratory tests so that we can determine the type of leprosy you have: (1) leprosy with few lesions (paucibacillary) or (2) leprosy with a greater number of lesions (multibacillary).

If you are classified as paucibacillary, you will participate in a random selection that will determine your participation in one of the 2 groups below: 
Group 1 - you will use the one regimen treatment consisting of six-dose of three medications and annual follow-up for 5 years after the completion of treatment (U-MDT),

Or

Group 2 - you will use the same regimen as presently used, consisting of six-dose of two medications and annual follow-up for 5 years after the completion of treatment (R-MDT).

If you are classified as multibacillary, you will participate in a random selection that will determine your participation in one of the 2 groups below:

Group 3 - you will receive six-dose of three medications and monthly follow-up for 6 months and annual follow-up for 5 years after the completion of treatment (U-MDT),

Or

Group 4 - you will receive twelve doses of three medications and annual follow-up for 5 years after the completion of treatment (R-MDT).

The medication will be taken every day at home and once a month at the Health Centre. The oral medications used daily have been used for the treatment of leprosy for over 25 years.

We will also collect blood and take a small piece of your skin (biopsy) for examination. A picture of your lesion will be taken as well, at the beginning of the treatment, for comparison in the case of relapse. These tests are important for your participation in this study.

A sample of your blood will be collected and stored and will only be used if authorised by the lead investigator of the study.

All the samples will be labelled with the patient number and their initials so that confidentiality is guaranteed. If any new test or component is discovered that would benefit the participant, the researcher will access the lead investigator's file-the only place where patient data will be stored-- the patient will be contacted and informed about this benefit.

During the duration of your treatment, you will be examined monthly to monitor the treatment. After that, you will be examined once a year for five years, and after that your participation in the study will end.

If during the study you present any leprosy reactions or any other health problem, you should come to the Health Centre and inform the research team.

If you present symptoms of leprosy again, your physician may start a new treatment, following the recommendations of the Ministry of Health.

\section{(4) Medications being researched}

You will not be the first person to use the medications prescribed in this study, they have been in use for the successful treatment of leprosy for the last 20 years. Initially, they were used for periods of 5 years, then the treatment was reduced to 2 years and now they are used for 1 year. This study seeks to obtain information about the ideal treatment duration and determine if it is possible to treat all patients with only one treatment regimen for 6 months, instead of the current 12 months. We are going to evaluate the efficacy of shorter treatment by studying the possibility of relapse.

(5) Duration of your participation: 6 or 12 months of treatment and 5 years of follow-up.

(6) Risks, side effects and discomforts.

It is important for you to know that the risks involved with the treatment of leprosy are minimal. When not treated, it can cause physical deformities. Death as a result of leprosy is very rare. 
The medications presently used in the standardised treatment of this disease (rifampicin, dapsone and clofazimine) are the same that will be used in this study. Occasional side effects can include nausea, redness in urine, and one of the drugs can temporarily change skin colour. All these side effects will disappear once the treatment is over. It is important to take the medication everyday to obtain good results.

After the completion of the treatment, you should return to be examined at the Health Centre once a year for the next five years. It is important that you return for these visits so that we can be sure that the treatment duration is adequate. Independent of the course of treatment used, a small percentage of patients could relapse, and in this case, the patient will need to be treated again with the same multidrug therapy as per Ministry of Health guidelines.

Only qualified health workers will administer treatment and examine the patients who voluntarily enrol in this study. They will observe you carefully to prevent any reaction and are prepared to treat you promptly, if necessary.

By participating in this study you will be contributing to the advancement of scientific knowledge about leprosy and as such you have certain responsibilities: follow closely the instructions given by your physician; come to the Health Centre on the dates scheduled; inform your doctor about any changes (good or bad) you notice during this study.

(7) Benefits.

The reduction of the treatment from 12 to 6 months for some patients and the possibility of having only one course for treatment for this disease will be of great benefit for all patients. Nevertheless, we cannot guarantee that this will be true for all patients.

In addition, you will be collaborating in a study that could benefit other people who may fall sick with the same disease.

The medical attention you receive is the principle benefit to you; there will be no monetary compensation for your participation in this study. At the same time, you will not incur any costs as a result of your participation. Given that you will often have to come to the Centre, you will receive bus vouchers to cover transportation costs for your visits.

(8) Identity confidentiality for the participants in this study.

The records of your participation in this study are confidential. However, these records will be available to the representatives of the institutions participating in the study, the Research Ethics Committees and health authorities. Your name will never be used in any study report.

(9) Your participation can be cancelled without your permission.

Your participation in this study can be interrupted if the state of your health begins to represent a risk to you in the opinion of the doctors responsible for this study.

(10) New significant findings.

Any important information that may become known during your participation in this study and that can affect your health will be given to you.

(11) Number of volunteers participating in this study.

A total of 2,122 patients will take part in this study, ranging from 5 to 65 years of age. 
Patients with known allergies (hypersensitivity) to the drugs used in this study and patients with associated diseases will not be able to participate in this study.

(12) Reimbursement and Compensation.

If it is proven that you have suffered any injury as a result of your participation in this study, you will be entitled to medical treatment and reimbursement according to item V.6 of Resolution 196/96 of the National Health Council of the Ministry of Health that covers all medical research involving human subjects. This resolution establishes that: "Research subjects, when injured in any way by any protocol done by the research study, stated or not in the consent form, and as a result of his participation, will be entitled to complete medical assistance and legal compensation".

(13) People and places to obtain answers to questions and further information related to the study.

Please contact one of the persons listed below in case you have questions related to this study or if you have any problem:

Dr. Maria Araci de Andrade Pontes - telephones: 3101-5452 / 9981- 8124;

Dr. Heitor de Sá Gonçalves - telephones: 3101-5452 / 9988- 0777;

Address: Centro de Dermatologia D. Libânia

Rua Pedro I, 1033 - Centro

Fortaleza - Ceará

If any symptoms of the disease return, please come immediately to the Dona Libânia National Dermatological Reference Centre.

You can and should ask any questions you might find necessary before agreeing to participate in this study and at any moment during the treatment. Your doctor can give you all the information about your health, your rights, and possible complications and benefits related to your participation in this study. If you did not understand any part of this document or the explanation that was given to you, ask the physician before signing the consent form.

IF YOU DID NOT UNDERSTAND ANY PART OF THIS DOCUMENT OR THE EXPLANATION THAT WAS GIVEN TO YOU, ASK THE PHYSICIAN BEFORE SIGNING THE CONSENT FORM. 


\section{RESEARCH SUBJECT OR LEGAL GUARDIAN'S (if subject is a minor < 15 yrs.) IDENTIFICATION DATA}

\section{PATIENT NAME:}

Sex: $\mathrm{M}(\mathrm{f}) \mathrm{F}(\mathrm{)})$ Date of birth: ........................ Age:

Address

District

$\mathrm{N}^{\circ}$

Postal code

Telephone: (.....).

\section{LEGAL GUARDIAN}

Name

Relation to the patient (relative, tutor, legal representative, etc)

Identity number

Date of birth: $. / \ldots \ldots \ldots . . . . \ldots \ldots$

Address $\mathrm{N}^{\circ}$

Apt.

District /Bairro

City Postal code

Tel: (....)

\section{ADDITIONAL INFORMATION}

Medical chart number in the Health Centre

Main symptom.

BCG scars: $\square$ No scar, $\square 1$ scar, $\square 2$ scars History of current disease (HDA)

How long have the symptoms been present: months Presently using any medication? NO YES List of medications:

Allergies: 


\section{FREE AND INFORMED CONSENT FORM}

I, , of sound mind, am 18 years of age or older and volunteer (name of the volunteer)

to participate in the study entitled "Independent study to establish the efficacy of the six dose uniform MDT regimen (U-MDT) for leprosy patients".

The implications of my voluntary participation, including the nature, duration and objective of this study, the methods and means of its conduction, as well as any problems and risks that might occur, were explained to me. I had the opportunity to clarify any doubts about the study and obtain explanations for those doubts. I voluntarily agree to participate in this study. I also understand that I can at any time withdraw my participation without punishment and retaining all my rights. My refusal to participate will not result in loss of any benefits I am otherwise entitled to. I will receive a copy of this statement and the consent form.

I

(Name of the volunteer)

authorise the use of the blood and skin samples collected in this

study for use in future studies.

Volunteer name

Witness name

For illiterate volunteers:
Signature or thumb print

Date and time of signature

I was present during the explanation of the study, and can confirm that the volunteer was given the opportunity to ask questions and has given his/her signature above.

Signature

Date and time of signature

\section{Researcher declaration:}

The objective of the study was explained to the volunteer. To the best of my knowledge, he/she understood the objectives, procedures, risks and benefits of this study.

Name of the researcher

Signature of the researcher

Date and time of signature 


\section{VOLUNTARY CONSENT FORM AND EXPLANATION FOR MINORS}

I, of sound mind, am 18 years of age or older and (name of legal guardian)

capable of giving consent for

(name of minor) and through this document,

I agree for him/her to volunteer as a participant of the study, "Independent study to establish the efficacy of the six-dose uniform MDT regimen (U-MDT) for leprosy patients".

The implications of his/her voluntary participation, including the nature, duration and objective of this study, the methods and means of its conduction, as well as any problems and risks that might occur, were explained to me. I had the opportunity to clarify any doubts about the study and obtain explanations to those doubts. I also understand that I can, at any time, withdraw my consent for the child under my responsibility to participate in this study, without any punishment to the child and retaining all his/her rights. I will receive a copy of this statement and the consent form.

I (Name of the volunteer) authorise the use of the blood and skin samples collected from the minor under my responsibility in this study for use in future studies.

Name of legal guardian

Signature or thumb print

Date and time of signature

For illiterate legal guardians:

I was present during the explanation of the study, and can confirm that the volunteer was given the opportunity to ask questions and has given his/her signature above.

Witness name

Signature

Date and time of signature

\section{Researcher declaration:}

The objective of the study was explained to the volunteer. As best as I can tell, he/she understood the objectives, procedures, risks and benefits of this study.

Name of the researcher

Signature of the researcher

Date and time of signature 


\section{INDEX}

Procedure timetable

Block I - Forms For Patient Data Collection upon Entry into the Study - 1st

Dose

1 Instructions to initiate the study - 1st dose

1.1 Criteria for inclusion/ exclusion from the study

1.2 Clinical and biopsy data from the patient

1.3 Clinical-dermatological evaluation

1.4 Examination of peripheral nerves

1.5 Simplified evaluation of neural function and complications 22

$1.6 \quad$ Request for laboratory exams 22

1.7 Results of laboratory tests - beginning of the study/1st dose 23

Instructions for monthly visits (months 2 to 12)

2 Block II - Monthly evaluation forms

2.1 Clinical-dermatological evaluation - 2nd dose 27

2.2 Examination of peripheral nerves -2 nd dose 28

$2.3 \quad$ Request for laboratory exams 28

$2.4 \quad$ Clinical-dermatological evaluation - 3rd dose 29

2.5 Examination of peripheral nerves - 3rd dose 30

$2.6 \quad$ Request for laboratory exams 30

2.7 Clinical-dermatological evaluation -4 th dose 31

2.8 Examination of peripheral nerves - 4th dose 32

2.9 Request for laboratory exams 32

2.10 Clinical-dermatological evaluation - 5th dose 33

2.11 Examination of peripheral nerves -5 th dose 34

2.12 Request for laboratory exams 34

2.13 Clinical-dermatological evaluation - 6th dose 35

2.14 Examination of peripheral nerves - 6th dose 36

2.15 Request for laboratory exams 36

2.16 Simplified evaluation of neural function and complications 37

2.17 Clinical-dermatological evaluation -7 th dose 39

2.18 Examination of peripheral nerves -7 th dose 40

2.19 Request for laboratory exams 40

2.20 Clinical-dermatological evaluation - 8th dose 41

$2.21 \quad$ Examination of peripheral nerves - 8th dose 42

2.22 Request for laboratory exams 42

2.23 Clinical-dermatological evaluation - 9th dose 43

2.24 Examination of peripheral nerves - 9th dose 44

2.25 Request for laboratory exams 44 
2.26 Clinical-dermatological evaluation - 10th dose 45

2.27 Examination of peripheral nerves - 10th dose 46

2.28 Request for laboratory exams 46

2.29 Clinical-dermatological evaluation -11 th dose $\quad 47$

$2.30 \quad$ Examination of peripheral nerves -11 th dose 48

$2.31 \quad$ Request for laboratory exams 48

2.32 Clinical-dermatological evaluation - 12th dose 49

2.33 Examination of peripheral nerves - 12th dose 50

2.34 Request for laboratory exams 50

Instructions for the end of the treatment - month 7 (PB) and 13 (MB) 51

$3 \quad$ Block III - Evaluation forms for the end of treatment 52

$3.1 \quad$ Clinical-dermatological evaluation - End of treatment 53

3.2 Examination of peripheral nerves - End of treatment 54

3.3 Simplified evaluation of neural function and complications - End of treatment 55

$\begin{array}{lll}3.4 & \text { Request for laboratory exams } & 57\end{array}$

Instructions for annual visits (Years 1 to 6 ) 58

Summary of the annual visits $\quad 59$

$4 \quad$ Block IV - Forms for annual follow-up visits $\quad \mathbf{6 0}$

4.1 Clinical-dermatological evaluation - 1st year 61

$4.2 \quad$ Examination of peripheral nerves - 1st year 62

$\begin{array}{lll}4.3 & \text { Request for laboratory exams } & 62\end{array}$

4.4 Simplified evaluation of neural function and complications - 1st year 63

$4.5 \quad$ Clinical-dermatological evaluation -2 nd year 65

4.6 Examination of peripheral nerves - 2nd year 66

$\begin{array}{lll}4.7 & \text { Request for laboratory exams } & 66\end{array}$

4.8 Simplified evaluation of neural function and complications - 2nd year 67

$\begin{array}{lll}4.9 & \text { Clinical-dermatological evaluation - 3rd year } & 69\end{array}$

4.10 Examination of peripheral nerves - 3rd year 70

$\begin{array}{lll}4.11 & \text { Request for laboratory exams } & 70\end{array}$

4.12 Simplified evaluation of neural function and complications - 3rd year 71

4.13 Clinical-dermatological evaluation - 4th year 73

4.14 Examination of peripheral nerves - 4th year 74

$\begin{array}{lll}4.15 & \text { Request for laboratory exams } & 74\end{array}$

4.16 Simplified evaluation of neural function and complications - 4th year 76

4.17 Clinical-dermatological evaluation - 5th year 77

4.18 Examination of peripheral nerves - 5th year 78

$\begin{array}{lll}4.19 & \text { Request for laboratory exams } & 78\end{array}$

4.20 Simplified evaluation of neural function and complications - 5th year 79

4.21 Clinical-dermatological evaluation - 6th year 81

4.22 Examination of peripheral nerves - 6th year 82 
4.23 Request for laboratory exams 82

4.24 Simplified evaluation of neural function and complications - 6th year 83

$5 \quad$ Block V-Miscellaneous forms $\quad 85$

$5.1 \quad$ Form for the diagnosis and follow-up of leprosy reactions 86-117

$\begin{array}{lll}5.2 & \text { Bacilloscopy test results } & 118\end{array}$

$\begin{array}{lll}5.3 & \text { Sulfonuria test results } & 119\end{array}$

$\begin{array}{lll}5.4 & \text { Protein C reactive results - Monthly } & 120\end{array}$

5.5 Protein C reactive results - Annual 121

5.6 Protein C reactive results - during reactive periods 122

$\begin{array}{lll}5.7 & \text { Registration of researched dose } & 123\end{array}$

$\begin{array}{lll}5.8 & \text { Registration of use of other medications } & 124\end{array}$

$\begin{array}{lll}5.9 & \text { Registration of adverse side effects } & 125\end{array}$

5.10. Comments about eventual serious side effects 126

5.11 Relapse

5.11.1 Clinical dermatological evaluation - relapse 127

$\begin{array}{lll}5.11 .2 & \text { Examination of peripheral nerves - relapse } & 128\end{array}$

$\begin{array}{lll}5.11 .3 & \text { Request for laboratory tests - relapse } & 128\end{array}$

$\begin{array}{lll}\text { 5.11.4 Simplified evaluation of neural function and complications - relapse } & 129\end{array}$

$\begin{array}{lll}5.11 .5 & \text { Relapse registration } & 131\end{array}$

$\begin{array}{lll}5.11 .6 & 132\end{array}$

$\begin{array}{lll}5.12 & \text { Form for withdrawal from the study } & 133\end{array}$ 


\section{PROCEDURE TIMETABLE}

\begin{tabular}{|c|c|c|c|c|c|}
\hline Evaluation & $\begin{array}{c}\text { Initial } \\
\text { visit }\end{array}$ & $\begin{array}{l}\text { Monthly } \\
\text { visits }\end{array}$ & $\begin{array}{l}\text { Final } \\
\text { visit } 7 \text { th } \\
\text { and 13th } \\
\text { months }\end{array}$ & $\begin{array}{c}\text { Visits } \\
\text { during } \\
\text { annual } \\
\text { follow-up }\end{array}$ & $\begin{array}{l}\text { In case of } \\
\text { Leprosy } \\
\text { Reactions }\end{array}$ \\
\hline Slinical-dermatological evaluation & $x$ & $x$ & $\times$ & $\times$ & -- \\
\hline xamination of peripheral nerves & $x$ & $x$ & $x$ & $x$ & $\mathbf{x}$ \\
\hline lassification of disabilities & $x$ & -- & $x$ & $x$ & -- \\
\hline 3acilloscopy ${ }^{1}$ & $x$ & -- & $x$ & $x$ & -- \\
\hline 3 iopsy ${ }^{2}$ & $x$ & -- & -- & -- & -- \\
\hline ML FLOW ${ }^{3}$ & $x$ & -- & -- & -- & -- \\
\hline Complete blood exam ${ }^{4}$ & $x$ & $\mathbf{x}$ & $\mathbf{x}$ & -- & -- \\
\hline Biochemistry & $\mathbf{x}$ & $\mathbf{x}$ & $\mathbf{x}$ & & -- \\
\hline reactive protein & $x$ & $x$ & $x$ & $x$ & $\mathbf{x}$ \\
\hline GOT, SGPT ${ }^{4}$ & $\mathbf{x}$ & $\mathbf{x}$ & $\mathbf{x}$ & & -- \\
\hline $\begin{array}{l}\text { Registration of the supervised dose during the } \\
\text { tudy }\end{array}$ & $x$ & $x$ & $x$ & $x$ & -- \\
\hline Side effects & $x$ & $x$ & $x$ & $x$ & $\mathbf{x}$ \\
\hline Jse of concurrent medications & $x$ & $x$ & $x$ & $x$ & $\mathbf{x}$ \\
\hline ulfonuria ${ }^{5}$ & -- & $x$ & -- & -- & -- \\
\hline
\end{tabular}

(1) Bacilloscopy will be performed in all patients during the initial phase of the study, and at the end of the treatment and during the annual follow-up in the patients with multibacillary disease

(2) The biopsy will be performed in all patients during the initial phase of the study and in case of suspected relapse

(3) The ML-Flow test will be performed in all patients during the initial phase of the study and in case of suspected relapse.

(4) Complete blood exam and SGOT/SGPT will be performed in all patients at all the monthly visits while the patient is taking MDT.

(5) Every month there will be a random selection of $10 \%$ of all patients to determine which will have the sulfonuria test performed, as proof of the regular intake of the self-administered medications. The patients will not be informed beforehand about the fact that this exam indicates "regularity" of treatment 


\section{General Instructions Form}

1. This patient research file contains one copy of the forms to be utilised for each visit during the study: forms for the commencement of the study, clinical visits (Months 2 to 12), annual follow-up visits (Years 1 to 6 ), and final study visit. Forms are also provided to record: bacilloscopy, the $C$ reactive protein (beginning of the study, months 2 to 12 , years 1 to 6 ), the supervised research dose, concurrent medications, side effects, comments about serious side effects, withdrawal from the study, follow-up of reaction episodes and of relapse.

2. In the case that additional forms are needed (e.g. for multiple side effects, etc) please include the appropriate alphabetical letter after the page number. For example, the first form for Side Effects should come as "Page 17 A"; the second form as "Page 17 B", etc.

3. Utilize black ink pen and write legibly.

4. All items should be filled out. The following abbreviations must be used when values or answers are not obtained:

ND - Not done

NA - Not applicable

5. The forms should be signed and dated by the researcher in the appropriate spaces.

6. In case a mistake occurs, draw a horizontal line across the item to be corrected in a way that it is still possible to read. Do not tear the form, use correction fluid or erase it. After each correction, number the alteration, date it and sign your initials. 


\section{BLOCK 1}

\section{FORMS FOR PATIENT DATA COLLECTION AT ENTRY INTO THE STUDY 1st DOSE}




\section{INSTRUCTIONS FOR PATIENT DATA COLLECTION AT ENTRY INTO THE STUDY - 1st DOSE}

1. Review the inclusion and exclusion criteria to verify the eligibility of the patient

$\square$ a. Obtain demographic information.

b. Verify the diagnosis of leprosy and the date treatment commenced.

c. Evaluate the cutaneous lesions and/or systemic symptoms.

d. Review the patient history of previous treatments, and confirm enrolment in study.

e. Verify history of intolerance to any of the medications.

2. Inform the patient about the risks and benefits of the study. Complete the informed consent form, signed by the patient and by a witness in case the patient is illiterate. Give a copy to the patient and keep one copy in the study files.

3. If the patient is qualified to enter the study and has signed the Consent Form, begin filling the CRF in the sequence of the study.

4. Classify the disease as paucibacillary (PB) or multibacillary (MB), according to the WHO norms, using ONLY the number of skin lesions.

5. The tests and procedures listed below must be conducted at the beginning of the study. (Treatment can be initiated before obtaining the results) If the tests have already been done, enter the results in the CRF; otherwise, begin examinations.

$\square$ a. Do the Clinical-dermatological evaluation.

b. Do the neurological examination; nerves must be palpated and evaluated for sensitivity and thickness.

$\square$ c. Classify the disability grade according to the norms of WHO/Brazilian Ministry of Health.

$\square$ d. Obtain blood for laboratory tests (full haemogram including differentials, biochemical tests (taken while fasting), $\mathrm{C}$ reactive protein) and undertake lymph bacilloscopy. File the results in the patient's chart and enter them in the form for Laboratory Exam Results.

$\square$ e. Obtain the biopsy and request the histopathology exam.

$\square$ f. Proceed with the ML Flow test and attach test results at the appropriate place.

6. Verify the treatment group for this patient on the randomisation table.

7. Give the medication under study to the patient. Register the number of pills given, using the Form for Registration of the Experimental Dosage, and record the lot number and the expiration date.

8. The researcher should check all the data registered on the Visit Form - Study Commencement and sign it at the bottom of the page. 


\section{CRITERIA FOR INCLUSION/ EXCLUSION FROM THE STUDY}

\begin{tabular}{|l|l|lll|}
\hline \multicolumn{4}{|c|}{ INCLUSION CRITERIA } \\
\hline 1. Five (05) to sixty-five (65) years of age & & 1.Yes & 2. No & 3. NA \\
\hline $\begin{array}{l}\text { 2. Leprosy with characteristic skin lesions, with or } \\
\text { without systemic symptoms or confirmed by } \\
\text { histopathological study }\end{array}$ & & & & \\
\hline $\begin{array}{l}\text { 3. Never treated or patient treated more than five } \\
\text { years ago }\end{array}$ & & 2. No & 3. NA \\
\hline 4. Signed consent form. & & 1.Yes & 2. No & 3. NA \\
\hline
\end{tabular}

NA - Not applicable

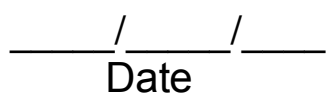

Signature

\begin{tabular}{|c|c|}
\hline \multicolumn{2}{|c|}{ EXCLUSION CRITERIA } \\
\hline 1. Absence of leprosy skin lesions & 1. Yes 2. No 3. NA \\
\hline 2. Pure neural leprosy (PNL) & 1. Yes 2. No 3. NA \\
\hline 3. Patient at risk of death & 1. Yes 2. No 3. NA \\
\hline $\begin{array}{l}\text { 4. Patient previously treated for leprosy less than } 5 \\
\text { years ago }\end{array}$ & 1. Yes 2. No 3. NA \\
\hline 5. History of intolerance to one of the medications & 1. Yes 2. No 3. NA \\
\hline $\begin{array}{l}\text { 6. Discharged as a result of the histopathological } \\
\text { findings. }\end{array}$ & 1. Yes 2. No 3. NA \\
\hline $\begin{array}{l}\text { 7. Association with other serious diseases such as } \\
\text { HIVIAIDS, Tuberculosis, Malaria, LTA, Visceral } \\
\text { Leishmaniasis, Lymphoma, Leukaemia, } \\
\text { Immunosuppression, etc. }\end{array}$ & 1. Yes 2. No 3. NA \\
\hline $\begin{array}{l}\text { 8. Patient with difficulty following the procedures of } \\
\text { the study }\end{array}$ & 1. Yes 2. No 3. NA \\
\hline
\end{tabular}

NA - Not applicable

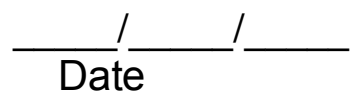




\section{2- PATIENT CLINICAL AND HISTOPATHOLOGICAL DATA}

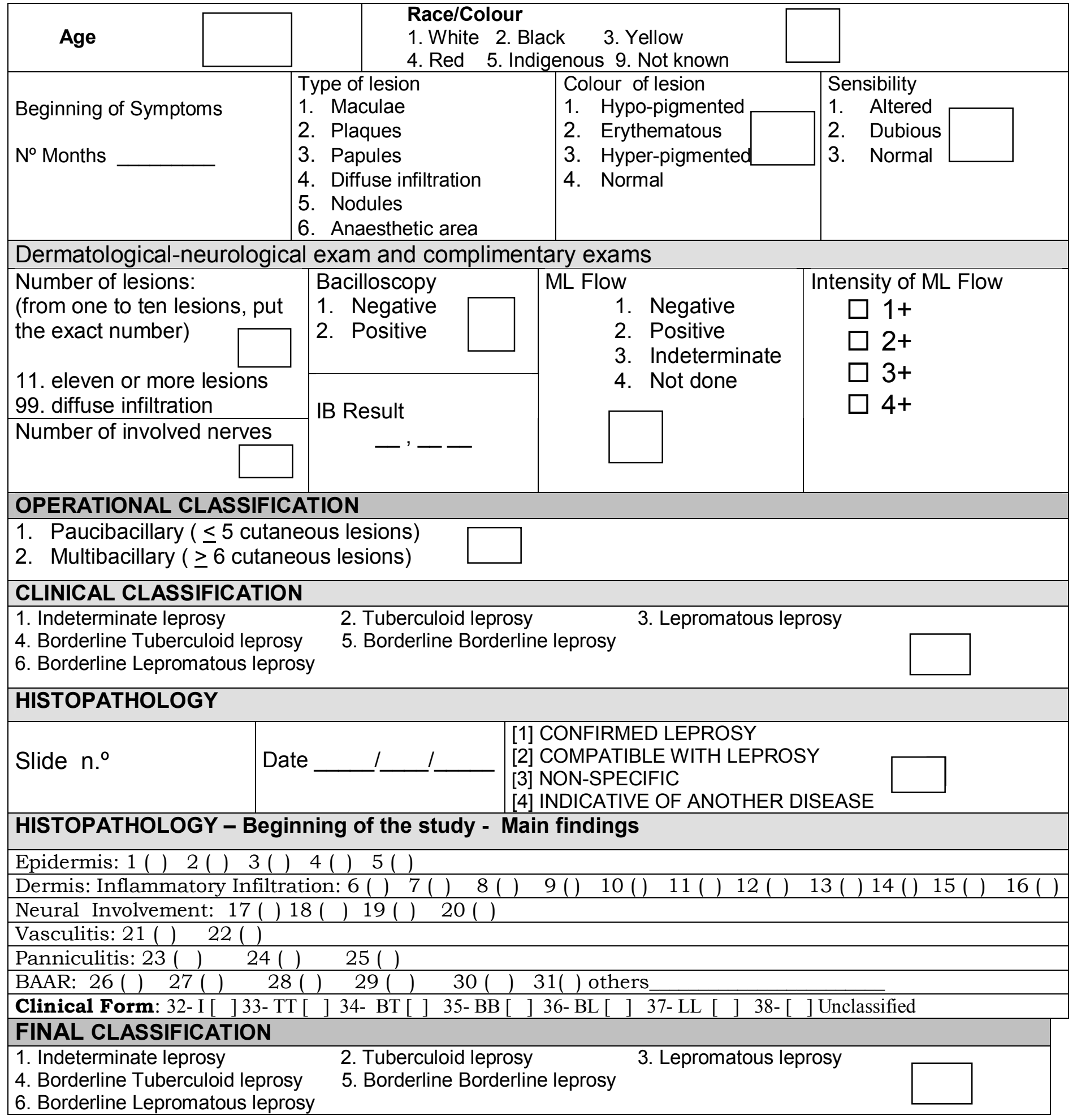




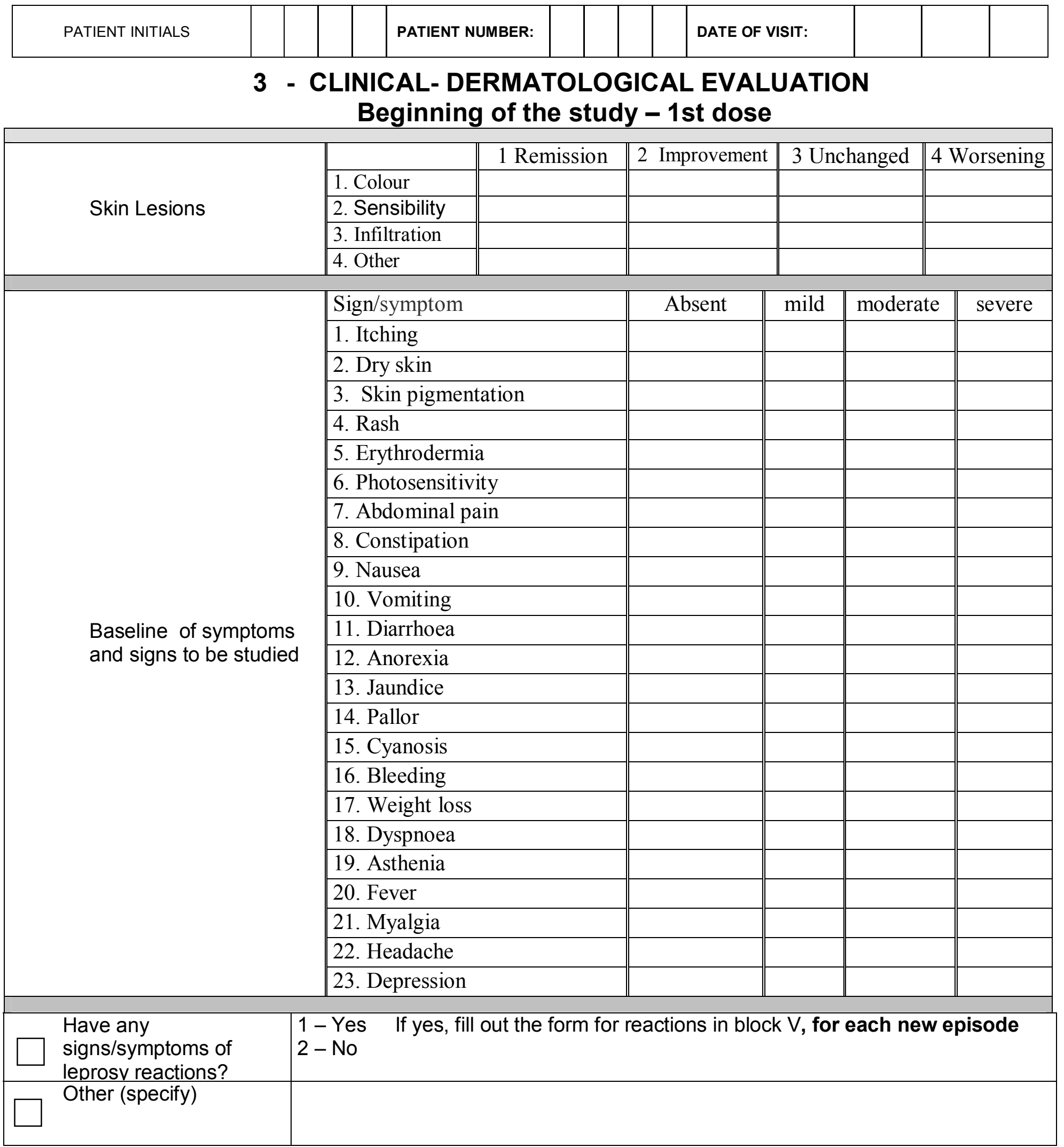




\section{4 - EXAMINATION OF PERIPHERAL NERVES Beginning of the study - 1st dose}

\begin{tabular}{|l|l|l|l|l|}
\hline & \multicolumn{2}{|l|}{$\begin{array}{l}\text { KEY } \\
\text { NERVE EXAMINATION } \\
\text { 0- Normal } \\
\text { 1- Thickened } \\
\text { 2- Nerve abscess }\end{array}$} & \multicolumn{2}{l|}{$\begin{array}{l}\text { KEY } \\
\text { SCALE OF NEURAL PAIN INDICATED } \\
\text { 0. No pain } \\
\text { 1. Weak pain } \\
\text { 2. Strong pain }\end{array}$} \\
\hline NERVES & \multicolumn{1}{|c|}{ RIGHT } & LEFT & \multicolumn{1}{c|}{ RIGHT } & \multicolumn{1}{|c|}{ LEFT } \\
\hline Median & & & & \\
\hline Radial & & & & \\
\hline Fibular & & & & \\
\hline Posterior Tibial & & & & \\
\hline Others & & & & \\
\hline
\end{tabular}

Signature and stamp of medical examiner 


\section{SIMPLIFIED EVALUATION OF NEURAL FUNCTION AND COMPLICATIONS Beginning of the study - 1st dose}

\begin{tabular}{|l|c|c|}
\hline \multicolumn{1}{|c|}{ Face } & & \\
\hline \multicolumn{1}{|c|}{ Nose } & R & L \\
\hline Main complaint & & \\
\hline dryness (S/N) & & \\
\hline abrasions (S/N) & & \\
\hline Perforation of the septum (S/N) & R & L \\
\hline \multicolumn{1}{|c|}{ Main complaint } & & \\
\hline Closes eyes w/o force (mm) & & \\
\hline Closes eyes w/ force (mm) & & \\
\hline Cornea diminished sensibility (S/N) & & \\
\hline Cornea opacity (S/N) & & \\
\hline Cataract (S/N) & & \\
\hline Visual acuity & & \\
\hline
\end{tabular}

\begin{tabular}{|l|c|c|}
\hline \multicolumn{1}{|c|}{ Upper limbs } & & \\
\hline Main complaint Nerve palpation & & \\
\hline \multicolumn{1}{|c|}{ R } & L \\
\hline Ulnar & & \\
\hline Median & & \\
\hline Radius & & \\
\hline
\end{tabular}

key: $\mathrm{N}=$ normal; $\mathrm{T}=$ thickened; $\mathrm{P}=$ pain; $\mathrm{S}=$ Tinel's sign $(+)$

\begin{tabular}{|l|l|l|l|}
\hline \multicolumn{2}{|c|}{ Strength evaluation } & R & L \\
\hline Opens little finger & & \\
Abduction of the $5^{\text {th }}$ finger (ulnar nerve) & -3 & & \\
\hline $\begin{array}{l}\text { Elevates thumb } \\
\text { Abduction of the thumb (median nerve) }\end{array}$ & 2 & & \\
\hline $\begin{array}{l}\text { Elevates wrist } \\
\text { Wrist extension (radial nerve) }\end{array}$ & & & \\
\hline
\end{tabular}

key: $\mathrm{S}=$ strong; $\mathrm{D}=$ diminished; $\mathrm{P}=$ paralysed or $5=$ strong; $4=$ partial resistance; $3=$ complete movement; $2=$ partial movement; $1=$ contraction; $0=$ paralysed

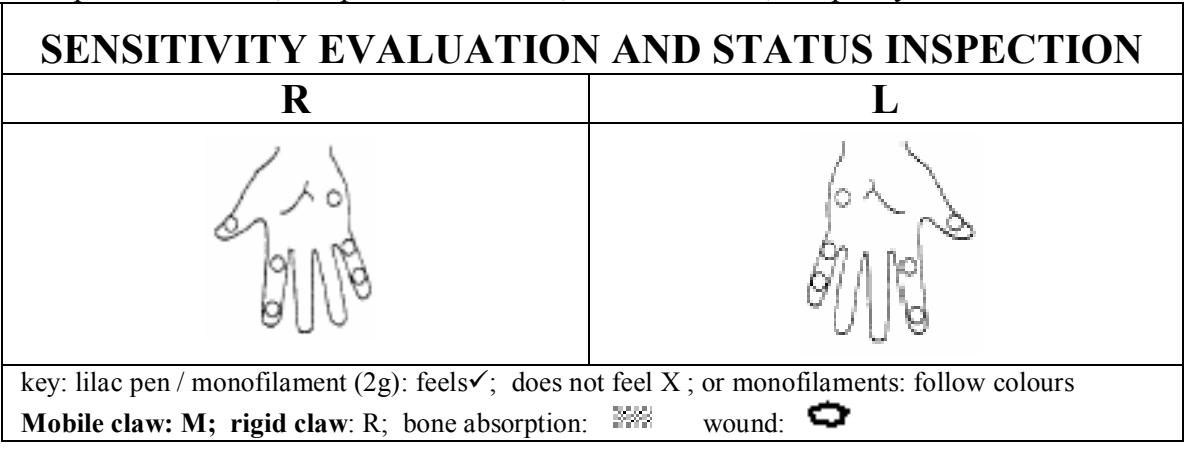

Signature and stamp of medical examiner 


\begin{tabular}{|l|c|c|}
\hline \multicolumn{1}{|c|}{ Lower limbs } & & \\
\hline Main complaint Nerve Palpation & & \\
\hline Fibular & R & L \\
\hline Posterior tibial & & \\
\hline
\end{tabular}

key: $\mathrm{N}=$ normal; $\mathrm{T}=$ thickened; $\mathrm{P}=$ pain; $\mathrm{S}=$ Tinel's sign $(+)$

\begin{tabular}{|l|c|c|c|}
\hline \multicolumn{2}{|c|}{ Strength evaluation } & R & L \\
\hline $\begin{array}{l}\text { Elevates hallux } \\
\text { Hallux extension (fibular nerve) }\end{array}$ & A & & \\
\hline $\begin{array}{l}\text { Elevate foot } \\
\text { Foot dorsiflexion (fibular nerve) }\end{array}$ & & & \\
\hline
\end{tabular}

key: $\mathrm{S}=$ strong; $\mathrm{D}=$ diminished; $\mathrm{P}=$ paralysed or $5=$ strong; $4=$ partial resistance; $3=$ complete movement; 2 = partial movement; $1=$ contracture; $0=$ paralysed

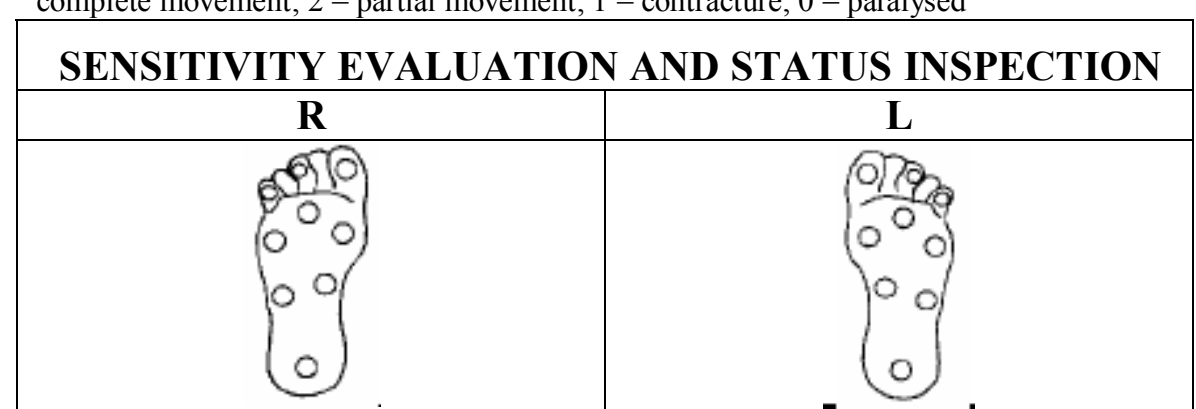

key: lilac pen / monofilament (2g): feels $\sqrt{ }$; does not feel X; or monofilaments: follow colours

Mobile claw: $\mathrm{M}$; rigid claw: $\mathrm{R}$; bone absorption: $\%$ wound: $\square$

\begin{tabular}{|c|c|c|c|c|c|c|c|c|}
\hline \multicolumn{9}{|c|}{ Classification of disability grade } \\
\hline Evaluation date & \multicolumn{2}{|c|}{ eyes } & \multicolumn{2}{|c|}{ hands } & \multicolumn{2}{|c|}{ feet } & \multirow[t]{2}{*}{ Highest grade } & \multirow[t]{2}{*}{ signature } \\
\hline & $\mathbf{R}$ & $\mathbf{L}$ & $\mathbf{R}$ & $\mathbf{L}$ & $\mathbf{R}$ & $\mathbf{L}$ & & \\
\hline Evaluation & & & & & & & & \\
\hline \multicolumn{9}{|c|}{ Monofilaments } \\
\hline Monofilament & \multicolumn{4}{|c|}{ strength in grams } & \multicolumn{4}{|c|}{ interpretation } \\
\hline $1-$ green & \multicolumn{4}{|c|}{0.05} & \multicolumn{4}{|c|}{ Normal sensitivity in hand and foot } \\
\hline 2 - blue & \multicolumn{4}{|c|}{0.20} & \multicolumn{4}{|c|}{$\begin{array}{l}\text { Diminished sensitivity in hand and normal in foot / Difficulty } \\
\text { in distinguishing texture (light touch) }\end{array}$} \\
\hline 3 - Lilac & \multicolumn{4}{|c|}{2.00} & \multicolumn{4}{|c|}{$\begin{array}{l}\text { Diminished protective sensitivity in hand / Incapable of } \\
\text { distinguishing texture / Difficulty in distinguishing forms and } \\
\text { temperatures }\end{array}$} \\
\hline 4 - dark red & \multicolumn{4}{|c|}{4.00} & \multicolumn{4}{|c|}{$\begin{array}{l}\text { Loss of protective sensitivity in hand and sometimes in foot } \\
\text { / loss of texture discrimination / Incapable of distinguishing } \\
\text { forms and temperatures }\end{array}$} \\
\hline 5 - orange or red (mark with an $X$ ) & \multicolumn{4}{|c|}{10.00} & \multicolumn{4}{|c|}{$\begin{array}{l}\text { Loss of protective sensitivity in foot / loss of texture } \\
\text { discrimination / Incapable of distinguishing forms and } \\
\text { temperatures }\end{array}$} \\
\hline 6 - red circle & \multicolumn{4}{|c|}{300.00} & \multicolumn{4}{|c|}{$\begin{array}{l}\text { Only has sensation when deep pressure is applied to hand } \\
\text { and foot }\end{array}$} \\
\hline 7 - black & \multicolumn{4}{|c|}{$\begin{array}{c}\text { No response to } 300 \mathrm{~g} \\
\text { monofilament }\end{array}$} & \multicolumn{4}{|c|}{ Loss of sensation even to deep pressure in hand and foot } \\
\hline
\end{tabular}




\section{REQUEST FOR LABORATORY EXAMS Beginning of the study - 1st dose}

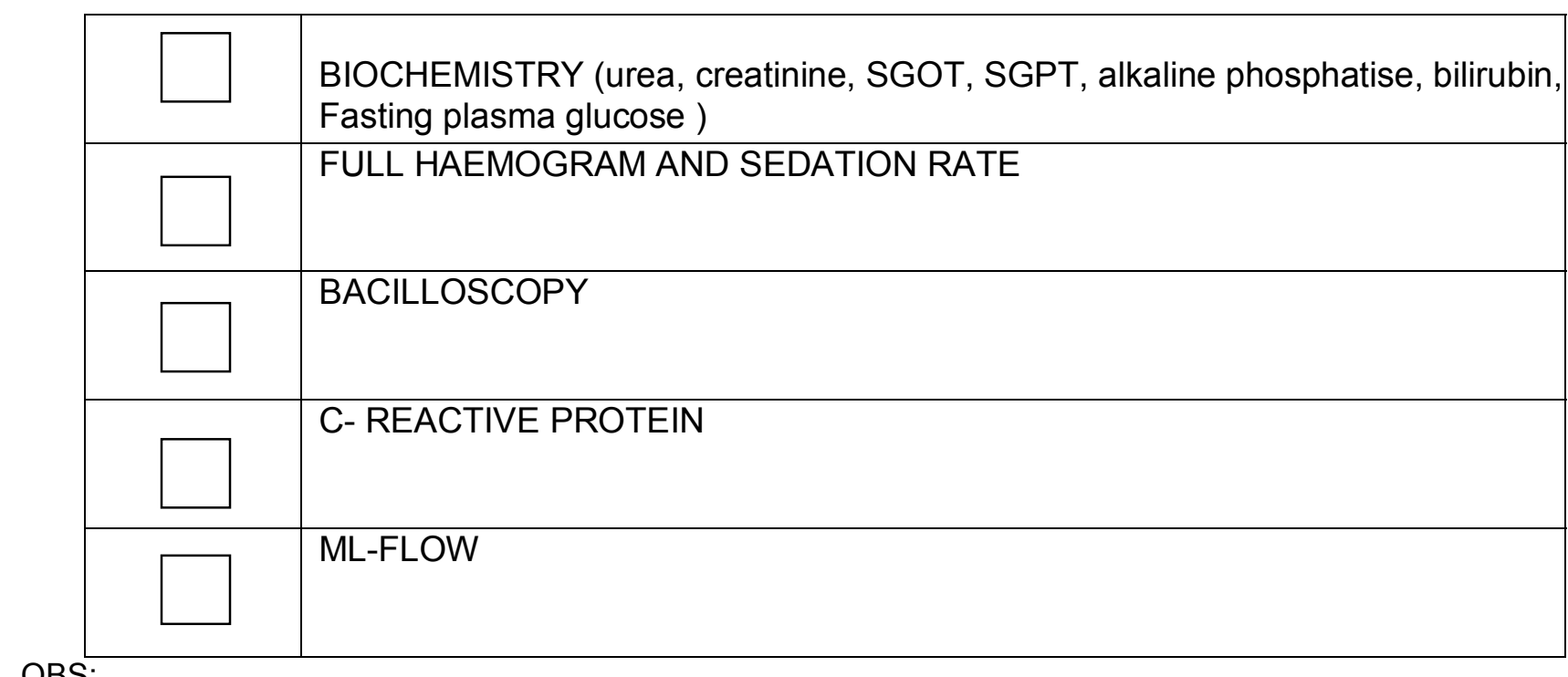

OBS:

Signature and stamp of medical examiner 
8. LABORATORY RESULTS

Beginning of the study - 1st dose

\begin{tabular}{|c|c|c|c|c|c|}
\hline \multicolumn{6}{|c|}{ BIOCHEMISTRY } \\
\hline TEST & Results & $\begin{array}{l}\text { Normal } \\
\text { values }\end{array}$ & units & $\begin{array}{c}\text { Clinically } \\
\text { significant } \\
\text { (" } \checkmark \text { ") }\end{array}$ & $\begin{array}{c}\text { COMMENTS } \\
\text { If test was not done, write } \\
\text { ND }\end{array}$ \\
\hline GLUCOSE & & $70-110$ & $\mathrm{mg} / \mathrm{dl}$ & & \\
\hline UREA & & $10-50$ & $\mathrm{mg} / \mathrm{dl}$ & & \\
\hline CREATININE & & $0,4-1,3$ & $\mathrm{mg} / \mathrm{dl}$ & & \\
\hline SGPT & & $4-32$ & $U / L$ & & \\
\hline SGOT & & $4-36$ & $U / L$ & & \\
\hline $\begin{array}{l}\text { ALKALINE } \\
\text { PHOSPH. }\end{array}$ & & $\begin{array}{l}A-13-43 \\
C-56-156\end{array}$ & $\mathrm{UI} / \mathrm{L}$ & & \\
\hline $\begin{array}{l}\text { TOTAL } \\
\text { BILIRRUBIN }\end{array}$ & & Up to 1,2 & $\mathrm{mg} / \mathrm{dl}$ & & \\
\hline $\begin{array}{l}\text { C-REACTIVE } \\
\text { PROTEIN }\end{array}$ & & Less than 8 & $\mathrm{mg} / \mathrm{L}$ & \multicolumn{2}{|c|}{ Results to be recorded in block V, page 120} \\
\hline \multicolumn{6}{|c|}{ FULL BLOOD EXAM } \\
\hline TEST & Results & Normal values & units & $\begin{array}{l}\text { Clinically } \\
\text { significant } \\
\text { (" } \checkmark ")\end{array}$ & $\begin{array}{c}\text { COMMENTS } \\
\text { If test was not done, write } \\
\text { ND }\end{array}$ \\
\hline $\begin{array}{l}\text { RED } \\
\text { BLOOD }\end{array}$ & & $4,0-5,5$ & tera/l & & \\
\hline $\mathrm{HB}$ & & $11-16$ & $\mathrm{~g} / \mathrm{dl}$ & & \\
\hline HCT & & $36-52$ & $\%$ & & \\
\hline MCV & & $82-92$ & $\mathrm{fl}$ & & \\
\hline $\mathrm{MCH}$ & & $27-31$ & $\mathrm{pg}$ & & \\
\hline $\mathrm{MCHC}$ & & $32-36$ & $\mathrm{~g} / \mathrm{dl}$ & & \\
\hline
\end{tabular}

Signature and stamp of medical examiner 


\begin{tabular}{|c|c|c|c|c|c|}
\hline \multicolumn{6}{|c|}{ FULL BLOOD EXAM (continuation) } \\
\hline TEST & Results & Normal values & Units & $\begin{array}{l}\text { Clinically } \\
\text { significant } \\
\text { (" } \checkmark ")\end{array}$ & $\begin{array}{c}\text { COMMENTS } \\
\text { If test was not done, write ND }\end{array}$ \\
\hline RDW & & $12-15$ & $\%$ & & \\
\hline PLATELETS & & $150000-450000$ & $\mu \mathrm{L}$ & & \\
\hline LEUKÓCYTES & & $4000-10000$ & $\mu \mathrm{L}$ & & \\
\hline$\%$ SEG & & $54-65$ & $\%$ & & \\
\hline$\%$ BAST & & 3-5 & $\%$ & & \\
\hline$\%$ NEUTRO & & $40-75$ & $\%$ & & \\
\hline$\%$ LYMPH & & $23-35$ & $\%$ & & \\
\hline$\%$ MONO & & $3-8$ & $\%$ & & \\
\hline$\%$ EOS & & $1-4$ & $\%$ & & \\
\hline$\%$ BASO & & $0-1$ & $\%$ & & \\
\hline \#SEG & & $2750-6500$ & $\mu \mathrm{L}$ & & \\
\hline \#BAST & & $150-500$ & $\mu \mathrm{L}$ & & \\
\hline \#NEUTRO & & $2500-7500$ & $\mathrm{ml}$ & & \\
\hline \#LYMPH & & $1150-3500$ & $\mu \mathrm{L}$ & & \\
\hline \#MONO & & $200-800$ & $\mu \mathrm{L}$ & & \\
\hline \#EOS & & $50-400$ & $\mu \mathrm{L}$ & & \\
\hline \#BASO & & $0-100$ & $\mu \mathrm{L}$ & & \\
\hline
\end{tabular}

Signature and stamp of medical examiner 
BLOCK II

Monthly Evaluations Forms 


\section{INSTRUCTIONS FOR MONTHLY VISITS (MONTHS 2 to 12)}

1. The following tests and procedures should be done during the monthly visits:

a. Do the Clinical-dermatological evaluation - months 2 through 6 for groups 1 and 2 of PB and months 2 through 12 for groups 3 and 4 of MB.

b. Perform the neurological exam that focuses on the detection of neuropathies. Nerves should be palpated and evaluated according to thickness and sensitivity. Record on the patient chart: examination of peripheral nerves.

c. Ask the patient about symptoms of leprosy reactions and evaluate the degree for each one of them. Register on the patient chart in the Diagnosis and Follow-up of Reactions Form.

d. Ask the patient about side effects and register them in the Clinical-Dermatological Evaluation Form

e. Enter the results for the C-reactive protein test.

f. Register the results of the sulfonuria test.

g. In case of the onset of a leprosy reaction, classify the disability level according to the norms of the Brazilian Ministry of Health and the World Health Organisation. Register this on the Diagnosis and Follow-up of Reactions Form.

2. Register the other medications being used concomitantly in the Use of Concurrent Medications Form, located in Block V.

3. Give the medication under study to the patient: doses 2 to 6 for groups 1 and 2 of PB and group 3 of $\mathrm{MB}$; and doses 2 to 12 for group 4 of MB. Register the number of capsules given on the Form for Registration of Dose under Study, as well as the lot number and the expiration date of the medication.

4. The principal researcher should review all the recorded data in the Visit Forms during the study and sign them at the bottom of the page 


\section{CLINICAL-DERMATOLOGICAL EVALUATION - $2^{\text {nd }}$ DOSE}

\begin{tabular}{|c|c|c|c|c|c|c|}
\hline \multirow{5}{*}{ Skin Lesions } & & 1 Remission & 2 Improvement & \multicolumn{2}{|c|}{3 Unchanged } & 4 Worsening \\
\hline & 1. Colour & & & & & \\
\hline & 2. Sensibility & & & & & \\
\hline & 3. Infiltration & & & & & \\
\hline & 4. Other & & & & & \\
\hline \multirow{24}{*}{$\begin{array}{l}\text { Symptoms and signs } \\
\text { of side effects from MDT }\end{array}$} & Sign/symptom & & Absent & mild & modera & severe \\
\hline & 1. Itching & & & & & \\
\hline & 2. Dry skin & & & & & \\
\hline & 3. Skin pigmen & tion & & & & \\
\hline & 4. Rash & & & & & \\
\hline & 5. Erythrodermi & & & & & \\
\hline & 6. Photosensitiv & & & & & \\
\hline & 7. Abdominal $p$ & & & & & \\
\hline & 8. Constipation & & & & & \\
\hline & 9. Nausea & & & & & \\
\hline & 10. Vomiting & & & & & \\
\hline & 11. Diarrhoea & & & & & \\
\hline & 12. Anorexia & & & & & \\
\hline & 13. Jaundice & & & & & \\
\hline & 14. Pallor & & & & & \\
\hline & 15. Cyanosis & & & & & \\
\hline & 16. Bleeding & & & & & \\
\hline & 17. Weight loss & & & & & \\
\hline & 18. Dyspnoea & & & & & \\
\hline & 19. Asthenia & & & & & \\
\hline & 20. Fever & & & & & \\
\hline & 21. Myalgia & & & & & \\
\hline & 22. Headache & & & & & \\
\hline & 23. Depression & & & & & \\
\hline $\begin{array}{l}\text { Have any signs/symptoms } \\
\text { of leprosy reaction? }\end{array}$ & \multicolumn{6}{|c|}{$\begin{array}{l}1-\text { Yes In this case, fill out the form for reactions in block } \mathrm{V} \text {, for each new episode* } \\
2-\text { No } \\
3 \text { - Continued symptoms of previous reaction }\end{array}$} \\
\hline
\end{tabular}

Signature and stamp of medical examiner

* In this study, a new episode of leprosy reaction is defined as when the patient develops new signs and symptoms of a reaction after a period of regression of the initial symptoms. It can happen during gradual reduction of the anti-reaction steroid therapy and requires a new intervention including adjustment of the medication dose. 
EXAMINATION OF PERIPHERAL NERVES - 2nd DOSE

\begin{tabular}{|c|c|c|c|c|}
\hline \multirow[b]{2}{*}{ NERVES } & \multicolumn{2}{|c|}{$\begin{array}{l}\text { KEY } \\
\text { NERVE EXAMINATION } \\
0 \text { - Normal } \\
\text { 1- Thickened } \\
\text { 2- Nerve abscess }\end{array}$} & \multicolumn{2}{|c|}{$\begin{array}{l}\text { KEY } \\
\text { SCALE OF INDICATED NEURAL PAIN } \\
0 \text { - No pain } \\
1 \text { - Weak pain } \\
2 \text { - Strong pain }\end{array}$} \\
\hline & RIGHT & LEFT & RIGHT & LEFT \\
\hline \multicolumn{5}{|l|}{ Ulnar } \\
\hline \multicolumn{5}{|l|}{ Median } \\
\hline \multicolumn{5}{|l|}{ Radial } \\
\hline \multicolumn{5}{|l|}{ Fibular } \\
\hline \multicolumn{5}{|l|}{ Posterior Tibial } \\
\hline Others & & & & \\
\hline
\end{tabular}

Signature and stamp of medical examiner

LABORATORY TEST REQUEST $-2^{\text {nd }}$ dose

\begin{tabular}{|l|l|}
\hline$\square$ & C-REACTIVE PROTEIN (Register result in Block V, page 120) \\
\hline$\square$ & FULL BLOOD EXAM \\
\hline$\square$ & SGOT / SGPT \\
\hline
\end{tabular}

OBS:

Signature and stamp of medical examiner 


\section{CLINICAL-DERMATOLOGICAL EVALUATION $-3^{\text {rd }}$ DOSE}

\begin{tabular}{|c|c|c|c|c|c|c|}
\hline \multirow{5}{*}{ Skin Lesions } & & 1 Remission & 2 Improvement & \multicolumn{2}{|c|}{3 Unchanged } & 4 Worsening \\
\hline & 1. Colour & & & & & \\
\hline & 2. Sensibility & & & & & \\
\hline & 3. Infiltration & & & & & \\
\hline & 4. Other & & & & & \\
\hline \multirow{24}{*}{$\begin{array}{l}\text { Symptoms and signs } \\
\text { of side effects from MDT }\end{array}$} & Sign/symptom & & Absent & mild & modera & severe \\
\hline & 1. Itching & & & & & \\
\hline & 2. Dry skin & & & & & \\
\hline & 3. Skin pigmen & ation & & & & \\
\hline & 4. Rash & & & & & \\
\hline & 5. Erythroderm & & & & & \\
\hline & 6. Photosensitiv & & & & & \\
\hline & 7. Abdominal $\mathrm{p}$ & & & & & \\
\hline & 8. Constipation & & & & & \\
\hline & 9. Nausea & & & & & \\
\hline & 10. Vomiting & & & & & \\
\hline & 11. Diarrhoea & & & & & \\
\hline & 12. Anorexia & & & & & \\
\hline & 13. Jaundice & & & & & \\
\hline & 14. Pallor & & & & & \\
\hline & 15. Cyanosis & & & & & \\
\hline & 16. Bleeding & & & & & \\
\hline & 17. Weight loss & & & & & \\
\hline & 18. Dyspnoea & & & & & \\
\hline & 19. Asthenia & & & & & \\
\hline & 20. Fever & & & & & \\
\hline & 21. Myalgia & & & & & \\
\hline & 22. Headache & & & & & \\
\hline & 23. Depression & & & & & \\
\hline $\begin{array}{l}\text { Have any signs/symptoms } \\
\text { of leprosy reaction? }\end{array}$ & \multicolumn{6}{|c|}{$\begin{array}{l}1-\text { Yes In this case, fill out the form for reactions in block V, for each new episode* } \\
2-\text { No } \\
3 \text { - Continued symptoms of previous reaction }\end{array}$} \\
\hline
\end{tabular}

Signature and stamp of medical examiner

*In this study, a new episode of leprosy reaction is defined as when the patient develops new signs and symptoms of a reaction after a period of regression of the initial symptoms. It can happen during gradual reduction of the anti-reaction steroid therapy and requires a new intervention including adjustment of the medication dose. 
EXAMINATION OF PERIPHERAL NERVES - $3^{\text {rd }}$ DOSE

\begin{tabular}{|c|c|c|c|c|}
\hline \multirow[b]{2}{*}{ NERVES } & \multicolumn{2}{|c|}{$\begin{array}{l}\text { KEY } \\
\text { NERVE EXAMINATION } \\
0 \text { - Normal } \\
\text { 1- Thickened } \\
\text { 2- Nerve abscess }\end{array}$} & \multicolumn{2}{|c|}{$\begin{array}{l}\text { KEY } \\
\text { SCALE OF INDICATED NEURAL PAIN } \\
0 \text { - No pain } \\
1 \text { - Weak pain } \\
2 \text { - Strong pain }\end{array}$} \\
\hline & RIGHT & LEFT & RIGHT & LEFT \\
\hline \multicolumn{5}{|l|}{ Ulnar } \\
\hline \multicolumn{5}{|l|}{ Median } \\
\hline \multicolumn{5}{|l|}{ Radial } \\
\hline \multicolumn{5}{|l|}{ Fibular } \\
\hline \multicolumn{5}{|l|}{ Posterior Tibial } \\
\hline Others & & & & \\
\hline
\end{tabular}

Signature and stamp of medical examiner

\section{LABORATORY TEST REQUEST $-3^{\text {rd }}$ dose}

\begin{tabular}{|l|l|}
\hline & C-REACTIVE PROTEIN (Register result in Block V, page 120) \\
\hline$\square$ & FULL BLOOD EXAM \\
\hline$\square$ & SGOT / SGPT \\
\hline
\end{tabular}

OBS:

Signature and stamp of medical examiner 


\begin{tabular}{|l|l|l|l|l|l|l|l|l|l|l|l|l|}
\hline PATIENT INITIALS & & & & & PATIENT NUMBER: & & & & & DATE OF VISIT: & \\
\hline PATIENT INITIALS & & & & & PATIENT NUMBER: & & & & & DATE OF VISIT: \\
\hline
\end{tabular}

\section{CLINICAL-DERMATOLOGICAL EVALUATION $-4^{\text {th }}$ DOSE}

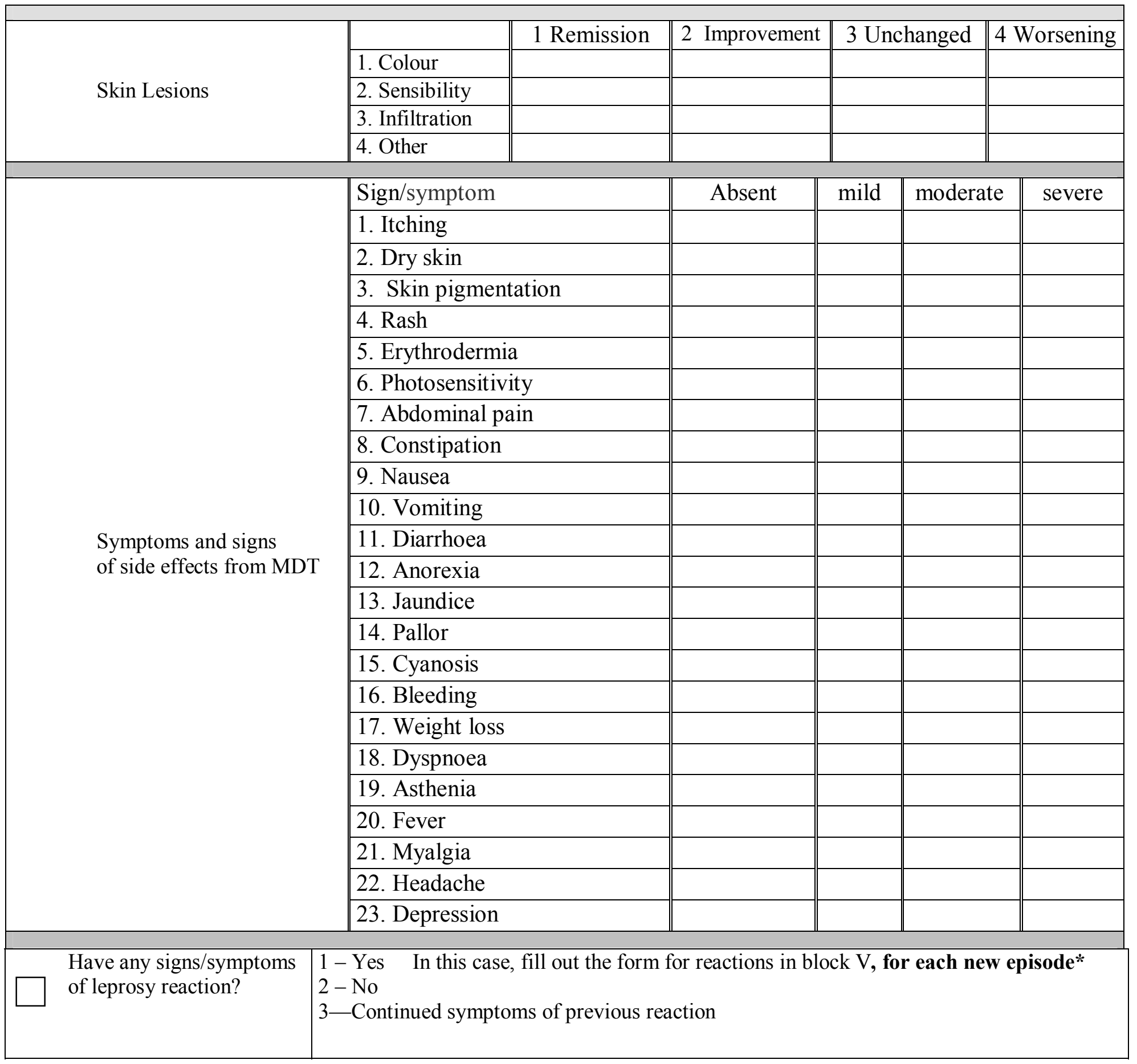

\section{Signature and stamp of medical examiner}

*In this study, a new episode of leprosy reaction is defined as when the patient develops new signs and symptoms of a reaction after a period of regression of the initial symptoms. It can happen during gradual reduction of the anti-reaction steroid therapy and requires a new intervention including adjustment of the medication dose. 
EXAMINATION OF PERIPHERAL NERVES $-4^{\text {th }}$ DOSE

\begin{tabular}{|c|c|c|c|c|}
\hline \multirow[b]{2}{*}{ NERVES } & \multicolumn{2}{|c|}{$\begin{array}{l}\text { KEY } \\
\text { NERVE EXAMINATION } \\
0 \text { - Normal } \\
\text { 1- Thickened } \\
\text { 2- Nerve abscess }\end{array}$} & \multicolumn{2}{|c|}{$\begin{array}{l}\text { KEY } \\
\text { SCALE OF INDICATED NEURAL PAIN } \\
0 \text { - No pain } \\
1 \text { - Weak pain } \\
2 \text { - Strong pain }\end{array}$} \\
\hline & RIGHT & LEFT & RIGHT & LEFT \\
\hline \multicolumn{5}{|l|}{ Ulnar } \\
\hline \multicolumn{5}{|l|}{ Median } \\
\hline \multicolumn{5}{|l|}{ Radial } \\
\hline \multicolumn{5}{|l|}{ Fibular } \\
\hline \multicolumn{5}{|l|}{ Posterior Tibial } \\
\hline Others & & & & \\
\hline
\end{tabular}

Signature and stamp of medical examiner

LABORATORY TEST REQUEST $-4^{\text {th }}$ dose

\begin{tabular}{|l|l|}
\hline & C-REACTIVE PROTEIN (Register result in Block V, page 120) \\
\hline$\square$ & FULL BLOOD EXAM \\
\hline$\square$ & SGOT / SGPT \\
\hline
\end{tabular}

OBS:

Signature and stamp of medical examiner 


\begin{tabular}{|l|l|l|l|l|l|l|l|l|l|l|l|}
\hline PATIENT INITIALS & & & & & PATIENT NUMBER: & & & & & DATE OF VISIT: \\
\hline
\end{tabular}

\section{CLINICAL-DERMATOLOGICAL EVALUATION $-5^{\text {th }}$ DOSE}

\begin{tabular}{|c|c|c|c|c|c|c|}
\hline \multirow{5}{*}{ Skin Lesions } & & 1 Remission & 2 Improvement & \multicolumn{2}{|c|}{3 Unchanged } & 4 Worsening \\
\hline & \multicolumn{6}{|l|}{ 1. Colour } \\
\hline & \multicolumn{6}{|l|}{ 2. Sensibility } \\
\hline & \multicolumn{6}{|l|}{ 3. Infiltration } \\
\hline & \multicolumn{6}{|l|}{ 4. Other } \\
\hline \multirow{24}{*}{$\begin{array}{l}\text { Symptoms and signs } \\
\text { of side effects from MDT }\end{array}$} & \multicolumn{2}{|l|}{ Sign/symptom } & Absent & mild & modera & severe \\
\hline & \multicolumn{2}{|l|}{ 1. Itching } & & & & \\
\hline & \multicolumn{2}{|l|}{ 2. Dry skin } & & & & \\
\hline & \multicolumn{2}{|c|}{ 3. Skin pigmentation } & & & & \\
\hline & \multicolumn{2}{|c|}{ 4. Rash } & & & & \\
\hline & \multicolumn{2}{|c|}{ 5. Erythrodermia } & & & & \\
\hline & \multicolumn{2}{|c|}{ 6. Photosensitivity } & & & & \\
\hline & \multicolumn{2}{|c|}{ 7. Abdominal pain } & & & & \\
\hline & \multicolumn{2}{|c|}{ 8. Constipation } & & & & \\
\hline & \multicolumn{2}{|l|}{ 9. Nausea } & & & & \\
\hline & \multicolumn{2}{|l|}{ 10. Vomiting } & & & & \\
\hline & \multicolumn{2}{|l|}{ 11. Diarrhoea } & & & & \\
\hline & \multicolumn{2}{|l|}{ 12. Anorexia } & & & & \\
\hline & \multicolumn{2}{|l|}{ 13. Jaundice } & & & & \\
\hline & \multicolumn{2}{|l|}{ 14. Pallor } & & & & \\
\hline & \multicolumn{2}{|l|}{ 15. Cyanosis } & & & & \\
\hline & \multicolumn{2}{|l|}{ 16. Bleeding } & & & & \\
\hline & \multicolumn{2}{|l|}{ 17. Weight loss } & & & & \\
\hline & \multicolumn{2}{|l|}{ 18. Dyspnoea } & & & & \\
\hline & \multicolumn{2}{|l|}{ 19. Asthenia } & & & & \\
\hline & \multicolumn{2}{|l|}{ 20. Fever } & & & & \\
\hline & \multicolumn{2}{|l|}{ 21. Myalgia } & & & & \\
\hline & \multicolumn{2}{|l|}{ 22. Headache } & & & & \\
\hline & 23. Depression & & & & & \\
\hline $\begin{array}{l}\text { Have any signs/symptoms } \\
\text { of leprosy reaction? }\end{array}$ & $\begin{array}{l}1-\text { Yes In this case } \\
2-\text { No } \\
3 \text { - Continued sympt }\end{array}$ & $\begin{array}{l}\text { fill out the form } \\
\text { ns of previous re }\end{array}$ & $\begin{array}{l}\text { or reactions in bl } \\
\text { ction }\end{array}$ & $\mathrm{ck} \mathrm{V,fo}$ & each ne & w episode* \\
\hline
\end{tabular}

Signature and stamp of medical examiner

*In this study, a new episode of leprosy reaction is defined as when the patient develops new signs and symptoms of a reaction after a period of regression of the initial symptoms. It can happen during gradual reduction of the anti-reaction steroid therapy and requires a new intervention including adjustment of the medication dose. 
EXAMINATION OF PERIPHERAL NERVES $-5^{\text {th }}$ DOSE

\begin{tabular}{|c|c|c|c|c|}
\hline \multirow[b]{2}{*}{ NERVES } & \multicolumn{2}{|c|}{$\begin{array}{l}\text { KEY } \\
\text { NERVE EXAMINATION } \\
0 \text { - Normal } \\
\text { 1- Thickened } \\
\text { 2- Nerve abscess }\end{array}$} & \multicolumn{2}{|c|}{$\begin{array}{l}\text { KEY } \\
\text { SCALE OF INDICATED NEURAL PAIN } \\
0 \text { - No pain } \\
1 \text { - Weak pain } \\
2 \text { - Strong pain }\end{array}$} \\
\hline & RIGHT & LEFT & RIGHT & LEFT \\
\hline \multicolumn{5}{|l|}{ Ulnar } \\
\hline \multicolumn{5}{|l|}{ Median } \\
\hline \multicolumn{5}{|l|}{ Radial } \\
\hline \multicolumn{5}{|l|}{ Fibular } \\
\hline \multicolumn{5}{|l|}{ Posterior Tibial } \\
\hline Others & & & & \\
\hline
\end{tabular}

Signature and stamp of medical examiner

LABORATORY TEST REQUEST $-5^{\text {th }}$ dose

\begin{tabular}{|l|l|}
\hline & C-REACTIVE PROTEIN (Register result in Block V, page 120) \\
\hline$\square$ & FULL BLOOD EXAM \\
\hline$\square$ & SGOT / SGPT \\
\hline
\end{tabular}

OBS:

Signature and stamp of medical examiner 


\section{CLINICAL-DERMATOLOGICAL EVALUATION $-6^{\text {th }}$ DOSE}

\begin{tabular}{|c|c|c|c|c|c|c|}
\hline \multirow{5}{*}{ Skin Lesions } & & 1 Remission & 2 Improvement & \multicolumn{2}{|c|}{3 Unchanged } & 4 Worsening \\
\hline & \multicolumn{6}{|l|}{ 1. Colour } \\
\hline & \multicolumn{6}{|l|}{ 2. Sensibility } \\
\hline & \multicolumn{6}{|l|}{ 3. Infiltration } \\
\hline & \multicolumn{6}{|l|}{ 4. Other } \\
\hline \multirow{24}{*}{$\begin{array}{l}\text { Symptoms and signs } \\
\text { of side effects from MDT }\end{array}$} & \multicolumn{2}{|l|}{ Sign/symptom } & Absent & mild & modera & severe \\
\hline & \multicolumn{2}{|l|}{ 1. Itching } & & & & \\
\hline & \multicolumn{2}{|l|}{ 2. Dry skin } & & & & \\
\hline & \multicolumn{2}{|c|}{ 3. Skin pigmentation } & & & & \\
\hline & \multicolumn{2}{|c|}{ 4. Rash } & & & & \\
\hline & \multicolumn{2}{|c|}{ 5. Erythrodermia } & & & & \\
\hline & \multicolumn{2}{|c|}{ 6. Photosensitivity } & & & & \\
\hline & \multicolumn{2}{|c|}{ 7. Abdominal pain } & & & & \\
\hline & \multicolumn{2}{|c|}{ 8. Constipation } & & & & \\
\hline & \multicolumn{2}{|l|}{ 9. Nausea } & & & & \\
\hline & \multicolumn{2}{|l|}{ 10. Vomiting } & & & & \\
\hline & \multicolumn{2}{|l|}{ 11. Diarrhoea } & & & & \\
\hline & \multicolumn{2}{|l|}{ 12. Anorexia } & & & & \\
\hline & \multicolumn{2}{|l|}{ 13. Jaundice } & & & & \\
\hline & \multicolumn{2}{|l|}{ 14. Pallor } & & & & \\
\hline & \multicolumn{2}{|l|}{ 15. Cyanosis } & & & & \\
\hline & \multicolumn{2}{|l|}{ 16. Bleeding } & & & & \\
\hline & \multicolumn{2}{|l|}{ 17. Weight loss } & & & & \\
\hline & \multicolumn{2}{|l|}{ 18. Dyspnoea } & & & & \\
\hline & \multicolumn{2}{|l|}{ 19. Asthenia } & & & & \\
\hline & \multicolumn{2}{|l|}{ 20. Fever } & & & & \\
\hline & \multicolumn{2}{|l|}{ 21. Myalgia } & & & & \\
\hline & \multicolumn{2}{|l|}{ 22. Headache } & & & & \\
\hline & 23. Depression & & & & & \\
\hline $\begin{array}{l}\text { Have any signs/symptoms } \\
\text { of leprosy reaction? }\end{array}$ & $\begin{array}{l}1-\text { Yes In this case } \\
2-\text { No } \\
3-\text { Continued sympto }\end{array}$ & $\begin{array}{l}\text { fill out the form } \\
\text { ns of previous re }\end{array}$ & $\begin{array}{l}\text { or reactions in blc } \\
\text { ction }\end{array}$ & ck V, fo & each ne & w episode* \\
\hline
\end{tabular}

Signature and stamp of medical examiner

*In this study, a new episode of leprosy reaction is defined as when the patient develops new signs and symptoms of a reaction after a period of regression of the initial symptoms. It can happen during gradual reduction of the anti-reaction steroid therapy and requires a new intervention including adjustment of the medication dose. 
EXAMINATION OF PERIPHERAL NERVES $-6^{\text {th }}$ DOSE

\begin{tabular}{|c|c|c|c|c|}
\hline \multirow[b]{2}{*}{ NERVES } & \multicolumn{2}{|c|}{$\begin{array}{l}\text { KEY } \\
\text { NERVE EXAMINATION } \\
0 \text { - Normal } \\
\text { 1- Thickened } \\
\text { 2- Nerve abscess }\end{array}$} & \multicolumn{2}{|c|}{$\begin{array}{l}\text { KEY } \\
\text { SCALE OF INDICATED NEURAL PAIN } \\
0 \text { - No pain } \\
1 \text { - Weak pain } \\
2 \text { - Strong pain }\end{array}$} \\
\hline & RIGHT & LEFT & RIGHT & LEFT \\
\hline \multicolumn{5}{|l|}{ Ulnar } \\
\hline \multicolumn{5}{|l|}{ Median } \\
\hline \multicolumn{5}{|l|}{ Radial } \\
\hline \multicolumn{5}{|l|}{ Fibular } \\
\hline \multicolumn{5}{|l|}{ Posterior Tibial } \\
\hline Others & & & & \\
\hline
\end{tabular}

Signature and stamp of medical examiner

\section{LABORATORY TEST REQUEST $-5^{\text {th }}$ dose}

\begin{tabular}{|l|l|}
\hline & C-REACTIVE PROTEIN (Register result in Block V, page 120) \\
\hline$\square$ & FULL BLOOD EXAM \\
\hline$\square$ & SGOT / SGPT \\
\hline
\end{tabular}

OBS: 


\section{SIMPLIFIED EVALUATION OF NEURAL FUNCTION AND COMPLICATIONS 7th DOSE (MB - group 4) and 1st month after U-MDT (MB - group 3)}

\begin{tabular}{|l|c|c|}
\hline \multicolumn{1}{|c|}{ Face } & & \\
\hline \multicolumn{1}{|c|}{ Nose } & R & L \\
\hline Main complaint $\quad$ Eyes & & \\
\hline dryness (S/N) & & \\
\hline abrasions (S/N) & & \\
\hline Perforation of the septum (S/N) & & L \\
\hline \multicolumn{1}{|c|}{ Main complaint } & & \\
\hline Closes eyes w/o force (mm) & & \\
\hline Closes eyes w/ force (mm) & & \\
\hline Cornea diminished sensibility (S/N) & & \\
\hline Cornea opacity (S/N) & & \\
\hline Cataract (S/N) & & \\
\hline Visual acuity & & \\
\hline
\end{tabular}

\begin{tabular}{|l|c|c|}
\hline \multicolumn{1}{|c|}{ Upper limbs } & & \\
\hline Main complaint Nerve palpation & & \\
\hline \multicolumn{1}{|c|}{ R } & L \\
\hline Ulnar & & \\
\hline Median & & \\
\hline Radius & & \\
\hline
\end{tabular}

key: $\mathrm{N}=$ normal; $\mathrm{T}=$ thickened; $\mathrm{P}=$ pain; $\mathrm{S}=$ Tinel's sign $(+)$

\begin{tabular}{|l|l|l|l|}
\hline \multicolumn{2}{|c|}{ Strength evaluation } & R & L \\
\hline Opens little finger & & \\
Abduction of the $5^{\text {th }}$ finger (ulnar nerve) & & \\
\hline Elevates thumb & & \\
Abduction of the thumb (median nerve) & & \\
\hline Elevates wrist & & \\
Wrist extension (radial nerve) & & & \\
\hline
\end{tabular}

key: $\mathrm{S}=$ strong; $\mathrm{D}=$ diminished; $\mathrm{P}=$ paralysed or $5=$ strong; $4=$ partial resistance; $3=$ complete movement; $2=$ partial movement $; 1=$ contraction; $0=$ paralysed

\section{SENSITIVITY EVALUATION AND STATUS INSPECTION}

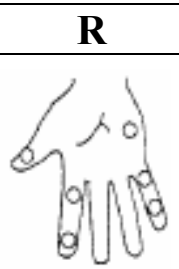

$\mathbf{L}$

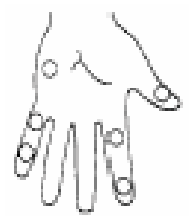

key: lilac pen / monofilament (2g): feels $\sqrt{ }$; does not feel X ; or monofilaments: follow colours Mobile claw: $M$; rigid claw: $\mathrm{R}$; bone absorption: 


\begin{tabular}{|c|l|l|l|l|l|l|l|l|l|l|l|l|}
\hline PATIENT INITIALS & & & & & PATIENT NUMBER: & & & & DATE OF VISIT: & \\
\hline PATIENT INITIALS & & & & & PATIENT NUMBER: & & & & & DATE OF VISIT: \\
\hline
\end{tabular}

\begin{tabular}{|l|l|l|}
\hline \multicolumn{1}{|c|}{ Lower limbs } & & \\
\hline Main complaint Nerve Palpation & & \\
\hline Fibular & R & L \\
\hline Posterior tibial & & \\
\hline
\end{tabular}

key: $\mathrm{N}=$ normal; $\mathrm{T}=$ thickened; $\mathrm{P}=$ pain; $\mathrm{S}=$ Tinel's sign $(+)$

\begin{tabular}{|l|l|l|l|}
\hline \multicolumn{2}{|c|}{ Strength evaluation } & R & L \\
\hline $\begin{array}{l}\text { Elevates hallux } \\
\text { Hallux extension (fibular nerve) }\end{array}$ & & \\
\hline $\begin{array}{l}\text { Elevate foot } \\
\text { Foot dorsiflexion (fibular nerve) }\end{array}$ & & \\
\hline
\end{tabular}

key: $\mathrm{S}=$ strong; $\mathrm{D}=$ diminished; $\mathrm{P}=$ paralysed or $5=$ strong; $4=$ partial resistance; $3=$ complete movement; 2 = partial movement; $1=$ contracture; $0=$ paralysed

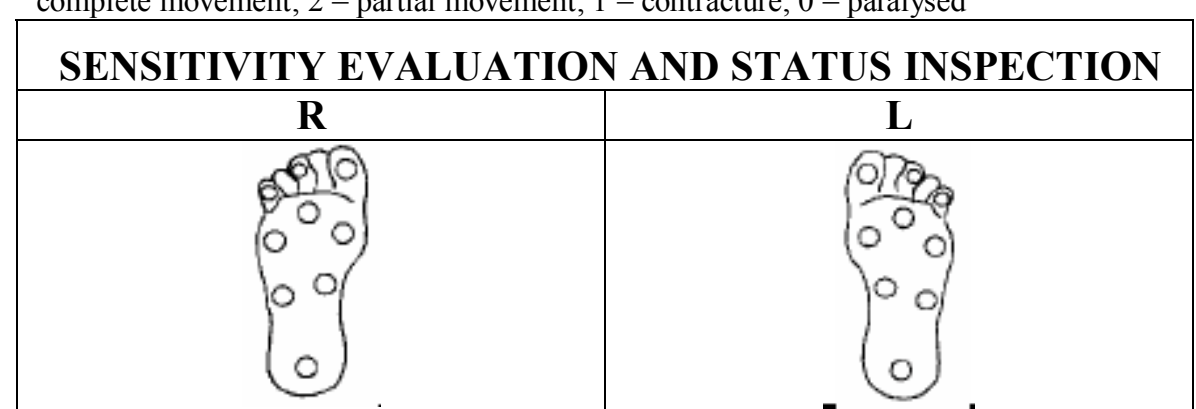

key: lilac pen / monofilament (2g): feels $\sqrt{ }$; does not feel X; or monofilaments: follow colours

Mobile claw: $\mathrm{M}$; rigid claw: $\mathrm{R}$; bone absorption: $\%$ wound: $\square$

\begin{tabular}{|c|c|c|c|c|c|c|c|c|}
\hline \multicolumn{9}{|c|}{ Classification of disability grade } \\
\hline Evaluation date & \multicolumn{2}{|c|}{ eyes } & \multicolumn{2}{|c|}{ hands } & \multicolumn{2}{|c|}{ feet } & \multirow[t]{2}{*}{ Highest grade } & \multirow[t]{2}{*}{ signature } \\
\hline & $\mathbf{R}$ & $\mathbf{L}$ & $\mathbf{R}$ & $\mathbf{L}$ & $\mathbf{R}$ & $\mathbf{L}$ & & \\
\hline Evaluation & & & & & & & & \\
\hline \multicolumn{9}{|c|}{ Monofilaments } \\
\hline Monofilament & \multicolumn{4}{|c|}{ strength in grams } & \multicolumn{4}{|c|}{ interpretation } \\
\hline 1 - green & \multicolumn{4}{|c|}{0.05} & \multicolumn{4}{|c|}{ Normal sensitivity in hand and foot } \\
\hline 2 - blue & \multicolumn{4}{|c|}{0.20} & \multicolumn{4}{|c|}{$\begin{array}{l}\text { Diminished sensitivity in hand and normal in foot / Difficulty } \\
\text { in distinguishing texture (light touch) }\end{array}$} \\
\hline 3 - Lilac & \multicolumn{4}{|c|}{2.00} & \multicolumn{4}{|c|}{$\begin{array}{l}\text { Diminished protective sensitivity in hand / Incapable of } \\
\text { distinguishing texture / Difficulty in distinguishing forms and } \\
\text { temperatures }\end{array}$} \\
\hline 4 - dark red & \multicolumn{4}{|c|}{4.00} & \multicolumn{4}{|c|}{$\begin{array}{l}\text { Loss of protective sensitivity in hand and sometimes in foot } \\
\text { / loss of texture discrimination / Incapable of distinguishing } \\
\text { forms and temperatures }\end{array}$} \\
\hline 5 - orange or red (mark with an $\mathrm{X}$ ) & \multicolumn{4}{|c|}{10.00} & \multicolumn{4}{|c|}{$\begin{array}{l}\text { Loss of protective sensitivity in foot / loss of texture } \\
\text { discrimination / Incapable of distinguishing forms and } \\
\text { temperatures }\end{array}$} \\
\hline 6 - red circle & \multicolumn{4}{|c|}{300.00} & \multicolumn{4}{|c|}{$\begin{array}{l}\text { Only has sensation when deep pressure is applied to hand } \\
\text { and foot }\end{array}$} \\
\hline 7 - black & \multicolumn{4}{|c|}{$\begin{array}{c}\text { No response to } 300 \mathrm{~g} \\
\text { monofilament }\end{array}$} & \multicolumn{4}{|c|}{ Loss of sensation even to deep pressure in hand and foot } \\
\hline
\end{tabular}


CLINICAL DERMATOLOGICAL EVALUATION 7th DOSE (MB - group 4) and 1st month after U-MDT (MB - group 3)

\begin{tabular}{|c|c|c|c|c|c|c|}
\hline \multirow{5}{*}{ Skin Lesions } & & 1 Remission & 2 Improvement & \multicolumn{2}{|c|}{3 Unchanged } & 4 Worsening \\
\hline & 1. Colour & & & & & \\
\hline & 2. Sensibility & & & & & \\
\hline & 3. Infiltration & & & & & \\
\hline & 4. Other & & & & & \\
\hline \multirow{24}{*}{$\begin{array}{l}\text { Symptoms and signs } \\
\text { of side effects from MDT }\end{array}$} & Sign/symptom & & Absent & mild & modera & severe \\
\hline & 1. Itching & & & & & \\
\hline & 2. Dry skin & & & & & \\
\hline & 3. Skin pigmen & tion & & & & \\
\hline & 4. Rash & & & & & \\
\hline & 5. Erythrodermi & & & & & \\
\hline & 6. Photosensitiv & & & & & \\
\hline & 7. Abdominal $\mathrm{p}$ & & & & & \\
\hline & 8. Constipation & & & & & \\
\hline & 9. Nausea & & & & & \\
\hline & 10. Vomiting & & & & & \\
\hline & 11. Diarrhoea & & & & & \\
\hline & 12. Anorexia & & & & & \\
\hline & 13. Jaundice & & & & & \\
\hline & 14. Pallor & & & & & \\
\hline & 15. Cyanosis & & & & & \\
\hline & 16. Bleeding & & & & & \\
\hline & 17. Weight loss & & & & & \\
\hline & 18. Dyspnoea & & & & & \\
\hline & 19. Asthenia & & & & & \\
\hline & 20. Fever & & & & & \\
\hline & 21. Myalgia & & & & & \\
\hline & 22. Headache & & & & & \\
\hline & 23. Depression & & & & & \\
\hline $\begin{array}{l}\text { Have any signs/symptoms } \\
\text { of leprosy reaction? }\end{array}$ & \multicolumn{6}{|c|}{$\begin{array}{l}1-\text { Yes In this case, fill out the form for reactions in block V, for each new episode* } \\
2-\text { No } \\
3 \text { - Continued symptoms of previous reaction }\end{array}$} \\
\hline
\end{tabular}

Signature and stamp of medical examiner

*In this study, a new episode of leprosy reaction is defined as when the patient develops new signs and symptoms of a reaction after a period of regression of the initial symptoms. It can happen during gradual reduction of the anti-reaction steroid therapy and requires a new intervention including adjustment of the medication dose. 
EXAMINATION OF PERIPHERAL NERVES -

7th DOSE (MB - group 4) and 1st month after U-MDT (MB - group 3)

\begin{tabular}{|c|c|c|c|c|}
\hline \multirow[b]{2}{*}{ NERVES } & \multicolumn{2}{|c|}{$\begin{array}{l}\text { KEY } \\
\text { NERVE EXAMINATION } \\
0 \text { - Normal } \\
\text { 1- Thickened } \\
\text { 2- Nerve abscess }\end{array}$} & \multicolumn{2}{|c|}{$\begin{array}{l}\text { KEY } \\
\text { SCALE OF INDICATED NEURAL PAIN } \\
0 \text { - No pain } \\
1 \text { - Weak pain } \\
2 \text { - Strong pain }\end{array}$} \\
\hline & RIGHT & LEFT & RIGHT & LEFT \\
\hline \multicolumn{5}{|l|}{ Ulnar } \\
\hline \multicolumn{5}{|l|}{ Median } \\
\hline \multicolumn{5}{|l|}{ Radial } \\
\hline \multicolumn{5}{|l|}{ Fibular } \\
\hline \multicolumn{5}{|l|}{ Posterior Tibial } \\
\hline Others & & & & \\
\hline
\end{tabular}

Signature and stamp of medical examiner

\section{LABORATORY TEST REQUEST}

7th DOSE (MB - group 4) and 1st month after U-MDT (MB - group 3)

\begin{tabular}{|l|l|}
\hline & C-REACTIVE PROTEIN (Register result in Block V, page 120) \\
\hline$\square$ & FULL BLOOD EXAM \\
\hline$\square$ & SGOT / SGPT \\
\hline
\end{tabular}

OBS: 


\section{CLINICAL DERMATOLOGICAL EVALUATION}

8th DOSE (MB - group 4) and 2nd month after U-MDT (MB - group 3)

\begin{tabular}{|c|c|c|c|c|c|c|}
\hline \multirow{5}{*}{ Skin Lesions } & & 1 Remission & 2 Improvement & \multicolumn{2}{|c|}{3 Unchanged } & 4 Worsening \\
\hline & 1. Colour & & & & & \\
\hline & 2. Sensibility & & & & & \\
\hline & 3. Infiltration & & & & & \\
\hline & 4. Other & & & & & \\
\hline \multirow{24}{*}{$\begin{array}{l}\text { Symptoms and signs } \\
\text { of side effects from MDT }\end{array}$} & \multicolumn{2}{|l|}{ Sign/symptom } & Absent & mild & moderate & severe \\
\hline & \multicolumn{2}{|l|}{ 1. Itching } & & & & \\
\hline & \multicolumn{2}{|l|}{ 2. Dry skin } & & & & \\
\hline & \multicolumn{2}{|c|}{ 3. Skin pigmentation } & & & & \\
\hline & \multicolumn{2}{|l|}{ 4. Rash } & & & & \\
\hline & \multicolumn{2}{|c|}{ 5. Erythrodermia } & & & & \\
\hline & \multicolumn{2}{|c|}{ 6. Photosensitivity } & & & & \\
\hline & \multicolumn{2}{|c|}{ 7. Abdominal pain } & & & & \\
\hline & \multicolumn{2}{|l|}{ 8. Constipation } & & & & \\
\hline & \multicolumn{2}{|l|}{ 9. Nausea } & & & & \\
\hline & \multicolumn{2}{|l|}{ 10. Vomiting } & & & & \\
\hline & \multicolumn{2}{|l|}{ 11. Diarrhoea } & & & & \\
\hline & \multicolumn{2}{|l|}{ 12. Anorexia } & & & & \\
\hline & \multicolumn{2}{|l|}{ 13. Jaundice } & & & & \\
\hline & \multicolumn{2}{|l|}{ 14. Pallor } & & & & \\
\hline & \multicolumn{2}{|l|}{ 15. Cyanosis } & & & & \\
\hline & \multicolumn{2}{|l|}{ 16. Bleeding } & & & & \\
\hline & \multicolumn{2}{|l|}{ 17. Weight loss } & & & & \\
\hline & \multicolumn{2}{|l|}{ 18. Dyspnoea } & & & & \\
\hline & \multicolumn{2}{|l|}{ 19. Asthenia } & & & & \\
\hline & \multicolumn{2}{|l|}{ 20. Fever } & & & & \\
\hline & \multicolumn{2}{|l|}{ 21. Myalgia } & & & & \\
\hline & \multicolumn{2}{|l|}{ 22. Headache } & & & & \\
\hline & \multicolumn{2}{|l|}{ 23. Depression } & & & & \\
\hline $\begin{array}{l}\text { Have any signs/symptoms } \\
\text { of leprosy reaction? }\end{array}$ & \multicolumn{6}{|c|}{$\begin{array}{l}1-\text { Yes In this case, fill out the forn } \\
2-\text { No }\end{array}$} \\
\hline
\end{tabular}

Signature and stamp of medical examiner

*In this study, a new episode of leprosy reaction is defined as when the patient develops new signs and symptoms of a reaction after a period of regression of the initial symptoms. It can happen during gradual reduction of the anti-reaction steroid therapy and requires a new intervention including adjustment of the medication dose. 
EXAMINATION OF PERIPHERAL NERVES -

8th DOSE (MB - group 4) and $2^{\text {nd }}$ month after U-MDT (MB - group 3)

\begin{tabular}{|c|c|c|c|c|}
\hline \multirow[b]{2}{*}{ NERVES } & \multicolumn{2}{|c|}{$\begin{array}{l}\text { KEY } \\
\text { NERVE EXAMINATION } \\
0 \text { - Normal } \\
\text { 1- Thickened } \\
\text { 2- Nerve abscess }\end{array}$} & \multicolumn{2}{|c|}{$\begin{array}{l}\text { KEY } \\
\text { SCALE OF INDICATED NEURAL PAIN } \\
0-\text { No pain } \\
1 \text { - Weak pain } \\
2 \text { - Strong pain }\end{array}$} \\
\hline & RIGHT & LEFT & RIGHT & LEFT \\
\hline \multicolumn{5}{|l|}{ Ulnar } \\
\hline \multicolumn{5}{|l|}{ Median } \\
\hline \multicolumn{5}{|l|}{ Radial } \\
\hline \multicolumn{5}{|l|}{ Fibular } \\
\hline \multicolumn{5}{|l|}{ Posterior Tibial } \\
\hline Others & & & & \\
\hline
\end{tabular}

Signature and stamp of medical examiner

REQUEST OF LABORATORY EXAMS

8th DOSE (MB - group 4) and 2nd month after U-MDT (MB - group 3)

\begin{tabular}{|l|l|}
\hline$\square$ & C-REACTIVE PROTEIN (Register result in Block V, page 120) \\
\hline$\square$ & FULL BLOOD EXAM \\
\hline$\square$ & SGOT / SGPT \\
\hline
\end{tabular}

OBS: 


\begin{tabular}{|c|l|l|l|l|l|l|l|l|l|l|l|l|}
\hline PATIENT INITIALS & & & & & PATIENT NUMBER: & & & & & DATE OF VISIT: & \\
\hline PATIENT INITIALS & & & & & PATIENT NUMBER: & & & & & DATE OF VISIT: \\
\hline
\end{tabular}

\section{CLINICAL DERMATOLOGICAL EXAMINATION}

9th DOSE (MB - group 4) and 3rd month after U-MDT (MB - group 3)

\begin{tabular}{|c|c|c|c|c|c|c|}
\hline \multirow{5}{*}{ Skin Lesions } & & 1 Remission & 2 Improvement & \multicolumn{2}{|c|}{3 Unchanged } & 4 Worsening \\
\hline & 1. Colour & & & & & \\
\hline & 2. Sensibility & & & & & \\
\hline & 3. Infiltration & & & & & \\
\hline & 4. Other & & & & & \\
\hline \multirow{24}{*}{$\begin{array}{l}\text { Symptoms and signs } \\
\text { of side effects from MDT }\end{array}$} & Sign/symptom & & Absent & mild & moderate & severe \\
\hline & 1. Itching & & & & & \\
\hline & 2. Dry skin & & & & & \\
\hline & 3. Skin pigmen & tion & & & & \\
\hline & 4. Rash & & & & & \\
\hline & 5. Erythrodermi & & & & & \\
\hline & 6. Photosensitiv & & & & & \\
\hline & 7. Abdominal $\mathrm{p}$ & & & & & \\
\hline & 8. Constipation & & & & & \\
\hline & 9. Nausea & & & & & \\
\hline & 10. Vomiting & & & & & \\
\hline & 11. Diarrhoea & & & & & \\
\hline & 12. Anorexia & & & & & \\
\hline & 13. Jaundice & & & & & \\
\hline & 14. Pallor & & & & & \\
\hline & 15. Cyanosis & & & & & \\
\hline & 16. Bleeding & & & & & \\
\hline & 17. Weight loss & & & & & \\
\hline & 18. Dyspnoea & & & & & \\
\hline & 19. Asthenia & & & & & \\
\hline & 20. Fever & & & & & \\
\hline & 21. Myalgia & & & & & \\
\hline & 22. Headache & & & & & \\
\hline & 23. Depression & & & & & \\
\hline $\begin{array}{l}\text { Have any signs/symptoms } \\
\text { of leprosy reaction? }\end{array}$ & \multicolumn{6}{|c|}{$\begin{array}{l}1-\text { Yes In this case, fill out the form for reactions in block V, for each new episode* } \\
2-\text { No } \\
3 \text { - Continued symptoms of previous reaction }\end{array}$} \\
\hline
\end{tabular}

Signature and stamp of medical examiner

*In this study, a new episode of leprosy reaction is defined as when the patient develops new signs and symptoms of a reaction after a period of regression of the initial symptoms. It can happen during gradual reduction of the anti-reaction steroid therapy and requires a new intervention including adjustment of the medication dose. 
EXAMINATION OF PERIPHERAL NERVES

9th DOSE (MB - group 4) and 3rd month after U-MDT (MB - group 3)

\begin{tabular}{|c|c|c|c|c|}
\hline \multirow[b]{2}{*}{ NERVES } & \multicolumn{2}{|c|}{$\begin{array}{l}\text { KEY } \\
\text { NERVE EXAMINATION } \\
0 \text { - Normal } \\
\text { 1- Thickened } \\
\text { 2- Nerve abscess }\end{array}$} & \multicolumn{2}{|c|}{$\begin{array}{l}\text { KEY } \\
\text { SCALE OF INDICATED NEURAL PAIN } \\
0 \text { - No pain } \\
1 \text { - Weak pain } \\
2 \text { - Strong pain }\end{array}$} \\
\hline & RIGHT & LEFT & RIGHT & LEFT \\
\hline \multicolumn{5}{|l|}{ Ulnar } \\
\hline \multicolumn{5}{|l|}{ Median } \\
\hline \multicolumn{5}{|l|}{ Radial } \\
\hline \multicolumn{5}{|l|}{ Fibular } \\
\hline \multicolumn{5}{|l|}{ Posterior Tibial } \\
\hline Others & & & & \\
\hline
\end{tabular}

Signature and stamp of medical examiner

REQUEST OF LABORATORY EXAMS

9th DOSE (MB - group 4) and 3rd month after U-MDT (MB - group 3)

\begin{tabular}{|l|l|}
\hline$\square$ & C-REACTIVE PROTEIN (Register result in Block V, page 120) \\
\hline$\square$ & FULL BLOOD EXAM \\
\hline$\square$ & SGOT / SGPT \\
\hline
\end{tabular}

OBS: 


\begin{tabular}{|c|l|l|l|l|l|l|l|l|l|l|l|l|}
\hline PATIENT INITIALS & & & & & PATIENT NUMBER: & & & & DATE OF VISIT: & \\
\hline PATIENT INITIALS & & & & & PATIENT NUMBER: & & & & & DATE OF VISIT: \\
\hline
\end{tabular}

CLINICAL DERMATOLOGICAL EXAMINATION

10th DOSE (MB - group 4) and $4^{\text {th }}$ month after U-MDT (MB - group 3)

\begin{tabular}{|c|c|c|c|c|c|c|}
\hline \multirow{5}{*}{ Skin Lesions } & & 1 Remission & 2 Improvement & \multicolumn{2}{|c|}{3 Unchanged } & 4 Worsening \\
\hline & 1. Colour & & & & & \\
\hline & 2. Sensibility & & & & & \\
\hline & 3. Infiltration & & & & & \\
\hline & 4. Other & & & & & \\
\hline \multirow{24}{*}{$\begin{array}{l}\text { Symptoms and signs } \\
\text { of side effects from MDT }\end{array}$} & \multicolumn{2}{|l|}{ Sign/symptom } & Absent & mild & moderate & severe \\
\hline & \multicolumn{2}{|l|}{ 1. Itching } & & & & \\
\hline & \multicolumn{2}{|l|}{ 2. Dry skin } & & & & \\
\hline & \multicolumn{2}{|c|}{ 3. Skin pigmentation } & & & & \\
\hline & \multicolumn{2}{|c|}{ 4. Rash } & & & & \\
\hline & \multicolumn{2}{|c|}{ 5. Erythrodermia } & & & & \\
\hline & \multicolumn{2}{|c|}{ 6. Photosensitivity } & & & & \\
\hline & \multicolumn{2}{|c|}{ 7. Abdominal pain } & & & & \\
\hline & \multicolumn{2}{|c|}{ 8. Constipation } & & & & \\
\hline & \multicolumn{2}{|l|}{ 9. Nausea } & & & & \\
\hline & \multicolumn{2}{|l|}{ 10. Vomiting } & & & & \\
\hline & \multicolumn{2}{|l|}{ 11. Diarrhoea } & & & & \\
\hline & \multicolumn{2}{|l|}{ 12. Anorexia } & & & & \\
\hline & \multicolumn{2}{|l|}{ 13. Jaundice } & & & & \\
\hline & \multicolumn{2}{|l|}{ 14. Pallor } & & & & \\
\hline & \multicolumn{2}{|l|}{ 15. Cyanosis } & & & & \\
\hline & \multicolumn{2}{|l|}{ 16. Bleeding } & & & & \\
\hline & \multicolumn{2}{|l|}{ 17. Weight loss } & & & & \\
\hline & \multicolumn{2}{|l|}{ 18. Dyspnoea } & & & & \\
\hline & \multicolumn{2}{|l|}{ 19. Asthenia } & & & & \\
\hline & \multicolumn{2}{|l|}{ 20. Fever } & & & & \\
\hline & \multicolumn{2}{|l|}{ 21. Myalgia } & & & & \\
\hline & \multicolumn{2}{|l|}{ 22. Headache } & & & & \\
\hline & \multicolumn{2}{|l|}{ 23. Depression } & & & & \\
\hline $\begin{array}{l}\text { Have any signs/symptoms } \\
\text { of leprosy reaction? }\end{array}$ & \multicolumn{6}{|c|}{$\begin{array}{l}\text { - Yes In this case, fill out the form for reactions in block V, for each new episode* } \\
\text { - No } \\
\text { - Continued symptoms of previous reaction }\end{array}$} \\
\hline
\end{tabular}

Signature and stamp of medical examiner

*In this study, a new episode of leprosy reaction is defined as when the patient develops new signs and symptoms of a reaction after a period of regression of the initial symptoms. It can happen during gradual reduction of the anti-reaction steroid therapy and requires a new intervention including adjustment of the medication dose. 


\section{EXAMINATION OF PERIPHERAL NERVES}

10th DOSE (MB - group 4) and 4th month after U-MDT (MB - group 3)

\begin{tabular}{|c|c|c|c|c|}
\hline \multirow[b]{2}{*}{ NERVES } & \multicolumn{2}{|c|}{$\begin{array}{l}\text { KEY } \\
\text { NERVE EXAMINATION } \\
0 \text { - Normal } \\
\text { 1- Thickened } \\
\text { 2- Nerve abscess }\end{array}$} & \multicolumn{2}{|c|}{$\begin{array}{l}\text { KEY } \\
\text { SCALE OF INDICATED NEURAL PAIN } \\
0 \text { - No pain } \\
1 \text { - Weak pain } \\
2 \text { - Strong pain }\end{array}$} \\
\hline & RIGHT & LEFT & RIGHT & LEFT \\
\hline \multicolumn{5}{|l|}{ Ulnar } \\
\hline \multicolumn{5}{|l|}{ Median } \\
\hline \multicolumn{5}{|l|}{ Radial } \\
\hline \multicolumn{5}{|l|}{ Fibular } \\
\hline \multicolumn{5}{|l|}{ Posterior Tibial } \\
\hline Others & & & & \\
\hline
\end{tabular}

Signature and stamp of medical examiner

REQUEST OF LABORATORY EXAMS

10th DOSE (MB - group 4) and 4th month after U-MDT (MB - group 3)

\begin{tabular}{|l|l|}
\hline & C-REACTIVE PROTEIN (Register result in Block V, page 120) \\
\hline$\square$ & FULL BLOOD EXAM \\
\hline$\square$ & SGOT / SGPT \\
\hline
\end{tabular}

OBS:

Signature and stamp of medical examiner 


\begin{tabular}{|c|l|l|l|l|l|l|l|l|l|l|l|l|}
\hline PATIENT INITIALS & & & & & PATIENT NUMBER: & & & & DATE OF VISIT: & \\
\hline PATIENT INITIALS & & & & & PATIENT NUMBER: & & & & & DATE OF VISIT: \\
\hline
\end{tabular}

CLINICAL DERMATOLOGICAL EXAMINATION

11th DOSE (MB - group 4) and 5th month after U-MDT (MB - group 3)

\begin{tabular}{|c|c|c|c|c|c|c|}
\hline \multirow{5}{*}{ Skin Lesions } & & 1 Remission & 2 Improvement & \multicolumn{2}{|c|}{3 Unchanged } & 4 Worsening \\
\hline & 1. Colour & & & & & \\
\hline & 2. Sensibility & & & & & \\
\hline & 3. Infiltration & & & & & \\
\hline & 4. Other & & & & & \\
\hline \multirow{24}{*}{$\begin{array}{l}\text { Symptoms and signs } \\
\text { of side effects from MDT }\end{array}$} & \multicolumn{2}{|l|}{ Sign/symptom } & Absent & mild & moderate & severe \\
\hline & \multicolumn{2}{|l|}{ 1. Itching } & & & & \\
\hline & \multicolumn{2}{|l|}{ 2. Dry skin } & & & & \\
\hline & \multicolumn{2}{|c|}{ 3. Skin pigmentation } & & & & \\
\hline & \multicolumn{2}{|c|}{ 4. Rash } & & & & \\
\hline & \multicolumn{2}{|c|}{ 5. Erythrodermia } & & & & \\
\hline & \multicolumn{2}{|c|}{ 6. Photosensitivity } & & & & \\
\hline & \multicolumn{2}{|c|}{ 7. Abdominal pain } & & & & \\
\hline & \multicolumn{2}{|l|}{ 8. Constipation } & & & & \\
\hline & \multicolumn{2}{|l|}{ 9. Nausea } & & & & \\
\hline & \multicolumn{2}{|l|}{ 10. Vomiting } & & & & \\
\hline & \multicolumn{2}{|l|}{ 11. Diarrhoea } & & & & \\
\hline & \multicolumn{2}{|l|}{ 12. Anorexia } & & & & \\
\hline & \multicolumn{2}{|l|}{ 13. Jaundice } & & & & \\
\hline & \multicolumn{2}{|l|}{ 14. Pallor } & & & & \\
\hline & \multicolumn{2}{|l|}{ 15. Cyanosis } & & & & \\
\hline & \multicolumn{2}{|l|}{ 16. Bleeding } & & & & \\
\hline & \multicolumn{2}{|l|}{ 17. Weight loss } & & & & \\
\hline & \multicolumn{2}{|l|}{ 18. Dyspnoea } & & & & \\
\hline & \multicolumn{2}{|l|}{ 19. Asthenia } & & & & \\
\hline & \multicolumn{2}{|l|}{ 20. Fever } & & & & \\
\hline & \multicolumn{2}{|l|}{ 21. Myalgia } & & & & \\
\hline & \multicolumn{2}{|l|}{ 22. Headache } & & & & \\
\hline & \multicolumn{2}{|l|}{ 23. Depression } & & & & \\
\hline $\begin{array}{l}\text { Have any signs/symptoms } \\
\text { of leprosy reaction? }\end{array}$ & \multicolumn{6}{|c|}{$\begin{array}{l}1 \text { - Yes In this case, fill out the form for reactions in block V, for each new episode* } \\
2-\text { No } \\
3 \text { - Continued symptoms of previous reaction }\end{array}$} \\
\hline
\end{tabular}

\section{Signature and stamp of medical examiner}

*In this study, a new episode of leprosy reaction is defined as when the patient develops new signs and symptoms of a reaction after a period of regression of the initial symptoms. It can happen during gradual reduction of the anti-reaction steroid therapy and requires a new intervention including adjustment of the medication dose. 
EXAMINATION OF PERIPHERAL NERVES

11th DOSE (MB - group 4) and 5th month after U-MDT (MB - group 3)

\begin{tabular}{|c|c|c|c|c|}
\hline \multirow[b]{2}{*}{ NERVES } & \multicolumn{2}{|c|}{$\begin{array}{l}\text { KEY } \\
\text { NERVE EXAMINATION } \\
0 \text { - Normal } \\
\text { 1- Thickened } \\
\text { 2- Nerve abscess }\end{array}$} & \multicolumn{2}{|c|}{$\begin{array}{l}\text { KEY } \\
\text { SCALE OF INDICATED NEURAL PAIN } \\
0-\text { No pain } \\
1 \text { - Weak pain } \\
2 \text { - Strong pain }\end{array}$} \\
\hline & RIGHT & LEFT & RIGHT & LEFT \\
\hline \multicolumn{5}{|l|}{ Ulnar } \\
\hline \multicolumn{5}{|l|}{ Median } \\
\hline \multicolumn{5}{|l|}{ Radial } \\
\hline \multicolumn{5}{|l|}{ Fibular } \\
\hline \multicolumn{5}{|l|}{ Posterior Tibial } \\
\hline Others & & & & \\
\hline
\end{tabular}

Signature and stamp of medical examiner

REQUEST OF LABORATORY EXAMS

11th DOSE (MB - group 4) and 5th month after U-MDT (MB - group 3)

\begin{tabular}{|l|l|}
\hline$\square$ & C-REACTIVE PROTEIN (Register result in Block V, page 120) \\
\hline$\square$ & FULL BLOOD EXAM \\
\hline$\square$ & SGOT / SGPT \\
\hline
\end{tabular}

OBS: 


\begin{tabular}{|c|l|l|l|l|l|l|l|l|l|l|l|l|l|}
\hline PATIENT INITIALS & & & & & PATIENT NUMBER: & & & & & DATE OF VISIT: & & \\
\hline PATIENT INITIALS & & & & & PATIENT NUMBER: & & & & & DATE OF VISIT: & & & \\
\hline
\end{tabular}

\section{CLINICAL DERMATOLOGICAL EVALUATION 12nd DOSE (MB - group 4) and 6th month after U-MDT (MB - group 3)}

\begin{tabular}{|c|c|c|c|c|c|c|}
\hline \multirow{5}{*}{ Skin Lesions } & & 1 Remission & 2 Improvement & \multicolumn{2}{|c|}{3 Unchanged } & 4 Worsening \\
\hline & 1. Colour & & & & & \\
\hline & 2. Sensibility & & & & & \\
\hline & 3. Infiltration & & & & & \\
\hline & 4. Other & & & & & \\
\hline \multirow{24}{*}{$\begin{array}{l}\text { Symptoms and signs } \\
\text { of side effects from MDI }\end{array}$} & \multicolumn{2}{|l|}{ Sign/symptom } & Absent & mild & moderate & severe \\
\hline & \multicolumn{2}{|l|}{ 1. Itching } & & & & \\
\hline & \multicolumn{2}{|l|}{ 2. Dry skin } & & & & \\
\hline & \multicolumn{2}{|c|}{ 3. Skin pigmentation } & & & & \\
\hline & \multicolumn{2}{|c|}{ 4. Rash } & & & & \\
\hline & \multicolumn{2}{|c|}{ 5. Erythrodermia } & & & & \\
\hline & \multicolumn{2}{|c|}{ 6. Photosensitivity } & & & & \\
\hline & \multicolumn{2}{|c|}{ 7. Abdominal pain } & & & & \\
\hline & \multicolumn{2}{|l|}{ 8. Constipation } & & & & \\
\hline & \multicolumn{2}{|l|}{ 9. Nausea } & & & & \\
\hline & \multicolumn{2}{|l|}{ 10. Vomiting } & & & & \\
\hline & \multicolumn{2}{|l|}{ 11. Diarrhoea } & & & & \\
\hline & \multicolumn{2}{|l|}{ 12. Anorexia } & & & & \\
\hline & \multicolumn{2}{|l|}{ 13. Jaundice } & & & & \\
\hline & \multicolumn{2}{|l|}{ 14. Pallor } & & & & \\
\hline & \multicolumn{2}{|l|}{ 15. Cyanosis } & & & & \\
\hline & \multicolumn{2}{|l|}{ 16. Bleeding } & & & & \\
\hline & \multicolumn{2}{|l|}{ 17. Weight loss } & & & & \\
\hline & \multicolumn{2}{|l|}{ 18. Dyspnoea } & & & & \\
\hline & \multicolumn{2}{|l|}{ 19. Asthenia } & & & & \\
\hline & \multicolumn{2}{|l|}{ 20. Fever } & & & & \\
\hline & \multicolumn{2}{|l|}{ 21. Myalgia } & & & & \\
\hline & \multicolumn{2}{|l|}{ 22. Headache } & & & & \\
\hline & \multicolumn{2}{|l|}{ 23. Depression } & & & & \\
\hline $\begin{array}{l}\text { Have any signs/symptoms } \\
\text { of leprosy reaction? }\end{array}$ & \multicolumn{6}{|c|}{$\begin{array}{l}1-\text { Yes In this case, fill out the form for reactions in block V, for each new episode* } \\
2-\text { No } \\
3 \text { - Continued symptoms of previous reaction }\end{array}$} \\
\hline
\end{tabular}

Signature and stamp of medical examiner

*In this study, a new episode of leprosy reaction is defined as when the patient develops new signs and symptoms of a reaction after a period of regression of the initial symptoms. It can happen during gradual reduction of the anti-reaction steroid therapy and requires a new intervention including adjustment of the medication dose. 


\section{EXAMINATION OF PERIPHERAL NERVES}

12th DOSE (MB - group 4) and 6th month after U-MDT (MB - group 3)

\begin{tabular}{|c|c|c|c|c|}
\hline \multirow[b]{2}{*}{ NERVES } & \multicolumn{2}{|c|}{$\begin{array}{l}\text { KEY } \\
\text { NERVE EXAMINATION } \\
0 \text { - Normal } \\
\text { 1- Thickened } \\
\text { 2- Nerve abscess }\end{array}$} & \multicolumn{2}{|c|}{$\begin{array}{l}\text { KEY } \\
\text { SCALE OF INDICATED NEURAL PAIN } \\
0 \text { - No pain } \\
1 \text { - Weak pain } \\
2 \text { - Strong pain }\end{array}$} \\
\hline & RIGHT & LEFT & RIGHT & LEFT \\
\hline \multicolumn{5}{|l|}{ Ulnar } \\
\hline \multicolumn{5}{|l|}{ Median } \\
\hline \multicolumn{5}{|l|}{ Radial } \\
\hline \multicolumn{5}{|l|}{ Fibular } \\
\hline \multicolumn{5}{|l|}{ Posterior Tibial } \\
\hline Others & & & & \\
\hline
\end{tabular}

Signature and stamp of medical examiner

REQUEST OF LABORATORY EXAMS

12th DOSE (MB - group 4) and 6th month after U-MDT (MB - group 3)

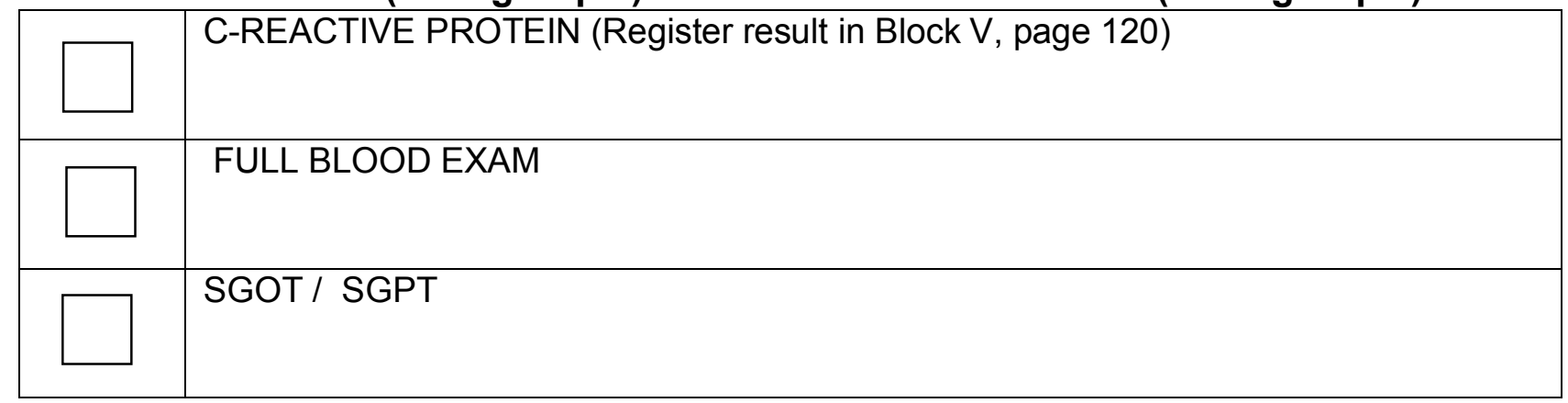

OBS:

Signature and stamp of medical examiner 


\section{INSTRUCTIONS FOR COMPLETION OF TREATMENT (MONTH 7 - GROUPS 1 AND 2 [PB]; MONTH 13 - GROUP 3 AND 4 [MB])}

1. The following tests and procedures should be done during the monthly visits:

a. Complete the clinical-dermatological examination.

b. Perform the neurological examination; nerves must be palpated and evaluated for sensitivity and thickness. Register information on the Examination of Peripheral Nerves Form.

c. Ask the patient about symptoms of leprosy reactions and evaluate the severity for each of them. Enter data on the Reaction Follow-up Form.

d. Record the C - Reactive Protein results.

$\square$ f. Enter bacilloscopy results.

g. Classify the disability grade according to the guidelines of the Brazilian Ministry of Health and the WHO

2. Register other medications in use by the patient in the Concurrent Medications Form.

3. The principal researcher should review all the data recorded on the Visit Forms during the study and sign them at the bottom of the page. 


\section{BLOCK III \\ Evaluation forms used at treatment completion}




\section{CLINICAL DERMATOLOGICAL EVALUATION - End of treatment}

\begin{tabular}{|c|c|c|c|c|c|c|c|}
\hline \multirow{5}{*}{ Skin Lesions } & & 1 Remission & 2 Improvement & \multicolumn{2}{|c|}{3 Unchanged } & \multicolumn{2}{|c|}{4 Worsening } \\
\hline & 1. Colour & & & & & & \\
\hline & 2. Sensibility & & & & & & \\
\hline & 3. Infiltration & & & & & & \\
\hline & 4. Other & & & & & & \\
\hline \multirow{24}{*}{$\begin{array}{l}\text { Symptoms and signs } \\
\text { of side effects from MDT }\end{array}$} & Sign/symptom & & Absent & mild & modera & & severe \\
\hline & 1. Itching & & & & & & \\
\hline & 2. Dry skin & & & & & & \\
\hline & 3. Skin pigmen & tion & & & & & \\
\hline & 4. Rash & & & & & & \\
\hline & 5. Erythrodermi & & & & & & \\
\hline & 6. Photosensitiv & & & & & & \\
\hline & 7. Abdominal $\mathrm{p}$ & & & & & & \\
\hline & 8. Constipation & & & & & & \\
\hline & 9. Nausea & & & & & & \\
\hline & 10. Vomiting & & & & & & \\
\hline & 11. Diarrhoea & & & & & & \\
\hline & 12. Anorexia & & & & & & \\
\hline & 13. Jaundice & & & & & & \\
\hline & 14. Pallor & & & & & & \\
\hline & 15. Cyanosis & & & & & & \\
\hline & 16. Bleeding & & & & & & \\
\hline & 17. Weight loss & & & & & & \\
\hline & 18. Dyspnoea & & & & & & \\
\hline & 19. Asthenia & & & & & & \\
\hline & 20. Fever & & & & & & \\
\hline & 21. Myalgia & & & & & & \\
\hline & 22. Headache & & & & & & \\
\hline & 23. Depression & & & & & & \\
\hline $\begin{array}{l}\text { Have any signs/symptoms } \\
\text { of leprosy reaction? }\end{array}$ & \multicolumn{7}{|c|}{$\begin{array}{l}1-\text { Yes In this case, fill out the form for reactions in block V, for each new episode* } \\
2-\text { No } \\
3 \text { - Continued symptoms of previous reaction }\end{array}$} \\
\hline
\end{tabular}

Signature and stamp of medical examiner

*In this study, a new episode of leprosy reaction is defined as when the patient develops new signs and symptoms of a reaction after a period of regression of the initial symptoms. It can happen during gradual reduction of the anti-reaction steroid therapy and requires a new intervention including adjustment of the medication dose. 
EXAMINATION OF PERIPHERAL NERVES

\section{End of Treatment}

\begin{tabular}{|c|c|c|c|c|}
\hline \multirow[b]{2}{*}{ NERVES } & \multicolumn{2}{|c|}{$\begin{array}{l}\text { KEY } \\
\text { NERVE EXAMINATION } \\
0 \text { - Normal } \\
\text { 1- Thickened } \\
\text { 2- Nerve abscess }\end{array}$} & \multicolumn{2}{|c|}{$\begin{array}{l}\text { KEY } \\
\text { SCALE OF INDICATED NEURAL PAIN } \\
0 \text { - No pain } \\
1 \text { - Weak pain } \\
2 \text { - Strong pain }\end{array}$} \\
\hline & RIGHT & LEFT & RIGHT & LEFT \\
\hline \multicolumn{5}{|l|}{ Ulnar } \\
\hline \multicolumn{5}{|l|}{ Median } \\
\hline \multicolumn{5}{|l|}{ Radial } \\
\hline \multicolumn{5}{|l|}{ Fibular } \\
\hline \multicolumn{5}{|l|}{ Posterior Tibial } \\
\hline Others & & & & \\
\hline
\end{tabular}

Signature and stamp of medical examiner 


\section{SIMPLIFIED EVALUATION OF NEURAL FUNCTION AND COMPLICATIONS End of Treatment}

\begin{tabular}{|l|c|c|}
\hline \multicolumn{1}{|c|}{ Face } & & \\
\hline \multicolumn{1}{|c|}{ Nose } & R & L \\
\hline Main complaint & & \\
\hline dryness (S/N) & & \\
\hline abrasions (S/N) & & \\
\hline Perforation of the septum (S/N) & R & L \\
\hline & & \\
\hline Main complaint w/o force (mm) & & \\
\hline Closes eyes wo & & \\
\hline Closes eyes w/ force (mm) & & \\
\hline Cornea diminished sensibility (S/N) & & \\
\hline Cornea opacity (S/N) & & \\
\hline Cataract (S/N) & & \\
\hline Visual acuity & & \\
\hline
\end{tabular}

\begin{tabular}{|l|c|c|}
\hline \multicolumn{1}{|c|}{ Upper limbs } & & \\
\hline Main complaint Nerve palpation & & \\
\hline \multicolumn{1}{|c|}{ R } & L \\
\hline Ulnar & & \\
\hline Median & & \\
\hline Radius & & \\
\hline
\end{tabular}

key: $\mathrm{N}=$ normal; $\mathrm{T}=$ thickened; $\mathrm{P}=$ pain; $\mathrm{S}=$ Tinel's sign $(+)$

Opens little finger

Strength evaluation

Abduction of the $5^{\text {th }}$ finger (ulnar nerve)

Elevates thumb

Abduction of the thumb (median nerve)

Elevates wrist

Wrist extension (radial nerve)

\begin{tabular}{|c|c|c|}
\hline & $\mathbf{R}$ & $\mathbf{L}$ \\
\hline$\frac{A}{4}$ & & \\
\hline "ै & & \\
\hline$\stackrel{\rightarrow}{3}$ & & \\
\hline
\end{tabular}

key: $\mathrm{S}=$ strong; $\mathrm{D}=$ diminished; $\mathrm{P}=$ paralysed $\quad$ or $5=$ strong; $4=$ partial resistance; $3=$ complete movement; $2=$ partial movement; $1=$ contraction; $0=$ paralysed

\section{SENSITIVITY EVALUATION AND STATUS INSPECTION}

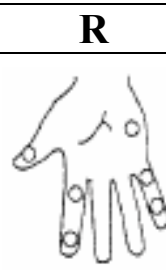

L

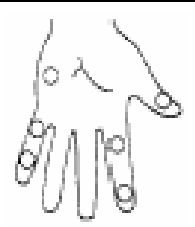

key: lilac pen / monofilament (2g): feels $\sqrt{ }$; does not feel X ; or monofilaments: follow colours

Mobile claw: $M$; rigid claw: $\mathrm{R}$; bone absorption: ${ }^{*}$ wound:

Signature and stamp of medical examiner 


\begin{tabular}{|l|c|c|}
\hline \multicolumn{1}{|c|}{ Lower limbs } & & \\
\hline Main complaint Nerve Palpation & & \\
\hline Fibular & R & L \\
\hline Posterior tibial & & \\
\hline
\end{tabular}

key: $\mathrm{N}=$ normal; $\mathrm{T}=$ thickened; $\mathrm{P}=$ pain; $\mathrm{S}=$ Tinel's sign $(+)$

Elevates hallux Strength evaluation

Hallux extension (fibular nerve)

Elevate foot

Foot dorsiflexion (fibular nerve)

\begin{tabular}{|l|l|l|}
\hline \multicolumn{1}{|c|}{} & $\mathbf{R}$ & $\mathbf{L}$ \\
\hline \multirow{2}{*}{$\mathrm{S}$} & & \\
\hline
\end{tabular}

key: $\mathrm{S}=$ strong; $\mathrm{D}=$ diminished; $\mathrm{P}=$ paralysed or $5=$ strong; $4=$ partial resistance; $3=$ complete movement; $2=$ partial movement; $1=$ contracture; $0=$ paralysed

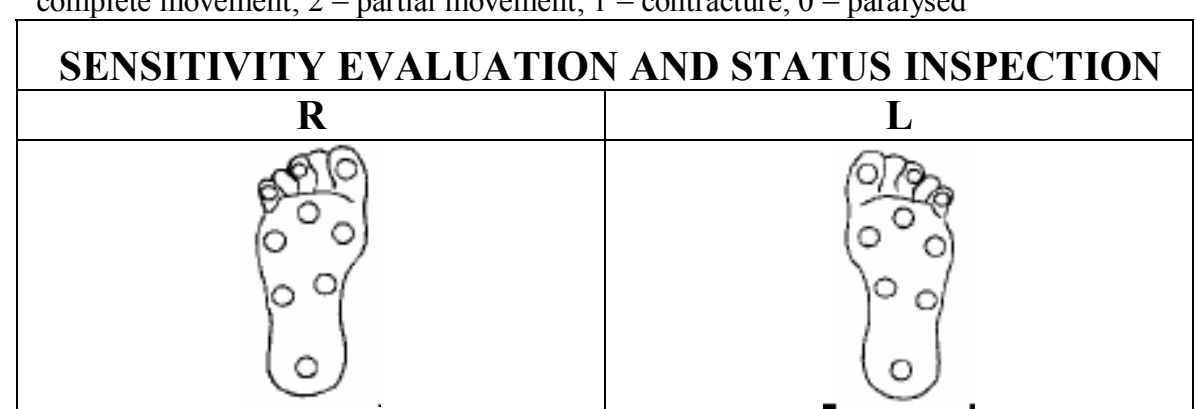

key: lilac pen / monofilament (2g): feels $\sqrt{ }$; does not feel X; or monofilaments: follow colours

Mobile claw: $\mathrm{M}$; rigid claw: $\mathrm{R}$; bone absorption: $\%$ wound: $\square$

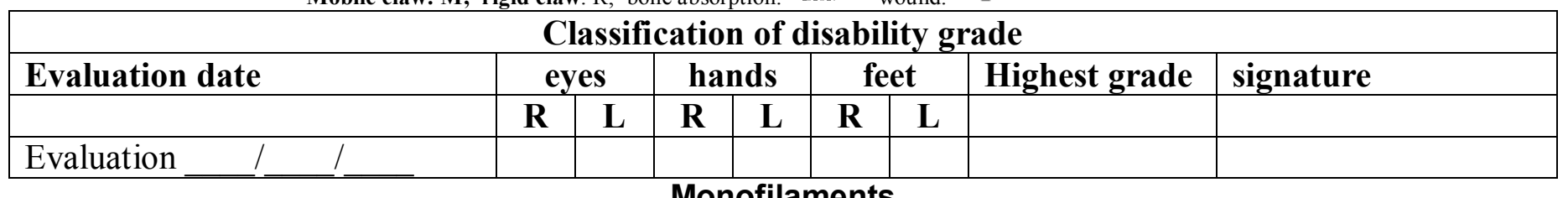

\begin{tabular}{|c|c|c|}
\hline Monofilament & strength in grams & interpretation \\
\hline $1-$ green & 0.05 & Normal sensitivity in hand and foot \\
\hline 2 - blue & 0.20 & $\begin{array}{l}\text { Diminished sensitivity in hand and normal in foot / Difficulty } \\
\text { in distinguishing texture (light touch) }\end{array}$ \\
\hline 3 - Lilac & 2.00 & $\begin{array}{l}\text { Diminished protective sensitivity in hand / Incapable of } \\
\text { distinguishing texture / Difficulty in distinguishing forms and } \\
\text { temperatures }\end{array}$ \\
\hline 4 - dark red & 4.00 & $\begin{array}{l}\text { Loss of protective sensitivity in hand and sometimes in foot } \\
\text { / loss of texture discrimination / Incapable of distinguishing } \\
\text { forms and temperatures }\end{array}$ \\
\hline 5 - orange or red (mark with an $\mathrm{X}$ ) & 10.00 & $\begin{array}{l}\text { Loss of protective sensitivity in foot / loss of texture } \\
\text { discrimination / Incapable of distinguishing forms and } \\
\text { temperatures }\end{array}$ \\
\hline 6 - red circle & 300.00 & $\begin{array}{l}\text { Only has sensation when deep pressure is applied to hand } \\
\text { and foot }\end{array}$ \\
\hline 7 - black & $\begin{array}{l}\text { No response to } 300 \mathrm{~g} \\
\text { monofilament }\end{array}$ & Loss of sensation even to deep pressure in hand and foot \\
\hline
\end{tabular}




\section{REQUEST FOR LABORATORY EXAMS} End of Treatment

\begin{tabular}{|l|l|}
\hline$\square$ & $\begin{array}{l}\text { BACILLOSCOPY (for all MB patients and those PB patients with positive bacilloscopy } \\
\text { at the beginning of the study (Record results in Block V, page 119) }\end{array}$ \\
\hline$\square$ & C-REACTIVE PROTEIN (Register result in Block V, page 121) \\
\hline$\square$ & FULL BLOOD EXAM \\
\hline
\end{tabular}

OBS:

Signature and stamp of medical examiner 


\section{INTRUCTIONS FOR ANNUAL VISITS (YEARS 1 to 6 )}

1. The following tests and procedures should be done at the time of the annual visits:

$\square$ a. Complete the clinical-dermatological examination.

b. Do the neurological examination; nerves must be palpated and evaluated for sensitivity and thickness. Register information on the Examination of Peripheral Nerves Form.

c. Ask the patient about symptoms of leprosy reactions and evaluate the severity for each of them. Enter data on the Reaction Follow-up Form.

$\square$ d. Histopathological exam to evaluate leprosy evolution of the paucibacillary patients.

e. Record the C - Reactive Protein results.

f. Enter bacilloscopy results.

g. Classify the disability grade according to the guidelines of the Brazilian Ministry of Health and the WHO.

2. Register other medications in use by the patient in the Concurrent Medications Form. This form is supplied in a separate section under Concurrent Medication Registry.

3. The principal researcher should review all the data recorded on the Visit Forms during the study and sign them at the bottom of the page. 


\section{SUMMARY OF THE ANNUAL VISITS}

$\square$ 1st year follow-up visit performed on ..................

$\square$ 2nd year follow-up visit performed on.................

$\square$ 3rd year follow-up visit performed on..................

$\square$ 4th year follow-up visit performed on.................

$\square$ 5th year follow-up visit performed on..................

$\square$ 6th year follow-up visit performed on.................. 


\section{BLOCK IV}

\section{Forms for annual follow-up visits}




\section{CLINICAL DERMATOLOGICAL EVALUATION 1st year follow-up}

\begin{tabular}{|c|c|c|c|c|c|c|}
\hline \multirow{5}{*}{ Skin Lesions } & & 1 Remission & 2 Improvement & \multicolumn{2}{|c|}{3 Unchanged } & 4 Worsening \\
\hline & 1. Colour & & & & & \\
\hline & 2. Sensibility & & & & & \\
\hline & 3. Infiltration & & & & & \\
\hline & 4. Other & & & & & \\
\hline \multirow{24}{*}{$\begin{array}{l}\text { Symptoms and signs } \\
\text { of side effects from MDT }\end{array}$} & Sign/symptom & & Absent & mild & modera & severe \\
\hline & 1. Itching & & & & & \\
\hline & 2. Dry skin & & & & & \\
\hline & 3. Skin pigmen & tion & & & & \\
\hline & 4. Rash & & & & & \\
\hline & 5. Erythrodermi & & & & & \\
\hline & 6. Photosensitiv & & & & & \\
\hline & 7. Abdominal p & & & & & \\
\hline & 8. Constipation & & & & & \\
\hline & 9. Nausea & & & & & \\
\hline & 10. Vomiting & & & & & \\
\hline & 11. Diarrhoea & & & & & \\
\hline & 12. Anorexia & & & & & \\
\hline & 13. Jaundice & & & & & \\
\hline & 14. Pallor & & & & & \\
\hline & 15. Cyanosis & & & & & \\
\hline & 16. Bleeding & & & & & \\
\hline & 17. Weight loss & & & & & \\
\hline & 18. Dyspnoea & & & & & \\
\hline & 19. Asthenia & & & & & \\
\hline & 20. Fever & & & & & \\
\hline & 21. Myalgia & & & & & \\
\hline & 22. Headache & & & & & \\
\hline & 23. Depression & & & & & \\
\hline $\begin{array}{l}\text { Any signs/symptoms of } \\
\text { leprosy reaction? }\end{array}$ & \multicolumn{6}{|c|}{$\begin{array}{l}1-\text { Yes In this case, fill out the form for reactions in block V, for each new episode* } \\
2-\text { No } \\
3 \text { - Continued symptoms of previous reaction }\end{array}$} \\
\hline $\begin{array}{l}\text { Any signs/symptoms of } \\
\text { relapse? }\end{array}$ & \multicolumn{6}{|c|}{$\begin{array}{l}1-\text { Yes } \\
2-\text { No }\end{array}$} \\
\hline
\end{tabular}




\begin{tabular}{|c|l|l|l|l|l|l|l|l|l|l|l|l|l|}
\hline PATIENT INITIALS & & & & & PATIENT NUMBER: & & & & & DATE OF VISIT: & & \\
\hline PATIENT INITIALS & & & & & PATIENT NUMBER: & & & & & DATE OF VISIT: & & \\
\hline
\end{tabular}

\section{EXAMINATION OF PERIPHERAL NERVES \\ 1st year follow-up}

\begin{tabular}{|c|c|c|c|c|}
\hline \multirow[b]{2}{*}{ NERVES } & \multicolumn{2}{|c|}{$\begin{array}{l}\text { KEY } \\
\text { NERVE EXAMINATION } \\
0 \text { - Normal } \\
\text { 1- Thickened } \\
\text { 2- Nerve abscess }\end{array}$} & \multicolumn{2}{|c|}{$\begin{array}{l}\text { KEY } \\
\text { SCALE OF INDICATED NEURAL PAIN } \\
0 \text { - No pain } \\
1 \text { - Weak pain } \\
2 \text { - Strong pain }\end{array}$} \\
\hline & RIGHT & LEFT & RIGHT & LEFT \\
\hline Ulnar & & & & \\
\hline Median & & & & \\
\hline Radial & & & & \\
\hline Fibular & & & & \\
\hline Posterior Tibial & & & & \\
\hline Others & & & & \\
\hline
\end{tabular}

\section{REQUEST FOR LABORATORY EXAMS 1st year follow-up}

\begin{tabular}{|l|l|}
\hline$\square$ & BACILLOSCOPY (Register results in Block V, page 119) \\
\hline$\square$ & C-REACTIVE PROTEIN (Register results in Block V, page 122) \\
\hline
\end{tabular}

OBS: 


\section{SIMPLIFIED EVALUATION OF NEURAL FUNCTION AND COMPLICATIONS 1st year follow-up}

\begin{tabular}{|l|c|c|}
\hline \multicolumn{1}{|c|}{ Face } & & \\
\hline \multicolumn{1}{|c|}{ Nose } & R & L \\
\hline Main complaint & & \\
\hline dryness (S/N) & & \\
\hline abrasions (S/N) & & \\
\hline Perforation of the septum (S/N) & R & L \\
\hline \multicolumn{1}{|c|}{ Main complaint } & & \\
\hline Closes eyes w/o force (mm) & & \\
\hline Closes eyes w/ force (mm) & & \\
\hline Cornea diminished sensibility (S/N) & & \\
\hline Cornea opacity (S/N) & & \\
\hline Cataract (S/N) & & \\
\hline Visual acuity & & \\
\hline
\end{tabular}

\begin{tabular}{|l|c|c|}
\hline \multicolumn{1}{|c|}{ Upper limbs } & & \\
\hline Main complaint Nerve palpation & & \\
\hline \multicolumn{1}{|c|}{ Rlnar } & & L \\
\hline Median & & \\
\hline Radius & & \\
\hline
\end{tabular}

key: $\mathrm{N}=$ normal; $\mathrm{T}=$ thickened; $\mathrm{P}=$ pain; $\mathrm{S}=$ Tinel's sign $(+)$

\begin{tabular}{|l|l|l|l|}
\hline \multicolumn{2}{|c|}{ Strength evaluation } & R & L \\
\hline Opens little finger & & \\
Abduction of the $5^{\text {th }}$ finger (ulnar nerve) & -3 & & \\
\hline $\begin{array}{l}\text { Elevates thumb } \\
\text { Abduction of the thumb (median nerve) }\end{array}$ & 2 & & \\
\hline $\begin{array}{l}\text { Elevates wrist } \\
\text { Wrist extension (radial nerve) }\end{array}$ & & & \\
\hline
\end{tabular}

key: $\mathrm{S}=$ strong; $\mathrm{D}=$ diminished; $\mathrm{P}=$ paralysed or $5=$ strong; $4=$ partial resistance; $3=$ complete movement; $2=$ partial movement; $1=$ contraction; $0=$ paralysed

\begin{tabular}{|l|l|}
\hline \multicolumn{2}{|c|}{ SENSITIVITY EVALUATION AND STATUS INSPECTION } \\
\hline $\mathbf{R}$ & L \\
\hline
\end{tabular}

Signature and stamp of medical examiner 


\begin{tabular}{|l|c|c|}
\hline \multicolumn{1}{|c|}{ Lower limbs } & & \\
\hline Main complaint Nerve Palpation & & \\
\hline Fibular & R & L \\
\hline Posterior tibial & & \\
\hline
\end{tabular}

key: $\mathrm{N}=$ normal; $\mathrm{T}=$ thickened; $\mathrm{P}=$ pain; $\mathrm{S}=$ Tinel's sign $(+)$

Elevates hallux Strength evaluation

Hallux extension (fibular nerve)

Elevate foot

Foot dorsiflexion (fibular nerve)

\begin{tabular}{|l|l|l|}
\hline \multicolumn{1}{|c|}{} & $\mathbf{R}$ & $\mathbf{L}$ \\
\hline \multirow{2}{*}{$\mathrm{S}$} & & \\
\hline
\end{tabular}

key: $\mathrm{S}=$ strong; $\mathrm{D}=$ diminished; $\mathrm{P}=$ paralysed or $5=$ strong; $4=$ partial resistance; $3=$ complete movement; $2=$ partial movement; $1=$ contracture; $0=$ paralysed

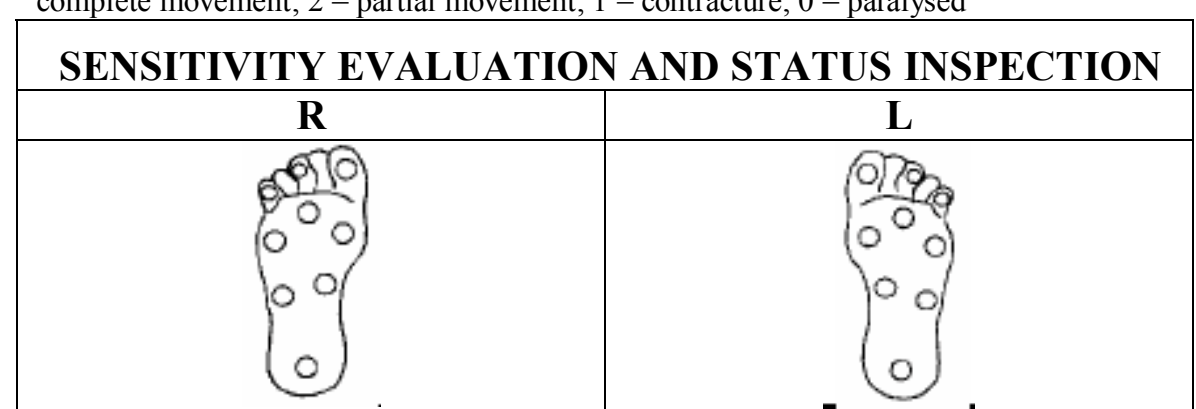

key: lilac pen / monofilament (2g): feels $\sqrt{ }$; does not feel X; or monofilaments: follow colours

Mobile claw: $\mathrm{M}$; rigid claw: $\mathrm{R}$; bone absorption: $\%$ wound: $\square$

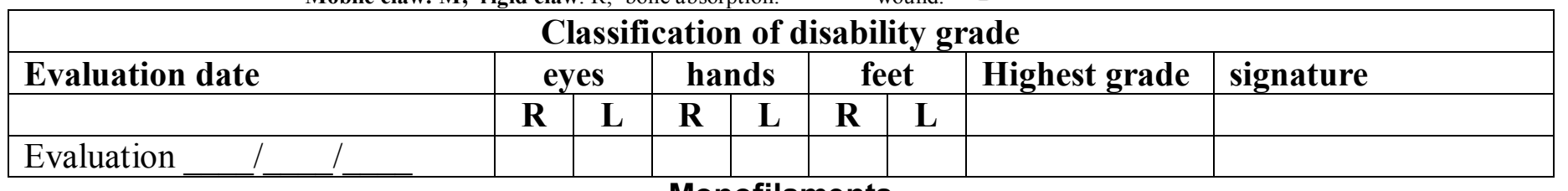

\begin{tabular}{|l|c|l|}
\multicolumn{2}{c|}{} & \multicolumn{2}{c|}{ Monofilaments } \\
\hline Monofilament & strength in grams & interpretation \\
\hline 2- blue & 0.05 & Normal sensitivity in hand and foot \\
\hline 3 - Lilac & 0.20 & $\begin{array}{l}\text { Diminished sensitivity in hand and normal in foot / Difficulty } \\
\text { in distinguishing texture (light touch) }\end{array}$ \\
\hline 4 - dark red & 2.00 & $\begin{array}{l}\text { Diminished protective sensitivity in hand / Incapable of } \\
\text { distinguishing texture / Difficulty in distinguishing forms and } \\
\text { temperatures }\end{array}$ \\
\hline 5 - orange or red (mark with an X) & 4.00 & $\begin{array}{l}\text { Loss of protective sensitivity in hand and sometimes in foot } \\
\text { /loss of texture discrimination / Incapable of distinguishing } \\
\text { forms and temperatures }\end{array}$ \\
\hline 6 - red circle & 10.00 & $\begin{array}{l}\text { Loss of protective sensitivity in foot / loss of texture } \\
\text { discrimination / Incapable of distinguishing forms and } \\
\text { temperatures }\end{array}$ \\
\hline 7 - black & 300.00 & $\begin{array}{l}\text { Only has sensation when deep pressure is applied to hand } \\
\text { and foot }\end{array}$ \\
\hline
\end{tabular}




\section{CLINICAL DERMATOLOGICAL EVALUATION $2^{\text {nd }}$ year follow-up}

\begin{tabular}{|c|c|c|c|c|c|c|}
\hline \multirow{5}{*}{ Skin Lesions } & & 1 Remission & 2 Improvement & \multicolumn{2}{|c|}{3 Unchanged } & 4 Worsening \\
\hline & 1. Colour & & & & & \\
\hline & 2. Sensibility & & & & & \\
\hline & 3. Infiltration & & & & & \\
\hline & 4. Other & & & & & \\
\hline \multirow{24}{*}{$\begin{array}{l}\text { Symptoms and signs } \\
\text { of side effects from MDT }\end{array}$} & Sign/symptom & & Absent & mild & moder & severe \\
\hline & 1. Itching & & & & & \\
\hline & 2. Dry skin & & & & & \\
\hline & 3. Skin pigmen & tion & & & & \\
\hline & 4. Rash & & & & & \\
\hline & 5. Erythrodermi & & & & & \\
\hline & 6. Photosensitiv & & & & & \\
\hline & 7. Abdominal pa & & & & & \\
\hline & 8. Constipation & & & & & \\
\hline & 9. Nausea & & & & & \\
\hline & 10. Vomiting & & & & & \\
\hline & 11. Diarrhoea & & & & & \\
\hline & 12. Anorexia & & & & & \\
\hline & 13. Jaundice & & & & & \\
\hline & 14. Pallor & & & & & \\
\hline & 15. Cyanosis & & & & & \\
\hline & 16. Bleeding & & & & & \\
\hline & 17. Weight loss & & & & & \\
\hline & 18. Dyspnoea & & & & & \\
\hline & 19. Asthenia & & & & & \\
\hline & 20. Fever & & & & & \\
\hline & 21. Myalgia & & & & & \\
\hline & 22. Headache & & & & & \\
\hline & 23. Depression & & & & & \\
\hline $\begin{array}{l}\text { Any signs/symptoms of } \\
\text { leprosy reaction? }\end{array}$ & \multicolumn{6}{|c|}{$\begin{array}{l}1-\text { Yes In this case, fill out the form for reactions in block } \mathrm{V} \text {, for each new episode* } \\
2-\text { No } \\
3 \text { - Continued symptoms of previous reaction }\end{array}$} \\
\hline $\begin{array}{l}\text { Any signs/symptoms of } \\
\text { relapse? }\end{array}$ & \multicolumn{6}{|c|}{$\begin{array}{l}1-\text { Yes } \text { In this case, fill out the relapse form in block V, page } 137 * \\
2-\text { No }\end{array}$} \\
\hline
\end{tabular}




\begin{tabular}{|c|l|l|l|l|l|l|l|l|l|l|l|l|l|}
\hline PATIENT INITIALS & & & & & PATIENT NUMBER: & & & & & DATE OF VISIT: & & \\
\hline PATIENT INITIALS & & & & & PATIENT NUMBER: & & & & & DATE OF VISIT: & & \\
\hline
\end{tabular}

\section{EXAMINATION OF PERIPHERAL NERVES $2^{\text {nd }}$ year follow-up}

\begin{tabular}{|c|c|c|c|c|}
\hline \multirow[b]{2}{*}{ NERVES } & \multicolumn{2}{|c|}{$\begin{array}{l}\text { KEY } \\
\text { NERVE EXAMINATION } \\
0 \text { - Normal } \\
\text { 1- Thickened } \\
\text { 2- Nerve abscess }\end{array}$} & \multicolumn{2}{|c|}{$\begin{array}{l}\text { KEY } \\
\text { SCALE OF INDICATED NEURAL PAIN } \\
0 \text { - No pain } \\
1 \text { - Weak pain } \\
2 \text { - Strong pain }\end{array}$} \\
\hline & RIGHT & LEFT & RIGHT & LEFT \\
\hline Ulnar & & & & \\
\hline Median & & & & \\
\hline Radial & & & & \\
\hline Fibular & & & & \\
\hline Posterior Tibial & & & & \\
\hline Others & & & & \\
\hline
\end{tabular}

\section{REQUEST FOR LABORATORY EXAMS $2^{\text {nd }}$ year follow-up}

\begin{tabular}{|l|l|}
\hline$\square$ & BACILLOSCOPY (Register results in Block V, page 119) \\
\hline$\square$ & C-REACTIVE PROTEIN (Register results in Block V, page 122) \\
\hline
\end{tabular}

OBS: 


\section{SIMPLIFIED EVALUATION OF NEURAL FUNCTION AND COMPLICATIONS $2^{\text {nd }}$ year follow-up}

\begin{tabular}{|l|c|c|}
\hline \multicolumn{1}{|c|}{ Face } & & \\
\hline \multicolumn{1}{|c|}{ Nose } & R & L \\
\hline Main complaint & & \\
\hline dryness (S/N) & & \\
\hline abrasions (S/N) & & \\
\hline Perforation of the septum (S/N) & R & L \\
\hline \multicolumn{1}{|c|}{ Main complaint } & & \\
\hline Closes eyes w/o force (mm) & & \\
\hline Closes eyes w/ force (mm) & & \\
\hline Cornea diminished sensibility (S/N) & & \\
\hline Cornea opacity (S/N) & & \\
\hline Cataract (S/N) & & \\
\hline Visual acuity & & \\
\hline
\end{tabular}

\begin{tabular}{|l|c|c|}
\hline \multicolumn{1}{|c|}{ Upper limbs } & & \\
\hline Main complaint Nerve palpation & & \\
\hline \multicolumn{1}{|c|}{ R } & L \\
\hline Ulnar & & \\
\hline Median & & \\
\hline Radius & & \\
\hline
\end{tabular}

key: $\mathrm{N}=$ normal; $\mathrm{T}=$ thickened; $\mathrm{P}=$ pain; $\mathrm{S}=$ Tinel's sign $(+)$

\begin{tabular}{|l|l|l|l|}
\hline \multicolumn{2}{|c|}{ Strength evaluation } & R & L \\
\hline Opens little finger & & \\
Abduction of the $5^{\text {th }}$ finger (ulnar nerve) & -3 & & \\
\hline $\begin{array}{l}\text { Elevates thumb } \\
\text { Abduction of the thumb (median nerve) }\end{array}$ & 2 & & \\
\hline $\begin{array}{l}\text { Elevates wrist } \\
\text { Wrist extension (radial nerve) }\end{array}$ & & & \\
\hline
\end{tabular}

key: $\mathrm{S}=$ strong; $\mathrm{D}=$ diminished; $\mathrm{P}=$ paralysed or $5=$ strong; $4=$ partial resistance; $3=$ complete movement; 2 = partial movement; $1=$ contraction; $0=$ paralysed

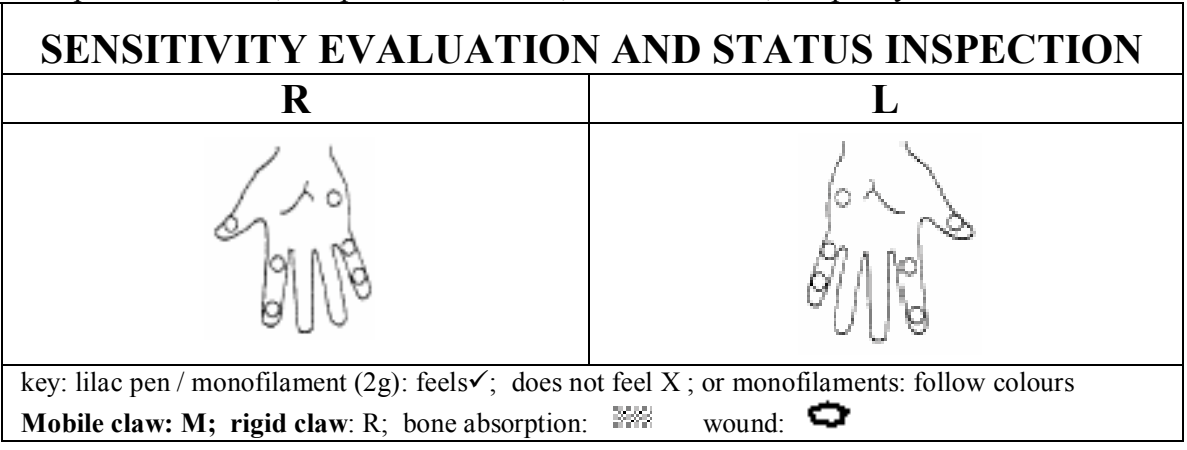

Signature and stamp of medical examiner 


\section{Classification of disability grade}

\begin{tabular}{|l|c|c|}
\hline \multicolumn{1}{|c|}{ Lower limbs } & & \\
\hline Main complaint Nerve Palpation & & \\
\hline Fibular & R & L \\
\hline Posterior tibial & & \\
\hline
\end{tabular}

key: $\mathrm{N}=$ normal; $\mathrm{T}=$ thickened; $\mathrm{P}=$ pain; $\mathrm{S}=$ Tinel's sign $(+)$

Elevates hallux Strength evaluation

Hallux extension (fibular nerve)

Elevate foot

Foot dorsiflexion (fibular nerve)

\begin{tabular}{|l|l|l|}
\hline \multicolumn{1}{|c|}{} & $\mathbf{R}$ & $\mathbf{L}$ \\
\hline \multirow{2}{*}{$\mathrm{S}$} & & \\
\hline
\end{tabular}

key: $\mathrm{S}=$ strong; $\mathrm{D}=$ diminished; $\mathrm{P}=$ paralysed or $5=$ strong; $4=$ partial resistance; $3=$ complete movement; $2=$ partial movement; $1=$ contracture; $0=$ paralysed

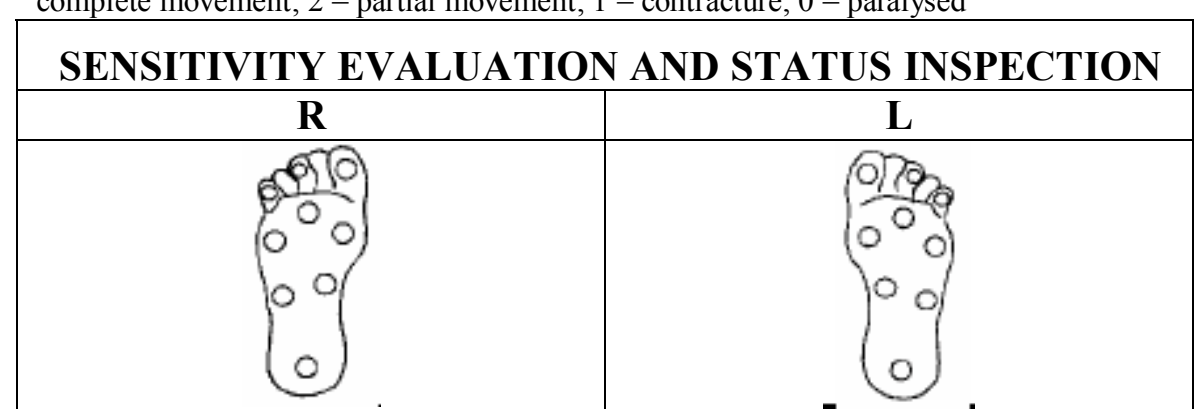

key: lilac pen / monofilament (2g): feels $\checkmark$; does not feel X; or monofilaments: follow colours

Mobile claw: $\mathrm{M}$; rigid claw: $\mathrm{R}$; bone absorption: $\%$ wound: $\square$

\begin{tabular}{|l|c|c|c|c|c|c|l|l|}
\hline Evaluation date & \multicolumn{2}{|c|}{ eyes } & \multicolumn{2}{|c|}{ hands } & \multicolumn{2}{|c|}{ feet } & Highest grade & signature \\
\hline & R & L & R & L & R & L & & \\
\hline Evaluation & & & & & & & & \\
\hline
\end{tabular}

\section{Monofilaments}

\begin{tabular}{|l|c|l|}
\hline Monofilament & strength in grams & interpretation \\
\hline 1 - green & 0.05 & Normal sensitivity in hand and foot \\
\hline 3 - blue & 0.20 & $\begin{array}{l}\text { Diminished sensitivity in hand and normal in foot / Difficulty } \\
\text { in distinguishing texture (light touch) }\end{array}$ \\
\hline 4 - dark red & 2.00 & $\begin{array}{l}\text { Diminished protective sensitivity in hand / Incapable of } \\
\text { distinguishing texture / Difficulty in distinguishing forms and } \\
\text { temperatures }\end{array}$ \\
\hline 5 - orange or red (mark with an X) & 4.00 & $\begin{array}{l}\text { Loss of protective sensitivity in hand and sometimes in foot } \\
\text { / loss of texture discrimination / Incapable of distinguishing } \\
\text { forms and temperatures }\end{array}$ \\
\hline 6 - red circle & 10.00 & $\begin{array}{l}\text { Loss of protective sensitivity in foot / loss of texture } \\
\text { discrimination / Incapable of distinguishing forms and } \\
\text { temperatures }\end{array}$ \\
\hline 7 - black & 300.00 & $\begin{array}{l}\text { Only has sensation when deep pressure is applied to hand } \\
\text { and foot }\end{array}$ \\
\hline
\end{tabular}

Signature and stamp of medical examiner 


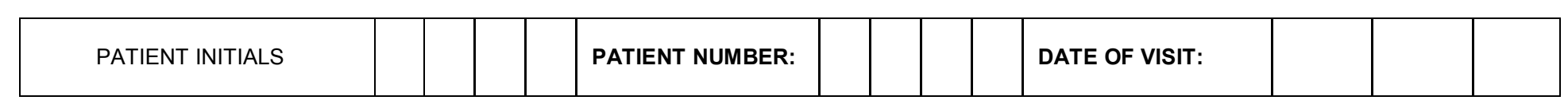

\section{CLINICAL DERMATOLOGICAL EVALUATION $3^{\text {rd }}$ year follow-up}

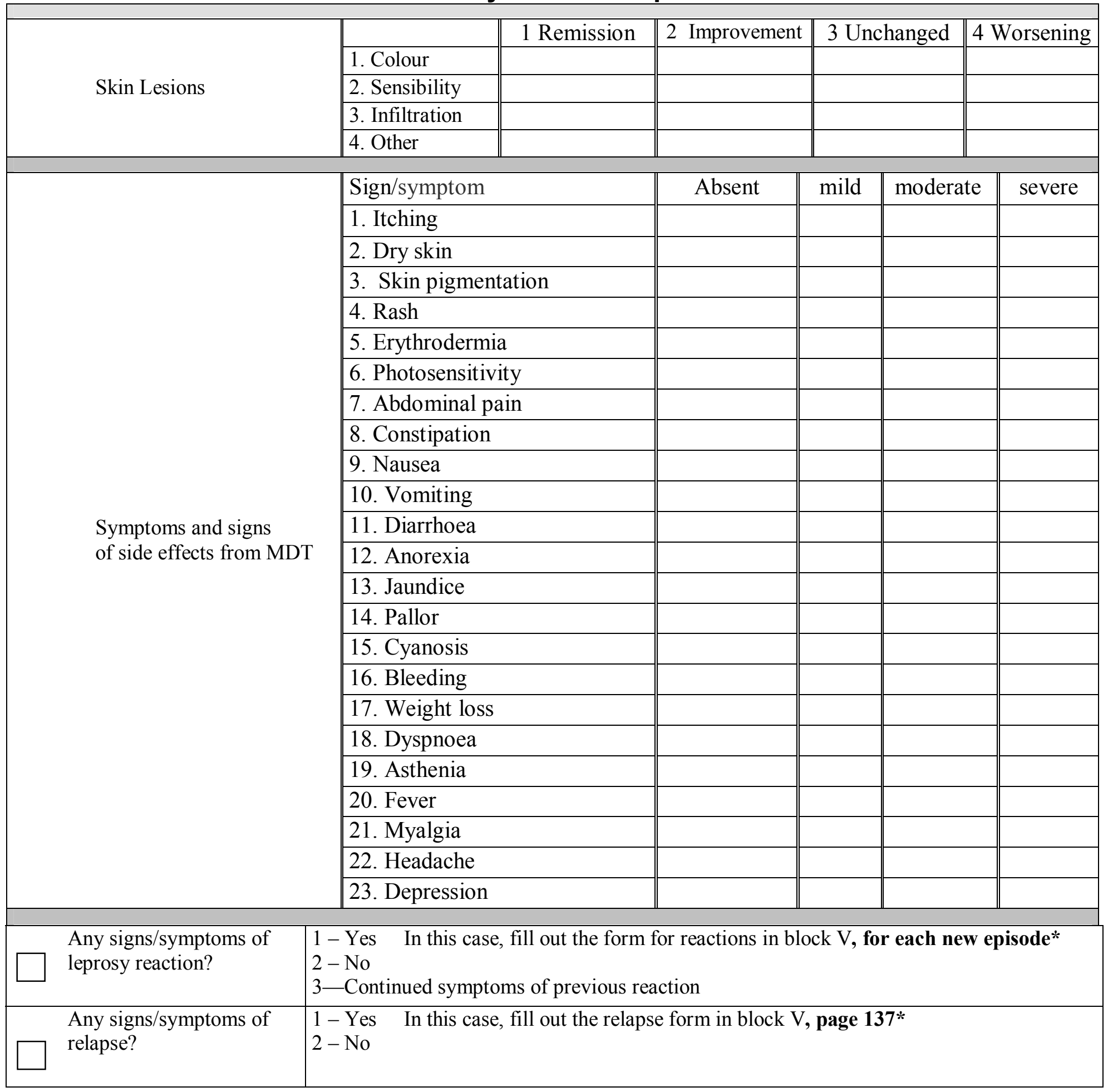




\section{EXAMINATION OF PERIPHERAL NERVES}

$3^{\text {rd }}$ year follow-up

\begin{tabular}{|c|c|c|c|c|}
\hline \multirow[b]{2}{*}{ NERVES } & \multicolumn{2}{|c|}{$\begin{array}{l}\text { KEY } \\
\text { NERVE EXAMINATION } \\
0 \text { - Normal } \\
\text { 1- Thickened } \\
\text { 2- Nerve abscess }\end{array}$} & \multicolumn{2}{|c|}{$\begin{array}{l}\text { KEY } \\
\text { SCALE OF INDICATED NEURAL PAIN } \\
0 \text { - No pain } \\
1 \text { - Weak pain } \\
2 \text { - Strong pain }\end{array}$} \\
\hline & RIGHT & LEFT & RIGHT & LEFT \\
\hline Ulnar & & & & \\
\hline Median & & & & \\
\hline Radial & & & & \\
\hline Fibular & & & & \\
\hline Posterior Tibial & & & & \\
\hline Others & & & & \\
\hline
\end{tabular}

\section{REQUEST FOR LABORATORY EXAMS $3^{\text {rd }}$ year follow-up}

\begin{tabular}{|l|l|}
\hline$\square$ & BACILLOSCOPY (Register results in Block V, page 119) \\
\hline$\square$ & C-REACTIVE PROTEIN (Register results in Block V, page 122) \\
\hline
\end{tabular}
OBS: 


\section{SIMPLIFIED EVALUATION OF NEURAL FUNCTION AND COMPLICATIONS 3rd year follow-up}

\begin{tabular}{|l|c|c|}
\hline \multicolumn{1}{|c|}{ Face } & & \\
\hline \multicolumn{1}{|c|}{ Nose } & R & L \\
\hline Main complaint & & \\
\hline dryness (S/N) & & \\
\hline abrasions (S/N) & & \\
\hline Perforation of the septum (S/N) & R & L \\
\hline & & \\
\hline Main complaint w/o force (mm) & & \\
\hline Closes eyes (m) & & \\
\hline Closes eyes w/ force (mm) & & \\
\hline Cornea diminished sensibility (S/N) & & \\
\hline Cornea opacity (S/N) & & \\
\hline Cataract (S/N) & & \\
\hline Visual acuity & & \\
\hline
\end{tabular}

\begin{tabular}{|l|c|c|}
\hline \multicolumn{1}{|c|}{ Upper limbs } & & \\
\hline Main complaint Nerve palpation & & \\
\hline \multicolumn{1}{|c|}{ Rlnar } & & L \\
\hline Median & & \\
\hline Radius & & \\
\hline
\end{tabular}

key: $\mathrm{N}=$ normal; $\mathrm{T}=$ thickened; $\mathrm{P}=$ pain; $\mathrm{S}=$ Tinel's sign $(+)$

Opens little finger

Abduction of the $5^{\text {th }}$ finger (ulnar nerve)

Elevates thumb

Abduction of the thumb (median nerve)

Elevates wrist

Wrist extension (radial nerve)

\begin{tabular}{|l|l|}
\hline $\mathbf{R}$ & $\mathbf{L}$ \\
\hline & \\
\hline & \\
\hline & \\
\hline
\end{tabular}

key: $\mathrm{S}=$ strong; $\mathrm{D}=$ diminished; $\mathrm{P}=$ paralysed or $5=$ strong; $4=$ partial resistance; $3=$ complete movement; $2=$ partial movement; $1=$ contraction; $0=$ paralysed

\section{SENSITIVITY EVALUATION AND STATUS INSPECTION}

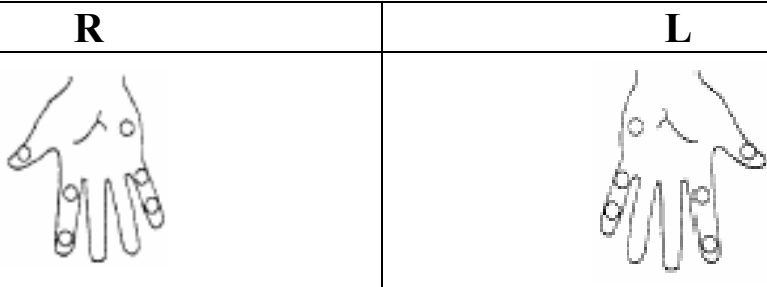

key: lilac pen / monofilament (2g): feels $\sqrt{ }$; does not feel X; or monofilaments: follow colours

Mobile claw: $\mathrm{M}$; rigid claw: $\mathrm{R}$; bone absorption: $\quad * \cdots$

wound:

\section{Signature and stamp of medical examiner}




\begin{tabular}{|l|c|c|}
\hline \multicolumn{1}{|c|}{ Lower limbs } & & \\
\hline Main complaint Nerve Palpation & & \\
\hline Fibular & R & L \\
\hline Posterior tibial & & \\
\hline
\end{tabular}

key: $\mathrm{N}=$ normal; $\mathrm{T}=$ thickened; $\mathrm{P}=$ pain; $\mathrm{S}=$ Tinel's sign $(+)$

Elevates hallux Strength evaluation

Hallux extension (fibular nerve)

Elevate foot

Foot dorsiflexion (fibular nerve)

\begin{tabular}{|l|l|l|}
\hline \multicolumn{1}{|c|}{} & $\mathbf{R}$ & $\mathbf{L}$ \\
\hline \multirow{2}{*}{$\mathrm{S}$} & & \\
\hline
\end{tabular}

key: $\mathrm{S}=$ strong; $\mathrm{D}=$ diminished; $\mathrm{P}=$ paralysed or $5=$ strong; $4=$ partial resistance; $3=$ complete movement; $2=$ partial movement; $1=$ contracture; $0=$ paralysed

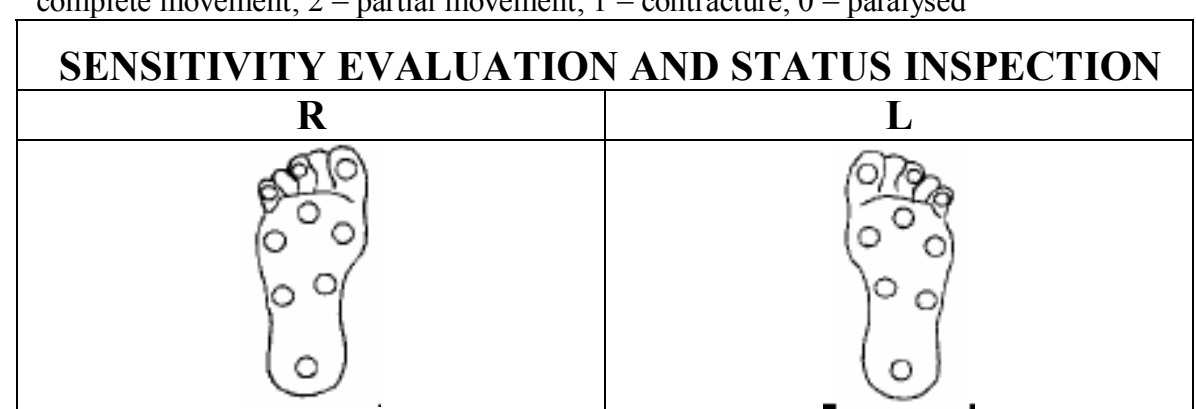

key: lilac pen / monofilament (2g): feels $\sqrt{ }$; does not feel X; or monofilaments: follow colours

Mobile claw: $\mathrm{M}$; rigid claw: $\mathrm{R}$; bone absorption: $\%$ wound: $\square$

\begin{tabular}{|c|c|c|c|c|c|c|c|c|}
\hline \multicolumn{9}{|c|}{ Classification of disability grade } \\
\hline Evaluation date & \multicolumn{2}{|c|}{ eyes } & \multicolumn{2}{|c|}{ hands } & \multicolumn{2}{|c|}{ feet } & \multirow[t]{2}{*}{ Highest grade } & \multirow[t]{2}{*}{ signature } \\
\hline & $\mathbf{R}$ & $\mathbf{L}$ & $\mathbf{R}$ & $\mathbf{L}$ & $\mathbf{R}$ & $\mathbf{L}$ & & \\
\hline Evaluation & & & & & & & & \\
\hline \multicolumn{9}{|c|}{ Monofilaments } \\
\hline Monofilament & \multicolumn{4}{|c|}{ strength in grams } & \multicolumn{4}{|c|}{ interpretation } \\
\hline $1-$ green & \multicolumn{4}{|c|}{0.05} & \multicolumn{4}{|c|}{ Normal sensitivity in hand and foot } \\
\hline 2 - blue & \multicolumn{4}{|c|}{0.20} & \multicolumn{4}{|c|}{$\begin{array}{l}\text { Diminished sensitivity in hand and normal in foot / Difficulty } \\
\text { in distinguishing texture (light touch) }\end{array}$} \\
\hline 3 - Lilac & \multicolumn{4}{|c|}{2.00} & \multicolumn{4}{|c|}{$\begin{array}{l}\text { Diminished protective sensitivity in hand / Incapable of } \\
\text { distinguishing texture / Difficulty in distinguishing forms and } \\
\text { temperatures }\end{array}$} \\
\hline 4 - dark red & \multicolumn{4}{|c|}{4.00} & \multicolumn{4}{|c|}{$\begin{array}{l}\text { Loss of protective sensitivity in hand and sometimes in foot } \\
\text { / loss of texture discrimination / Incapable of distinguishing } \\
\text { forms and temperatures }\end{array}$} \\
\hline 5 - orange or red (mark with an $X$ ) & \multicolumn{4}{|c|}{10.00} & \multicolumn{4}{|c|}{$\begin{array}{l}\text { Loss of protective sensitivity in foot / loss of texture } \\
\text { discrimination / Incapable of distinguishing forms and } \\
\text { temperatures }\end{array}$} \\
\hline 6 - red circle & \multicolumn{4}{|c|}{300.00} & \multicolumn{4}{|c|}{$\begin{array}{l}\text { Only has sensation when deep pressure is applied to hand } \\
\text { and foot }\end{array}$} \\
\hline 7 - black & \multicolumn{4}{|c|}{$\begin{array}{c}\text { No response to } 300 \mathrm{~g} \\
\text { monofilament }\end{array}$} & \multicolumn{4}{|c|}{ Loss of sensation even to deep pressure in hand and foot } \\
\hline
\end{tabular}

Signature and stamp of medical examiner 


\section{CLINICAL DERMATOLOGICAL EVALUATION - 4th year follow-up}

\begin{tabular}{|c|c|c|c|c|c|c|c|}
\hline \multirow{5}{*}{ Skin Lesions } & & 1 Remission & 2 Improvement & \multicolumn{2}{|c|}{3 Unchanged } & \multicolumn{2}{|c|}{4 Worsening } \\
\hline & \multicolumn{7}{|l|}{ 1. Colour } \\
\hline & \multicolumn{7}{|l|}{ 2. Sensibility } \\
\hline & \multicolumn{7}{|l|}{ 3. Infiltration } \\
\hline & \multicolumn{7}{|l|}{ 4. Other } \\
\hline \multirow{24}{*}{$\begin{array}{l}\text { Symptoms and signs } \\
\text { of side effects from MDT }\end{array}$} & \multicolumn{2}{|l|}{ Sign/symptom } & Absent & mild & modera & & severe \\
\hline & \multicolumn{2}{|l|}{ 1. Itching } & & & & & \\
\hline & \multicolumn{2}{|c|}{ 2. Dry skin } & & & & & \\
\hline & \multicolumn{2}{|c|}{ 3. Skin pigmentation } & & & & & \\
\hline & \multicolumn{2}{|c|}{ 4. Rash } & & & & & \\
\hline & \multicolumn{2}{|c|}{ 5. Erythrodermia } & & & & & \\
\hline & \multicolumn{2}{|c|}{ 6. Photosensitivity } & & & & & \\
\hline & \multicolumn{2}{|c|}{ 7. Abdominal pain } & & & & & \\
\hline & \multicolumn{2}{|c|}{ 8. Constipation } & & & & & \\
\hline & \multicolumn{2}{|l|}{ 9. Nausea } & & & & & \\
\hline & \multicolumn{2}{|l|}{ 10. Vomiting } & & & & & \\
\hline & \multicolumn{2}{|l|}{ 11. Diarrhoea } & & & & & \\
\hline & \multicolumn{2}{|l|}{ 12. Anorexia } & & & & & \\
\hline & \multicolumn{2}{|l|}{ 13. Jaundice } & & & & & \\
\hline & \multicolumn{2}{|l|}{ 14. Pallor } & & & & & \\
\hline & \multicolumn{2}{|l|}{ 15. Cyanosis } & & & & & \\
\hline & \multicolumn{2}{|l|}{ 16. Bleeding } & & & & & \\
\hline & \multicolumn{2}{|l|}{ 17. Weight loss } & & & & & \\
\hline & \multicolumn{2}{|l|}{ 18. Dyspnoea } & & & & & \\
\hline & \multicolumn{2}{|l|}{ 19. Asthenia } & & & & & \\
\hline & \multicolumn{2}{|l|}{ 20. Fever } & & & & & \\
\hline & \multicolumn{2}{|l|}{ 21. Myalgia } & & & & & \\
\hline & 22. Headache & & & & & & \\
\hline & 23. Depression & & & & & & \\
\hline $\begin{array}{l}\text { Any signs/symptoms of } \\
\text { leprosy reaction? }\end{array}$ & $\begin{array}{l}1-\text { Yes In this case } \\
2-\text { No } \\
3 \text { - Continued sympto }\end{array}$ & $\begin{array}{l}\text { fill out the form } \\
\text { is of previous } r\end{array}$ & $\begin{array}{l}\text { or reactions in bl } \\
\text { ction }\end{array}$ & $\mathrm{ck} \mathrm{V,f}$ & each ne & $\mathbf{w}$ ef & sode* \\
\hline $\begin{array}{l}\text { Any signs/symptoms of } \\
\text { relapse? }\end{array}$ & $\begin{array}{l}1-\text { Yes } \\
2-\text { No this case }\end{array}$ & fill out the relap & form in block V & page 1 & & & \\
\hline
\end{tabular}




\section{EXAMINATION OF PERIPHERAL NERVES} 4th year follow-up

\begin{tabular}{|c|c|c|c|c|}
\hline \multirow[b]{2}{*}{ NERVES } & \multicolumn{2}{|c|}{$\begin{array}{l}\text { KEY } \\
\text { NERVE EXAMINATION } \\
0 \text { - Normal } \\
\text { 1- Thickened } \\
\text { 2- Nerve abscess }\end{array}$} & \multicolumn{2}{|c|}{$\begin{array}{l}\text { KEY } \\
\text { SCALE OF INDICATED NEURAL PAIN } \\
0 \text { - No pain } \\
1 \text { - Weak pain } \\
2 \text { - Strong pain }\end{array}$} \\
\hline & RIGHT & LEFT & RIGHT & LEFT \\
\hline Ulnar & & & & \\
\hline Median & & & & \\
\hline Radial & & & & \\
\hline Fibular & & & & \\
\hline Posterior Tibial & & & & \\
\hline Others & & & & \\
\hline
\end{tabular}

\section{REQUEST FOR LABORATORY TESTS 4th year follow-up}

\begin{tabular}{|l|l|}
\hline$\square$ & BACILLOSCOPY (Register result in Block V, page 119) \\
\hline$\square$ & C-REACTIVE PROTEIN (Register result in Block V, page 122) \\
\hline
\end{tabular}

OBS: 


\section{SIMPLIFIED EVALUATION OF NEURAL FUNCTIONS AND COMPLICATIONS 4th year follow-up}

\begin{tabular}{|l|c|c|}
\hline \multicolumn{1}{|c|}{ Face } & & \\
\hline \multicolumn{1}{|c|}{ Nose } & R & L \\
\hline Main complaint $\quad$ Eyes & & \\
\hline dryness (S/N) & & \\
\hline abrasions (S/N) & & \\
\hline Perforation of the septum (S/N) & & L \\
\hline \multicolumn{1}{|c|}{ Main complaint w/o force (mm) } & & \\
\hline Closes eyes w/o $(\mathrm{mm})$ & & \\
\hline Closes eyes w/ force & & \\
\hline Cornea diminished sensibility (S/N) & & \\
\hline Cornea opacity (S/N) & & \\
\hline Cataract (S/N) & & \\
\hline Visual acuity & & \\
\hline
\end{tabular}

\begin{tabular}{|l|c|c|}
\hline \multicolumn{1}{|c|}{ Upper limbs } & & \\
\hline Main complaint Nerve palpation & & \\
\hline \multicolumn{1}{|c|}{ R } & R & L \\
\hline Ulnar & & \\
\hline Median & & \\
\hline Radius & & \\
\hline
\end{tabular}

key: $\mathrm{N}=$ normal; $\mathrm{T}=$ thickened; $\mathrm{P}=$ pain; $\mathrm{S}=$ Tinel's sign $(+)$

\begin{tabular}{|l|l|l|l|}
\hline \multicolumn{2}{|c|}{ Strength evaluation } & R & L \\
\hline Opens little finger & & \\
Abduction of the $5^{\text {th }}$ finger (ulnar nerve) & & & \\
\hline $\begin{array}{l}\text { Elevates thumb } \\
\text { Abduction of the thumb (median nerve) }\end{array}$ & Elevates wrist & & \\
\hline $\begin{array}{l}\text { Wrist extension (radial nerve) } \\
\text { Ela }\end{array}$ & & \\
\hline
\end{tabular}

key: $\mathrm{S}=$ strong; $\mathrm{D}=$ diminished; $\mathrm{P}=$ paralysed or $5=$ strong; $4=$ partial resistance; $3=$ complete movement; $2=$ partial movement; $1=$ contraction; $0=$ paralysed

\section{SENSITIVITY EVALUATION AND STATUS INSPECTION}

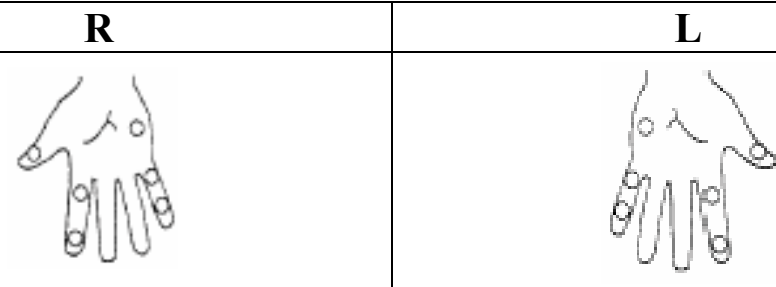

key: lilac pen / monofilament (2g): feels $\sqrt{ }$; does not feel X ; or monofilaments: follow colours

Mobile claw: $\mathrm{M}$; rigid claw: $\mathrm{R}$; bone absorption: $\mathbb{N}^{*}$ wound:

\section{Signature and stamp of medical examiner}




\begin{tabular}{|c|l|l|l|l|l|l|l|l|l|l|l|l|}
\hline PATIENT INITIALS & & & & & PATIENT NUMBER: & & & & DATE OF VISIT: & \\
\hline PATIENT INITIALS & & & & & PATIENT NUMBER: & & & & & DATE OF VISIT: \\
\hline
\end{tabular}

\begin{tabular}{|l|l|l|}
\hline \multicolumn{1}{|c|}{ Lower limbs } & & \\
\hline Main complaint Nerve Palpation & & \\
\hline Fibular & R & L \\
\hline Posterior tibial & & \\
\hline
\end{tabular}

key: $\mathrm{N}=$ normal; $\mathrm{T}=$ thickened; $\mathrm{P}=$ pain; $\mathrm{S}=$ Tinel's sign $(+)$

\begin{tabular}{|l|l|l|l|}
\hline \multicolumn{2}{|c|}{ Strength evaluation } & R & L \\
\hline $\begin{array}{l}\text { Elevates hallux } \\
\text { Hallux extension (fibular nerve) }\end{array}$ & & \\
\hline $\begin{array}{l}\text { Elevate foot } \\
\text { Foot dorsiflexion (fibular nerve) }\end{array}$ & & \\
\hline
\end{tabular}

key: $\mathrm{S}=$ strong; $\mathrm{D}=$ diminished; $\mathrm{P}=$ paralysed or $5=$ strong; $4=$ partial resistance; $3=$ complete movement; 2 = partial movement; $1=$ contracture; $0=$ paralysed

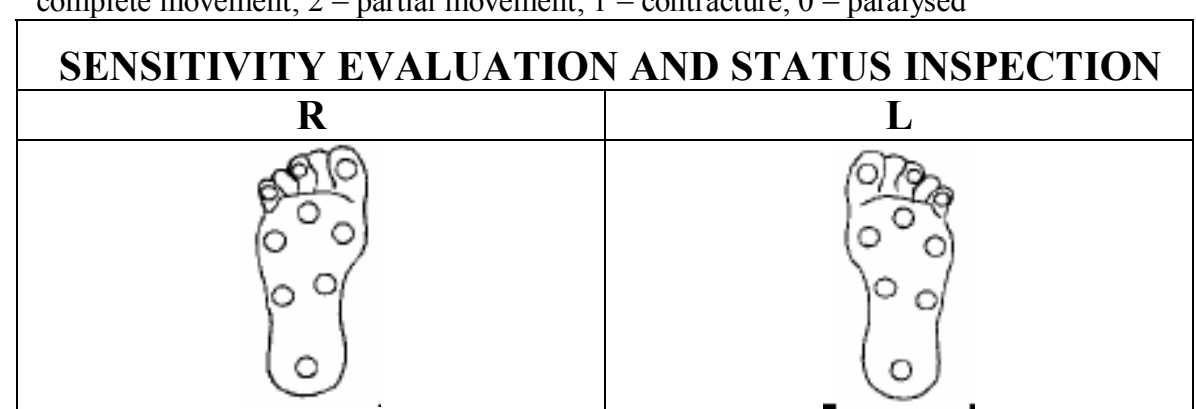

key: lilac pen / monofilament (2g): feels $\sqrt{ }$; does not feel X; or monofilaments: follow colours

Mobile claw: $\mathrm{M}$; rigid claw: $\mathrm{R}$; bone absorption: $\%$ wound: $\square$

\begin{tabular}{|c|c|c|c|c|c|c|c|c|}
\hline \multicolumn{9}{|c|}{ Classification of disability grade } \\
\hline Evaluation date & \multicolumn{2}{|c|}{ eyes } & \multicolumn{2}{|c|}{ hands } & \multicolumn{2}{|c|}{ feet } & \multirow[t]{2}{*}{ Highest grade } & \multirow[t]{2}{*}{ signature } \\
\hline & $\mathbf{R}$ & $\mathbf{L}$ & $\mathbf{R}$ & $\mathbf{L}$ & $\mathbf{R}$ & $\mathbf{L}$ & & \\
\hline Evaluation & & & & & & & & \\
\hline \multicolumn{9}{|c|}{ Monofilaments } \\
\hline Monofilament & \multicolumn{4}{|c|}{ strength in grams } & \multicolumn{4}{|c|}{ interpretation } \\
\hline 1 - green & \multicolumn{4}{|c|}{0.05} & \multicolumn{4}{|c|}{ Normal sensitivity in hand and foot } \\
\hline 2 - blue & \multicolumn{4}{|c|}{0.20} & \multicolumn{4}{|c|}{$\begin{array}{l}\text { Diminished sensitivity in hand and normal in foot / Difficulty } \\
\text { in distinguishing texture (light touch) }\end{array}$} \\
\hline 3 - Lilac & \multicolumn{4}{|c|}{2.00} & \multicolumn{4}{|c|}{$\begin{array}{l}\text { Diminished protective sensitivity in hand / Incapable of } \\
\text { distinguishing texture / Difficulty in distinguishing forms and } \\
\text { temperatures }\end{array}$} \\
\hline 4 - dark red & \multicolumn{4}{|c|}{4.00} & \multicolumn{4}{|c|}{$\begin{array}{l}\text { Loss of protective sensitivity in hand and sometimes in foot } \\
\text { / loss of texture discrimination / Incapable of distinguishing } \\
\text { forms and temperatures }\end{array}$} \\
\hline 5 - orange or red (mark with an $\mathrm{X}$ ) & \multicolumn{4}{|c|}{10.00} & \multicolumn{4}{|c|}{$\begin{array}{l}\text { Loss of protective sensitivity in foot / loss of texture } \\
\text { discrimination / Incapable of distinguishing forms and } \\
\text { temperatures }\end{array}$} \\
\hline 6 - red circle & \multicolumn{4}{|c|}{300.00} & \multicolumn{4}{|c|}{$\begin{array}{l}\text { Only has sensation when deep pressure is applied to hand } \\
\text { and foot }\end{array}$} \\
\hline 7 - black & \multicolumn{4}{|c|}{$\begin{array}{c}\text { No response to } 300 \mathrm{~g} \\
\text { monofilament }\end{array}$} & \multicolumn{4}{|c|}{ Loss of sensation even to deep pressure in hand and foot } \\
\hline
\end{tabular}

Signature and stamp of medical examiner 
CLINICAL DERMATOLOGICAL EVALUATION - 5th year follow-up

\begin{tabular}{|c|c|c|c|c|c|c|}
\hline & & 1 Remission & 2 Improvement & $3 \mathrm{Un}$ & anged & 4 Worsening \\
\hline & 1. Colour & & & & & \\
\hline Skin Lesions & 2. Sensibility & & & & & \\
\hline & 3. Infiltration & & & & & \\
\hline & 4. Other & & & & & \\
\hline & Sign/symptom & & Absent & mild & moderate & severe \\
\hline & 1. Itching & & & & & \\
\hline & 2. Dry skin & & & & & \\
\hline & 3. Skin pigmer & ation & & & & \\
\hline & 4. Rash & & & & & \\
\hline & 5. Erythroderm & & & & & \\
\hline & 6. Photosensiti & & & & & \\
\hline & 7. Abdominal $\mathrm{p}$ & & & & & \\
\hline & 8. Constipation & & & & & \\
\hline & 9. Nausea & & & & & \\
\hline & 10. Vomiting & & & & & \\
\hline Symptoms and signs & 11. Diarrhoea & & & & & \\
\hline of side effects from MDT & 12. Anorexia & & & & & \\
\hline & 13. Jaundice & & & & & \\
\hline & 14. Pallor & & & & & \\
\hline & 15. Cyanosis & & & & & \\
\hline & 16. Bleeding & & & & & \\
\hline & 17. Weight loss & & & & & \\
\hline & 18. Dyspnoea & & & & & \\
\hline & 19. Asthenia & & & & & \\
\hline & 20. Fever & & & & & \\
\hline & 21. Myalgia & & & & & \\
\hline & 22. Headache & & & & & \\
\hline & 23. Depression & & & & & \\
\hline $\begin{array}{l}\text { Any signs/symptoms of } \\
\text { leprosy reaction? }\end{array}$ & $\begin{array}{l}1-\text { Yes In this cas } \\
2-\text { No } \\
3-\text { Continued sympt }\end{array}$ & $\begin{array}{l}\text { fill out the form } \\
\text { ns of previous } r\end{array}$ & $\begin{array}{l}\text { or reactions in bla } \\
\text { ction }\end{array}$ & $\mathrm{ck} V, f$ & each new & vepisode* \\
\hline \begin{tabular}{ll}
\multicolumn{1}{l|}{ Any signs/symptoms of } \\
\begin{tabular}{|l} 
relapse?
\end{tabular}
\end{tabular} & $\begin{array}{ll}1-\text { Yes } & \text { In this cas } \\
2-\mathrm{No} & \end{array}$ & fill out the relap & e form in block $\mathrm{V}$ & page 1 & & \\
\hline
\end{tabular}

Signature and stamp of medical examiner 
EXAMINATION OF PERIPHERAL NERVES

5th year follow-up

\begin{tabular}{|c|c|c|c|c|}
\hline \multirow[b]{2}{*}{ NERVES } & \multicolumn{2}{|c|}{$\begin{array}{l}\text { KEY } \\
\text { NERVE EXAMINATION } \\
0 \text { - Normal } \\
\text { 1- Thickened } \\
\text { 2- Nerve abscess }\end{array}$} & \multicolumn{2}{|c|}{$\begin{array}{l}\text { KEY } \\
\text { SCALE OF INDICATED NEURAL PAIN } \\
0 \text { - No pain } \\
1 \text { - Weak pain } \\
2 \text { - Strong pain }\end{array}$} \\
\hline & RIGHT & LEFT & RIGHT & LEFT \\
\hline Ulnar & & & & \\
\hline Median & & & & \\
\hline Radial & & & & \\
\hline Fibular & & & & \\
\hline Posterior Tibial & & & & \\
\hline Others & & & & \\
\hline
\end{tabular}

REQUEST FOR LABORATORY TESTS 5th year follow-up

\begin{tabular}{|l|l|}
\hline$\square$ & BACILLOSCOPY (Register results in Block V, page 119) \\
\hline$\square$ & C-REACTIVE PROTEIN (Register results in Block V, page 122) \\
\hline
\end{tabular}

OBS: 


\section{SIMPLIFIED EVALUATION OF NEURAL FUNCTION AND COMPLICATIONS 5th year follow-up}

\begin{tabular}{|l|c|c|}
\hline \multicolumn{1}{|c|}{ Face } & & \\
\hline \multicolumn{1}{|c|}{ Nose } & R & L \\
\hline Main complaint & & \\
\hline dryness (S/N) & & \\
\hline abrasions (S/N) & & \\
\hline Perforation of the septum (S/N) & R & L \\
\hline \multicolumn{1}{|c|}{ Main complaint } & & \\
\hline Closes eyes w/o force (mm) & & \\
\hline Closes eyes w/ force (mm) & & \\
\hline Cornea diminished sensibility (S/N) & & \\
\hline Cornea opacity (S/N) & & \\
\hline Cataract (S/N) & & \\
\hline Visual acuity & & \\
\hline
\end{tabular}

\begin{tabular}{|l|c|c|}
\hline \multicolumn{1}{|c|}{ Upper limbs } & & \\
\hline Main complaint Nerve palpation & & \\
\hline \multicolumn{1}{|c|}{ R } & L \\
\hline Ulnar & & \\
\hline Median & & \\
\hline Radius & & \\
\hline
\end{tabular}

key: $\mathrm{N}=$ normal; $\mathrm{T}=$ thickened; $\mathrm{P}=$ pain; $\mathrm{S}=$ Tinel's sign $(+)$

Opens little finger

\section{Strength evaluation}

Abduction of the $5^{\text {th }}$ finger (ulnar nerve)

Elevates thumb

Abduction of the thumb (median nerve)

Elevates wrist

Wrist extension (radial nerve)

key: $\mathrm{S}=$ strong; $\mathrm{D}=$ diminished; $\mathrm{P}=$ paralysed or $5=$ strong; $4=$ partial resistance; $3=$ complete movement; 2 = partial movement; $1=$ contraction; $0=$ paralysed

\section{SENSITIVITY EVALUATION AND STATUS INSPECTION}

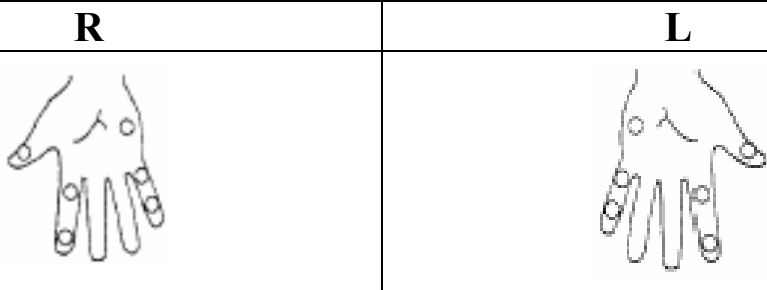

key: lilac pen / monofilament (2g): feels $\sqrt{ }$; does not feel X ; or monofilaments: follow colours

Mobile claw: $\mathrm{M}$; rigid claw: $\mathrm{R}$; bone absorption:

wound:

Signature and stamp of medical examiner 


\begin{tabular}{|c|l|l|l|l|l|l|l|l|l|l|l|l|}
\hline PATIENT INITIALS & & & & & PATIENT NUMBER: & & & & & DATE OF VISIT: & \\
\hline PATIENT INITIALS & & & & & PATIENT NUMBER: & & & & & DATE OF VISIT: \\
\hline
\end{tabular}

\begin{tabular}{|l|c|c|}
\hline \multicolumn{1}{|c|}{ Lower limbs } & & \\
\hline Main complaint Nerve Palpation & & \\
\hline Fibular & R & L \\
\hline Posterior tibial & & \\
\hline
\end{tabular}

key: $\mathrm{N}=$ normal; $\mathrm{T}=$ thickened; $\mathrm{P}=$ pain; $\mathrm{S}=$ Tinel's sign $(+)$

\begin{tabular}{|l|l|l|l|}
\hline \multicolumn{2}{|c|}{ Strength evaluation } & R & L \\
\hline $\begin{array}{l}\text { Elevates hallux } \\
\text { Hallux extension (fibular nerve) }\end{array}$ & & \\
\hline $\begin{array}{l}\text { Elevate foot } \\
\text { Foot dorsiflexion (fibular nerve) }\end{array}$ & & \\
\hline
\end{tabular}

key: $\mathrm{S}=$ strong; $\mathrm{D}=$ diminished; $\mathrm{P}=$ paralysed or $5=$ strong; $4=$ partial resistance; $3=$ complete movement; 2 = partial movement; $1=$ contracture; $0=$ paralysed

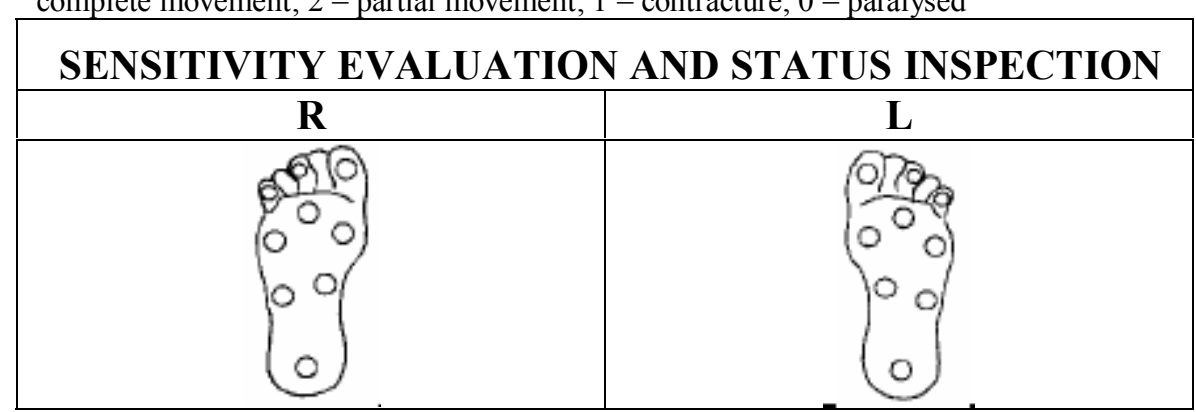

key: lilac pen / monofilament (2g): feels $\checkmark$; does not feel X; or monofilaments: follow colours

Mobile claw: M; rigid claw: R; bone absorption: $m$ wound: $\vec{c}$

\begin{tabular}{|l|c|c|c|c|c|c|c|c|}
\hline \multicolumn{7}{|c|}{ Classification of disability grade } \\
\hline Evaluation date & \multicolumn{2}{|c|}{ eyes } & hands & \multicolumn{2}{|c|}{ feet } & Highest grade & signature \\
\hline & R & L & R & L & R & L & & \\
\hline Evaluation / / & & & & & & & & \\
\hline
\end{tabular}

\section{Monofilaments}

\begin{tabular}{|l|c|l|}
\hline Monofilament & strength in grams & interpretation \\
\hline 1 - green & 0.05 & Normal sensitivity in hand and foot \\
\hline 3 - blue & 0.20 & $\begin{array}{l}\text { Diminished sensitivity in hand and normal in foot / Difficulty } \\
\text { in distinguishing texture (light touch) }\end{array}$ \\
\hline 4 - dark red & 2.00 & $\begin{array}{l}\text { Diminished protective sensitivity in hand / Incapable of } \\
\text { distinguishing texture / Difficulty in distinguishing forms and } \\
\text { temperatures }\end{array}$ \\
\hline 5 - orange or red (mark with an X) & 4.00 & $\begin{array}{l}\text { Loss of protective sensitivity in hand and sometimes in foot } \\
\text { / loss of texture discrimination / Incapable of distinguishing } \\
\text { forms and temperatures }\end{array}$ \\
\hline 6 - red circle & 10.00 & $\begin{array}{l}\text { Loss of protective sensitivity in foot / loss of texture } \\
\text { discrimination / Incapable of distinguishing forms and } \\
\text { temperatures }\end{array}$ \\
\hline 7 - black & 300.00 & $\begin{array}{l}\text { Only has sensation when deep pressure is applied to hand } \\
\text { and foot }\end{array}$ \\
\hline
\end{tabular}

Signature and stamp of medical examiner 


\section{CLINICAL DERMATOLOGICAL EVALUATION - 6th year follow-up}

\begin{tabular}{|c|c|c|c|c|c|c|}
\hline \multirow{5}{*}{ Skin Lesions } & & 1 Remission & 2 Improvement & \multicolumn{2}{|c|}{3 Unchanged } & 4 Worsening \\
\hline & 1. Colour & & & & & \\
\hline & 2. Sensibility & & & & & \\
\hline & 3. Infiltration & & & & & \\
\hline & 4. Other & & & & & \\
\hline \multirow{24}{*}{$\begin{array}{l}\text { Symptoms and signs } \\
\text { of side effects from MDT }\end{array}$} & Sign/symptom & & Absent & mild & moderate & severe \\
\hline & 1. Itching & & & & & \\
\hline & 2. Dry skin & & & & & \\
\hline & 3. Skin pigme & tion & & & & \\
\hline & 4. Rash & & & & & \\
\hline & 5. Erythrodern & & & & & \\
\hline & 6. Photosensiti & & & & & \\
\hline & 7. Abdominal & & & & & \\
\hline & 8. Constipatior & & & & & \\
\hline & 9. Nausea & & & & & \\
\hline & 10. Vomiting & & & & & \\
\hline & 11. Diarrhoea & & & & & \\
\hline & 12. Anorexia & & & & & \\
\hline & 13. Jaundice & & & & & \\
\hline & 14. Pallor & & & & & \\
\hline & 15. Cyanosis & & & & & \\
\hline & 16. Bleeding & & & & & \\
\hline & 17. Weight los & & & & & \\
\hline & 18. Dyspnoea & & & & & \\
\hline & 19. Asthenia & & & & & \\
\hline & 20. Fever & & & & & \\
\hline & 21. Myalgia & & & & & \\
\hline & 22. Headache & & & & & \\
\hline & 23. Depression & & & & & \\
\hline \begin{tabular}{|l} 
\\
$\square$ Any signs/symptoms of \\
leprosy reaction?
\end{tabular} & \multicolumn{6}{|c|}{$\begin{array}{l}1 \text { - Yes In this case, fill out the form for reactions in block V, for each new episode* } \\
2-\text { No } \\
3 \text { - Continued symptoms of previous reaction }\end{array}$} \\
\hline \begin{tabular}{|l}
\multicolumn{1}{c}{ Any signs/symptoms of } \\
relapse?
\end{tabular} & \multicolumn{6}{|c|}{$\begin{array}{l}1-\text { Yes } \\
2-\text { No }\end{array}$ In this case, fill out the relapse form in block V, page $137^{*}$} \\
\hline
\end{tabular}

Signature and stamp of medical examiner 
EXAMINATION OF PERIPHERAL NERVES

6th year follow-up

\begin{tabular}{|c|c|c|c|c|}
\hline \multirow[b]{2}{*}{ NERVES } & \multicolumn{2}{|c|}{$\begin{array}{l}\text { KEY } \\
\text { NERVE EXAMINATION } \\
0 \text { - Normal } \\
\text { 1- Thickened } \\
\text { 2- Nerve abscess }\end{array}$} & \multicolumn{2}{|c|}{$\begin{array}{l}\text { KEY } \\
\text { SCALE OF INDICATED NEURAL PAIN } \\
0 \text { - No pain } \\
1 \text { - Weak pain } \\
2 \text { - Strong pain }\end{array}$} \\
\hline & RIGHT & LEFT & RIGHT & LEFT \\
\hline Ulnar & & & & \\
\hline Median & & & & \\
\hline Radial & & & & \\
\hline Fibular & & & & \\
\hline Posterior Tibial & & & & \\
\hline Others & & & & \\
\hline
\end{tabular}

REQUEST FOR LABORATORY TESTS 6th year follow-up

\begin{tabular}{|l|l|}
\hline$\square$ & BACILLOSCOPY (Register results in Block V, page119) \\
\hline$\square$ & C-REACTIVE PROTEIN (Register results in Block V, page 122) \\
\hline
\end{tabular}

OBS: 


\section{SIMPLIFIED EVALUATION OF NEURAL FUNCTION AND COMPLICATIONS 6th year follow-up}

\begin{tabular}{|l|c|c|}
\hline \multicolumn{1}{|c|}{ Face } & & \\
\hline \multicolumn{1}{|c|}{ Nose } & R & L \\
\hline Main complaint & & \\
\hline dryness (S/N) & & \\
\hline abrasions (S/N) & & \\
\hline Perforation of the septum (S/N) & R & L \\
\hline Main complaint & & \\
\hline Closes eyes w/o force (mm) & & \\
\hline Closes eyes w/ force (mm) & & \\
\hline Cornea diminished sensibility (S/N) & & \\
\hline Cornea opacity (S/N) & & \\
\hline Cataract (S/N) & & \\
\hline Visual acuity & & \\
\hline
\end{tabular}

\begin{tabular}{|l|c|c|}
\hline \multicolumn{1}{|c|}{ Upper limbs } & & \\
\hline Main complaint Nerve palpation & & \\
\hline \multicolumn{1}{|c|}{ R } & L \\
\hline Ulnar & & \\
\hline Median & & \\
\hline Radius & & \\
\hline
\end{tabular}

key: $\mathrm{N}=$ normal; $\mathrm{T}=$ thickened; $\mathrm{P}=$ pain; $\mathrm{S}=$ Tinel's sign $(+)$

\begin{tabular}{|l|l|l|l|}
\hline \multicolumn{2}{|c|}{ Strength evaluation } & R & L \\
\hline Opens little finger & & \\
Abduction of the $5^{\text {th }}$ finger (ulnar nerve) & -4 & & \\
\hline $\begin{array}{l}\text { Elevates thumb } \\
\text { Abduction of the thumb (median nerve) }\end{array}$ & 3 & & \\
\hline $\begin{array}{l}\text { Elevates wrist } \\
\text { Wrist extension (radial nerve) }\end{array}$ & & & \\
\hline
\end{tabular}

key: $\mathrm{S}=$ strong; $\mathrm{D}=$ diminished; $\mathrm{P}=$ paralysed or $5=$ strong; $4=$ partial resistance; $3=$ complete movement; 2 = partial movement; $1=$ contraction; $0=$ paralysed

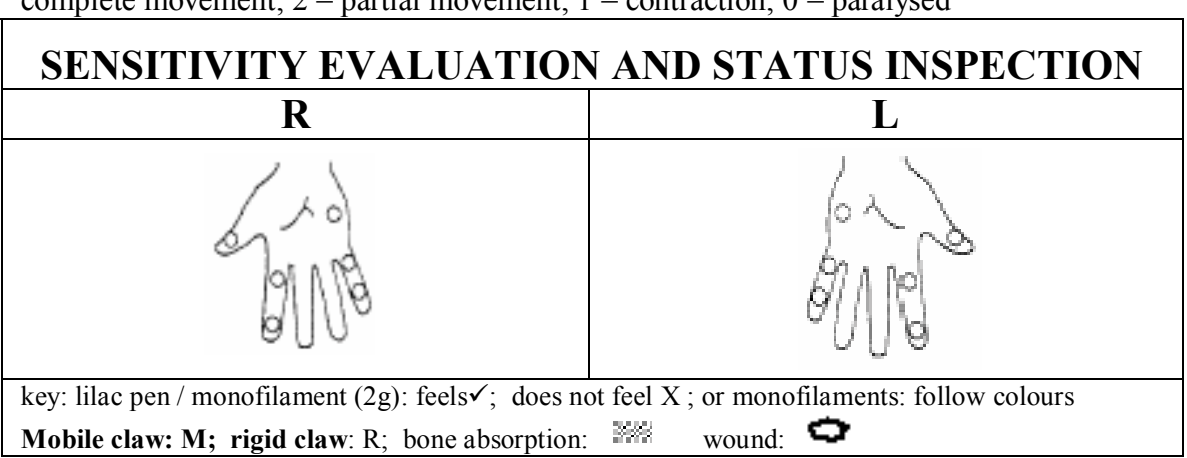

Signature and stamp of medical examiner 


\begin{tabular}{|l|c|c|}
\hline \multicolumn{1}{|c|}{ Lower limbs } & & \\
\hline Main complaint Nerve Palpation & & \\
\hline Fibular & R & L \\
\hline Posterior tibial & & \\
\hline
\end{tabular}

key: $\mathrm{N}=$ normal; $\mathrm{T}=$ thickened; $\mathrm{P}=$ pain; $\mathrm{S}=$ Tinel's sign $(+)$

\begin{tabular}{|l|c|c|c|}
\hline \multicolumn{2}{|c|}{ Strength evaluation } & R & L \\
\hline Elevates hallux & & \\
Hallux extension (fibular nerve) & 4 & & \\
\hline $\begin{array}{l}\text { Elevate foot } \\
\text { Foot dorsiflexion (fibular nerve) }\end{array}$ & & \\
\hline
\end{tabular}

key: $\mathrm{S}=$ strong; $\mathrm{D}=$ diminished; $\mathrm{P}=$ paralysed or $5=$ strong; $4=$ partial resistance; $3=$ complete movement; 2 = partial movement; $1=$ contracture; $0=$ paralysed

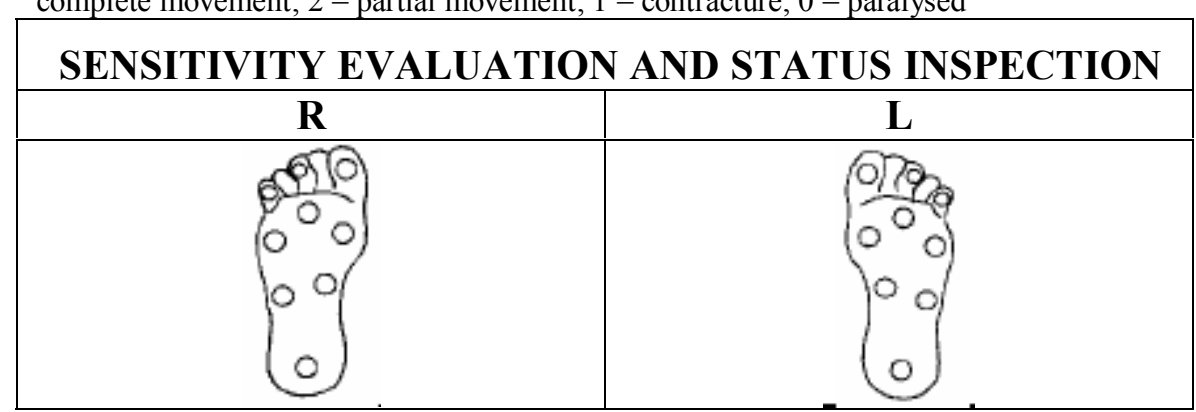

key: lilac pen / monofilament (2g): feels $\checkmark$; does not feel X; or monofilaments: follow colours

Mobile claw: $\mathrm{M}$; rigid claw: $\mathrm{R}$; bone absorption: $M$ wound:

\begin{tabular}{|l|c|c|c|c|c|c|c|c|}
\hline \multicolumn{7}{|c|}{ Classification of disability grade } \\
\hline Evaluation date & \multicolumn{2}{c|}{ eyes } & \multicolumn{2}{|c|}{ hands } & \multicolumn{2}{|c|}{ feet } & Highest grade & signature \\
\hline & R & L & R & L & R & L & & \\
\hline Evaluation L / & & & & & & & & \\
\hline
\end{tabular}

\section{Monofilaments}

\begin{tabular}{|l|c|l|}
\hline Monofilament & strength in grams & interpretation \\
\hline 1 - green & 0.05 & Normal sensitivity in hand and foot \\
\hline 3 - blue & 0.20 & $\begin{array}{l}\text { Diminished sensitivity in hand and normal in foot / Difficulty } \\
\text { in distinguishing texture (light touch) }\end{array}$ \\
\hline 4 - dark red & 2.00 & $\begin{array}{l}\text { Diminished protective sensitivity in hand / Incapable of } \\
\text { distinguishing texture / Difficulty in distinguishing forms and } \\
\text { temperatures }\end{array}$ \\
\hline 5 - orange or red (mark with an X) & 4.00 & $\begin{array}{l}\text { Loss of protective sensitivity in hand and sometimes in foot } \\
\text { / loss of texture discrimination / Incapable of distinguishing } \\
\text { forms and temperatures }\end{array}$ \\
\hline 6 - red circle & 10.00 & $\begin{array}{l}\text { Loss of protective sensitivity in foot / loss of texture } \\
\text { discrimination / Incapable of distinguishing forms and } \\
\text { temperatures }\end{array}$ \\
\hline 7 - black & 300.00 & $\begin{array}{l}\text { Only has sensation when deep pressure is applied to hand } \\
\text { and foot }\end{array}$ \\
\hline
\end{tabular}

Signature and stamp of medical examiner 
BLOCK V

Miscellaneous forms 
EPISODE NUMBER:

DIAGNOSIS AND FOLLOW-UP OF REACTION FORM

\begin{tabular}{|l|l|l|l|}
\hline $\mathbf{1}$ & Adverse reaction & $\mathbf{1 8}$ & Neuritis \\
\hline $\mathbf{2}$ & ENL & $\mathbf{1 9}$ & Neuritis + Adverse reaction \\
\hline $\mathbf{3}$ & Necrotizing ENL & $\mathbf{2 0}$ & Neuritis + ENL \\
\hline $\mathbf{4}$ & Polymorphous erythema & $\mathbf{2 1}$ & Neuritis + Mixed reaction \\
\hline $\mathbf{5}$ & Arthritis & $\mathbf{2 2}$ & Neuritis + Necrotizing ENL \\
\hline $\mathbf{6}$ & Lymphadenopathy & $\mathbf{2 3}$ & Neuritis + Polymorphous erythema \\
\hline $\mathbf{7}$ & Orchitis & $\mathbf{2 4}$ & Neuritis + Arthritis \\
\hline $\mathbf{8}$ & Iritis/Iridocyclitis & $\mathbf{2 5}$ & Neuritis + Lymphadenopathy \\
\hline $\mathbf{9}$ & Reaction hand and foot & $\mathbf{2 6}$ & Neuritis + Orchitis \\
\hline $\mathbf{1 0}$ & ENL+ Necrotizing ENL & $\mathbf{2 7}$ & Neuritis + Iritis/ Iridocyclitis \\
\hline $\mathbf{1 1}$ & ENL+ polymorphous erythema & $\mathbf{2 8}$ & Neuritis + Reaction hand/foot \\
\hline $\mathbf{1 2}$ & ENL+ orchitis & $\mathbf{2 9}$ & Neuritis + ENL+ Necrotizing ENL \\
\hline $\mathbf{1 3}$ & ENL+ arthritis & $\mathbf{3 0}$ & Neuritis + ENL+ Polymorphous erythema \\
\hline $\mathbf{1 4}$ & ENL+ Lymphadenopathy & $\mathbf{3 1}$ & Neuritis + ENL+ orchitis \\
\hline $\mathbf{1 5}$ & ENL+ Iritis/ Iridocyclitis & $\mathbf{3 2}$ & Neuritis + ENL+ arthritis \\
\hline $\mathbf{1 6}$ & ENL+ Reaction hand/foot & $\mathbf{3 3}$ & Neuritis + ENL+ Lymphadenopathy \\
\hline $\mathbf{1 7}$ & Mixed reaction/ Type 1 + Type 2 & $\mathbf{3 4}$ & Neuritis + ENL+ Iritis/lridocyclitis \\
\hline & & $\mathbf{3 5}$ & Neuritis + ENL+ Reaction hand/foot \\
\hline
\end{tabular}

Involvement:

\begin{tabular}{|l|l|l|l|}
\hline $\mathbf{1}$ & Cutaneous & $\mathbf{4}$ & Cutaneous + Systemic \\
\hline $\mathbf{2}$ & Neural & $\mathbf{5}$ & Neural + Systemic \\
\hline $\mathbf{3}$ & Cutaneous + Neural & $\mathbf{6}$ & Cutaneous + Neural + Systemic \\
\hline
\end{tabular}

\section{Possible triggering factors:}

\begin{tabular}{|l|l|l|l|}
\hline $\mathbf{1}$ & Concomitant infections & $\mathbf{5}$ & Medication \\
\hline $\mathbf{2}$ & Pregnancy & $\mathbf{6}$ & Vaccination \\
\hline $\mathbf{3}$ & Surgery & $\mathbf{7}$ & Not identified \\
\hline $\mathbf{4}$ & Emotional distress & $\mathbf{8}$ & Others \\
\hline
\end{tabular}

Treatment:

\begin{tabular}{|l|l|l|l|}
\hline $\mathbf{1}$ & Corticosteroids & $\mathbf{8}$ & Thalidomide+ Clofazimine \\
\hline $\mathbf{2}$ & Thalidomide & $\mathbf{9}$ & Thalidomide + Pentoxifylline \\
\hline $\mathbf{3}$ & Clofazimine & $\mathbf{1 0}$ & Corticosteroids + Thalidomide + Clofazimine \\
\hline $\mathbf{4}$ & Pentoxifylline & $\mathbf{1 1}$ & Corticosteroids + Pentoxifylline + Thalidomide \\
\hline $\mathbf{5}$ & Corticosteroids + Thalidomide & $\mathbf{1 2}$ & Corticosteroids + Pentoxifylline + Clofazimine \\
\hline $\mathbf{6}$ & Corticosteroids + Clofazimine & $\mathbf{1 3}$ & $\begin{array}{l}\text { Corticosteroids + Pentoxifylline + Clofazimine + } \\
\text { Thalidomide }\end{array}$ \\
\hline $\mathbf{7}$ & Corticosteroids + Pentoxifylline & $\mathbf{1 4}$ & Others \\
\hline
\end{tabular}


EXAMINATION OF PERIPHERAL NERVES

Diagnosis and follow-up of reaction episodes

\begin{tabular}{|c|c|c|c|c|}
\hline \multirow[b]{2}{*}{ NERVES } & \multicolumn{2}{|c|}{$\begin{array}{l}\text { KEY } \\
\text { NERVE EXAMINATION } \\
0 \text { - Normal } \\
\text { 1- Thickened } \\
\text { 2- Nerve abscess } \\
\end{array}$} & \multicolumn{2}{|c|}{$\begin{array}{l}\text { KEY } \\
\text { SCALE OF INDICATED NEURAL PAIN } \\
0 \text { - No pain } \\
1 \text { - Weak pain } \\
2 \text { - Strong pain }\end{array}$} \\
\hline & RIGHT & LEFT & RIGHT & LEFT \\
\hline \multicolumn{5}{|l|}{ Ulnar } \\
\hline \multicolumn{5}{|l|}{ Median } \\
\hline \multicolumn{5}{|l|}{ Radial } \\
\hline \multicolumn{5}{|l|}{ Fibular } \\
\hline \multicolumn{5}{|l|}{ Posterior Tibial } \\
\hline Others & & & & \\
\hline
\end{tabular}

Signature and stamp of medical examiner

\section{REQUEST FOR LABORATORY TESTS - reaction episodes}

C-REACTIVE PROTEIN (Register result in the Block V, page 123)

OBS: 


\section{SIMPLIFIED EVALUATION OF NEURAL FUNCTION AND COMPLICATIONS Diagnosis and follow-up of reactions}

\begin{tabular}{|l|c|c|}
\hline \multicolumn{1}{|c|}{ Face } & & \\
\hline \multicolumn{1}{|c|}{ Nose } & R & L \\
\hline Main complaint & & \\
\hline dryness (S/N) & & \\
\hline abrasions (S/N) & & \\
\hline Perforation of the septum (S/N) & R & L \\
\hline & & \\
\hline Main complaint w/o force (mm) & & \\
\hline Closes eyes wo & & \\
\hline Closes eyes w/ force (mm) & & \\
\hline Cornea diminished sensibility (S/N) & & \\
\hline Cornea opacity (S/N) & & \\
\hline Cataract (S/N) & & \\
\hline Visual acuity & & \\
\hline
\end{tabular}

\begin{tabular}{|l|c|c|}
\hline \multicolumn{1}{|c|}{ Upper limbs } & & \\
\hline Main complaint Nerve palpation & & \\
\hline \multicolumn{1}{|c|}{ R } & L \\
\hline Ulnar & & \\
\hline Median & & \\
\hline Radius & & \\
\hline
\end{tabular}

key: $\mathrm{N}=$ normal; $\mathrm{T}=$ thickened; $\mathrm{P}=$ pain; $\mathrm{S}=$ Tinel's sign $(+)$

Opens little finger

Strength evaluation

Abduction of the $5^{\text {th }}$ finger (ulnar nerve)

Elevates thumb

Abduction of the thumb (median nerve)

Elevates wrist

Wrist extension (radial nerve)

\begin{tabular}{|c|c|c|}
\hline & $\mathbf{R}$ & $\mathbf{L}$ \\
\hline$\frac{A}{4}$ & & \\
\hline "ै & & \\
\hline$\stackrel{\rightarrow}{3}$ & & \\
\hline
\end{tabular}

key: $\mathrm{S}=$ strong; $\mathrm{D}=$ diminished; $\mathrm{P}=$ paralysed $\quad$ or $5=$ strong; $4=$ partial resistance; $3=$ complete movement; $2=$ partial movement; $1=$ contraction; $0=$ paralysed

\section{SENSITIVITY EVALUATION AND STATUS INSPECTION}

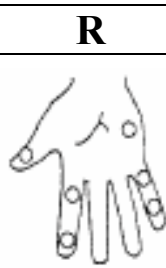

L

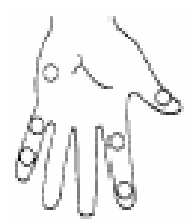

key: lilac pen / monofilament (2g): feels $\sqrt{ }$; does not feel X ; or monofilaments: follow colours

Mobile claw: $M$; rigid claw: $\mathrm{R}$; bone absorption: ${ }^{*}$ wound: ?

Signature and stamp of medical examiner 


\begin{tabular}{|c|l|l|l|l|l|l|l|l|l|l|l|l|}
\hline PATIENT INITIALS & & & & & PATIENT NUMBER: & & & & DATE OF VISIT: & \\
\hline PATIENT INITIALS & & & & & PATIENT NUMBER: & & & & & DATE OF VISIT: \\
\hline
\end{tabular}

\begin{tabular}{|l|l|l|}
\hline \multicolumn{1}{|c|}{ Lower limbs } & & \\
\hline Main complaint Nerve Palpation & & \\
\hline Fibular & R & L \\
\hline Posterior tibial & & \\
\hline
\end{tabular}

key: $\mathrm{N}=$ normal; $\mathrm{T}=$ thickened; $\mathrm{P}=$ pain; $\mathrm{S}=$ Tinel's sign $(+)$

\begin{tabular}{|l|l|l|l|}
\hline \multicolumn{2}{|c|}{ Strength evaluation } & R & L \\
\hline $\begin{array}{l}\text { Elevates hallux } \\
\text { Hallux extension (fibular nerve) }\end{array}$ & & \\
\hline $\begin{array}{l}\text { Elevate foot } \\
\text { Foot dorsiflexion (fibular nerve) }\end{array}$ & & \\
\hline
\end{tabular}

key: $\mathrm{S}=$ strong; $\mathrm{D}=$ diminished; $\mathrm{P}=$ paralysed or $5=$ strong; $4=$ partial resistance; $3=$ complete movement; 2 = partial movement; $1=$ contracture; $0=$ paralysed

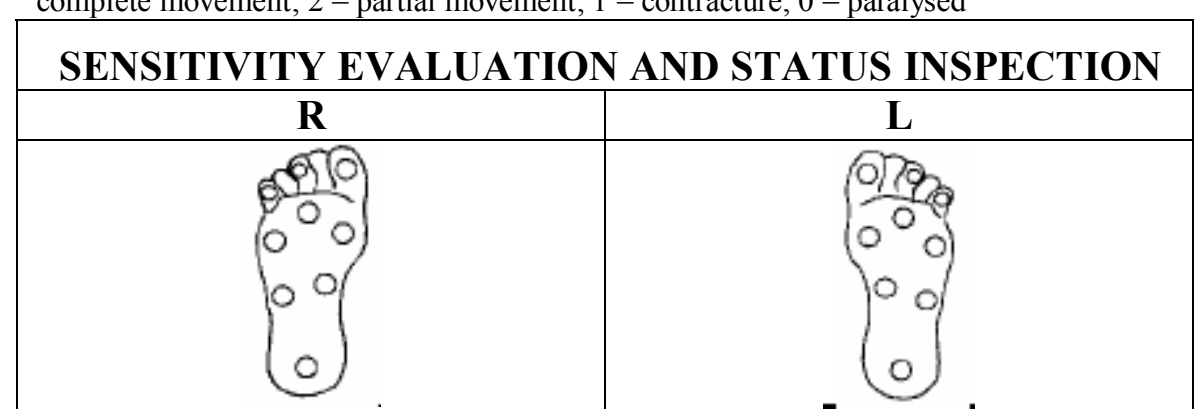

key: lilac pen / monofilament (2g): feels $\sqrt{ }$; does not feel X; or monofilaments: follow colours

Mobile claw: $\mathrm{M}$; rigid claw: $\mathrm{R}$; bone absorption: $\%$ wound: $\square$

\begin{tabular}{|c|c|c|c|c|c|c|c|c|}
\hline \multicolumn{9}{|c|}{ Classification of disability grade } \\
\hline Evaluation date & \multicolumn{2}{|c|}{ eyes } & \multicolumn{2}{|c|}{ hands } & \multicolumn{2}{|c|}{ feet } & \multirow[t]{2}{*}{ Highest grade } & \multirow[t]{2}{*}{ signature } \\
\hline & $\mathbf{R}$ & $\mathbf{L}$ & $\mathbf{R}$ & $\mathbf{L}$ & $\mathbf{R}$ & $\mathbf{L}$ & & \\
\hline Evaluation & & & & & & & & \\
\hline \multicolumn{9}{|c|}{ Monofilaments } \\
\hline Monofilament & \multicolumn{4}{|c|}{ strength in grams } & \multicolumn{4}{|c|}{ interpretation } \\
\hline 1 - green & \multicolumn{4}{|c|}{0.05} & \multicolumn{4}{|c|}{ Normal sensitivity in hand and foot } \\
\hline 2 - blue & \multicolumn{4}{|c|}{0.20} & \multicolumn{4}{|c|}{$\begin{array}{l}\text { Diminished sensitivity in hand and normal in foot / Difficulty } \\
\text { in distinguishing texture (light touch) }\end{array}$} \\
\hline 3 - Lilac & \multicolumn{4}{|c|}{2.00} & \multicolumn{4}{|c|}{$\begin{array}{l}\text { Diminished protective sensitivity in hand / Incapable of } \\
\text { distinguishing texture / Difficulty in distinguishing forms and } \\
\text { temperatures }\end{array}$} \\
\hline 4 - dark red & \multicolumn{4}{|c|}{4.00} & \multicolumn{4}{|c|}{$\begin{array}{l}\text { Loss of protective sensitivity in hand and sometimes in foot } \\
\text { / loss of texture discrimination / Incapable of distinguishing } \\
\text { forms and temperatures }\end{array}$} \\
\hline 5 - orange or red (mark with an $\mathrm{X}$ ) & \multicolumn{4}{|c|}{10.00} & \multicolumn{4}{|c|}{$\begin{array}{l}\text { Loss of protective sensitivity in foot / loss of texture } \\
\text { discrimination / Incapable of distinguishing forms and } \\
\text { temperatures }\end{array}$} \\
\hline 6 - red circle & \multicolumn{4}{|c|}{300.00} & \multicolumn{4}{|c|}{$\begin{array}{l}\text { Only has sensation when deep pressure is applied to hand } \\
\text { and foot }\end{array}$} \\
\hline 7 - black & \multicolumn{4}{|c|}{$\begin{array}{c}\text { No response to } 300 \mathrm{~g} \\
\text { monofilament }\end{array}$} & \multicolumn{4}{|c|}{ Loss of sensation even to deep pressure in hand and foot } \\
\hline
\end{tabular}

Signature and stamp of medical examiner 
DIAGNOSIS AND FOLLOW-UP OF REACTION FORM

EPISODE NUMBER: REACTION

\begin{tabular}{|l|l|l|l|}
\hline $\mathbf{1}$ & Adverse reaction & $\mathbf{1 8}$ & Neuritis \\
\hline $\mathbf{2}$ & ENL & $\mathbf{1 9}$ & Neuritis + Adverse reaction \\
\hline $\mathbf{3}$ & Necrotizing ENL & $\mathbf{2 0}$ & Neuritis + ENL \\
\hline $\mathbf{4}$ & Polymorphous erythema & $\mathbf{2 1}$ & Neuritis + Mixed reaction \\
\hline $\mathbf{5}$ & Arthritis & $\mathbf{2 2}$ & Neuritis + Necrotizing ENL \\
\hline $\mathbf{6}$ & Lymphadenopathy & $\mathbf{2 3}$ & Neuritis + Polymorphous erythema \\
\hline $\mathbf{7}$ & Orchitis & $\mathbf{2 4}$ & Neuritis + Arthritis \\
\hline $\mathbf{8}$ & Iritis/Iridocyclitis & $\mathbf{2 5}$ & Neuritis + Lymphadenopathy \\
\hline $\mathbf{9}$ & Reaction hand and foot & $\mathbf{2 6}$ & Neuritis + Orchitis \\
\hline $\mathbf{1 0}$ & ENL+ Necrotizing ENL & $\mathbf{2 7}$ & Neuritis + Iritis/ Iridocyclitis \\
\hline $\mathbf{1 1}$ & ENL+ polymorphous erythema & $\mathbf{2 8}$ & Neuritis + Reaction hand/foot \\
\hline $\mathbf{1 2}$ & ENL+ orchitis & $\mathbf{2 9}$ & Neuritis + ENL+ Necrotizing ENL \\
\hline $\mathbf{1 3}$ & ENL+ arthritis & $\mathbf{3 0}$ & Neuritis + ENL+ Polymorphous erythema \\
\hline $\mathbf{1 4}$ & ENL+ Lymphadenopathy & $\mathbf{3 1}$ & Neuritis + ENL+ orchitis \\
\hline $\mathbf{1 5}$ & ENL+ Iritis/ Iridocyclitis & $\mathbf{3 2}$ & Neuritis + ENL+ arthritis \\
\hline $\mathbf{1 6}$ & ENL+ Reaction hand/foot & 33 & Neuritis + ENL+ Lymphadenopathy \\
\hline $\mathbf{1 7}$ & Mixed reaction/ Type 1 + Type 2 & $\mathbf{3 4}$ & Neuritis + ENL+ Iritis/lridocyclitis \\
\hline & & $\mathbf{3 5}$ & Neuritis + ENL+ Reaction hand/foot \\
\hline
\end{tabular}

Involvement:

\begin{tabular}{|l|l|l|l|}
\hline $\mathbf{1}$ & Cutaneous & $\mathbf{4}$ & Cutaneous + Systemic \\
\hline $\mathbf{2}$ & Neural & $\mathbf{5}$ & Neural + Systemic \\
\hline $\mathbf{3}$ & Cutaneous + Neural & $\mathbf{6}$ & Cutaneous + Neural + Systemic \\
\hline
\end{tabular}

Possible triggering factors:

\begin{tabular}{|l|l|l|l|}
\hline $\mathbf{1}$ & Concomitant infections & $\mathbf{5}$ & Medication \\
\hline $\mathbf{2}$ & Pregnancy & $\mathbf{6}$ & Vaccination \\
\hline $\mathbf{3}$ & Surgery & $\mathbf{7}$ & Not identified \\
\hline $\mathbf{4}$ & Emotional distress & $\mathbf{8}$ & Others \\
\hline
\end{tabular}

Treatment:

\begin{tabular}{|l|l|l|l|}
\hline $\mathbf{1}$ & Corticosteroids & $\mathbf{8}$ & Thalidomide+ Clofazimine \\
\hline $\mathbf{2}$ & Thalidomide & $\mathbf{9}$ & Thalidomide + Pentoxifylline \\
\hline $\mathbf{3}$ & Clofazimine & $\mathbf{1 0}$ & Corticosteroids + Thalidomide + Clofazimine \\
\hline $\mathbf{4}$ & Pentoxifylline & $\mathbf{1 1}$ & Corticosteroids + Pentoxifylline + Thalidomide \\
\hline $\mathbf{5}$ & Corticosteroids + Thalidomide & $\mathbf{1 2}$ & Corticosteroids + Pentoxifylline + Clofazimine \\
\hline $\mathbf{6}$ & Corticosteroids + Clofazimine & $\mathbf{1 3}$ & $\begin{array}{l}\text { Corticosteroids + Pentoxifylline + Clofazimine + } \\
\text { Thalidomide }\end{array}$ \\
\hline $\mathbf{7}$ & Corticosteroids + Pentoxifylline & $\mathbf{1 4}$ & Others \\
\hline
\end{tabular}




\section{EXAMINATION OF PERIPHERAL NERVES}

Diagnosis and follow-up of reaction episodes

\begin{tabular}{|c|c|c|c|c|}
\hline \multirow[b]{2}{*}{ NERVES } & \multicolumn{2}{|c|}{$\begin{array}{l}\text { KEY } \\
\text { NERVE EXAMINATION } \\
0 \text { - Normal } \\
\text { 1- Thickened } \\
\text { 2- Nerve abscess } \\
\end{array}$} & \multicolumn{2}{|c|}{$\begin{array}{l}\text { KEY } \\
\text { SCALE OF INDICATED NEURAL PAIN } \\
0 \text { - No pain } \\
1 \text { - Weak pain } \\
2 \text { - Strong pain }\end{array}$} \\
\hline & RIGHT & LEFT & RIGHT & LEFT \\
\hline \multicolumn{5}{|l|}{ Ulnar } \\
\hline \multicolumn{5}{|l|}{ Median } \\
\hline \multicolumn{5}{|l|}{ Radial } \\
\hline \multicolumn{5}{|l|}{ Fibular } \\
\hline \multicolumn{5}{|l|}{ Posterior Tibial } \\
\hline Others & & & & \\
\hline
\end{tabular}

Signature and stamp of medical examiner

\section{REQUEST FOR LABORATORY TESTS - reaction episodes}

C-REACTIVE PROTEIN (Register result in Block V, page 123)

OBS: 


\section{SIMPLIFIED EVALUATION OF NEURAL FUNCTION AND COMPLICATIONS Diagnosis and follow-up of reaction episodes}

\begin{tabular}{|l|c|c|}
\hline \multicolumn{1}{|c|}{ Face } & & \\
\hline \multicolumn{1}{|c|}{ Nose } & R & L \\
\hline Main complaint & & \\
\hline dryness (S/N) & & \\
\hline abrasions (S/N) & & \\
\hline Perforation of the septum (S/N) & R & L \\
\hline & & \\
\hline Main complaint w/o force (mm) & & \\
\hline Closes eyes wo & & \\
\hline Closes eyes w/ force (mm) & & \\
\hline Cornea diminished sensibility (S/N) & & \\
\hline Cornea opacity (S/N) & & \\
\hline Cataract (S/N) & & \\
\hline Visual acuity & & \\
\hline
\end{tabular}

\begin{tabular}{|l|c|c|}
\hline \multicolumn{1}{|c|}{ Upper limbs } & & \\
\hline Main complaint Nerve palpation & & \\
\hline \multicolumn{1}{|c|}{ R } & L \\
\hline Ulnar & & \\
\hline Median & & \\
\hline Radius & & \\
\hline
\end{tabular}

key: $\mathrm{N}=$ normal; $\mathrm{T}=$ thickened; $\mathrm{P}=$ pain; $\mathrm{S}=$ Tinel's sign $(+)$

\begin{tabular}{|l|l|l|l|}
\hline \multicolumn{2}{|c|}{ Strength evaluation } & R & L \\
\hline Opens little finger & & \\
Abduction of the $5^{\text {th }}$ finger (ulnar nerve) & & & \\
\hline $\begin{array}{l}\text { Elevates thumb } \\
\text { Abduction of the thumb (median nerve) }\end{array}$ & & & \\
\hline $\begin{array}{l}\text { Elevates wrist } \\
\text { Wrist extension (radial nerve) }\end{array}$ & & & \\
\hline
\end{tabular}

key: $\mathrm{S}=$ strong; $\mathrm{D}=$ diminished; $\mathrm{P}=$ paralysed $\quad$ or $5=$ strong; $4=$ partial resistance; $3=$ complete movement; $2=$ partial movement; $1=$ contraction; $0=$ paralysed

\section{SENSITIVITY EVALUATION AND STATUS INSPECTION}

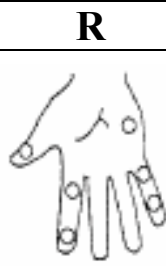

L

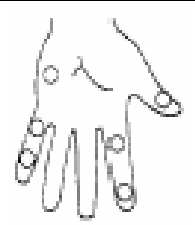

key: lilac pen / monofilament (2g): feels $\sqrt{ }$; does not feel X; or monofilaments: follow colours

Mobile claw: $M$; rigid claw: $\mathrm{R}$; bone absorption: $*$ wound: 난 


\begin{tabular}{|c|l|l|l|l|l|l|l|l|l|l|l|l|}
\hline PATIENT INITIALS & & & & & PATIENT NUMBER: & & & & DATE OF VISIT: & \\
\hline PATIENT INITIALS & & & & & PATIENT NUMBER: & & & & & DATE OF VISIT: \\
\hline
\end{tabular}

\begin{tabular}{|l|c|c|}
\hline \multicolumn{1}{|c|}{ Lower limbs } & & \\
\hline Main complaint Nerve Palpation & & \\
\hline \multicolumn{1}{|c|}{ R } & L \\
\hline Fibular & & \\
\hline Posterior tibial & & \\
\hline
\end{tabular}

key: $\mathrm{N}=$ normal; $\mathrm{T}=$ thickened; $\mathrm{P}=$ pain; $\mathrm{S}=$ Tinel's sign $(+)$

\begin{tabular}{|l|l|l|l|}
\hline \multicolumn{2}{|c|}{ Strength evaluation } & R & L \\
\hline $\begin{array}{l}\text { Elevates hallux } \\
\text { Hallux extension (fibular nerve) }\end{array}$ & & \\
\hline $\begin{array}{l}\text { Elevate foot } \\
\text { Foot dorsiflexion (fibular nerve) }\end{array}$ & & \\
\hline
\end{tabular}

key: $\mathrm{S}=$ strong; $\mathrm{D}=$ diminished; $\mathrm{P}=$ paralysed or $5=$ strong; $4=$ partial resistance; $3=$ complete movement; $2=$ partial movement; $1=$ contracture; $0=$ paralysed

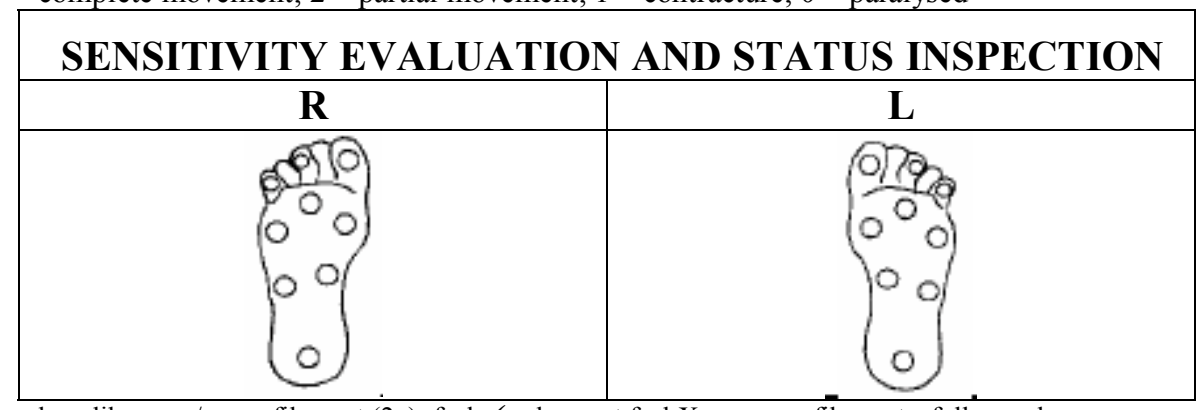

key: lilac pen / monofilament (2g): feels $\sqrt{ }$; does not feel X ; or monofilaments: follow colours

Mobile claw: M; rigid claw: $\mathrm{R}$; bone absorption: $\%$ wound:

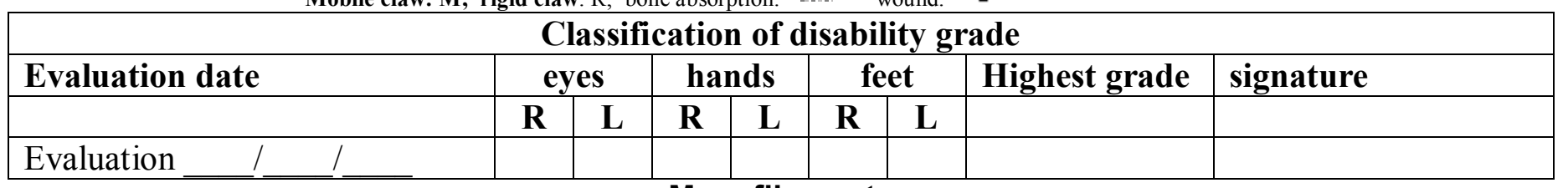

Monofilaments

\begin{tabular}{|c|c|c|}
\hline Monofilament & strength in grams & interpretation \\
\hline $1-$ green & 0.05 & Normal sensitivity in hand and foot \\
\hline 2 - blue & 0.20 & $\begin{array}{l}\text { Diminished sensitivity in hand and normal in foot / Difficulty } \\
\text { in distinguishing texture (light touch) }\end{array}$ \\
\hline 3 - Lilac & 2.00 & $\begin{array}{l}\text { Diminished protective sensitivity in hand / Incapable of } \\
\text { distinguishing texture / Difficulty in distinguishing forms and } \\
\text { temperatures }\end{array}$ \\
\hline 4 - dark red & 4.00 & $\begin{array}{l}\text { Loss of protective sensitivity in hand and sometimes in foot } \\
\text { / loss of texture discrimination / Incapable of distinguishing } \\
\text { forms and temperatures }\end{array}$ \\
\hline 5 - orange or red (mark with an $\mathrm{X}$ ) & 10.00 & $\begin{array}{l}\text { Loss of protective sensitivity in foot / loss of texture } \\
\text { discrimination / Incapable of distinguishing forms and } \\
\text { temperatures }\end{array}$ \\
\hline 6 - red circle & 300.00 & $\begin{array}{l}\text { Only has sensation when deep pressure is applied to hand } \\
\text { and foot }\end{array}$ \\
\hline 7 - black & $\begin{array}{l}\text { No response to } 300 \mathrm{~g} \\
\text { monofilament }\end{array}$ & Loss of sensation even to deep pressure in hand and foot \\
\hline
\end{tabular}


EPISODE NUMBER:

DIAGNOSIS AND FOLLOW-UP OF REACTION FORM REACTION

\begin{tabular}{|l|l|l|l|}
\hline $\mathbf{1}$ & Adverse reaction & $\mathbf{1 8}$ & Neuritis \\
\hline $\mathbf{2}$ & ENL & $\mathbf{1 9}$ & Neuritis + Adverse reaction \\
\hline $\mathbf{3}$ & Necrotizing ENL & $\mathbf{2 0}$ & Neuritis + ENL \\
\hline $\mathbf{4}$ & Polymorphous erythema & $\mathbf{2 1}$ & Neuritis + Mixed reaction \\
\hline $\mathbf{5}$ & Arthritis & $\mathbf{2 2}$ & Neuritis + Necrotizing ENL \\
\hline $\mathbf{6}$ & Lymphadenopathy & $\mathbf{2 3}$ & Neuritis + Polymorphous erythema \\
\hline $\mathbf{7}$ & Orchitis & $\mathbf{2 4}$ & Neuritis + Arthritis \\
\hline $\mathbf{8}$ & Iritis/Iridocyclitis & $\mathbf{2 5}$ & Neuritis + Lymphadenopathy \\
\hline $\mathbf{9}$ & Reaction hand and foot & $\mathbf{2 6}$ & Neuritis + Orchitis \\
\hline $\mathbf{1 0}$ & ENL+ Necrotizing ENL & $\mathbf{2 7}$ & Neuritis + Iritis/ Iridocyclitis \\
\hline $\mathbf{1 1}$ & ENL+ polymorphous erythema & $\mathbf{2 8}$ & Neuritis + Reaction hand/foot \\
\hline $\mathbf{1 2}$ & ENL+ orchitis & $\mathbf{2 9}$ & Neuritis + ENL+ Necrotizing ENL \\
\hline $\mathbf{1 3}$ & ENL+ arthritis & $\mathbf{3 0}$ & Neuritis + ENL+ Polymorphous erythema \\
\hline $\mathbf{1 4}$ & ENL+ Lymphadenopathy & $\mathbf{3 1}$ & Neuritis + ENL+ orchitis \\
\hline $\mathbf{1 5}$ & ENL+ Iritis/ Iridocyclitis & $\mathbf{3 2}$ & Neuritis + ENL+ arthritis \\
\hline $\mathbf{1 6}$ & ENL+ Reaction hand/foot & $\mathbf{3 3}$ & Neuritis + ENL+ Lymphadenopathy \\
\hline $\mathbf{1 7}$ & Mixed reaction/ Type 1 + Type 2 & $\mathbf{3 4}$ & Neuritis + ENL+ Iritis/lridocyclitis \\
\hline & & $\mathbf{3 5}$ & Neuritis + ENL+ Reaction hand/foot \\
\hline
\end{tabular}

Involvement:

\begin{tabular}{|l|l|l|l|}
\hline $\mathbf{1}$ & Cutaneous & $\mathbf{4}$ & Cutaneous + Systemic \\
\hline $\mathbf{2}$ & Neural & $\mathbf{5}$ & Neural + Systemic \\
\hline $\mathbf{3}$ & Cutaneous + Neural & $\mathbf{6}$ & Cutaneous + Neural + Systemic \\
\hline
\end{tabular}

Possible triggering factors:

\begin{tabular}{|l|l|l|l|}
\hline $\mathbf{1}$ & Concomitant infections & $\mathbf{5}$ & Medication \\
\hline $\mathbf{2}$ & Pregnancy & $\mathbf{6}$ & Vaccination \\
\hline $\mathbf{3}$ & Surgery & $\mathbf{7}$ & Not identified \\
\hline $\mathbf{4}$ & Emotional distress & $\mathbf{8}$ & Others \\
\hline
\end{tabular}

Treatment:

\begin{tabular}{|c|l|l|l|}
\hline $\mathbf{1}$ & Corticosteroids & $\mathbf{8}$ & Thalidomide+ Clofazimine \\
\hline $\mathbf{2}$ & Thalidomide & $\mathbf{9}$ & Thalidomide + Pentoxifylline \\
\hline $\mathbf{3}$ & Clofazimine & $\mathbf{1 0}$ & Corticosteroids + Thalidomide + Clofazimine \\
\hline $\mathbf{4}$ & Pentoxifylline & $\mathbf{1 1}$ & Corticosteroids + Pentoxifylline + Thalidomide \\
\hline $\mathbf{5}$ & Corticosteroids + Thalidomide & $\mathbf{1 2}$ & Corticosteroids + Pentoxifylline + Clofazimine \\
\hline $\mathbf{6}$ & Corticosteroids + Clofazimine & $\mathbf{1 3}$ & $\begin{array}{l}\text { Corticosteroids + Pentoxifylline + Clofazimine + } \\
\text { Thalidomide }\end{array}$ \\
\hline $\mathbf{7}$ & Corticosteroids + Pentoxifylline & $\mathbf{1 4}$ & Others \\
\hline
\end{tabular}


EXAMINATION OF PERIPHERAL NERVES

Diagnosis and follow-up of reaction episodes

\begin{tabular}{|l|c|c|c|c|}
\hline & \multicolumn{2}{|l|}{$\begin{array}{l}\text { KEY } \\
\text { NERVE EXAMINATION } \\
\text { 0- Normal } \\
\text { 1- Thickened } \\
\text { 2- Nerve abscess }\end{array}$} & \multicolumn{2}{l|}{$\begin{array}{l}\text { KEY } \\
\text { SCALE OF INDICATED NEURAL PAIN } \\
\text { 0- No pain } \\
\text { 1- Weak pain } \\
\text { 2- Strong pain }\end{array}$} \\
\hline \multicolumn{1}{|c|}{ NERVES } & \multicolumn{1}{|l|}{ RIGHT } & LEFT & \multicolumn{1}{c|}{ RIGHT } & LEFT \\
\hline Ulnar & & & & \\
\hline Median & & & & \\
\hline Radial & & & & \\
\hline Fibular & & & & \\
\hline Posterior Tibial & & & & \\
\hline Others & & & & \\
\hline
\end{tabular}

Signature and stamp of medical examiner

\section{REQUEST OF LABORATORY TESTS - Reaction episodes}

C-REACTIVE PROTEIN (Register result in Block V, page 123)

OBS:

Signature and stamp of medical examiner 


\section{SIMPLIFIED EVALUATION OF NEURAL FUNCTION AND COMPLICATIONS Diagnosis and follow-up of reaction episodes}

\begin{tabular}{|l|c|c|}
\hline \multicolumn{1}{|c|}{ Face } & & \\
\hline \multicolumn{1}{|c|}{ Nose } & R & L \\
\hline Main complaint & & \\
\hline dryness (S/N) & & \\
\hline abrasions (S/N) & & \\
\hline Perforation of the septum (S/N) & R & L \\
\hline & & \\
\hline Main complaint w/o force (mm) & & \\
\hline Closes eyes wo & & \\
\hline Closes eyes w/ force (mm) & & \\
\hline Cornea diminished sensibility (S/N) & & \\
\hline Cornea opacity (S/N) & & \\
\hline Cataract (S/N) & & \\
\hline Visual acuity & & \\
\hline
\end{tabular}

\begin{tabular}{|l|c|c|}
\hline \multicolumn{1}{|c|}{ Upper limbs } & & \\
\hline Main complaint Nerve palpation & & \\
\hline \multicolumn{1}{|c|}{ R } & L \\
\hline Ulnar & & \\
\hline Median & & \\
\hline Radius & & \\
\hline
\end{tabular}

key: $\mathrm{N}=$ normal; $\mathrm{T}=$ thickened; $\mathrm{P}=$ pain; $\mathrm{S}=$ Tinel's sign $(+)$

\begin{tabular}{|l|l|l|l|}
\hline \multicolumn{2}{|c|}{ Strength evaluation } & R & L \\
\hline Opens little finger & & \\
Abduction of the $5^{\text {th }}$ finger (ulnar nerve) & & & \\
\hline $\begin{array}{l}\text { Elevates thumb } \\
\text { Abduction of the thumb (median nerve) }\end{array}$ & & & \\
\hline $\begin{array}{l}\text { Elevates wrist } \\
\text { Wrist extension (radial nerve) }\end{array}$ & & & \\
\hline
\end{tabular}

key: $\mathrm{S}=$ strong; $\mathrm{D}=$ diminished; $\mathrm{P}=$ paralysed $\quad$ or $5=$ strong; $4=$ partial resistance; $3=$ complete movement; $2=$ partial movement; $1=$ contraction; $0=$ paralysed

\section{SENSITIVITY EVALUATION AND STATUS INSPECTION}

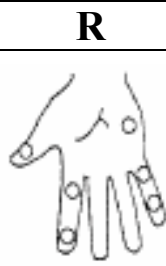

L

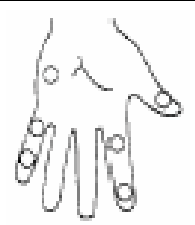

key: lilac pen / monofilament (2g): feels $\sqrt{ }$; does not feel X; or monofilaments: follow colours

Mobile claw: $M$; rigid claw: $\mathrm{R}$; bone absorption: $*$ wound: 난 


\begin{tabular}{|c|l|l|l|l|l|l|l|l|l|l|l|l|}
\hline PATIENT INITIALS & & & & & PATIENT NUMBER: & & & & DATE OF VISIT: & \\
\hline PATIENT INITIALS & & & & & PATIENT NUMBER: & & & & & DATE OF VISIT: \\
\hline
\end{tabular}

\begin{tabular}{|l|c|c|}
\hline \multicolumn{1}{|c|}{ Lower limbs } & & \\
\hline Main complaint Nerve Palpation & & \\
\hline \multicolumn{1}{|c|}{ R } & L \\
\hline Fibular & & \\
\hline Posterior tibial & & \\
\hline
\end{tabular}

key: $\mathrm{N}=$ normal; $\mathrm{T}=$ thickened; $\mathrm{P}=$ pain; $\mathrm{S}=$ Tinel's sign $(+)$

\begin{tabular}{|l|l|l|l|}
\hline \multicolumn{2}{|c|}{ Strength evaluation } & R & L \\
\hline $\begin{array}{l}\text { Elevates hallux } \\
\text { Hallux extension (fibular nerve) }\end{array}$ & & \\
\hline $\begin{array}{l}\text { Elevate foot } \\
\text { Foot dorsiflexion (fibular nerve) }\end{array}$ & & \\
\hline
\end{tabular}

key: $\mathrm{S}=$ strong; $\mathrm{D}=$ diminished; $\mathrm{P}=$ paralysed or $5=$ strong; $4=$ partial resistance; $3=$ complete movement; $2=$ partial movement; $1=$ contracture; $0=$ paralysed

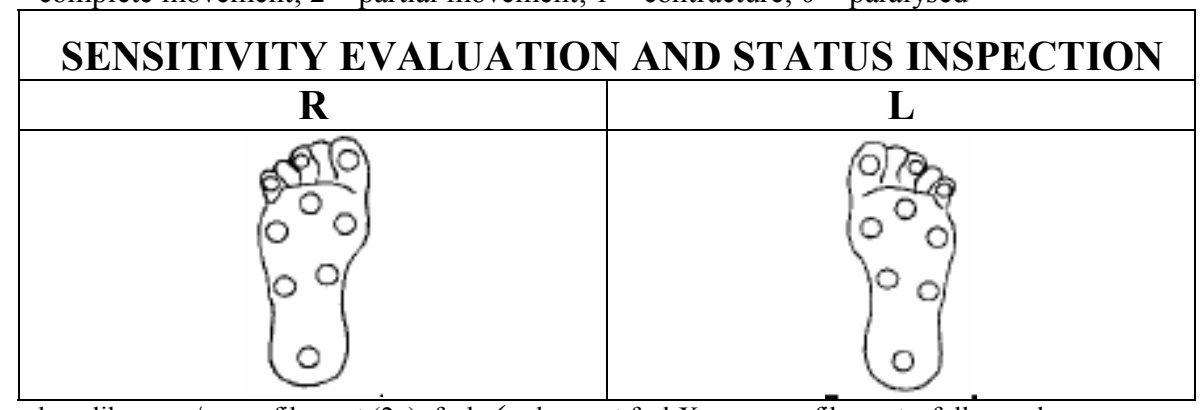

key: lilac pen / monofilament (2g): feels $\sqrt{ }$; does not feel X ; or monofilaments: follow colours

Mobile claw: M; rigid claw: $\mathrm{R}$; bone absorption: $\%$ wound:

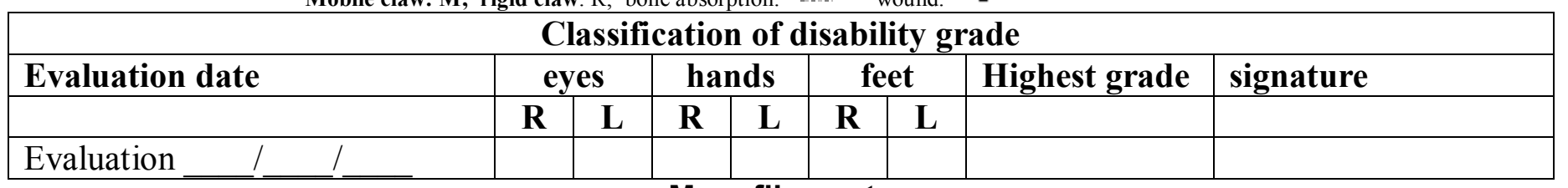

Monofilaments

\begin{tabular}{|l|c|l|}
\hline Monofilament & strength in grams & interpretation \\
\hline 1 - green & 0.05 & Normal sensitivity in hand and foot \\
\hline 2 - blue & 0.20 & $\begin{array}{l}\text { Diminished sensitivity in hand and normal in foot / Difficulty } \\
\text { in distinguishing texture (light touch) }\end{array}$ \\
\hline 4 - Lilac & 2.00 & $\begin{array}{l}\text { Diminished protective sensitivity in hand / Incapable of } \\
\text { distinguishing texture / Difficulty in distinguishing forms and } \\
\text { temperatures }\end{array}$ \\
\hline 5 - orange or red (mark with an X) & 4.00 & $\begin{array}{l}\text { Loss of protective sensitivity in hand and sometimes in foot } \\
\text { / loss of texture discrimination / Incapable of distinguishing } \\
\text { forms and temperatures }\end{array}$ \\
\hline 6 - red circle & 10.00 & $\begin{array}{l}\text { Loss of protective sensitivity in foot / loss of texture } \\
\text { discrimination / Incapable of distinguishing forms and } \\
\text { temperatures }\end{array}$ \\
\hline 7 - black & 300.00 & $\begin{array}{l}\text { Only has sensation when deep pressure is applied to hand } \\
\text { and foot }\end{array}$ \\
\hline
\end{tabular}


EPISODE NUMBER:

DIAGNOSIS AND FOLLOW-UP OF REACTION FORM REACTION

\begin{tabular}{|l|l|l|l|}
\hline $\mathbf{1}$ & Adverse reaction & $\mathbf{1 8}$ & Neuritis \\
\hline $\mathbf{2}$ & ENL & $\mathbf{1 9}$ & Neuritis + Adverse reaction \\
\hline $\mathbf{3}$ & Necrotizing ENL & $\mathbf{2 0}$ & Neuritis + ENL \\
\hline $\mathbf{4}$ & Polymorphous erythema & $\mathbf{2 1}$ & Neuritis + Mixed reaction \\
\hline $\mathbf{5}$ & Arthritis & $\mathbf{2 2}$ & Neuritis + Necrotizing ENL \\
\hline $\mathbf{6}$ & Lymphadenopathy & $\mathbf{2 3}$ & Neuritis + Polymorphous erythema \\
\hline $\mathbf{7}$ & Orchitis & $\mathbf{2 4}$ & Neuritis + Arthritis \\
\hline $\mathbf{8}$ & Iritis/Iridocyclitis & $\mathbf{2 5}$ & Neuritis + Lymphadenopathy \\
\hline $\mathbf{9}$ & Reaction hand and foot & $\mathbf{2 6}$ & Neuritis + Orchitis \\
\hline $\mathbf{1 0}$ & ENL+ Necrotizing ENL & $\mathbf{2 7}$ & Neuritis + Iritis/ Iridocyclitis \\
\hline $\mathbf{1 1}$ & ENL+ polymorphous erythema & $\mathbf{2 8}$ & Neuritis + Reaction hand/foot \\
\hline $\mathbf{1 2}$ & ENL+ orchitis & $\mathbf{2 9}$ & Neuritis + ENL+ Necrotizing ENL \\
\hline $\mathbf{1 3}$ & ENL+ arthritis & $\mathbf{3 0}$ & Neuritis + ENL+ Polymorphous erythema \\
\hline $\mathbf{1 4}$ & ENL+ Lymphadenopathy & $\mathbf{3 1}$ & Neuritis + ENL+ orchitis \\
\hline $\mathbf{1 5}$ & ENL+ Iritis/ Iridocyclitis & $\mathbf{3 2}$ & Neuritis + ENL+ arthritis \\
\hline $\mathbf{1 6}$ & ENL+ Reaction hand/foot & $\mathbf{3 3}$ & Neuritis + ENL+ Lymphadenopathy \\
\hline $\mathbf{1 7}$ & Mixed reaction/ Type 1 + Type 2 & $\mathbf{3 4}$ & Neuritis + ENL+ Iritis/lridocyclitis \\
\hline & & $\mathbf{3 5}$ & Neuritis + ENL+ Reaction hand/foot \\
\hline
\end{tabular}

Involvement:

\begin{tabular}{|l|l|l|l|}
\hline $\mathbf{1}$ & Cutaneous & $\mathbf{4}$ & Cutaneous + Systemic \\
\hline $\mathbf{2}$ & Neural & $\mathbf{5}$ & Neural + Systemic \\
\hline $\mathbf{3}$ & Cutaneous + Neural & $\mathbf{6}$ & Cutaneous + Neural + Systemic \\
\hline
\end{tabular}

Possible triggering factors:

\begin{tabular}{|l|l|l|l|}
\hline $\mathbf{1}$ & Concomitant infections & $\mathbf{5}$ & Medication \\
\hline $\mathbf{2}$ & Pregnancy & $\mathbf{6}$ & Vaccination \\
\hline $\mathbf{3}$ & Surgery & $\mathbf{7}$ & Not identified \\
\hline $\mathbf{4}$ & Emotional distress & $\mathbf{8}$ & Others \\
\hline
\end{tabular}

Treatment:

\begin{tabular}{|c|l|l|l|}
\hline $\mathbf{1}$ & Corticosteroids & $\mathbf{8}$ & Thalidomide+ Clofazimine \\
\hline $\mathbf{2}$ & Thalidomide & $\mathbf{9}$ & Thalidomide + Pentoxifylline \\
\hline $\mathbf{3}$ & Clofazimine & $\mathbf{1 0}$ & Corticosteroids + Thalidomide + Clofazimine \\
\hline $\mathbf{4}$ & Pentoxifylline & $\mathbf{1 1}$ & Corticosteroids + Pentoxifylline + Thalidomide \\
\hline $\mathbf{5}$ & Corticosteroids + Thalidomide & $\mathbf{1 2}$ & Corticosteroids + Pentoxifylline + Clofazimine \\
\hline $\mathbf{6}$ & Corticosteroids + Clofazimine & $\mathbf{1 3}$ & $\begin{array}{l}\text { Corticosteroids + Pentoxifylline + Clofazimine + } \\
\text { Thalidomide }\end{array}$ \\
\hline $\mathbf{7}$ & Corticosteroids + Pentoxifylline & $\mathbf{1 4}$ & Others \\
\hline
\end{tabular}




\begin{tabular}{|c|l|l|l|l|l|l|l|l|l|l|l|l|}
\hline PATIENT INITIALS & & & & & PATIENT NUMBER: & & & & & DATE OF VISIT: & \\
\hline PATIENT INITIALS & & & & & PATIENT NUMBER: & & & & & DATE OF VISIT: \\
\hline
\end{tabular}

\section{EXAMINATION OF PERIPHERAL NERVES \\ Diagnosis and follow-up of reaction episodes}

\begin{tabular}{|c|c|c|c|c|}
\hline \multirow[b]{2}{*}{ NERVES } & \multicolumn{2}{|c|}{$\begin{array}{l}\text { KEY } \\
\text { NERVE EXAMINATION } \\
0 \text { - Normal } \\
\text { 1- Thickened } \\
\text { 2- Nerve abscess } \\
\end{array}$} & \multicolumn{2}{|c|}{$\begin{array}{l}\text { KEY } \\
\text { SCALE OF INDICATED NEURAL PAIN } \\
0 \text { - No pain } \\
1 \text { - Weak pain } \\
2 \text { - Strong pain } \\
\end{array}$} \\
\hline & RIGHT & LEFT & RIGHT & LEFT \\
\hline \multicolumn{5}{|l|}{ Ulnar } \\
\hline \multicolumn{5}{|l|}{ Median } \\
\hline \multicolumn{5}{|l|}{ Radial } \\
\hline \multicolumn{5}{|l|}{ Fibular } \\
\hline \multicolumn{5}{|l|}{ Posterior Tibial } \\
\hline Others & & & & \\
\hline
\end{tabular}

Signature and stamp of medical examiner

\section{REQUEST OF LABORATORY TESTS - reaction episodes}

C-REACTIVE PROTEIN (Register result in Block V, page 123)

OBS: 


\section{SIMPLIFIED EVALUATION OF NEURAL FUNCTION AND COMPLICATIONS Diagnosis and follow-up of reaction episodes}

\begin{tabular}{|l|c|c|}
\hline \multicolumn{1}{|c|}{ Face } & & \\
\hline \multicolumn{1}{|c|}{ Nose } & R & L \\
\hline Main complaint & & \\
\hline dryness (S/N) & & \\
\hline abrasions (S/N) & & \\
\hline Perforation of the septum (S/N) & R & L \\
\hline & & \\
\hline Main complaint & & \\
\hline Closes eyes w/o force (mm) & & \\
\hline Closes eyes w/ force (mm) & & \\
\hline Cornea diminished sensibility (S/N) & & \\
\hline Cornea opacity (S/N) & & \\
\hline Cataract (S/N) & & \\
\hline Visual acuity & & \\
\hline
\end{tabular}

\begin{tabular}{|l|c|c|}
\hline \multicolumn{1}{|c|}{ Upper limbs } & & \\
\hline Main complaint Nerve palpation & & \\
\hline \multicolumn{1}{|c|}{ R } & L \\
\hline Ulnar & & \\
\hline Median & & \\
\hline Radius & & \\
\hline
\end{tabular}

key: $\mathrm{N}=$ normal; $\mathrm{T}=$ thickened; $\mathrm{P}=$ pain; $\mathrm{S}=$ Tinel's sign $(+)$

Opens little finger

\section{Strength evaluation}

Abduction of the $5^{\text {th }}$ finger (ulnar nerve)

Elevates thumb

Abduction of the thumb (median nerve)

Elevates wrist

Wrist extension (radial nerve)

key: $\mathrm{S}=$ strong; $\mathrm{D}=$ diminished; $\mathrm{P}=$ paralysed or $5=$ strong; $4=$ partial resistance; $3=$ complete movement; $2=$ partial movement; $1=$ contraction; $0=$ paralysed

\section{SENSITIVITY EVALUATION AND STATUS INSPECTION}

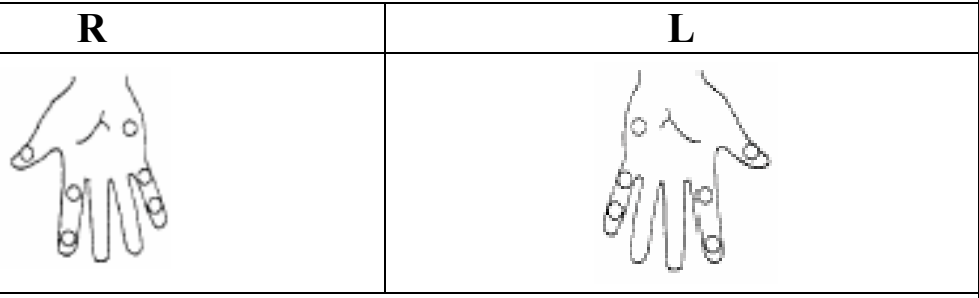

key: lilac pen / monofilament (2g): feels $\sqrt{ }$; does not feel X ; or monofilaments: follow colours

Mobile claw: $\mathrm{M}$; rigid claw: $\mathrm{R}$; bone absorption: $\quad * \cdots$ wound: 


\begin{tabular}{|c|l|l|l|l|l|l|l|l|l|l|l|l|}
\hline PATIENT INITIALS & & & & & PATIENT NUMBER: & & & & DATE OF VISIT: & \\
\hline PATIENT INITIALS & & & & & PATIENT NUMBER: & & & & & DATE OF VISIT: \\
\hline
\end{tabular}

\begin{tabular}{|l|c|c|}
\hline \multicolumn{1}{|c|}{ Lower limbs } & & \\
\hline Main complaint Nerve Palpation & & \\
\hline \multicolumn{1}{|c|}{ R } & L \\
\hline Fibular & & \\
\hline Posterior tibial & & \\
\hline
\end{tabular}

key: $\mathrm{N}=$ normal; $\mathrm{T}=$ thickened; $\mathrm{P}=$ pain; $\mathrm{S}=$ Tinel's sign $(+)$

\begin{tabular}{|l|l|l|l|}
\hline \multicolumn{2}{|c|}{ Strength evaluation } & R & L \\
\hline $\begin{array}{l}\text { Elevates hallux } \\
\text { Hallux extension (fibular nerve) }\end{array}$ & & \\
\hline $\begin{array}{l}\text { Elevate foot } \\
\text { Foot dorsiflexion (fibular nerve) }\end{array}$ & & \\
\hline
\end{tabular}

key: $\mathrm{S}=$ strong; $\mathrm{D}=$ diminished; $\mathrm{P}=$ paralysed or $5=$ strong; $4=$ partial resistance; $3=$ complete movement; $2=$ partial movement; $1=$ contracture; $0=$ paralysed

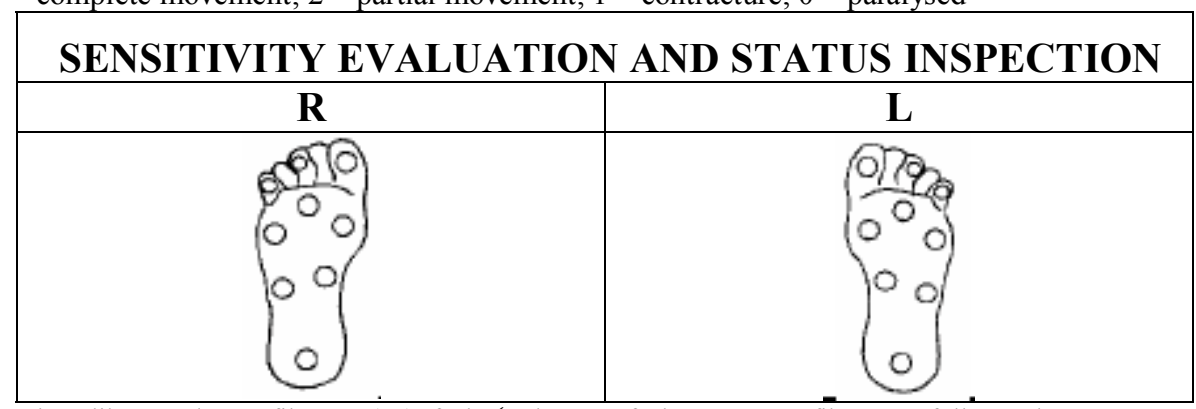

key: lilac pen / monofilament (2g): feels $\sqrt{ }$; does not feel X ; or monofilaments: follow colours

Mobile claw: M; rigid claw: R; bone absorption: $\%$ wound:

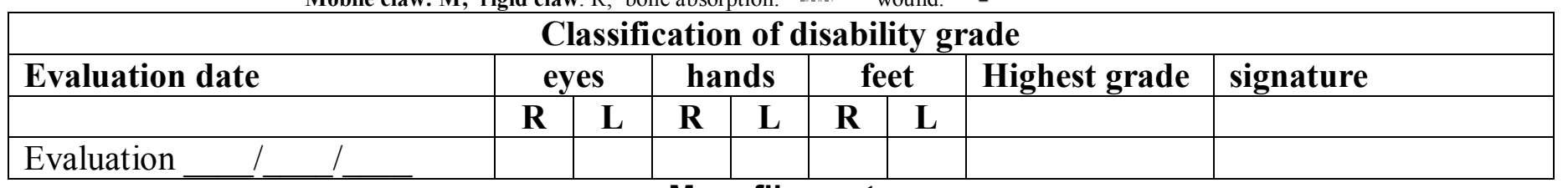

\section{Monofilaments}

\begin{tabular}{|c|c|c|}
\hline Monofilament & strength in grams & interpretation \\
\hline $1-$ green & 0.05 & Normal sensitivity in hand and foot \\
\hline 2 - blue & 0.20 & $\begin{array}{l}\text { Diminished sensitivity in hand and normal in foot / Difficulty } \\
\text { in distinguishing texture (light touch) }\end{array}$ \\
\hline 3 - Lilac & 2.00 & $\begin{array}{l}\text { Diminished protective sensitivity in hand / Incapable of } \\
\text { distinguishing texture / Difficulty in distinguishing forms and } \\
\text { temperatures }\end{array}$ \\
\hline 4 - dark red & 4.00 & $\begin{array}{l}\text { Loss of protective sensitivity in hand and sometimes in foot } \\
\text { / loss of texture discrimination / Incapable of distinguishing } \\
\text { forms and temperatures }\end{array}$ \\
\hline 5 - orange or red (mark with an $\mathrm{X}$ ) & 10.00 & $\begin{array}{l}\text { Loss of protective sensitivity in foot / loss of texture } \\
\text { discrimination / Incapable of distinguishing forms and } \\
\text { temperatures }\end{array}$ \\
\hline 6 - red circle & 300.00 & $\begin{array}{l}\text { Only has sensation when deep pressure is applied to hand } \\
\text { and foot }\end{array}$ \\
\hline 7 - black & $\begin{array}{c}\text { No response to } 300 \mathrm{~g} \\
\text { monofilament }\end{array}$ & Loss of sensation even to deep pressure in hand and foot \\
\hline
\end{tabular}

EPISODE NUMBER: 


\begin{tabular}{|l|l|l|l|}
\hline $\mathbf{1}$ & Adverse reaction & $\mathbf{1 8}$ & Neuritis \\
\hline $\mathbf{2}$ & ENL & $\mathbf{1 9}$ & Neuritis + Adverse reaction \\
\hline $\mathbf{3}$ & Necrotizing ENL & $\mathbf{2 0}$ & Neuritis + ENL \\
\hline $\mathbf{4}$ & Polymorphous erythema & $\mathbf{2 1}$ & Neuritis + Mixed reaction \\
\hline $\mathbf{5}$ & Arthritis & $\mathbf{2 2}$ & Neuritis + Necrotizing ENL \\
\hline $\mathbf{6}$ & Lymphadenopathy & $\mathbf{2 3}$ & Neuritis + Polymorphous erythema \\
\hline $\mathbf{7}$ & Orchitis & $\mathbf{2 4}$ & Neuritis + Arthritis \\
\hline $\mathbf{8}$ & Iritis/lridocyclitis & $\mathbf{2 5}$ & Neuritis + Lymphadenopathy \\
\hline $\mathbf{9}$ & Reaction hand and foot & $\mathbf{2 6}$ & Neuritis + Orchitis \\
\hline $\mathbf{1 0}$ & ENL+ Necrotizing ENL & $\mathbf{2 7}$ & Neuritis + Iritis/ Iridocyclitis \\
\hline $\mathbf{1 1}$ & ENL+ polymorphous erythema & $\mathbf{2 8}$ & Neuritis + Reaction hand/foot \\
\hline $\mathbf{1 2}$ & ENL+ orchitis & $\mathbf{2 9}$ & Neuritis + ENL + Necrotizing ENL \\
\hline $\mathbf{1 3}$ & ENL+ arthritis & $\mathbf{3 0}$ & Neuritis + ENL+ Polymorphous erythema \\
\hline $\mathbf{1 4}$ & ENL+ Lymphadenopathy & $\mathbf{3 1}$ & Neuritis + ENL+ orchitis \\
\hline $\mathbf{1 5}$ & ENL+ Iritis/ Iridocyclitis & $\mathbf{3 2}$ & Neuritis + ENL+ arthritis \\
\hline $\mathbf{1 6}$ & ENL+ Reaction hand/foot & $\mathbf{3 3}$ & Neuritis + ENL+ Lymphadenopathy \\
\hline $\mathbf{1 7}$ & Mixed reaction/ Type 1 + Type 2 & $\mathbf{3 4}$ & Neuritis + ENL+ Iritis/lridocyclitis \\
\hline & & $\mathbf{3 5}$ & Neuritis + ENL+ Reaction hand/foot \\
\hline
\end{tabular}

\section{Involvement:}

\begin{tabular}{|l|l|l|l|}
\hline $\mathbf{1}$ & Cutaneous & $\mathbf{4}$ & Cutaneous + Systemic \\
\hline $\mathbf{2}$ & Neural & $\mathbf{5}$ & Neural + Systemic \\
\hline $\mathbf{3}$ & Cutaneous + Neural & $\mathbf{6}$ & Cutaneous + Neural + Systemic \\
\hline
\end{tabular}

\section{Possible triggering factors:}

\begin{tabular}{|l|l|l|l|}
\hline $\mathbf{1}$ & Concomitant infections & $\mathbf{5}$ & Medication \\
\hline $\mathbf{2}$ & Pregnancy & $\mathbf{6}$ & Vaccination \\
\hline $\mathbf{3}$ & Surgery & $\mathbf{7}$ & Not identified \\
\hline $\mathbf{4}$ & Emotional distress & $\mathbf{8}$ & Others \\
\hline
\end{tabular}

Treatment:

\begin{tabular}{|c|l|l|l|}
\hline $\mathbf{1}$ & Corticosteroids & $\mathbf{8}$ & Thalidomide+ Clofazimine \\
\hline $\mathbf{2}$ & Thalidomide & $\mathbf{9}$ & Thalidomide + Pentoxifylline \\
\hline $\mathbf{3}$ & Clofazimine & $\mathbf{1 0}$ & Corticosteroids + Thalidomide + Clofazimine \\
\hline $\mathbf{4}$ & Pentoxifylline & $\mathbf{1 1}$ & Corticosteroids + Pentoxifylline + Thalidomide \\
\hline $\mathbf{5}$ & Corticosteroids + Thalidomide & $\mathbf{1 2}$ & Corticosteroids + Pentoxifylline + Clofazimine \\
\hline $\mathbf{6}$ & Corticosteroids + Clofazimine & $\mathbf{1 3}$ & $\begin{array}{l}\text { Corticosteroids + Pentoxifylline + Clofazimine + } \\
\text { Thalidomide }\end{array}$ \\
\hline $\mathbf{7}$ & Corticosteroids + Pentoxifylline & $\mathbf{1 4}$ & Others \\
\hline
\end{tabular}


EXAMINATION OF PERIPHERAL NERVES

Diagnosis and follow-up of reaction episodes

\begin{tabular}{|c|c|c|c|c|}
\hline \multirow[b]{2}{*}{ NERVES } & \multicolumn{2}{|c|}{$\begin{array}{l}\text { KEY } \\
\text { NERVE EXAMINATION } \\
0 \text { - Normal } \\
\text { 1- Thickened } \\
\text { 2- Nerve abscess } \\
\end{array}$} & \multicolumn{2}{|c|}{$\begin{array}{l}\text { KEY } \\
\text { SCALE OF INDICATED NEURAL PAIN } \\
0 \text { - No pain } \\
1 \text { - Weak pain } \\
2 \text { - Strong pain }\end{array}$} \\
\hline & RIGHT & LEFT & RIGHT & LEFT \\
\hline \multicolumn{5}{|l|}{ Ulnar } \\
\hline \multicolumn{5}{|l|}{ Median } \\
\hline \multicolumn{5}{|l|}{ Radial } \\
\hline \multicolumn{5}{|l|}{ Fibular } \\
\hline \multicolumn{5}{|l|}{ Posterior Tibial } \\
\hline Others & & & & \\
\hline
\end{tabular}

Signature and stamp of medical examiner

\section{REQUEST OF LABORATORY EXAMS - reaction episodes}

C-REACTIVE PROTEIN (Register result in Block V, page 123)

OBS:

Signature and stamp from medical examiner 


\section{SIMPLIFIED EVALUATION OF NEURAL FUNCTION AND COMPLICATIONS Diagnosis and follow-up of reaction episodes}

\begin{tabular}{|l|c|c|}
\hline \multicolumn{1}{|c|}{ Face } & & \\
\hline \multicolumn{1}{|c|}{ Nose } & R & L \\
\hline Main complaint & & \\
\hline dryness (S/N) & & \\
\hline abrasions (S/N) & & \\
\hline Perforation of the septum (S/N) & R & L \\
\hline & & \\
\hline Main complaint w/o force (mm) & & \\
\hline Closes eyes wo & & \\
\hline Closes eyes w/ force (mm) & & \\
\hline Cornea diminished sensibility (S/N) & & \\
\hline Cornea opacity (S/N) & & \\
\hline Cataract (S/N) & & \\
\hline Visual acuity & & \\
\hline
\end{tabular}

\begin{tabular}{|l|c|c|}
\hline \multicolumn{1}{|c|}{ Upper limbs } & & \\
\hline Main complaint Nerve palpation & & \\
\hline \multicolumn{1}{|c|}{ R } & L \\
\hline Ulnar & & \\
\hline Median & & \\
\hline Radius & & \\
\hline
\end{tabular}

key: $\mathrm{N}=$ normal; $\mathrm{T}=$ thickened; $\mathrm{P}=$ pain; $\mathrm{S}=$ Tinel's sign $(+)$

\begin{tabular}{|l|l|l|l|}
\hline \multicolumn{2}{|c|}{ Strength evaluation } & R & L \\
\hline Opens little finger & & \\
Abduction of the $5^{\text {th }}$ finger (ulnar nerve) & & & \\
\hline $\begin{array}{l}\text { Elevates thumb } \\
\text { Abduction of the thumb (median nerve) }\end{array}$ & & & \\
\hline $\begin{array}{l}\text { Elevates wrist } \\
\text { Wrist extension (radial nerve) }\end{array}$ & & & \\
\hline
\end{tabular}

key: $\mathrm{S}=$ strong; $\mathrm{D}=$ diminished; $\mathrm{P}=$ paralysed $\quad$ or $5=$ strong; $4=$ partial resistance; $3=$ complete movement; $2=$ partial movement; $1=$ contraction; $0=$ paralysed

\section{SENSITIVITY EVALUATION AND STATUS INSPECTION}

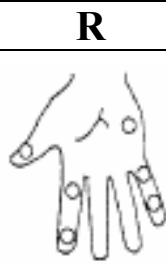

L

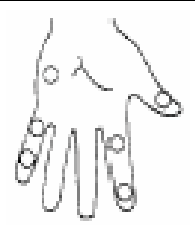

key: lilac pen / monofilament (2g): feels $\sqrt{ }$; does not feel X; or monofilaments: follow colours

Mobile claw: $M$; rigid claw: $\mathrm{R}$; bone absorption: $*$ wound: 난 


\begin{tabular}{|l|c|c|}
\hline \multicolumn{1}{|c|}{ Lower limbs } & & \\
\hline Main complaint Nerve Palpation & & \\
\hline \multicolumn{1}{|c|}{ R } & L \\
\hline Fibular & & \\
\hline Posterior tibial & & \\
\hline
\end{tabular}

key: $\mathrm{N}=$ normal; $\mathrm{T}=$ thickened; $\mathrm{P}=$ pain; $\mathrm{S}=$ Tinel's sign $(+)$

\begin{tabular}{|l|l|l|l|}
\hline \multicolumn{2}{|c|}{ Strength evaluation } & R & L \\
\hline Elevates hallux & 4 & & \\
\hline $\begin{array}{l}\text { Hallux extension (fibular nerve) } \\
\text { Foot dorsiflexion (fibular nerve) }\end{array}$ & & & \\
\hline
\end{tabular}

key: $\mathrm{S}=$ strong; $\mathrm{D}=$ diminished; $\mathrm{P}=$ paralysed or $5=$ strong; $4=$ partial resistance; $3=$ complete movement; $2=$ partial movement; $1=$ contracture; $0=$ paralysed

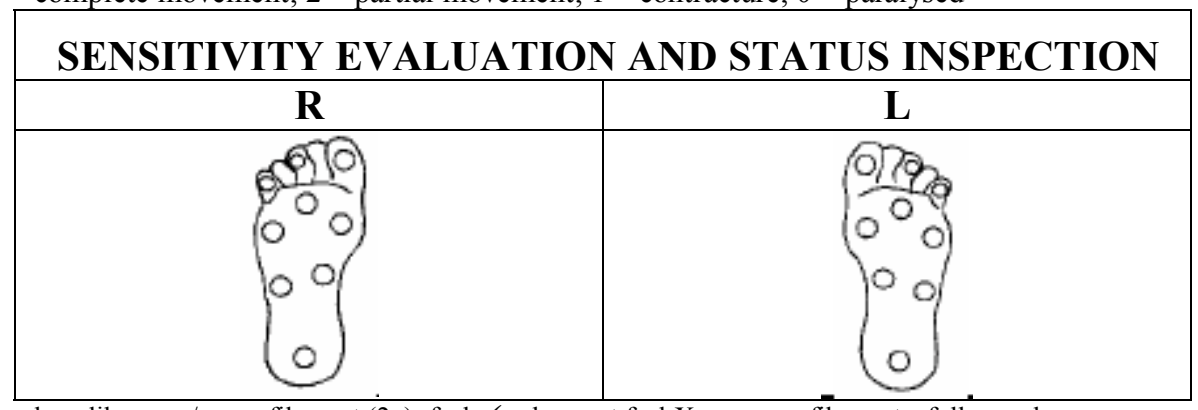

key: lilac pen / monofilament (2g): feels $\checkmark$; does not feel X ; or monofilaments: follow colours

Mobile claw: $\mathrm{M}$; rigid claw: $\mathrm{R}$; bone absorption: $\%$ wound:

\begin{tabular}{|c|c|c|c|c|c|c|c|c|}
\hline \multicolumn{9}{|c|}{ Classification of disability grade } \\
\hline Evaluation date & & & & & & & Highest grade & signature \\
\hline & $\mathbf{R}$ & $\mathbf{L}$ & $\mathbf{R}$ & $\mathbf{L}$ & $\mathbf{R}$ & $\mathbf{L}$ & & \\
\hline Evaluation & & & & & & & & \\
\hline
\end{tabular}

\section{Monofilaments}

\begin{tabular}{|l|c|l|}
\hline Monofilament & strength in grams & interpretation \\
\hline 1 - green & 0.05 & Normal sensitivity in hand and foot \\
\hline 3 - blue & 0.20 & $\begin{array}{l}\text { Diminished sensitivity in hand and normal in foot / Difficulty } \\
\text { in distinguishing texture (light touch) }\end{array}$ \\
\hline $4-$ dark red & 2.00 & $\begin{array}{l}\text { Diminished protective sensitivity in hand / Incapable of } \\
\text { distinguishing texture / Difficulty in distinguishing forms and } \\
\text { temperatures }\end{array}$ \\
\hline 5 - orange or red (mark with an X) & 4.00 & $\begin{array}{l}\text { Loss of protective sensitivity in hand and sometimes in foot } \\
\text { / loss of texture discrimination / Incapable of distinguishing } \\
\text { forms and temperatures }\end{array}$ \\
\hline 6 - red circle & 10.00 & $\begin{array}{l}\text { Loss of protective sensitivity in foot / loss of texture } \\
\text { discrimination / Incapable of distinguishing forms and } \\
\text { temperatures }\end{array}$ \\
\hline 7 - black & 300.00 & $\begin{array}{l}\text { Only has sensation when deep pressure is applied to hand } \\
\text { and foot }\end{array}$ \\
\hline
\end{tabular}


DIAGNOSIS AND FOLLOW-UP OF REACTION FORM

EPISODE NUMBER:

REACTION

\begin{tabular}{|l|l|l|l|}
\hline $\mathbf{1}$ & Adverse reaction & $\mathbf{1 8}$ & Neuritis \\
\hline $\mathbf{2}$ & ENL & $\mathbf{1 9}$ & Neuritis + Adverse reaction \\
\hline $\mathbf{3}$ & Necrotizing ENL & $\mathbf{2 0}$ & Neuritis + ENL \\
\hline $\mathbf{4}$ & Polymorphous erythema & $\mathbf{2 1}$ & Neuritis + Mixed reaction \\
\hline $\mathbf{5}$ & Arthritis & $\mathbf{2 2}$ & Neuritis + Necrotizing ENL \\
\hline $\mathbf{6}$ & Lymphadenopathy & $\mathbf{2 3}$ & Neuritis + Polymorphous erythema \\
\hline $\mathbf{7}$ & Orchitis & $\mathbf{2 4}$ & Neuritis + Arthritis \\
\hline $\mathbf{8}$ & Iritis/Iridocyclitis & $\mathbf{2 5}$ & Neuritis + Lymphadenopathy \\
\hline $\mathbf{9}$ & Reaction hand and foot & $\mathbf{2 6}$ & Neuritis + Orchitis \\
\hline $\mathbf{1 0}$ & ENL+ Necrotizing ENL & $\mathbf{2 7}$ & Neuritis + Iritis/ Iridocyclitis \\
\hline $\mathbf{1 1}$ & ENL+ polymorphous erythema & $\mathbf{2 8}$ & Neuritis + Reaction hand/foot \\
\hline $\mathbf{1 2}$ & ENL+ orchitis & $\mathbf{2 9}$ & Neuritis + ENL+ Necrotizing ENL \\
\hline $\mathbf{1 3}$ & ENL+ arthritis & $\mathbf{3 0}$ & Neuritis + ENL+ Polymorphous erythema \\
\hline $\mathbf{1 4}$ & ENL+ Lymphadenopathy & $\mathbf{3 1}$ & Neuritis + ENL+ orchitis \\
\hline $\mathbf{1 5}$ & ENL+ Iritis/ Iridocyclitis & $\mathbf{3 2}$ & Neuritis + ENL+ arthritis \\
\hline $\mathbf{1 6}$ & ENL+ Reaction hand/foot & $\mathbf{3 3}$ & Neuritis + ENL+ Lymphadenopathy \\
\hline $\mathbf{1 7}$ & Mixed reaction/ Type 1 + Type 2 & $\mathbf{3 4}$ & Neuritis + ENL+ Iritis/lridocyclitis \\
\hline & & $\mathbf{3 5}$ & Neuritis + ENL+ Reaction hand/foot \\
\hline
\end{tabular}

Involvement:

\begin{tabular}{|l|l|l|l|}
\hline $\mathbf{1}$ & Cutaneous & $\mathbf{4}$ & Cutaneous + Systemic \\
\hline $\mathbf{2}$ & Neural & $\mathbf{5}$ & Neural + Systemic \\
\hline $\mathbf{3}$ & Cutaneous + Neural & $\mathbf{6}$ & Cutaneous + Neural + Systemic \\
\hline
\end{tabular}

Possible triggering factors:

\begin{tabular}{|l|l|l|l|}
\hline $\mathbf{1}$ & Concomitant infections & $\mathbf{5}$ & Medication \\
\hline $\mathbf{2}$ & Pregnancy & $\mathbf{6}$ & Vaccination \\
\hline $\mathbf{3}$ & Surgery & $\mathbf{7}$ & Not identified \\
\hline $\mathbf{4}$ & Emotional distress & $\mathbf{8}$ & Others \\
\hline
\end{tabular}

Treatment:

\begin{tabular}{|l|l|l|l|}
\hline $\mathbf{1}$ & Corticosteroids & $\mathbf{8}$ & Thalidomide+ Clofazimine \\
\hline $\mathbf{2}$ & Thalidomide & $\mathbf{9}$ & Thalidomide + Pentoxifylline \\
\hline $\mathbf{3}$ & Clofazimine & $\mathbf{1 0}$ & Corticosteroids + Thalidomide + Clofazimine \\
\hline $\mathbf{4}$ & Pentoxifylline & $\mathbf{1 1}$ & Corticosteroids + Pentoxifylline + Thalidomide \\
\hline $\mathbf{5}$ & Corticosteroids + Thalidomide & $\mathbf{1 2}$ & Corticosteroids + Pentoxifylline + Clofazimine \\
\hline $\mathbf{6}$ & Corticosteroids + Clofazimine & $\mathbf{1 3}$ & $\begin{array}{l}\text { Corticosteroids + Pentoxifylline + Clofazimine + } \\
\text { Thalidomide }\end{array}$ \\
\hline $\mathbf{7}$ & Corticosteroids + Pentoxifylline & $\mathbf{1 4}$ & Others \\
\hline
\end{tabular}




\begin{tabular}{|c|l|l|l|l|l|l|l|l|l|l|l|l|}
\hline PATIENT INITIALS & & & & & PATIENT NUMBER: & & & & & DATE OF VISIT: & \\
\hline PATIENT INITIALS & & & & & PATIENT NUMBER: & & & & & DATE OF VISIT: \\
\hline
\end{tabular}

EXAMINATION OF PERIPHERAL NERVES

Diagnosis and follow-up of reaction episodes

\begin{tabular}{|c|c|c|c|c|}
\hline \multirow[b]{2}{*}{ NERVES } & \multicolumn{2}{|c|}{$\begin{array}{l}\text { KEY } \\
\text { NERVE EXAMINATION } \\
0 \text { - Normal } \\
1 \text { - Thickened } \\
\text { 2- Nerve abscess } \\
\end{array}$} & \multicolumn{2}{|c|}{$\begin{array}{l}\text { KEY } \\
\text { SCALE OF INDICATED NEURAL PAIN } \\
0 \text { - No pain } \\
1 \text { - Weak pain } \\
2 \text { - Strong pain }\end{array}$} \\
\hline & RIGHT & LEFT & RIGHT & LEFT \\
\hline \multicolumn{5}{|l|}{ Ulnar } \\
\hline \multicolumn{5}{|l|}{ Median } \\
\hline \multicolumn{5}{|l|}{ Radial } \\
\hline \multicolumn{5}{|l|}{ Fibular } \\
\hline \multicolumn{5}{|l|}{ Posterior Tibial } \\
\hline Others & & & & \\
\hline
\end{tabular}

Signature and stamp of medical examiner

\section{REQUEST OF LABORATORY EXAMS - reaction episodes}

\begin{tabular}{|l|l|}
\hline & C-REACTIVE PROTEIN (Register result in Block V, page 123) \\
\hline
\end{tabular}

OBS: 


\section{SIMPLIFIED EVALUATION OF NEURAL FUNCTION AND COMPLICATIONS Diagnosis and follow-up of reaction episodes}

\begin{tabular}{|l|c|c|}
\hline \multicolumn{1}{|c|}{ Face } & & \\
\hline \multicolumn{1}{|c|}{ Nose } & R & L \\
\hline Main complaint & & \\
\hline dryness (S/N) & & \\
\hline abrasions (S/N) & & \\
\hline Perforation of the septum (S/N) & R & L \\
\hline & & \\
\hline Main complaint w/o force (mm) & & \\
\hline Closes eyes wo & & \\
\hline Closes eyes w/ force (mm) & & \\
\hline Cornea diminished sensibility (S/N) & & \\
\hline Cornea opacity (S/N) & & \\
\hline Cataract (S/N) & & \\
\hline Visual acuity & & \\
\hline
\end{tabular}

\begin{tabular}{|l|c|c|}
\hline \multicolumn{1}{|c|}{ Upper limbs } & & \\
\hline Main complaint Nerve palpation & & \\
\hline \multicolumn{1}{|c|}{ R } & L \\
\hline Ulnar & & \\
\hline Median & & \\
\hline Radius & & \\
\hline
\end{tabular}

key: $\mathrm{N}=$ normal; $\mathrm{T}=$ thickened; $\mathrm{P}=$ pain; $\mathrm{S}=$ Tinel's sign $(+)$

\begin{tabular}{|l|l|l|l|}
\hline \multicolumn{2}{|c|}{ Strength evaluation } & R & L \\
\hline Opens little finger & & \\
Abduction of the $5^{\text {th }}$ finger (ulnar nerve) & & & \\
\hline $\begin{array}{l}\text { Elevates thumb } \\
\text { Abduction of the thumb (median nerve) }\end{array}$ & & & \\
\hline $\begin{array}{l}\text { Elevates wrist } \\
\text { Wrist extension (radial nerve) }\end{array}$ & & & \\
\hline
\end{tabular}

key: $\mathrm{S}=$ strong; $\mathrm{D}=$ diminished; $\mathrm{P}=$ paralysed $\quad$ or $5=$ strong; $4=$ partial resistance; $3=$ complete movement; $2=$ partial movement; $1=$ contraction; $0=$ paralysed

\section{SENSITIVITY EVALUATION AND STATUS INSPECTION}

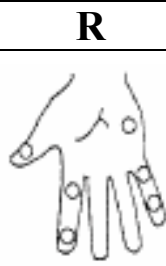

L

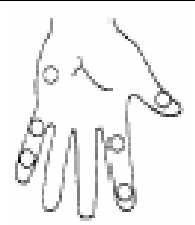

key: lilac pen / monofilament (2g): feels $\sqrt{ }$; does not feel X; or monofilaments: follow colours

Mobile claw: $M$; rigid claw: $\mathrm{R}$; bone absorption: $*$ wound: 난 


\begin{tabular}{|l|c|c|}
\hline \multicolumn{1}{|c|}{ Lower limbs } & & \\
\hline Main complaint Nerve Palpation & & \\
\hline \multicolumn{1}{|c|}{ R } & L \\
\hline Fibular & & \\
\hline Posterior tibial & & \\
\hline
\end{tabular}

key: $\mathrm{N}=$ normal; $\mathrm{T}=$ thickened; $\mathrm{P}=$ pain; $\mathrm{S}=$ Tinel's sign $(+)$

\begin{tabular}{|l|l|l|l|}
\hline \multicolumn{2}{|c|}{ Strength evaluation } & R & L \\
\hline Elevates hallux & 4 & & \\
\hline $\begin{array}{l}\text { Hallux extension (fibular nerve) } \\
\text { Foot dorsiflexion (fibular nerve) }\end{array}$ & & & \\
\hline
\end{tabular}

key: $\mathrm{S}=$ strong; $\mathrm{D}=$ diminished; $\mathrm{P}=$ paralysed or $5=$ strong; $4=$ partial resistance; $3=$ complete movement; $2=$ partial movement; $1=$ contracture; $0=$ paralysed

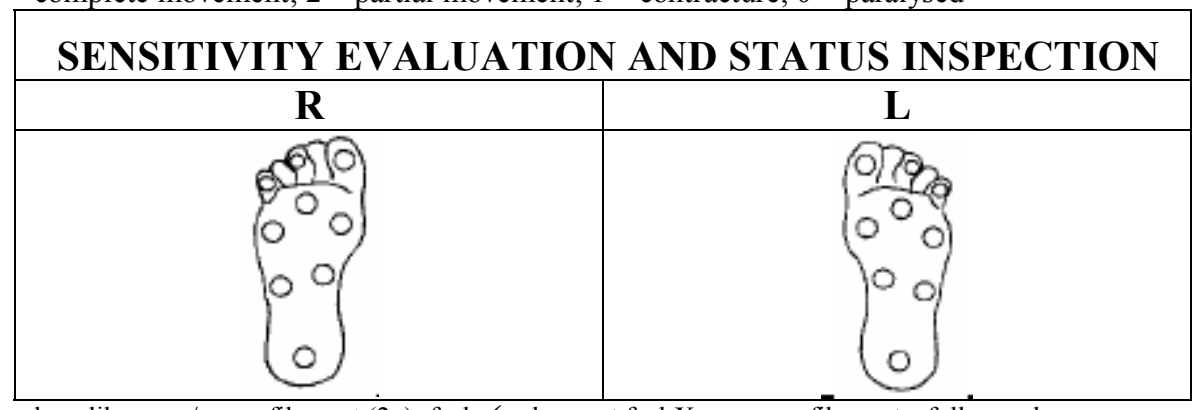

key: lilac pen / monofilament (2g): feels $\checkmark$; does not feel X ; or monofilaments: follow colours

Mobile claw: $\mathrm{M}$; rigid claw: $\mathrm{R}$; bone absorption: $\%$ wound:

\begin{tabular}{|c|c|c|c|c|c|c|c|c|}
\hline \multicolumn{9}{|c|}{ Classification of disability grade } \\
\hline Evaluation date & & & & & & & Highest grade & signature \\
\hline & $\mathbf{R}$ & $\mathbf{L}$ & $\mathbf{R}$ & $\mathbf{L}$ & $\mathbf{R}$ & $\mathbf{L}$ & & \\
\hline Evaluation & & & & & & & & \\
\hline
\end{tabular}

\section{Monofilaments}

\begin{tabular}{|l|c|l|}
\hline Monofilament & strength in grams & interpretation \\
\hline 1 - green & 0.05 & Normal sensitivity in hand and foot \\
\hline 3 - blue & 0.20 & $\begin{array}{l}\text { Diminished sensitivity in hand and normal in foot / Difficulty } \\
\text { in distinguishing texture (light touch) }\end{array}$ \\
\hline $4-$ dark red & 2.00 & $\begin{array}{l}\text { Diminished protective sensitivity in hand / Incapable of } \\
\text { distinguishing texture / Difficulty in distinguishing forms and } \\
\text { temperatures }\end{array}$ \\
\hline 5 - orange or red (mark with an X) & 4.00 & $\begin{array}{l}\text { Loss of protective sensitivity in hand and sometimes in foot } \\
\text { / loss of texture discrimination / Incapable of distinguishing } \\
\text { forms and temperatures }\end{array}$ \\
\hline 6 - red circle & 10.00 & $\begin{array}{l}\text { Loss of protective sensitivity in foot / loss of texture } \\
\text { discrimination / Incapable of distinguishing forms and } \\
\text { temperatures }\end{array}$ \\
\hline 7 - black & 300.00 & $\begin{array}{l}\text { Only has sensation when deep pressure is applied to hand } \\
\text { and foot }\end{array}$ \\
\hline
\end{tabular}


EPISODE NUMBER:

\begin{tabular}{|l|l|l|}
\hline $\mathbf{1}$ & Adverse reaction & 18 \\
\hline $\mathbf{2}$ & ENL & 19 \\
\hline $\mathbf{3}$ & Necrotizing ENL & 2 \\
\hline $\mathbf{4}$ & Polymorphous erythema & 21 \\
\hline $\mathbf{5}$ & Arthritis & 22 \\
\hline $\mathbf{6}$ & Lymphadenopathy & 23 \\
\hline $\mathbf{7}$ & Orchitis & 25 \\
\hline $\mathbf{8}$ & Iritis/Iridocyclitis & 26 \\
\hline $\mathbf{9}$ & Reaction hand and foot & 27 \\
\hline $\mathbf{1 0}$ & ENL+ Necrotizing ENL & 28 \\
\hline $\mathbf{1 1}$ & ENL+ polymorphous erythema & 29 \\
\hline 12 & ENL+ orchitis & 30 \\
\hline 13 & ENL+ arthritis & 31 \\
\hline 14 & ENL+ Lymphadenopathy & 32 \\
\hline 15 & ENL+ Iritis/ Iridocyclitis & 33 \\
\hline 16 & ENL+ Reaction hand/foot & 34 \\
\hline 17 & Mixed reaction/ Type 1 + Type 2 & 35 \\
\hline & & \\
\hline
\end{tabular}

\section{REACTION DIAGNOSIS AND FOLLOW-UP FORM REACTION}

\begin{tabular}{|l|l|}
\hline $\mathbf{1 8}$ & Neuritis \\
\hline $\mathbf{1 9}$ & Neuritis + Adverse reaction \\
\hline $\mathbf{2 0}$ & Neuritis + ENL \\
$\mathbf{2 1}$ & Neuritis + Mixed reaction \\
\hline $\mathbf{2 2}$ & Neuritis + Necrotizing ENL \\
\hline $\mathbf{2 3}$ & Neuritis + Polymorphous erythema \\
\hline $\mathbf{2 4}$ & Neuritis + Arthritis \\
\hline $\mathbf{2 5}$ & Neuritis + Lymphadenopathy \\
\hline $\mathbf{2 6}$ & Neuritis + Orchitis \\
\hline $\mathbf{2 7}$ & Neuritis + Iritis/ Iridocyclitis \\
\hline $\mathbf{2 8}$ & Neuritis + Reaction hand/foot \\
\hline $\mathbf{2 9}$ & Neuritis + ENL+ Necrotizing ENL \\
\hline $\mathbf{3 0}$ & Neuritis + ENL+ Polymorphous erythema \\
\hline $\mathbf{3 1}$ & Neuritis + ENL+ orchitis \\
\hline $\mathbf{3 2}$ & Neuritis + ENL+ arthritis \\
\hline $\mathbf{3 3}$ & Neuritis + ENL+ Lymphadenopathy \\
\hline $\mathbf{3 4}$ & Neuritis + ENL+ Iritis/Iridocyclitis \\
\hline $\mathbf{3 5}$ & Neuritis + ENL+ Reaction hand/foot \\
\hline
\end{tabular}

Involvement:

\begin{tabular}{|l|l|l|l|}
\hline $\mathbf{1}$ & Cutaneous & $\mathbf{4}$ & Cutaneous + Systemic \\
\hline $\mathbf{2}$ & Neural & $\mathbf{5}$ & Neural + Systemic \\
\hline $\mathbf{3}$ & Cutaneous + Neural & $\mathbf{6}$ & Cutaneous + Neural + Systemic \\
\hline
\end{tabular}

Possible triggering factors:

\begin{tabular}{|l|l|l|l|}
\hline $\mathbf{1}$ & Concomitant infections & $\mathbf{5}$ & Medication \\
\hline $\mathbf{2}$ & Pregnancy & $\mathbf{6}$ & Vaccination \\
\hline $\mathbf{3}$ & Surgery & $\mathbf{7}$ & Not identified \\
\hline $\mathbf{4}$ & Emotional distress & $\mathbf{8}$ & Others \\
\hline
\end{tabular}

\section{Treatment:}

\begin{tabular}{|l|l|l|l|}
\hline $\mathbf{1}$ & Corticosteroids & $\mathbf{8}$ & Thalidomide+ Clofazimine \\
\hline $\mathbf{2}$ & Thalidomide & $\mathbf{9}$ & Thalidomide + Pentoxifylline \\
\hline $\mathbf{3}$ & Clofazimine & $\mathbf{1 0}$ & Corticosteroids + Thalidomide + Clofazimine \\
\hline $\mathbf{4}$ & Pentoxifylline & $\mathbf{1 1}$ & Corticosteroids + Pentoxifylline + Thalidomide \\
\hline $\mathbf{5}$ & Corticosteroids + Thalidomide & $\mathbf{1 2}$ & Corticosteroids + Pentoxifylline + Clofazimine \\
\hline $\mathbf{6}$ & Corticosteroids + Clofazimine & $\mathbf{1 3}$ & $\begin{array}{l}\text { Corticosteroids + Pentoxifylline + Clofazimine + } \\
\text { Thalidomide }\end{array}$ \\
\hline $\mathbf{7}$ & Corticosteroids + Pentoxifylline & $\mathbf{1 4}$ & Others \\
\hline
\end{tabular}




\begin{tabular}{|c|l|l|l|l|l|l|l|l|l|l|l|l|}
\hline PATIENT INITIALS & & & & & PATIENT NUMBER: & & & & & DATE OF VISIT: & \\
\hline PATIENT INITIALS & & & & & PATIENT NUMBER: & & & & & DATE OF VISIT: \\
\hline
\end{tabular}

EXAMINATION OF PERIPHERAL NERVES

Diagnosis and follow-up of reaction episodes

\begin{tabular}{|c|c|c|c|c|}
\hline \multirow[b]{2}{*}{ NERVES } & \multicolumn{2}{|c|}{$\begin{array}{l}\text { KEY } \\
\text { NERVE EXAMINATION } \\
0 \text { - Normal } \\
\text { 1- Thickened } \\
\text { 2- Nerve abscess }\end{array}$} & \multicolumn{2}{|c|}{$\begin{array}{l}\text { KEY } \\
\text { SCALE OF INDICATED NEURAL PAIN } \\
0 \text { - No pain } \\
1 \text { - Weak pain } \\
2 \text { - Strong pain }\end{array}$} \\
\hline & RIGHT & LEFT & RIGHT & LEFT \\
\hline Ulnar & & & & \\
\hline Median & & & & \\
\hline Radial & & & & \\
\hline Fibular & & & & \\
\hline Posterior Tibial & & & & \\
\hline Others & & & & \\
\hline
\end{tabular}

Signature and stamp of medical examiner

\section{REQUEST FOR LABORATORY EXAMS - reaction episodes}

C-REACTIVE PROTEIN (Register result in Block V, page 123)

OBS:

Signature and stamp of medical examiner 


\section{SIMPLIFIED EVALUATION OF NEURAL FUNCTION AND COMPLICATIONS Diagnosis and follow-up of reaction episodes}

\begin{tabular}{|l|c|c|}
\hline \multicolumn{1}{|c|}{ Face } & & \\
\hline \multicolumn{1}{|c|}{ Nose } & R & L \\
\hline Main complaint & & \\
\hline dryness (S/N) & & \\
\hline abrasions (S/N) & & \\
\hline Perforation of the septum (S/N) & R & L \\
\hline Main complaint & & \\
\hline Closes eyes w/o force (mm) & & \\
\hline Closes eyes w/ force (mm) & & \\
\hline Cornea diminished sensibility (S/N) & & \\
\hline Cornea opacity (S/N) & & \\
\hline Cataract (S/N) & & \\
\hline Visual acuity & & \\
\hline
\end{tabular}

\begin{tabular}{|l|c|c|}
\hline \multicolumn{1}{|c|}{ Upper limbs } & & \\
\hline Main complaint Nerve palpation & & \\
\hline \multicolumn{1}{|c|}{ R } & L \\
\hline Ulnar & & \\
\hline Median & & \\
\hline Radius & & \\
\hline
\end{tabular}

key: $\mathrm{N}=$ normal; $\mathrm{T}=$ thickened; $\mathrm{P}=$ pain; $\mathrm{S}=$ Tinel's sign $(+)$

\begin{tabular}{|l|l|l|l|}
\hline \multicolumn{2}{|c|}{ Strength evaluation } & R & L \\
\hline Opens little finger & & \\
Abduction of the $5^{\text {th }}$ finger (ulnar nerve) & -3 & & \\
\hline $\begin{array}{l}\text { Elevates thumb } \\
\text { Abduction of the thumb (median nerve) }\end{array}$ & -3 & & \\
\hline $\begin{array}{l}\text { Elevates wrist } \\
\text { Wrist extension (radial nerve) }\end{array}$ & & & \\
\hline
\end{tabular}

key: $\mathrm{S}=$ strong; $\mathrm{D}=$ diminished; $\mathrm{P}=$ paralysed or $5=$ strong; $4=$ partial resistance; $3=$ complete movement; $2=$ partial movement; $1=$ contraction; $0=$ paralysed

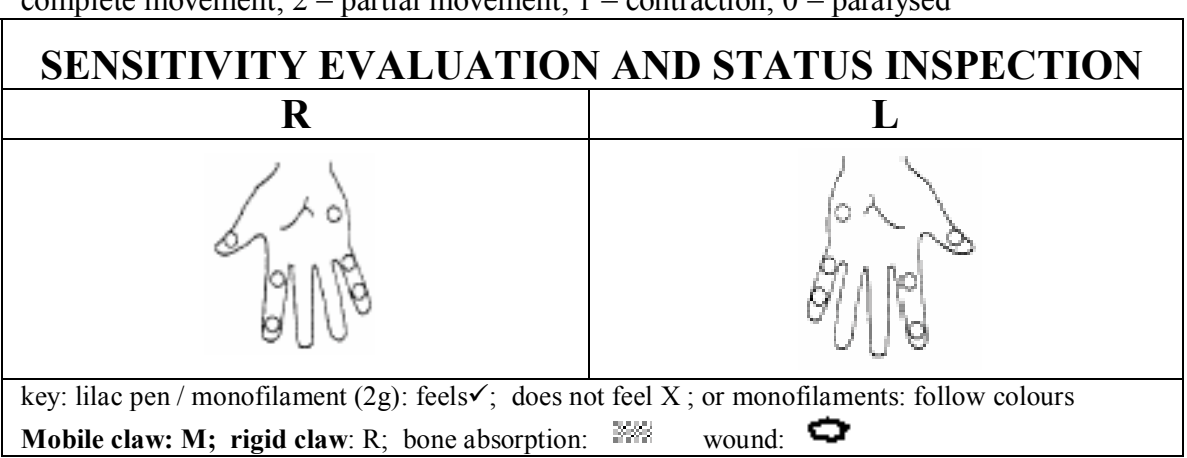

Signature and stamp of medical examiner 


\begin{tabular}{|l|c|c|}
\hline \multicolumn{1}{|c|}{ Lower limbs } & & \\
\hline Main complaint Nerve Palpation & & \\
\hline \multicolumn{1}{|c|}{ R } & L \\
\hline Fibular & & \\
\hline Posterior tibial & & \\
\hline
\end{tabular}

key: $\mathrm{N}=$ normal; $\mathrm{T}=$ thickened; $\mathrm{P}=$ pain; $\mathrm{S}=$ Tinel's sign $(+)$

\begin{tabular}{|l|l|l|l|}
\hline \multicolumn{2}{|c|}{ Strength evaluation } & R & L \\
\hline $\begin{array}{l}\text { Elevates hallux } \\
\text { Hallux extension (fibular nerve) }\end{array}$ & AL & & \\
\hline $\begin{array}{l}\text { Elevate foot } \\
\text { Foot dorsiflexion (fibular nerve) }\end{array}$ & & & \\
\hline
\end{tabular}

key: $\mathrm{S}=$ strong; $\mathrm{D}=$ diminished; $\mathrm{P}=$ paralysed or $5=$ strong; $4=$ partial resistance; $3=$ complete movement; $2=$ partial movement; $1=$ contracture; $0=$ paralysed

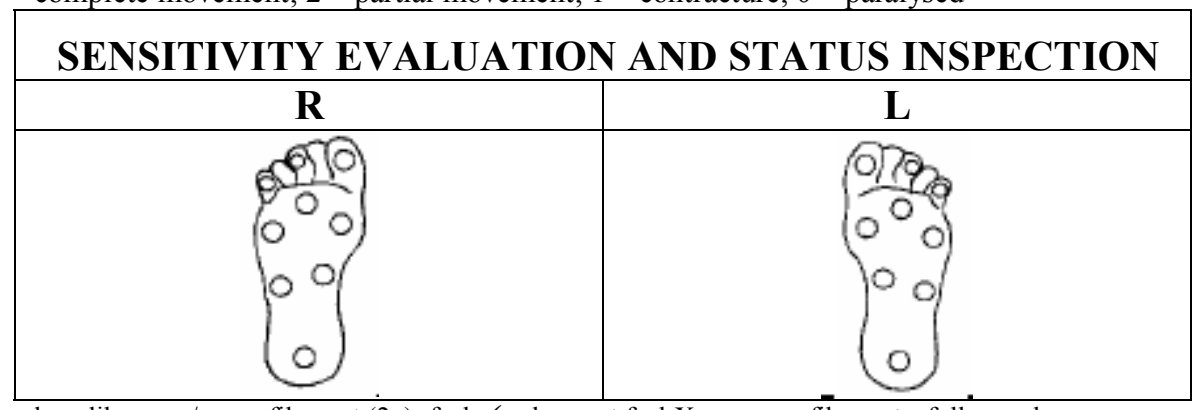

key: lilac pen / monofilament (2g): feels $\checkmark$; does not feel X ; or monofilaments: follow colours

Mobile claw: $\mathrm{M}$; rigid claw: $\mathrm{R}$; bone absorption: $\%$ wound:

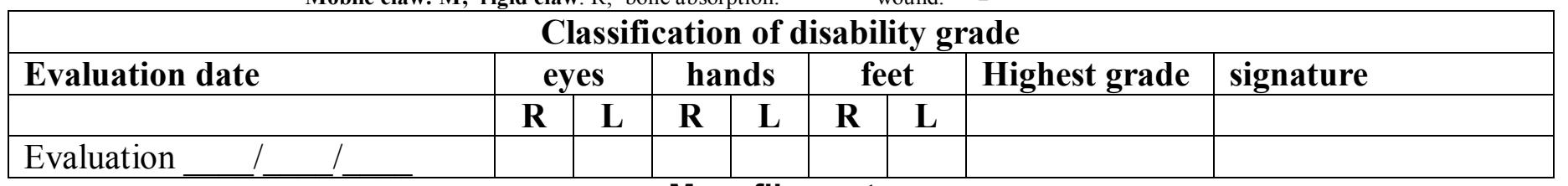

\section{Monofilaments}

\begin{tabular}{|l|c|l|}
\hline Monofilament & strength in grams & interpretation \\
\hline 1 - green & 0.05 & Normal sensitivity in hand and foot \\
\hline 3 - blue & 0.20 & $\begin{array}{l}\text { Diminished sensitivity in hand and normal in foot / Difficulty } \\
\text { in distinguishing texture (light touch) }\end{array}$ \\
\hline $4-$ dark red & 2.00 & $\begin{array}{l}\text { Diminished protective sensitivity in hand / Incapable of } \\
\text { distinguishing texture / Difficulty in distinguishing forms and } \\
\text { temperatures }\end{array}$ \\
\hline 5 - orange or red (mark with an X) & 4.00 & $\begin{array}{l}\text { Loss of protective sensitivity in hand and sometimes in foot } \\
\text { / loss of texture discrimination / Incapable of distinguishing } \\
\text { forms and temperatures }\end{array}$ \\
\hline 6 - red circle & 10.00 & $\begin{array}{l}\text { Loss of protective sensitivity in foot / loss of texture } \\
\text { discrimination / Incapable of distinguishing forms and } \\
\text { temperatures }\end{array}$ \\
\hline 7 - black & 300.00 & $\begin{array}{l}\text { Only has sensation when deep pressure is applied to hand } \\
\text { and foot }\end{array}$ \\
\hline
\end{tabular}




\section{DIAGNOSIS AND FOLLOW-UP OF REACTION FORM}

EPISODE NUMBER:

REACTION

\begin{tabular}{|l|l|l|l|}
\hline $\mathbf{1}$ & Adverse reaction & $\mathbf{1 8}$ & Neuritis \\
\hline $\mathbf{2}$ & ENL & $\mathbf{1 9}$ & Neuritis + Adverse reaction \\
\hline $\mathbf{3}$ & Necrotizing ENL & $\mathbf{2 0}$ & Neuritis + ENL \\
\hline $\mathbf{4}$ & Polymorphous erythema & $\mathbf{2 1}$ & Neuritis + Mixed reaction \\
\hline $\mathbf{5}$ & Arthritis & $\mathbf{2 2}$ & Neuritis + Necrotizing ENL \\
\hline $\mathbf{6}$ & Lymphadenopathy & $\mathbf{2 3}$ & Neuritis + Polymorphous erythema \\
\hline $\mathbf{7}$ & Orchitis & $\mathbf{2 4}$ & Neuritis + Arthritis \\
\hline $\mathbf{8}$ & Iritis/Iridocyclitis & $\mathbf{2 5}$ & Neuritis + Lymphadenopathy \\
\hline $\mathbf{9}$ & Reaction hand and foot & $\mathbf{2 6}$ & Neuritis + Orchitis \\
\hline $\mathbf{1 0}$ & ENL+ Necrotizing ENL & $\mathbf{2 7}$ & Neuritis + Iritis/ Iridocyclitis \\
\hline $\mathbf{1 1}$ & ENL+ polymorphous erythema & $\mathbf{2 8}$ & Neuritis + Reaction hand/foot \\
\hline $\mathbf{1 2}$ & ENL+ orchitis & $\mathbf{2 9}$ & Neuritis + ENL+ Necrotizing ENL \\
\hline $\mathbf{1 3}$ & ENL+ arthritis & $\mathbf{3 0}$ & Neuritis + ENL+ Polymorphous erythema \\
\hline $\mathbf{1 4}$ & ENL+ Lymphadenopathy & $\mathbf{3 1}$ & Neuritis + ENL+ orchitis \\
\hline $\mathbf{1 5}$ & ENL+ Iritis/ Iridocyclitis & $\mathbf{3 2}$ & Neuritis + ENL+ arthritis \\
\hline $\mathbf{1 6}$ & ENL+ Reaction hand/foot & $\mathbf{3 3}$ & Neuritis + ENL+ Lymphadenopathy \\
\hline $\mathbf{1 7}$ & Mixed reaction/ Type 1 + Type 2 & $\mathbf{3 4}$ & Neuritis + ENL+ Iritis/lridocyclitis \\
\hline & & $\mathbf{3 5}$ & Neuritis + ENL+ Reaction hand/foot \\
\hline
\end{tabular}

Involvement:

\begin{tabular}{|l|l|l|l|}
\hline $\mathbf{1}$ & Cutaneous & $\mathbf{4}$ & Cutaneous + Systemic \\
\hline $\mathbf{2}$ & Neural & $\mathbf{5}$ & Neural + Systemic \\
\hline $\mathbf{3}$ & Cutaneous + Neural & $\mathbf{6}$ & Cutaneous + Neural + Systemic \\
\hline
\end{tabular}

Possible triggering factors:

\begin{tabular}{|l|l|l|l|}
\hline $\mathbf{1}$ & Concomitant infections & $\mathbf{5}$ & Medication \\
\hline $\mathbf{2}$ & Pregnancy & $\mathbf{6}$ & Vaccination \\
\hline $\mathbf{3}$ & Surgery & $\mathbf{7}$ & Not identified \\
\hline $\mathbf{4}$ & Emotional distress & $\mathbf{8}$ & Others \\
\hline
\end{tabular}

\begin{tabular}{|l|l|l|l|}
\hline \multicolumn{2}{c|}{ Treatment: } \\
\hline $\mathbf{1}$ & Corticosteroids & $\mathbf{8}$ & Thalidomide+ Clofazimine \\
\hline $\mathbf{2}$ & Thalidomide & $\mathbf{9}$ & Thalidomide + Pentoxifylline \\
\hline $\mathbf{3}$ & Clofazimine & $\mathbf{1 0}$ & Corticosteroids + Thalidomide + Clofazimine \\
\hline $\mathbf{4}$ & Pentoxifylline & $\mathbf{1 1}$ & Corticosteroids + Pentoxifylline + Thalidomide \\
\hline $\mathbf{5}$ & Corticosteroids + Thalidomide & $\mathbf{1 2}$ & Corticosteroids + Pentoxifylline + Clofazimine \\
\hline $\mathbf{6}$ & Corticosteroids + Clofazimine & $\mathbf{1 3}$ & $\begin{array}{l}\text { Corticosteroids + Pentoxifylline + Clofazimine + } \\
\text { Thalidomide }\end{array}$ \\
\hline $\mathbf{7}$ & Corticosteroids + Pentoxifylline & $\mathbf{1 4}$ & Others \\
\hline
\end{tabular}


EXAMINATION OF PERIPHERAL NERVES

Diagnosis and follow-up of reaction episodes

\begin{tabular}{|l|c|c|c|c|}
\hline & \multicolumn{2}{|l|}{$\begin{array}{l}\text { KEY } \\
\text { NERVE EXAMINATION } \\
\text { 0- Normal } \\
\text { 1- Thickened } \\
\text { 2- Nerve abscess }\end{array}$} & \multicolumn{2}{l|}{$\begin{array}{l}\text { KEY } \\
\text { SCALE OF INDICATED NEURAL PAIN } \\
\text { 0- No pain } \\
\text { 1- Weak pain } \\
\text { 2- Strong pain }\end{array}$} \\
\hline \multicolumn{1}{|c|}{ NERVES } & \multicolumn{1}{|l|}{ RIGHT } & LEFT & \multicolumn{1}{c|}{ RIGHT } & LEFT \\
\hline Ulnar & & & & \\
\hline Median & & & & \\
\hline Radial & & & & \\
\hline Fibular & & & & \\
\hline Posterior Tibial & & & & \\
\hline Others & & & & \\
\hline
\end{tabular}

Signature and stamp of medical examiner

\section{REQUEST FOR LABORATORY TESTS - reactions}

\section{C-REACTIVE PROTEIN (Register result in Block V, page 123)}

OBS: 


\section{SIMPLIFIED EVALUATION OF NEURAL FUNCTION AND COMPLICATIONS Diagnosis and follow-up of reaction episodes}

\begin{tabular}{|l|c|c|}
\hline \multicolumn{1}{|c|}{ Face } & & \\
\hline \multicolumn{1}{|c|}{ Nose } & R & L \\
\hline Main complaint & & \\
\hline dryness (S/N) & & \\
\hline abrasions (S/N) & & \\
\hline Perforation of the septum (S/N) & R & L \\
\hline & & \\
\hline Main complaint w/o force (mm) & & \\
\hline Closes eyes wo & & \\
\hline Closes eyes w/ force (mm) & & \\
\hline Cornea diminished sensibility (S/N) & & \\
\hline Cornea opacity (S/N) & & \\
\hline Cataract (S/N) & & \\
\hline Visual acuity & & \\
\hline
\end{tabular}

\begin{tabular}{|l|c|c|}
\hline \multicolumn{1}{|c|}{ Upper limbs } & & \\
\hline Main complaint Nerve palpation & & \\
\hline \multicolumn{1}{|c|}{ R } & L \\
\hline Ulnar & & \\
\hline Median & & \\
\hline Radius & & \\
\hline
\end{tabular}

key: $\mathrm{N}=$ normal; $\mathrm{T}=$ thickened; $\mathrm{P}=$ pain; $\mathrm{S}=$ Tinel's sign $(+)$

\begin{tabular}{|l|l|l|l|}
\hline \multicolumn{2}{|c|}{ Strength evaluation } & R & L \\
\hline Opens little finger & & \\
Abduction of the $5^{\text {th }}$ finger (ulnar nerve) & & & \\
\hline $\begin{array}{l}\text { Elevates thumb } \\
\text { Abduction of the thumb (median nerve) }\end{array}$ & & & \\
\hline $\begin{array}{l}\text { Elevates wrist } \\
\text { Wrist extension (radial nerve) }\end{array}$ & & & \\
\hline
\end{tabular}

key: $\mathrm{S}=$ strong; $\mathrm{D}=$ diminished; $\mathrm{P}=$ paralysed $\quad$ or $5=$ strong; $4=$ partial resistance; $3=$ complete movement; $2=$ partial movement; $1=$ contraction; $0=$ paralysed

\section{SENSITIVITY EVALUATION AND STATUS INSPECTION}

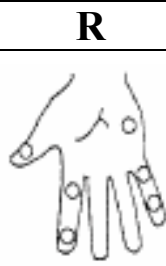

L

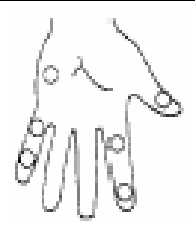

key: lilac pen / monofilament (2g): feels $\sqrt{ }$; does not feel X; or monofilaments: follow colours

Mobile claw: $M$; rigid claw: $\mathrm{R}$; bone absorption: $*$ wound: 난 


\begin{tabular}{|l|c|c|}
\hline \multicolumn{1}{|c|}{ Lower limbs } & & \\
\hline Main complaint Nerve Palpation & & \\
\hline \multicolumn{1}{|c|}{ R } & L \\
\hline Fibular & & \\
\hline Posterior tibial & & \\
\hline
\end{tabular}

key: $\mathrm{N}=$ normal; $\mathrm{T}=$ thickened; $\mathrm{P}=$ pain; $\mathrm{S}=$ Tinel's sign $(+)$

\begin{tabular}{|l|l|l|l|}
\hline \multicolumn{2}{|c|}{ Strength evaluation } & R & L \\
\hline $\begin{array}{l}\text { Elevates hallux } \\
\text { Hallux extension (fibular nerve) }\end{array}$ & AL & & \\
\hline $\begin{array}{l}\text { Elevate foot } \\
\text { Foot dorsiflexion (fibular nerve) }\end{array}$ & & & \\
\hline
\end{tabular}

key: $\mathrm{S}=$ strong; $\mathrm{D}=$ diminished; $\mathrm{P}=$ paralysed or $5=$ strong; $4=$ partial resistance; $3=$ complete movement; $2=$ partial movement; $1=$ contracture; $0=$ paralysed

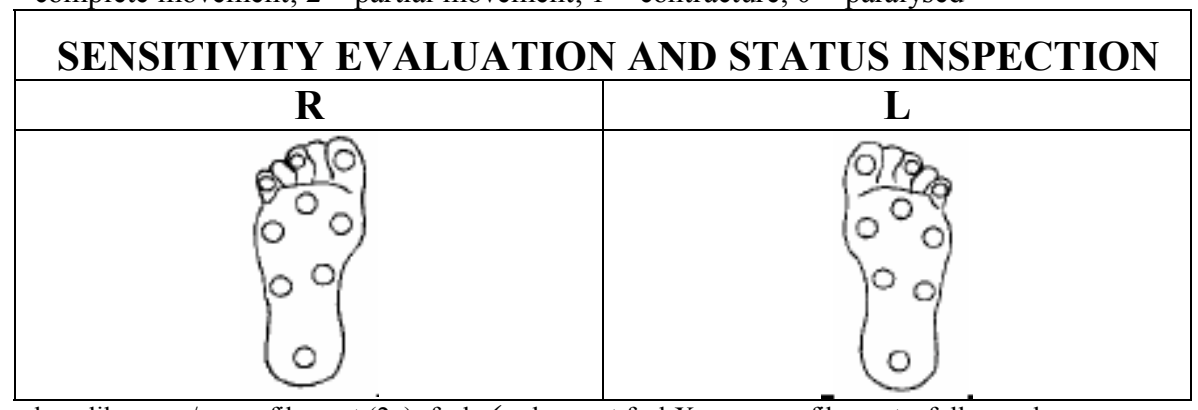

key: lilac pen / monofilament (2g): feels $\checkmark$; does not feel X ; or monofilaments: follow colours

Mobile claw: $\mathrm{M}$; rigid claw: $\mathrm{R}$; bone absorption: $\%$ wound:

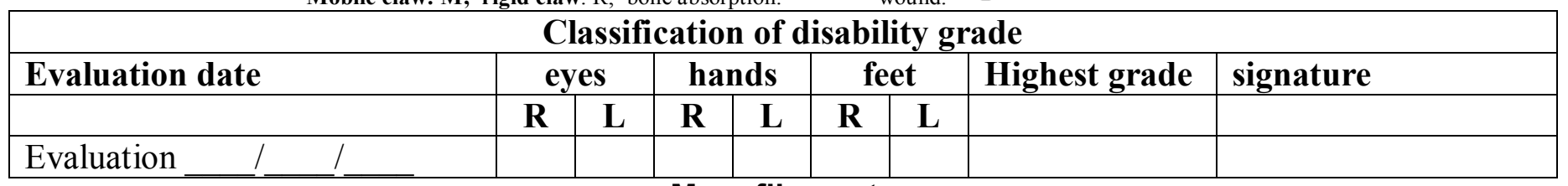

\section{Monofilaments}

\begin{tabular}{|l|c|l|}
\hline Monofilament & strength in grams & interpretation \\
\hline 1 - green & 0.05 & Normal sensitivity in hand and foot \\
\hline 3 - blue & 0.20 & $\begin{array}{l}\text { Diminished sensitivity in hand and normal in foot / Difficulty } \\
\text { in distinguishing texture (light touch) }\end{array}$ \\
\hline $4-$ dark red & 2.00 & $\begin{array}{l}\text { Diminished protective sensitivity in hand / Incapable of } \\
\text { distinguishing texture / Difficulty in distinguishing forms and } \\
\text { temperatures }\end{array}$ \\
\hline 5 - orange or red (mark with an X) & 4.00 & $\begin{array}{l}\text { Loss of protective sensitivity in hand and sometimes in foot } \\
\text { / loss of texture discrimination / Incapable of distinguishing } \\
\text { forms and temperatures }\end{array}$ \\
\hline 6 - red circle & 10.00 & $\begin{array}{l}\text { Loss of protective sensitivity in foot / loss of texture } \\
\text { discrimination / Incapable of distinguishing forms and } \\
\text { temperatures }\end{array}$ \\
\hline 7 - black & 300.00 & $\begin{array}{l}\text { Only has sensation when deep pressure is applied to hand } \\
\text { and foot }\end{array}$ \\
\hline
\end{tabular}




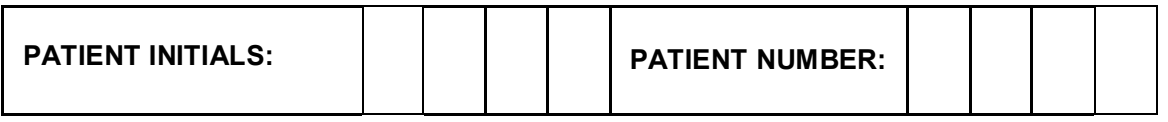

BACILLOSCOPY RESULTS

\begin{tabular}{|c|c|c|c|c|c|}
\hline & $\begin{array}{l}\text { Right ear } \\
\text { lobe }\end{array}$ & Left ear lobe & $\begin{array}{c}\text { Elbow } \\
\quad \mathbf{R}\end{array}$ & $\begin{array}{c}\text { Elbow } \\
\text { L }\end{array}$ & $\begin{array}{l}\text { Average of } \\
\text { bacteriological } \\
\text { indexes - BI }\end{array}$ \\
\hline $\begin{array}{l}\text { Beginning of the } \\
\text { study } \\
\text { Date }\end{array}$ & & & & & \\
\hline $\begin{array}{l}\text { End of treatment } \\
\text { Date }\end{array}$ & & & & & \\
\hline $\begin{array}{l}\text { 1st year visit post- } \\
\text { discharge } \\
\text { Date }\end{array}$ & & & & & \\
\hline $\begin{array}{l}2^{\text {nd }} \text { year visit post- } \\
\text { discharge } \\
\text { Date }\end{array}$ & & & & & \\
\hline $\begin{array}{l}\text { 3rd year visit post- } \\
\text { discharge } \\
\text { Date }\end{array}$ & & & & & \\
\hline $\begin{array}{l}\text { 4th year visit post- } \\
\text { discharge } \\
\text { Date }\end{array}$ & & & & & \\
\hline $\begin{array}{l}\text { 5th year visit post- } \\
\text { discharge } \\
\text { Date }\end{array}$ & & & & & \\
\hline $\begin{array}{l}\text { 6th year visit post- } \\
\text { discharge } \\
\text { Date }\end{array}$ & & & & & \\
\hline
\end{tabular}

* 13th month for groups 3 and 4 of multibacillary patients 


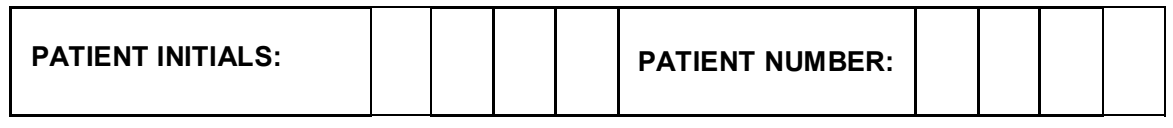

SULFONURIA RESULTS

\begin{tabular}{|l|l|l|}
\hline \multicolumn{3}{|c|}{ SULFONURIA - RESULTS (Positive or negative) } \\
\hline Test & & Comments \\
\hline 1st month \\
date I I
\end{tabular}

* For group 4 of multibacillary patients 


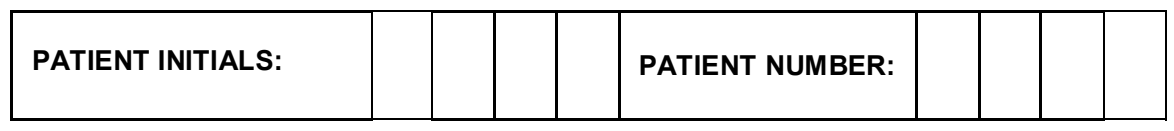

C- REACTIVE PROTEIN RESULTS - Monthly

\begin{tabular}{|c|c|c|c|}
\hline TEST & Results & $\begin{array}{c}\text { Clinically } \\
\text { significant } \\
\text { (“`“) }\end{array}$ & $\begin{array}{l}\text { COMMENTS } \\
\text { If test was not done, indicate with ND }\end{array}$ \\
\hline $\begin{array}{l}\text { BEGINNING OF THE } \\
\text { STUDY 1st dose/ Date }\end{array}$ & & & \\
\hline 2nd DOSE/ Date & & & \\
\hline 3rd DOSE / Date & & & \\
\hline 4th DOSE / Date & & & \\
\hline 5th DOSE / Date & & & \\
\hline 6th DOSE / Date & & & \\
\hline 7th DOSE / Date & & & \\
\hline 8th DOSE / Date & & & \\
\hline 9th DOSE / Date & & & \\
\hline 10th DOSE / Date & & & \\
\hline 11th DOSE / Date & & & \\
\hline 12th DOSE / Date & & & \\
\hline End of treatment / Date & & & \\
\hline
\end{tabular}

Normal value $<8$ units $\mathrm{mg} / \mathrm{L}$

* For groups 3 and 4 of Multibacillary patients

Signature and stamp of medical examiner 


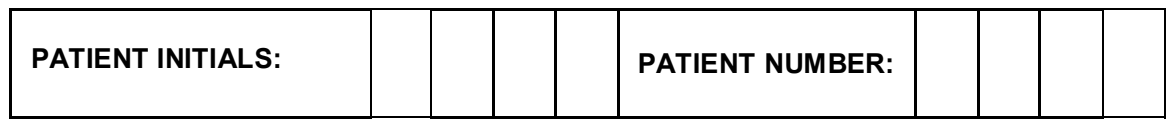

\section{C - REACTIVE PROTEIN RESULTS - Annual}

\begin{tabular}{|c|l|l|l|}
\hline TEST & Results & $\begin{array}{c}\text { Clinically } \\
\text { significant } \\
\text { (“ } \checkmark \text { ") }\end{array}$ & $\begin{array}{c}\text { COMMENTS } \\
\text { If test was not done, indicate with ND }\end{array}$ \\
\hline 1st Year/ Date & & & \\
\hline 2nd Year/ Date & & & \\
\hline 3rd Year/ Date & & & \\
\hline 4th Year/ Date & & & \\
\hline 5th Year/ Date & & & \\
\hline 6th Year/ Date & & & \\
\hline
\end{tabular}

Normal value $<8$ units $\mathrm{mg} / \mathrm{L}$

Signature and stamp of medical examiner 


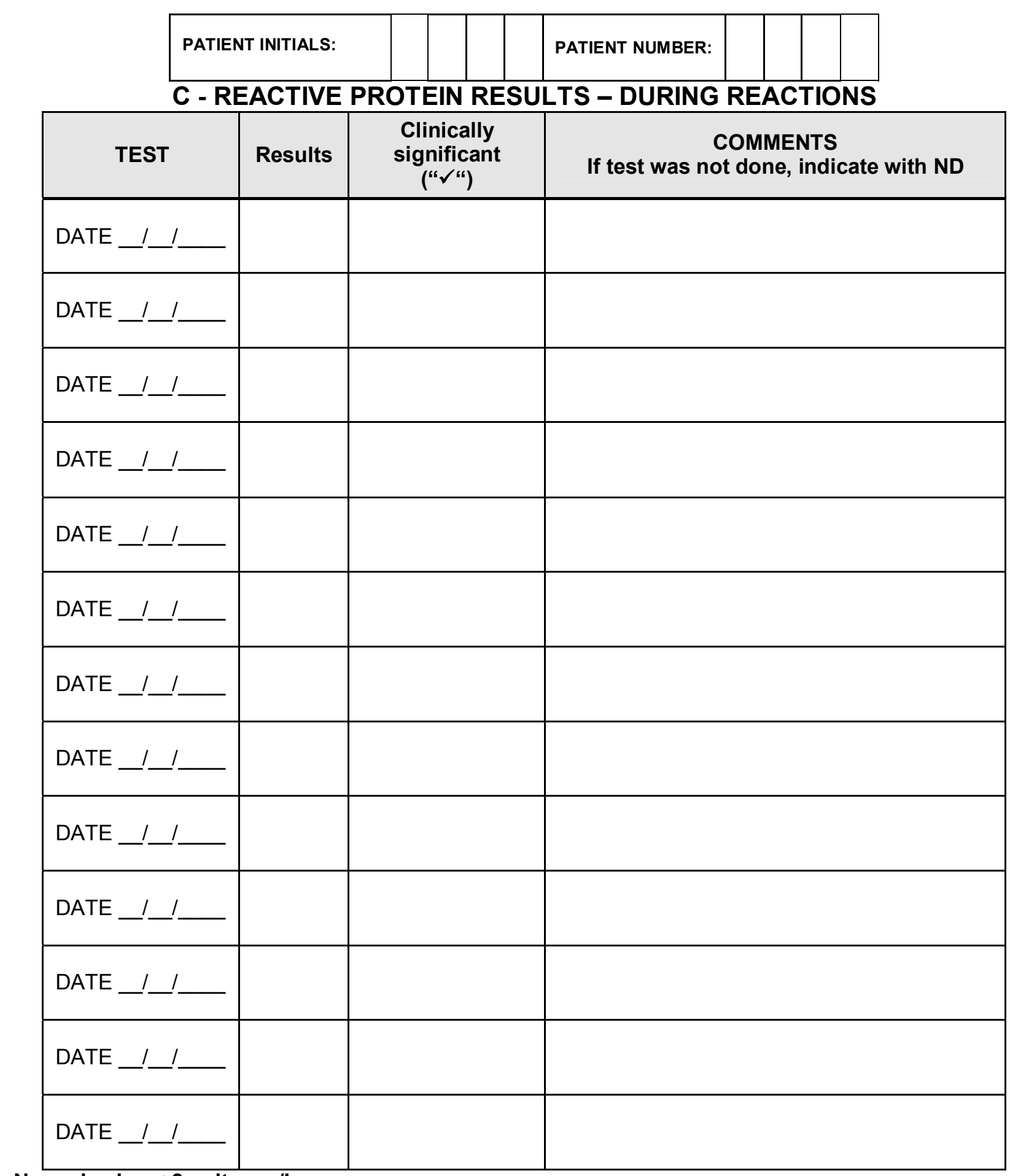

Normal value $<8$ units $\mathrm{mg} / \mathrm{L}$

Signature and stamp of medical examiner 


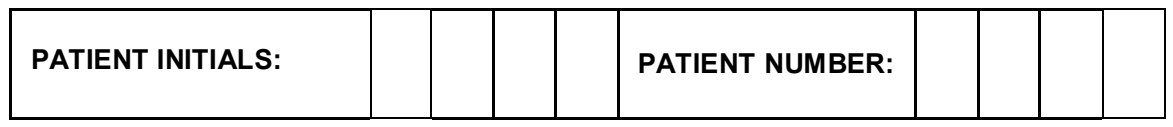

\section{REGISTRATION OF DOSE UNDER STUDY}

\begin{tabular}{|c|c|c|c|c|}
\hline VISIT & $\begin{array}{l}\text { Date of Visit } \\
\text { (day /month/ } \\
\text { year) }\end{array}$ & $\begin{array}{l}\text { Number of pills } \\
\text { given }\end{array}$ & Lot no. & $\begin{array}{l}\text { Expiration } \\
-I_{-}---\end{array}$ \\
\hline $\begin{array}{l}\text { BEGINNING OF } \\
\text { THE STUDY 1st } \\
\text { DOSE }\end{array}$ & -1 & & & \\
\hline 2nd DOSE & -1 & & & \\
\hline 3rd DOSE & -1 & & & \\
\hline 4th DOSE & 1 & & & \\
\hline 5th DOSE & 1 & & & \\
\hline 6th DOSE & 1 & & & \\
\hline 7th DOSE* & 1 & & & \\
\hline 8th DOSE* & - I I & & & \\
\hline 9th DOSE* & 1 & & & \\
\hline 10th DOSE* & -1 & & & \\
\hline 11th DOSE* & 1 & & & \\
\hline 12th DOSE* & 1 & & & \\
\hline
\end{tabular}

* For group 4 of multibacillary patients

"I affirm that the information on this form was verified by me and is true." 


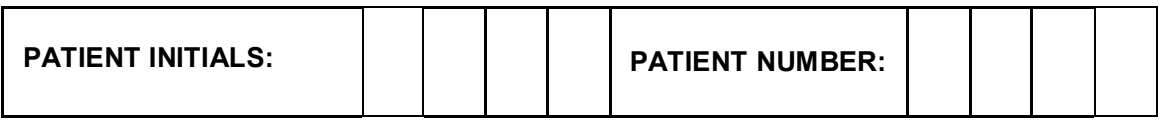

\section{REGISTRATION OF CONCURRENT MEDICATIONS}

\begin{tabular}{|l|l|l|}
\hline MEDICATION & BEGINNING DATE & ENDING DATE \\
\hline (Generic name) & (DAYIMONTH/YEAR) & (DAYIMONTH/YEAR)) \\
\hline & & \\
\hline & & \\
\hline & & \\
\hline & & \\
\hline & & \\
\hline & & \\
\hline & & \\
\hline & & \\
\hline
\end{tabular}

Signature and stamp of medical examiner 


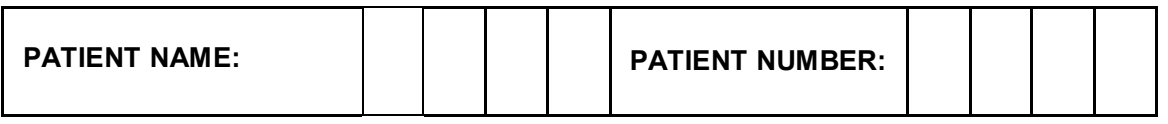

\section{REGISTRATION OF SIDE EFFECTS}

\begin{tabular}{|c|c|c|c|}
\hline Side Effects & $\begin{array}{l}\text { Beginning Date } \\
\text { (day/month/year) }\end{array}$ & $\begin{array}{c}\text { Ending Date } \\
\text { (day/month/year) }\end{array}$ & Action taken \\
\hline & & & \\
\hline & & & \\
\hline & & & \\
\hline & & & \\
\hline & & & \\
\hline & & & \\
\hline & & & \\
\hline & & & \\
\hline & & & \\
\hline & & & \\
\hline & & & \\
\hline
\end{tabular}




\section{DESCRIPTION OF CRITICAL SIDE EFFECTS}

\begin{tabular}{|c|c|c|}
\hline DATE & RESEARCHER & DESCRIPTION \\
\hline & & \\
\hline & & \\
\hline & & \\
\hline & & \\
\hline & & \\
\hline & & \\
\hline & & \\
\hline & & \\
\hline & & \\
\hline & & \\
\hline & & \\
\hline & & \\
\hline & & \\
\hline & & \\
\hline & & \\
\hline & & \\
\hline & & \\
\hline & & \\
\hline
\end{tabular}


CLINICAL DERMATOLOGICAL EVALUATION - RELAPSE

\begin{tabular}{|c|c|}
\hline $\begin{array}{l}\text { KEY: } \\
\begin{array}{ll}\text { 1. Altered } & \text { 2. Normal }\end{array}\end{array}$ & Alterations observed \\
\hline Cardiovascular & \\
\hline Musculoskeletal & \\
\hline Respiratory & \\
\hline Gastrointestinal & \\
\hline Liver & \\
\hline Metabolic/Endocrine & \\
\hline Genital-Urinary & \\
\hline Neurological & \\
\hline Psychiatric & \\
\hline $\begin{array}{l}\text { Haematological/ } \\
\text { Lymphatic }\end{array}$ & \\
\hline Musculoskeletal & \\
\hline $\begin{array}{l}\text { Signs/ symptoms of } \\
\text { reaction present? }\end{array}$ & $\begin{array}{l}1-\text { Yes } \\
2-\mathrm{No}\end{array}$ \\
\hline Other (specify) & \\
\hline
\end{tabular}




\begin{tabular}{|c|l|l|l|l|l|l|l|l|l|l|l|l|}
\hline PATIENT INITIALS & & & & & PATIENT NUMBER: & & & & & DATE OF VISIT: & & \\
\hline PATIENT INITIALS & & & & & PATIENT NUMBER: & & & & & DATE OF VISIT: & & \\
\hline
\end{tabular}

\section{EXAMINATION OF PERIPHERAL NERVES - RELAPSE FORM}

\begin{tabular}{|c|c|c|c|c|}
\hline \multirow[b]{2}{*}{ NERVES } & \multicolumn{2}{|c|}{$\begin{array}{l}\text { KEY } \\
\text { NERVE EXAMINATION } \\
0 \text { - Normal } \\
\text { 1- Thickened } \\
\text { 2- Nerve abscess }\end{array}$} & \multicolumn{2}{|c|}{$\begin{array}{l}\text { KEY } \\
\text { SCALE OF INDICATED NEURAL PAIN } \\
0 \text { - No pain } \\
1 \text { - Weak pain } \\
2 \text { - Strong pain }\end{array}$} \\
\hline & RIGHT & LEFT & RIGHT & LEFT \\
\hline \multicolumn{5}{|l|}{ Ulnar } \\
\hline \multicolumn{5}{|l|}{ Median } \\
\hline \multicolumn{5}{|l|}{ Radial } \\
\hline \multicolumn{5}{|l|}{ Fibular } \\
\hline \multicolumn{5}{|l|}{ Posterior Tibial } \\
\hline Others & & & & \\
\hline
\end{tabular}

Signature and stamp of medical examiner

REQUEST FOR LABORATORY EXAMS - RELAPSE FORM

\begin{tabular}{|l|l|}
\hline$\square$ & BACILLOSCOPY \\
\hline$\square$ & HISTOPATHOLOGICAL \\
\hline$\square$ & ML-FLOW $\quad$ affix the tape here \\
\hline
\end{tabular}

OBS: 


\section{SIMPLIFIED EVALUATION OF NEURAL FUNCTION AND COMPLICATIONS RELAPSE FORM}

\begin{tabular}{|l|c|c|}
\hline \multicolumn{1}{|c|}{ Face } & & \\
\hline \multicolumn{1}{|c|}{ Nose } & R & L \\
\hline Main complaint & & \\
\hline dryness (S/N) & & \\
\hline abrasions (S/N) & & \\
\hline Perforation of the septum (S/N) & R & L \\
\hline Main complaint & & \\
\hline Closes eyes w/o force (mm) & & \\
\hline Closes eyes w/ force (mm) & & \\
\hline Cornea diminished sensibility (S/N) & & \\
\hline Cornea opacity (S/N) & & \\
\hline Cataract (S/N) & & \\
\hline Visual acuity & & \\
\hline
\end{tabular}

\begin{tabular}{|l|c|c|}
\hline \multicolumn{1}{|c|}{ Upper limbs } & & \\
\hline Main complaint Nerve palpation & & \\
\hline \multicolumn{1}{|c|}{ Ulnar } & R & L \\
\hline Median & & \\
\hline Radius & & \\
\hline
\end{tabular}

key: $\mathrm{N}=$ normal; $\mathrm{T}=$ thickened; $\mathrm{P}=$ pain; $\mathrm{S}=$ Tinel's sign $(+)$

Opens little finger

Abduction of the $5^{\text {th }}$ finger (ulnar nerve)

Elevates thumb

Abduction of the thumb (median nerve)

Elevates wrist

Wrist extension (radial nerve)

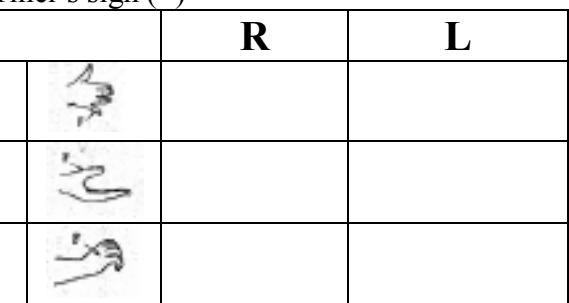

key: $\mathrm{S}=$ strong; $\mathrm{D}=$ diminished; $\mathrm{P}=$ paralysed $\quad$ or $5=$ strong; $4=$ partial resistance; $3=$ complete movement; $2=$ partial movement; $1=$ contraction; $0=$ paralysed

\section{SENSITIVITY EVALUATION AND STATUS INSPECTION}

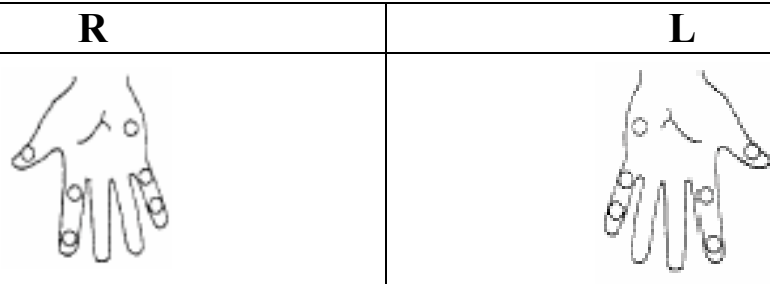

key: lilac pen / monofilament (2g): feels $\sqrt{ }$; does not feel X ; or monofilaments: follow colours

Mobile claw: $\mathrm{M}$; rigid claw: $\mathrm{R}$; bone absorption: $*$ wound:

Signature and stamp of medical examiner 


\begin{tabular}{|c|l|l|l|l|l|l|l|l|l|l|l|l|}
\hline PATIENT INITIALS & & & & & PATIENT NUMBER: & & & & DATE OF VISIT: & \\
\hline PATIENT INITIALS & & & & & PATIENT NUMBER: & & & & & DATE OF VISIT: \\
\hline
\end{tabular}

\begin{tabular}{|l|c|c|}
\hline \multicolumn{1}{|c|}{ Lower limbs } & & \\
\hline Main complaint Nerve Palpation & & \\
\hline \multicolumn{1}{|c|}{ R } & L \\
\hline Fibular & & \\
\hline Posterior tibial & & \\
\hline
\end{tabular}

key: $\mathrm{N}=$ normal; $\mathrm{T}=$ thickened; $\mathrm{P}=$ pain; $\mathrm{S}=$ Tinel's sign $(+)$

\begin{tabular}{|l|l|l|l|}
\hline \multicolumn{2}{|c|}{ Strength evaluation } & R & L \\
\hline $\begin{array}{l}\text { Elevates hallux } \\
\text { Hallux extension (fibular nerve) }\end{array}$ & & \\
\hline $\begin{array}{l}\text { Elevate foot } \\
\text { Foot dorsiflexion (fibular nerve) }\end{array}$ & & \\
\hline
\end{tabular}

key: $\mathrm{S}=$ strong; $\mathrm{D}=$ diminished; $\mathrm{P}=$ paralysed or $5=$ strong; $4=$ partial resistance; $3=$ complete movement; $2=$ partial movement; $1=$ contracture; $0=$ paralysed

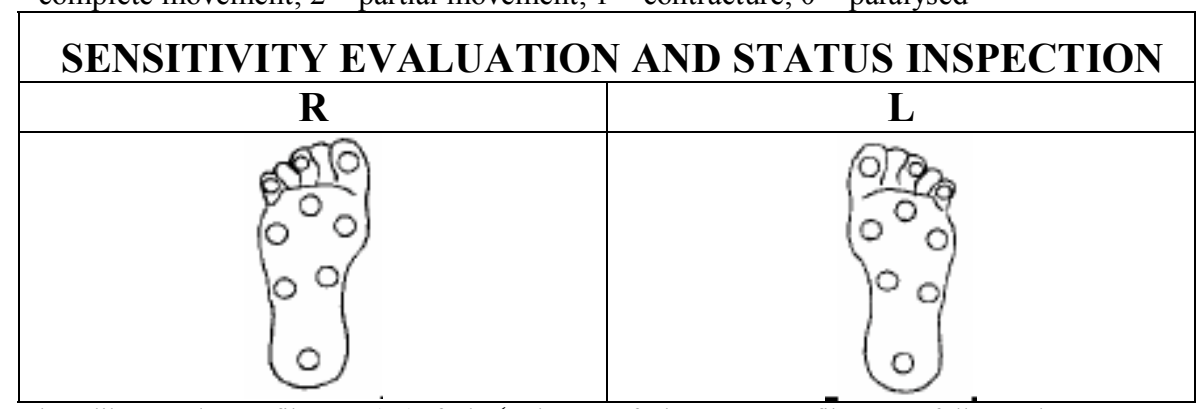

key: lilac pen / monofilament (2g): feels $\sqrt{ }$; does not feel X ; or monofilaments: follow colours

Mobile claw: M; rigid claw: $\mathrm{R}$; bone absorption: $\%$ wound:

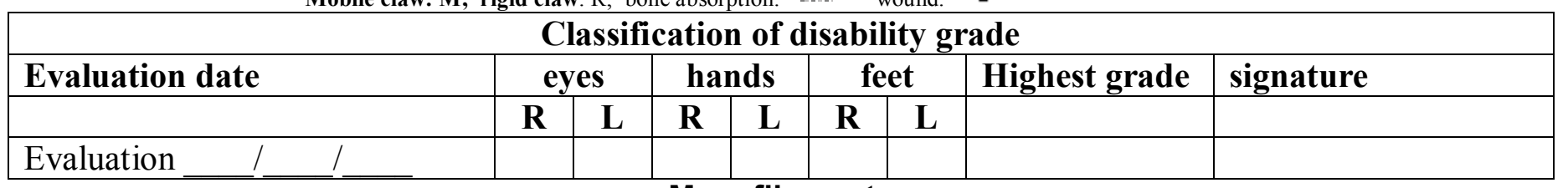

Monofilaments

\begin{tabular}{|c|c|c|}
\hline Monofilament & strength in grams & interpretation \\
\hline $1-$ green & 0.05 & Normal sensitivity in hand and foot \\
\hline 2 - blue & 0.20 & $\begin{array}{l}\text { Diminished sensitivity in hand and normal in foot / Difficulty } \\
\text { in distinguishing texture (light touch) }\end{array}$ \\
\hline 3 - Lilac & 2.00 & $\begin{array}{l}\text { Diminished protective sensitivity in hand / Incapable of } \\
\text { distinguishing texture / Difficulty in distinguishing forms and } \\
\text { temperatures }\end{array}$ \\
\hline 4 - dark red & 4.00 & $\begin{array}{l}\text { Loss of protective sensitivity in hand and sometimes in foot } \\
\text { / loss of texture discrimination / Incapable of distinguishing } \\
\text { forms and temperatures }\end{array}$ \\
\hline 5 - orange or red (mark with an $\mathrm{X}$ ) & 10.00 & $\begin{array}{l}\text { Loss of protective sensitivity in foot / loss of texture } \\
\text { discrimination / Incapable of distinguishing forms and } \\
\text { temperatures }\end{array}$ \\
\hline 6 - red circle & 300.00 & $\begin{array}{l}\text { Only has sensation when deep pressure is applied to hand } \\
\text { and foot }\end{array}$ \\
\hline 7 - black & $\begin{array}{l}\text { No response to } 300 \mathrm{~g} \\
\text { monofilament }\end{array}$ & Loss of sensation even to deep pressure in hand and foot \\
\hline
\end{tabular}




\section{RELAPSE REGISTRATION}

\begin{tabular}{|c|c|}
\hline \multicolumn{2}{|c|}{ DERMATOLOGICAL-NEUROLOGICAL EXAM AND COI } \\
\hline & Type of lesion \\
\hline Beginning of current symptoms & 7. Maculae \\
\hline No. of months & 9. Papules \\
\hline & $\begin{array}{l}\text { 10. Diffuse infliltration } \\
\text { 11. Nodules } \\
\text { 12. Anaesthetic area }\end{array}$ \\
\hline
\end{tabular}

Number of lesions (from 1 to 10 lesions, enter the exact number)

11. Eleven or more lesior

88. linfiltração difusa

Bacilloscopy

3. Negative

4. Positive

Colour of lesion

5. Hypo-chromatic

6. Erythematose

7. Hyper-chromatic

8. Normal (same as surrounding skin)

88. In

Número de nervos comprometidos

Resultado do IB

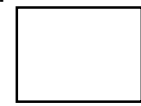

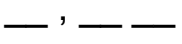

$\mid \begin{array}{ll}\text { ML Flow } & \\ 5 . & \text { Negative } \\ 6 . & \text { Positive } \\ 7 . & \text { Inconclusive } \\ 8 . & \text { Not done } \\ & \\ & \end{array}$

Sensitivity

4. Altered

5. Inconclusive

6. Normal

Intensity of ML Flow

$\square \quad 1+$

$\square \quad 2+$

$\square \quad 3+$

$\square \quad 4+$

\section{OPERATIONAL CLASSIFICATION}

1. Paucibacillary ( $\leq 5$ skin lesions)

2. Multibacillary ( $\geq 6$ skin lesions)

\section{CLINICAL CLASSIFICATION}
1. Indeterminate leprosy
4. Borderline Tuberculoid leprosy
6. Borderline Lepromatous leprosy
2. Tuberculoid leprosy
5. Borderline Borderline leprosy
3. Lepromatous leprosy

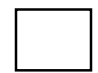

\begin{tabular}{|l|l|}
\hline BIOPSY \\
\hline Slide no. & Date ________
\end{tabular}

LEVEL OF CERTAINTY

[39] CONFIRMED LEPROSY

[40] CONSISTENT WITH LEPROSY

[41] NON-SPECIFIC

[42] INDICATIVE OF ANOTHER DISEASE

\section{BIOPSY - Beginning of study - Principle findings}

Epidermis: 1 ( ) 2 ( ) 3( ) 4( ) 5( )

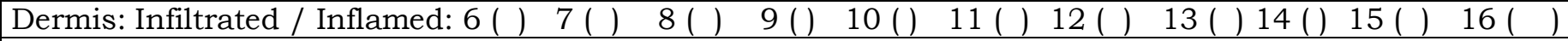

Nerve damage: $17($ ) 18 ( ) 19 ( ) 20 ( )

Vasculitis: 21 ( ) $22($ )

Panniculitis: 23 ( ) 24( ) 25( )

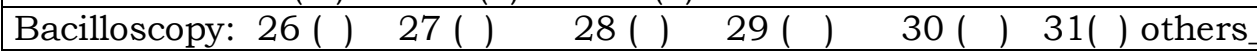

Clinical form: 32- I [ ] 33- TT [ ] 34- BT [ ] 35- BB [ ] 36- BL [ ] 37- LL [ ] 38- [ ] Not classified

\section{FINAL CLASSIFICATION}

1. Indeterminate leprosy

4. Borderline Tuberculoid leprosy

6. Borderline Lepromatous leprosy
2. Tuberculoid leprosy

5. Borderline Borderline leprosy

\section{Lepromatous leprosy}

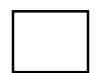




\section{FORM FOR WITHDRAWAL FROM THE STUDY}

\begin{tabular}{|l|l|l|l|}
\hline & 1 YES & 2 NO & DATE \\
\hline COMPLETED THE TREATMENT REGIMEN? & & & \\
\hline DATE OF LAST DOSE & & & \\
\hline WITHDRAWAL FROM THE STUDY & & COMMENTS \\
\hline \multicolumn{1}{|c|}{ REASON FOR WITHDRAWAL (More than 1 option may be } \\
chosen):
\end{tabular}

"I affirm that the information in this form was verified by me and is true"."

Date: 
Independent study to establish the efficacy of the six dose uniform MDT regimen

(U-MDT) for leprosy patients

\section{APPENDIX I of SOP UMDT 013}

Note - To facilitate the keeping of records, this appendix is available in Microsoft Excel

(Located in file name: amostras.xls).

\begin{tabular}{|c|c|c|c|c|c|c|}
\hline \multicolumn{7}{|c|}{ Place here the name of the Centre where the sample is being collected } \\
\hline & & Boxes & $\mathrm{A} \quad \mathrm{B} \quad \mathrm{C}$ & & tes & \\
\hline & Chart No. & $\begin{array}{l}\text { No. project } \\
\text { CRF }\end{array}$ & Name of Patient & Birth. & Sample & $\begin{array}{l}\text { Professional } \\
\text { Responsible }\end{array}$ \\
\hline A1 & & & & & & \\
\hline A2 & & & & & & \\
\hline A3 & & & & & & \\
\hline A4 & & & & & & \\
\hline A5 & & & & & & \\
\hline A6 & & & & & & \\
\hline A7 & & & & & & \\
\hline A8 & & & & & & \\
\hline A9 & & & & & & \\
\hline A10 & & & & & & \\
\hline A11 & & & & & & \\
\hline A12 & & & & & & \\
\hline & & & & & & \\
\hline B1 & & & & & & \\
\hline B2 & & & & & & \\
\hline B3 & & & & & & \\
\hline B4 & & & & & & \\
\hline B5 & & & & & & \\
\hline B6 & & & & & & \\
\hline B7 & & & & & & \\
\hline B8 & & & & & & \\
\hline B9 & & & & & & \\
\hline B10 & & & & & & \\
\hline B11 & & & & & & \\
\hline B12 & & & & & & \\
\hline
\end{tabular}

The numbering of samples is always preceded by the letter of alphabet so that each letter will be

followed by numerals from 1 to 12 . 
APPENDIX I of SOP UMDT 015

PROJECT: MDT - U

Name:

Age: __ Date of birth: ___ __ __ Sex:

Date of biopsy: 1

RESULTS OF HISTOPATHOLOGICAL EXAM

Macroscopy:

- Skin biopsy with punch $\mathrm{cm}$ in the widest section.

- State of biopsy specimen: Adequate ( ) Inadequate ( ) Limited ( )

Microscopy:

- Epidermis:

$1($ ) atrophic 2( ) acanthotic 3( ) ulcerated $4($ ) damaged (eroded) $5($ ) normal

- Dermis:

Inflammatory infiltrate: 6 ( ) focal 7( ) diffuse

8( )mononuclear perivascular 9( )mononuclear/perivascular/periannexal/erector muscle

10( ) mononuclear with epithelioid cells 11( ) few and limited granulomas with epithelioid cells

12( ) multiple granulomas with epithelioid cells 13( ) plasmacytes 14( ) neutrophiles

15( ) Virchow cells 16( ) Langerhans cells

Nerves affected: 17( )yes 18( )no 19( )doubtful 20( ) nerve sheath not seen

Vasculitis: 21( ) yes 22( ) no

Panniculitis: 23( ) yes 24( ) no 25( )Subcutaneous layer not present

Bacilloscopy: $26(+/ 6+)$ yes $27($ )intact 28 ( )fragmented 29( ) granulated 30( ) no

31 - Other:

- Classification: $32-\mathrm{I}($ ) 33 - TT(） 34 - BT(） 35 - BB（）

36-BL（） 37-LL（） 38-（)Non-classifiable

- Degree of certainty:

39 - Confirmed leprosy

40 - Consistent with leprosy, but diagnosis not confirmed

41 - Unspecific

42 - Indicative of other disease

43 - If other disease confirmed, indicate which:

44 - Obs.:

Responding Physician:

Date 